\title{
Private finance and governance of REDD+ projects in Indonesia
}

By

Rowan James Dixon

A thesis submitted to the Victoria University of Wellington in fulfilment of the requirements for the degree of Doctor of Philosophy

Victoria University of Wellington

(2016) 

'The private sector brings a very clear sight on what is required for a return on investment, and that's about looking for undervalued environmental assets. That's of course what the central thesis is about: that we have deplorable and at great scale undervalued the ecosystem services on which we rely. What we need is capital markets to begin to recognise that' (Investor 4).

'REDD+ and a green economy has to make sense for the businessman. It's important to remember that there is no such thing as the private sector; it's a very heterogeneous beast, Linking the financial and the physical economy' (International Consultant 2). 



\section{Abstract}

This thesis explores the role of private finance within REDD+ (Reducing Emissions from Deforestation and forest Degradation) programmes in Indonesia. Since its debut in 2007 as a potential investment opportunity, enterprising and innovative private sector actors have moved to establish REDD+ projects within a voluntary carbon market, while the United Nations Convention on Climate Change continues negotiations to establish a comprehensive global mechanism. These profit-seeking actors have invested millions of dollars developing REDD+ projects within a rapidly evolving voluntary market that has emerged alongside the turmoil of global climate change negotiations. This dynamic market context brought about a wide variety of expressions of REDD+ in Indonesia, which this research seeks to untangle and illuminate. The thesis yields insights into the workings of market environmentalism, and complicates widespread notions of 'private finance' as a homogenous and predictable category of actor.

In order to better understand the emergent REDD+ industry in Indonesia, and the role of private finance in shaping it, this research draws on the global value chain (GVC) framework to analyse processes of commodification and governance within REDD+ projects and 'supply chains'. This approach identifies key private finance actors, and explores why they are involved across motivations for social, environmental and financial outcomes. It also reveals REDD+ projects as a produced commodity and provides insight into the multiple ways they are valued. The research thus highlights how private finance actors evaluate REDD+ commodities as they engage with them. These logics, and the profit-seeking rationale of private finance actors, are seen to have important governance implications in shaping the characteristics of REDD+ projects and the networks of actors involved in them. However, simultaneously, the malleable and selective characteristics of the REDD+ commodity itself shapes certain governing implications of private finance. This thesis 
contributes to debates concerning the commodification of nature within market environmentalism and the neoliberalisation of nature, providing insights into the nature and agency of private finance. 


\section{Acknowledgements}

Undertaking this research and thesis led me on a journey of thought I did not anticipate, changing me in ways that I will continue to benefit from. For this opportunity I remain grateful the project team chose me and continued to support me throughout, specifically Ed Challies and Andrew McGregor.

I could not have done this without my partners, colleagues, friends and fellow PhD victims Rini Astuti and Peter Howson. The three of us managed to pull off a feat of collaboration to become the most famous 'fellowship of the REDD+' trio between Indonesia and New Zealand. This thesis is stronger because of it and I am really excited about what the future holds for us as a team and as individuals.

I am sincerely grateful for the many diverse people from local communities, NGOs, businesses, governments and international finance that sacrificed their precious time to entertain my questions and probing insistence. I hope that your patience and insight is reflected here and my interpretations do justice to your optimistic enterprise for sustainable and equitable societies in Indonesia and globally.

My fiancé, family and friends all share responsibility for getting me over this line, supporting me through the ups and downs, and inspiring me to take on the challenge in the first place. I share this with you all and feel so proud to do so. 


\section{Contents}

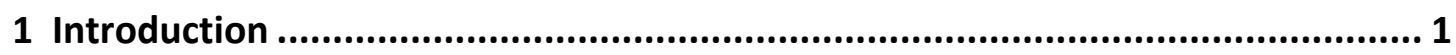

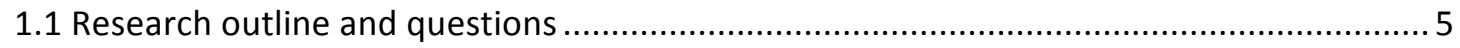

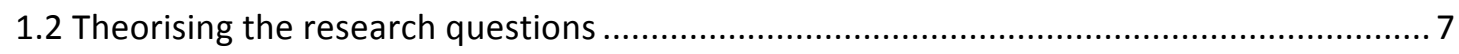

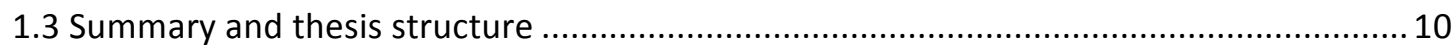

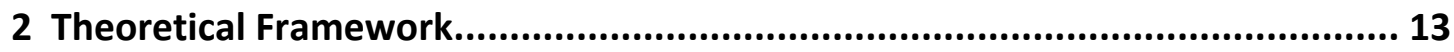

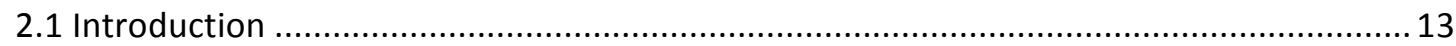

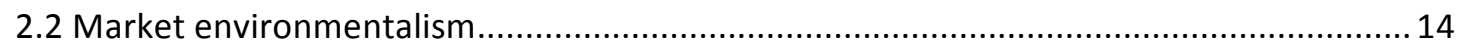

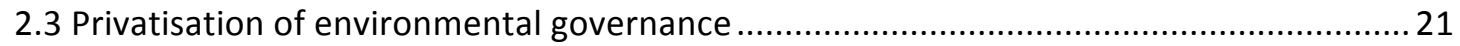

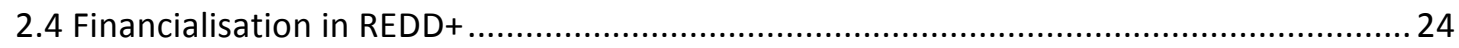

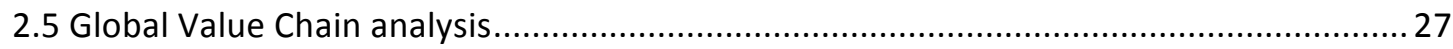

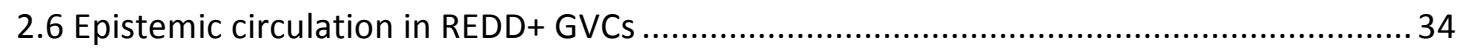

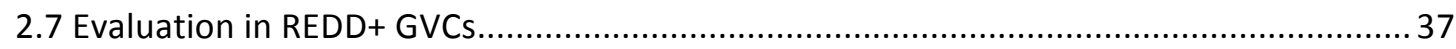

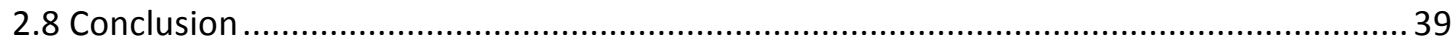

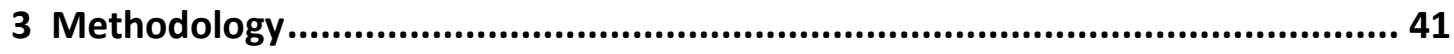

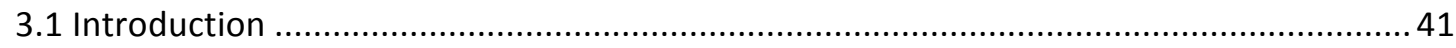

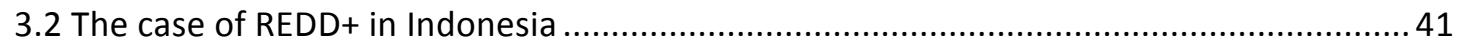

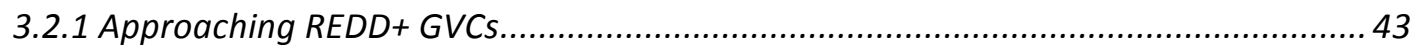

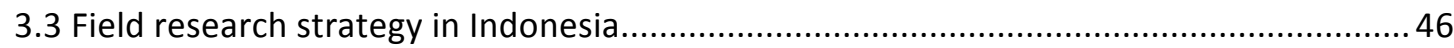

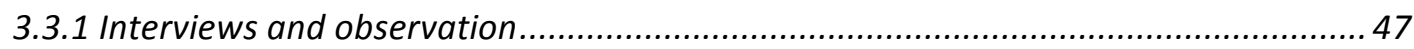

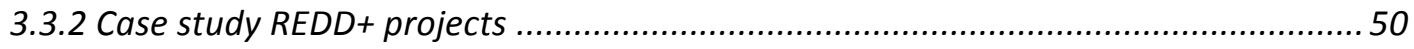

3.4 Coffee and batik to beer and suits: Positionality and reflexivity .....................................52

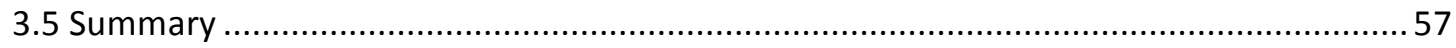




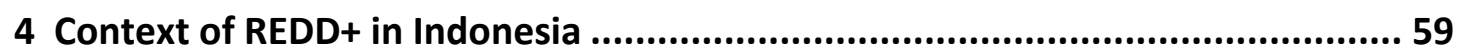

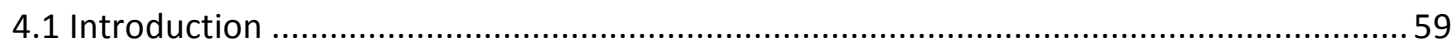

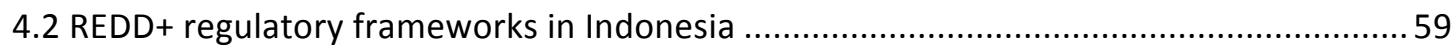

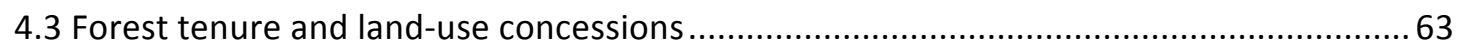

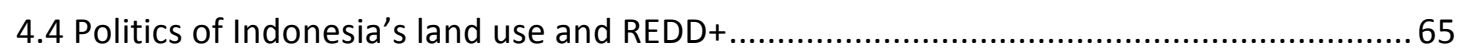

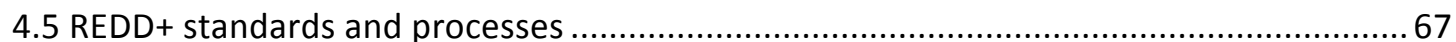

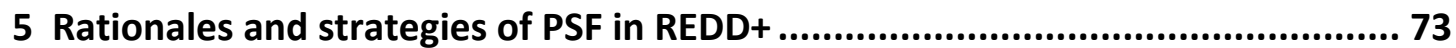

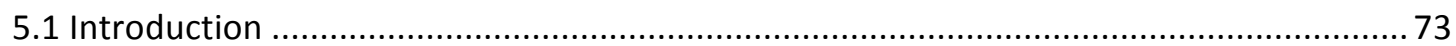

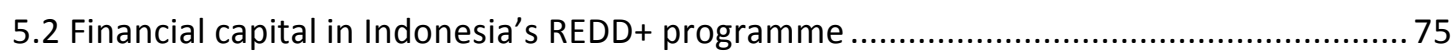

5.3 Beyond carbon as core business? Shifting rationales and strategies...............................79

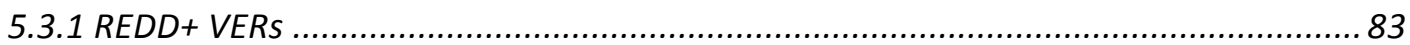

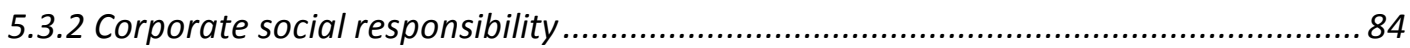

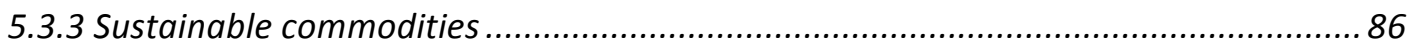

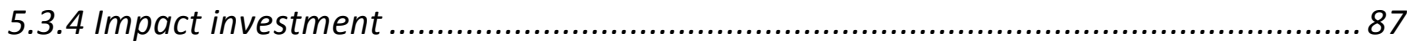

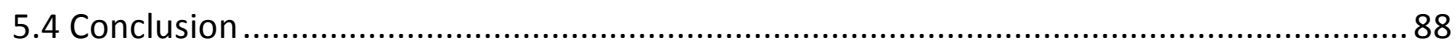

6 A GVC framework and analysis for REDD+ in Indonesia ................................ 91

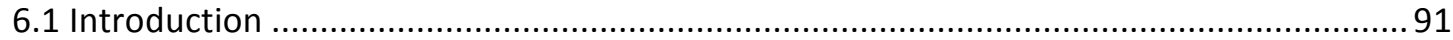

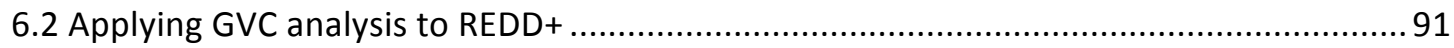

6.2.1 A GVC framework for REDD+ projects.................................................................. 94

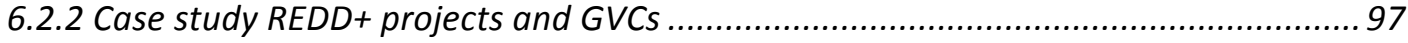

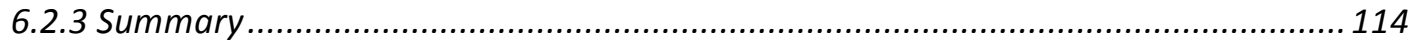

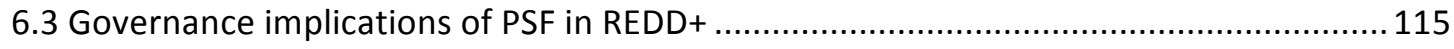

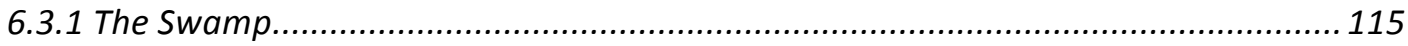

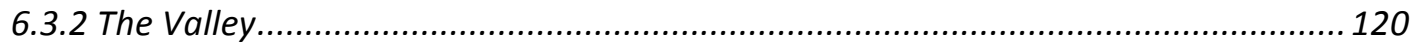

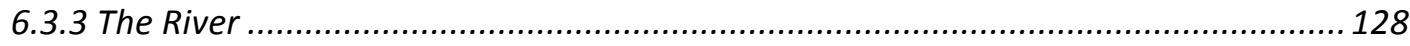

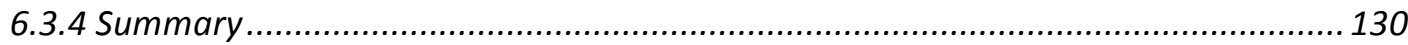

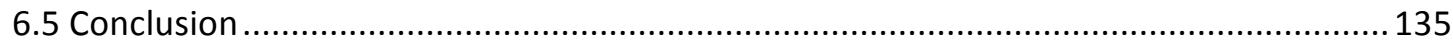

7 REDD+ Commodification and Commodity ..................................................... 139 
7.1 Introduction

7.1.1 REDD+ projects and PSF stories

7.2 Locating the REDD+ commodity.

7.2.1 The VER hook for REDD+ Outcomes........................................................... 146

7.3 Story meanings beyond REDD+ VER exchange and REDD+ Outcomes ........................ 148

7.3.1 Disconnecting from VERs ............................................................... 153

7.4 Abandoning REDD+ for sustainable commodity revenue ........................................ 155

7.5 REDD+ knowledge commodities and epistemic circulation ..................................... 158

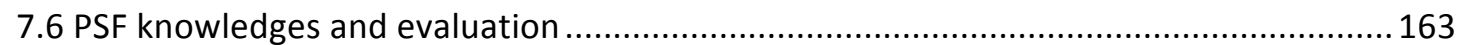

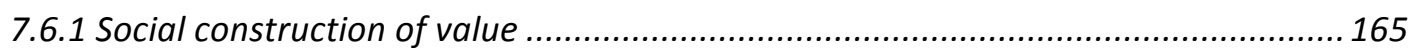

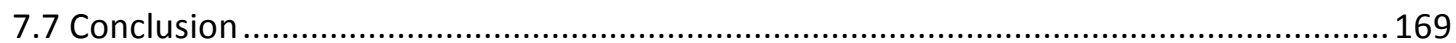

8 Financialisation across REDD+ GVCs..................................................... 171

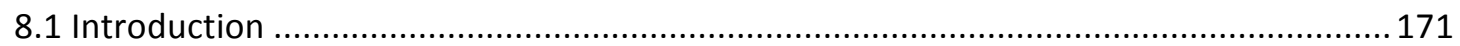

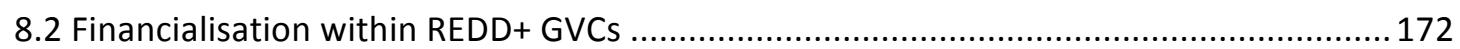

8.2.1 Regulating for financialisation .......................................................... 176

8.2.2 Necessity of standards and opportunity of bonds........................................... 179

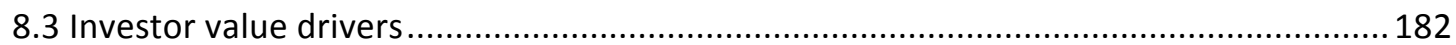

8.4 Company value drivers ................................................................................ 187

8.5 Customer, public and shareholder value drivers ............................................... 191

8.6 Local value drivers..................................................................................... 196

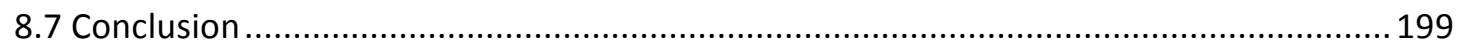

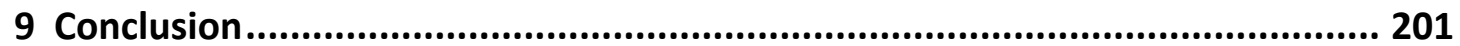

9.1 Who are PSF actors that support REDD+ projects? .............................................. 202

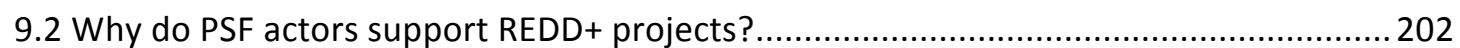

9.2.1 Why PSF actors desire REDD+ knowledge commodities ................................... 204

9.3 What are the governance implications of PSF actors on REDD+ projects? ................. 206

9.3.1 PSF governing rationales and strategies...................................................... 207

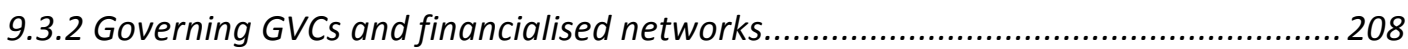


References.

Appendices 234

Appendix A - interview guide 234

Appendix B - ethics approval, information sheets and consent form 235

Human ethics approval 235

Interview and observation information sheets. 236

Interview and observation consent forms..... 239

Appendix C - list of non-government informants. 242 


\section{List of figures}

Figure 1.1: The following thesis structure. ........................................................ 11

Figure 2.1: Narrative and approach Chapter 2................................................ 14

Figure 2.2: Types of GVC governance adapted from (Gereffi et al., 2005, p. 89)....... 30

Figure 2.3: Conceptual model of REDD+ market environmentalism in Indonesia...... 39

Figure 5.1. Financial bottom lines, social and environmental benefits, and risk in

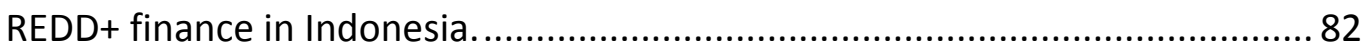

Figure 6.1: REDD+ project template (populated with sample actors/activities). ....... 95

Figure 6.2: GVC diagram of The Swamp REDD+ project. ...................................... 100

Figure 6.3: GVC diagram of The Valley REDD+ project. ........................................ 106

Figure 6.4: GVC diagram of The River REDD+ project........................................ 110

Figure 6.5: Governance types and forms of coordination on The Swamp REDD+

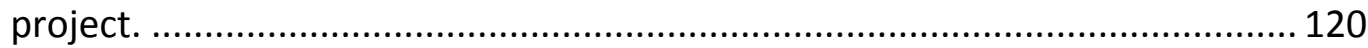

Figure 6.6: Governance types and forms of coordination on The Valley REDD+

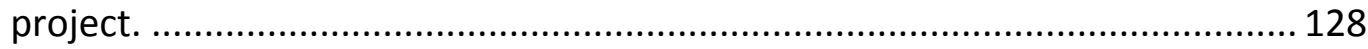

Figure 6.7: Governance types and forms of coordination on The River REDD+ project.

Figure 6.8: The conceptual locations of the three REDD+ GVC case studies............ 131

Figure 7.1: The REDD+ commodity of exchange................................................. 144

Figure 7.2: The REDD+ knowledge commodity. .................................................. 162 


\section{List of tables}

Table 3.1: Number of informants of different types. ............................................ 47

Table 4.1: Common criteria and sub criteria of REDD+ standards (Roe et al., 2013). 69

Table 6.1: Comparison of governance and forms of coordination across The Swamp

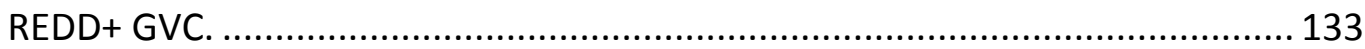

Table 6.2: Comparison of governance and forms of coordination across The Valley

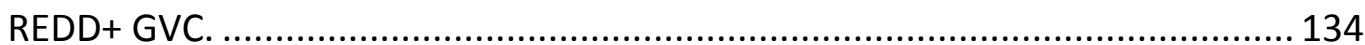

Table 6.3: Comparison of governance and forms of coordination across The River

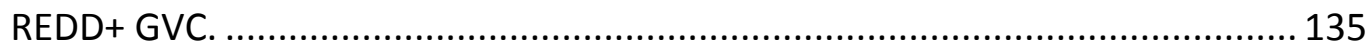




\section{List of acronyms}

CCB Community, Climate and Biodiversity standard

CDM Clean Development Mechanism

CIFOR Centre for International Forestry Research

COP UNFCCC Conference of the Parties

CSR Corporate Social Responsibility

ERC Ecosystem Restoration Concession

ESG Environmental, Social and Governance issues

FCPF Forest Carbon Partnership Facility

FPIC Free Prior and Informed Consent

FREDDI Fund for REDD+ Indonesia

FSC Forestry Stewardship Council

GDP Gross Domestic Product

GHG Greenhouse Gas

GVC Global Value Chain

IFC International Finance Corporation

IFCA Indonesia Forest Climate Alliance

INGO International Non-Governmental Organisation

LNGO Local Non-Governmental Organisation

Lol Letter of Intent

MoEF Ministry of Environment and Forestry 


$\begin{array}{ll}\text { MoF } & \text { Ministry of Forestry } \\ \text { MRV } & \text { Measuring, Reporting and Verification } \\ \text { NGO } & \text { Non-Governmental Organisation } \\ \text { PDD } & \text { Project Design Document } \\ \text { PES } & \text { Payment for Ecosystem Services } \\ \text { PIN } & \text { Project Idea Note } \\ \text { PNGO } & \text { Private NGO } \\ \text { PRISAI } & \text { Principles, Criteria, Indicators for REDD+ Safeguards in Indonesia } \\ \text { PSF } & \text { Profit-Seeking Finance } \\ \text { RAN GRK } & \text { National Action Plan to Reduce Greenhouse Gas Emissions } \\ \text { REDD+ } & \text { Reducing Emissions from Deforestation and forest Degradation } \\ \text { RSPO } & \text { Roundtable on Sustainable Palm Oil } \\ \text { VCS } & \text { Verified Carbon Standard } \\ \text { UNFCCC } & \text { United Nations Convention on Climate Change } \\ \text { UN-REDD } & \text { United Nations Collaborative Programme on REDD+ } \\ & \end{array}$

Parts of Chapter 1, Chapter 5 and section 9.3 include edited excerpts from a paper published in a special issue of Asia Pacific Viewpoint (Dixon \& Challies 2015). Ed Challies acted as co-author by assisting with editing the final version of the article. All sections of the article and its replication here were written by the primary author and author of this thesis, Rowan Dixon. 


\section{Introduction}

Forests have recently attracted attention from investors seeking capital gains from a novel commodity. Not traditionally the concern of international finance, the carbon stored within forests has emerged as an investable object. Following global efforts to reduce greenhouse gas emissions, the conservation of forest carbon has been touted to deliver capital profits through carbon markets. The intervention is through the REDD+ (Reducing Emissions from Deforestation and forest Degradation plus) ${ }^{1}$ mechanism (UN-REDD, 2015). REDD+ is a real world exercise in "putting a value on nature [emphasis added]" (Sukhdev, 2011), aiming to revalue and reconstitute forests as commodities that can be invested in. Profit-seeking finance packages forests as environmental assets for exchange and accumulation. However, this entanglement between REDD+ and profit-seeking finance in Indonesia has yielded mixed results.

Despite supposed coherence as a global programme - championed by the United Nations Collaborative Programme on REDD+ (UN-REDD) and the World Bank's Forest Carbon Partnership Facility (FCPF) - REDD+ is emerging in highly contingent ways across the global South. As part of wider voluntary carbon market mechanisms, REDD+ has developed in a decentralised fashion, with minimal formal regulation, and confronting numerous methodological obstacles. Sometimes considered the 'wild west' of the carbon economy, these voluntary forest carbon markets evolved alongside the various and much larger compliance markets established under the international climate regime, most notably the Clean Development Mechanism (CDM). The process of consolidation and regulation for REDD+ has brought about increasingly reputable voluntary private standards. However, REDD+ offsets remain a

\footnotetext{
${ }^{1}$ The ' $t$ ' refers to the sustainable management of forests and conservation and enhancement of forest carbon stocks.
} 
small part of the voluntary carbon market, accounting for around nine per cent of transactions (Kossoy \& Guigon, 2012; Peters-Stanley \& Yin, 2013).

The future costs of addressing climate change are unclear, and estimates of the financial resources required over the coming decades vary widely. The United Nations Convention on Climate Change (UNFCCC, 2007) estimated new and additional investment required by 2030 to be around $0.3-0.5$ per cent of global GDP per annum. This is expected to include $\$ 200-210$ billion for mitigation and $\$ 49-171$ billion for adaptation. ${ }^{2}$ These preliminary figures have since been described as considerably under-estimated (e.g. Fankhauser, 2010; Parry, Lowe, \& Hanson, 2009). Efforts to 'cost' climate change typically reference impacts on (global) GDP, and take as given a need for continued economic growth. While such cost estimates are therefore prone to the same critiques as GDP as a flawed indicator of social welfare and development (Fleurbaey, 2009), international climate change policy is currently shaped by a dominant narrative constructed around the financial costs of mitigation and adaptation, and the need to leverage considerable new and additional finance.

The likely costs are therefore assumed to be very high and to outstrip the resources available to national governments and multilateral institutions (Ervine, 2013). Consequently, the 'private sector' has been invoked as the last bastion with sufficient finance to fund mitigation and adaptation (Newell \& Paterson, 2010). This assertion runs counter to the standard liberal notion of states as the investors of last resort. However, given the considerable financial resources controlled by the private sector, and considering the role that private business has played in driving global emissions, private finance is touted as a potential source of socially just climate change mitigation and adaptation investment. This desired co-option of private finance has driven the establishment of requisite market mechanisms. This favour of 'flexible mechanisms' has brought about the preference of emissions trading and offsets, rather than mitigation via command and control. Subsequently, increasing attention focuses upon optimising markets and incentivising the shifting of global

\footnotetext{
${ }^{2}$ All references to dollars refer to US dollars.
} 
private investment patterns towards mitigation and adaptation activities (Corbera, 2012; Fulton \& Capalino, 2014; Héritier \& Lehmkuhl, 2008; Petherick, 2011; UNEP-FI, 2014; World Economic Forum, 2013).

Despite the UNFCCC's slow progress in developing a mechanism to avoid deforestation, significant public sector resources have been channelled into REDD+ (Nakhooda et al., 2013). Bilateral grant - and conditional loan - based finance from donor countries (e.g. Norway, Germany, the United States) and multilateral institutions (e.g. the World Bank, UN-REDD) ${ }^{3}$ has comprised the vast majority of finance so far. It has focused primarily on research and capacity building in order to help forested countries attain 'REDD+ readiness' through establishing the institutions, strategies and practices required to implement national-scale REDD+ programmes. Anticipating this market readiness and inclusion within compliance markets like the CDM, a diversity of REDD+ projects or demonstration activities have been developed in a number of developing countries. Just as private market actors boosted emissions trading while the Kyoto process lagged through the late 1990s (Newell \& Paterson, 2010), diverse non-state actors have driven an early proliferation of REDD+ projects.

This research is focused on the emergence of REDD+ in Indonesia, which has been of major relevance to global forest carbon mitigation efforts because of the country's large forest area, extensive peatlands, and high rates of deforestation (Margono et al., 2014). At the same time palm oil, timber, mining and other extractive land-based industries represent politically and economically powerful, deeply embedded interests. As such, Indonesian forests have become ideal candidates for REDD+ finance, and Indonesia has sought to position itself internationally as a REDD+ pioneer.

Indonesia began concerted planning for REDD+ relatively early on, and actively sought a lead role in piloting avoided deforestation. In advance of the 2007 Bali

\footnotetext{
${ }^{3}$ For detail on climate funds focusing on REDD+ finance see http://www.climatefundsupdate.org/themes/redd (Accessed 30.10.2015).
} 
climate talks, the Indonesian Ministry of Forestry oversaw the Indonesia Forest Climate Alliance (IFCA), which explored the feasibility of implementing REDD+ in Indonesia. Since 2007 Indonesia has built on the IFCA assessment with a number of supporting laws and landmark achievements. By 2009 the Government of Indonesia committed to a national emissions reduction target of 26 per cent below businessas-usual by 2020 , or 41 per cent with international support. Shortly after, the Government established the Indonesia Climate Change Trust Fund to link international donor funds to national mitigation and adaptation activities. The National Action Plan Addressing Climate Change was also established, and forest rehabilitation was included in Indonesia's 2010-2014 National Medium Term Development Plan.

In 2011 Indonesia attracted significant international support for its efforts, signing a Letter of Intent with Norway, which committed \$1 billion in support. In response, Indonesia established a moratorium on new permits to clear primary forests. By late 2011 the national REDD+ Task Force was established to implement the moratorium and oversee Indonesia's REDD+ programme. The Task Force launched Indonesia's National REDD+ Strategy in 2012. Meanwhile, Indonesia has continued to progress within UN-REDD and FCPF programmes to support its national REDD+ readiness and finance efforts. Exact figures are hard to come by but between 44 and 77 REDD+ projects and provincial REDD+ pilots are currently in various states of operation (Jaung \& Bae, 2012; Minang et al., 2014; Myers et al, 2010).

Indonesia was selected as the case for this research because of its high rates of carbon emissions from deforestation (approximately 903,000 tonnes per annum) and the REDD+ activities it is pursuing to mitigate them (Indrarto et al., 2012). The Indonesian Government has sought to demonstrate commitment and leadership in the emerging global REDD+ programme through efforts to balance deforestation drivers like palm oil, timber, pulp and paper and mining with ambitions for forest conservation. This has seen the establishment of institutional structures and strategies to prepare REDD+ systems for implementation across Indonesia. These efforts to create a supportive context for REDD+ have increased the attractiveness 
of, and investment appetite for, REDD+ demonstration and pilot projects in Indonesia, and drawn in a variety of private and profit-seeking finance. Together, these developments make Indonesia an ideal case to investigate the influence of REDD+ finance in the context of market-environmentalist efforts to mitigate climate change.

\subsection{Research outline and questions}

REDD+ is an example of market environmentalism, which seeks to govern resources via market mechanisms whilst optimising economic, social and environmental ends (Anderson \& Leal, 2001). Drawing on principles of environmental economics, market environmentalism seeks to address environmental problems by internalising environmental externalities within market exchanges (Anderson \& Leal, 2001).

Concepts like 'ecological overshoot' (Parry et al., 2009; Wackernagel et al., 2002) and 'limits to growth' (Ekins, 1993; Meadows, Meadows, Randers, \& Behrens, 1972) have encouraged research on 'sustainable development' (Rogers, Jalal, \& Boyd, 2008), 'green growth' (Bowen \& Fankhauser, 2011; Hallegatte, Heal, Fay, \& Treguer, 2011; OECD, 2011) and even 'de-growth' (Kerschner, 2010; Martínez-Alier, 2009; MartínezAlier, Pascual, Vivien, \& Zaccai, 2010). Initiatives in pursuit of these ideas have mobilised from diverse coalitions of interests and historical-political agreements and compromises - from formal global governance institutions like the United Nations ${ }^{4}$ and the Global Green Growth Institute to locally inspired actions of individuals (Adger, Arnell, \& Tompkins, 2005; Cash et al., 2006).

Historically depending upon unpredictable financial aid, market environmentalism espouses that such efforts would receive reliable financial support if they are subject to the same financial allocation logics as the wider global market-based economy (Adler, 2002; Bakker, 2005; Ervine, 2013; Newell \& Paterson, 2010). However, the revaluation of global forests is complicated by an unstable relationship between

\footnotetext{
${ }^{4}$ Notably the 1992 United Nations Conference on Environment and Development (UNCED), and the 2012 follow-up United Nations Conference on Sustainable Development (UNCSD).
} 
profit-seeking finance and the novel REDD+ forest carbon asset (Boyd, Boykoff, \& Newell, 2011). The response and behaviour of profit-seeking finance has proven heterogeneous, with each foray into REDD+ characterised by different strategies and measures of success (Fosci, 2013; Kossoy \& Guigon, 2012; Peters-Stanley \& Yin, 2013; UNEP-FI, 2014).

These behaviours remain relatively unexplored (Bernard, McFatridge, \& Minang, 2012), but through a market environmentalism lens they reflect the evaluative costbenefit decisions that capital makes in its search for profits. Subsequently, understanding the ways that profit-seeking finance evaluates REDD+ investment opportunities offers insight into the rationales and motivations that in turn shape REDD+ and forest-climate governance (Lövbrand \& Stripple, 2012; Nadvi, 2008; Okereke, Bulkeley, \& Schroeder, 2009; Steurer, 2013). It is this broad theme of market environmentalism and the privatisation of environmental governance that this thesis explores, via detailed empirical inquiry into how and why profit-seeking finance has engaged with REDD+ and how that involvement is influencing forestclimate governance.

This thesis uses the term 'profit-seeking finance' rather than 'private finance' to refer to the collection of finance that is seeking a return on its investment in REDD+. By doing so it excludes aid-based or grant finance that does not seek a return, and is thus not profit-seeking - falling outside of market environmentalism. The term 'profit-seeking finance', which may include public and private investments, is preferred as it directly connects the profit-seeking mode of governance and allocation that is espoused within market environmentalism. In contrast the term 'private finance' refers to finance that is privately owned and thus it is also likely to be, but not necessarily, seeking a return on investment.

Charitable private finance, for example, may not seek a profit. The public/private finance distinction risks further muddling as 'public finance' need not be charitable, and may instead seek returns on investment. For these reasons 'profit-seeking finance' (PSF) is used to refer to finance in REDD+ that is seeking financial returns on 
investment (Lövbrand \& Stripple, 2012). However, in following the environmental governance literature, the governing role and influence of PSF and actors within it is examined as an important manifestation of 'private governance', in terms of governance by 'new' governing actors beyond the state and its agencies.

Forest conservation initiatives based on PSF principles and the 'neoliberalisation of nature' have attracted critique for exploiting forests and forest peoples for financial profit (Castree, 2008; McAfee, 1999). The focus of this research is to explore and unpack the diverse engagements of often homogenised 'profit-seeking' actors in these processes (Lövbrand \& Stripple, 2012). In so doing, the aim is to bring to the surface and tease out the diverse characteristics of PSF actors and their influence as agents of private governance within REDD+ projects in Indonesia. Three core questions guide this research:

1. Who are PSF actors that support REDD+ projects?

2. Why do PSF actors support REDD+ projects?

3. What are the governance implications of PSF actors on REDD+ projects?

This thesis has been written in the context of a wider Marsden-funded research project investigating the political ecology of REDD+ in Indonesia (Dixon \& Challies, 2015; McGregor et al., 2015; McGregor, 2015). The research draws on key informant interviews with actors across Indonesia's REDD+ community, focusing upon those relevant to PSF. Three REDD+ projects were selected as case studies to analyse and illuminate the above questions. These case study projects involve a variety of PSF actors and exemplify the differing governance characteristics and influences they exert in the creation and evaluation of REDD+ projects. The theoretical basis for this research is introduced below.

\subsection{Theorising the research questions}

Within their market environmentalism framing, REDD+ projects are often conceptualised as commodities. As a form of commodity REDD+ projects are open to 
analyses of their movement and circulation within global value chains (Gereffi, Korzeniewicz, \& Korzeniewicz, 1994; Gereffi \& Fernandez-Stark, 2011). This research draws on the global value chain (GVC) framework to analyse REDD+. Such an approach facilitates exposure and in-depth analysis of the practices by which actors coalesce and commodify bundles of REDD+ attributes (conservation and enhancement of forest carbon stocks, sustainable management of forests, community development, biodiversity conservation) and 'put a value on' them.

A GVC framework supports close analysis and helps provide a clear picture of exactly what REDD+ projects and attributes are and the ways that they are governed. It helps gather and interpret the components and actors on 'supply chains' that contribute to the 'production' of commodities (Bernstein \& Campling, 2006a, 2006b), and in doing so, expose the inner workings of such commodities. A GVC framework can also assist in teasing out the governance characteristics within and amongst REDD+ projects, including the influence of private actors. Here a broad definition of governance is taken (following Kooiman, 2003) as encompassing a wide spectrum of arrangements among societal actors (within and across the public and private sectors, and civil society) aimed at negotiating and securing collective interests. Governance, in this vein, comprises:

the totality of interactions in which public as well as private actors participate, aimed at solving societal problems or creating societal opportunities; attending to the institutions as contexts for these governing interactions; and establishing a normative foundation for all those activities (Kooiman, 2003, p. 4).

Such a definition demands that governance research explores the roles and strategies of a variety of the 'non-traditional' governing actors beyond the state. Processes of commodification occur within institutional contexts manifested by public and private cross-scalar regulation across forestry, land-use, economic and environmental sectors. These contextual and institutional settings influence the way that PSF actors evaluate REDD+ projects, which in turn affects the nature and dynamics of forest-climate governance more generally. In this way, REDD+ projects 
introduce the desires of investors, companies, customers, shareholders, public and local actors into broader governing frameworks (Fieldman, 2013; Harmes, 2011; Lazonick \& O'Sullivan, 2000; Sullivan, 2013). This influence of PSF actors is captured within the term financialisation, which refers to the increasing role of financial motives, markets, actors and institutions in the operation of economies (Epstein, 2005; Knox-Hayes, 2015).

Exploring REDD+ through a GVC lens has been suggested by some authors (Bumpus \& Liverman, 2011; Gibbon, Bair, \& Ponte, 2008), but so far has not been undertaken. Whilst some practitioners have described REDD+ supply chains in a general sense (Bernard et al., 2012), this thesis responds to the opportunity to connect REDD+ with insights from GVC approaches and contribute to the advancement of these literatures. In addition to focusing on the commodity, the actors and the governance relations among them, a GVC approach can also shed light on the circulation of meanings and knowledges as epistemic circulation (Büscher, 2014; Graham, 2006). Here, epistemic circulation is defined in line with Büscher (2014, pp. 79-80) as:

general circulation of interpretations of value through time and space with a particular focus on ... a specific community of experts sharing a belief in a common set of cause-and-effect relationships as well as common values to which policies governing these relationships will be applied.

In the context of this research, this implies a focus on the ways in which REDD+ projects are about the creation and exchange of meanings along a GVC and within an economy that is primarily concerned with knowledge. For REDD+ this knowledge concerns the meanings that are being made within forest conservation and development activities supported by specific REDD+ standards. This extends the scope of analysis beyond the material flows that concern many traditional GVC analyses, and moves into the spatial circulation of meanings.

The GVC framework becomes particularly useful in exposing the processes and politics that 'put a value on' natural forest, thereby illuminating what REDD+ 'is'. 
With an improved understanding of how natural forests are valued within REDD+, the evaluative practices of PSF actors can also be examined and interpreted to better understand why they are involved (Gibbon et al., 2008; Starosta, 2010a; Vagneron \& Roquigny, 2011).

\subsection{Summary and thesis structure}

In linking these ideas, this research feeds into broader thinking about market environmentalism. The case of PSF in REDD+ contributes an instructive example of the complex processes of valuing nature. Market environmentalism sits at the awkward intersection between subjective private perceptions of an ecosystem's and community's value, and the supposed objective valuations of REDD+ standards and natural capital accounting techniques. REDD+ projects analysed here demonstrate the contradictions of capitalism that rest at the centre of market environmentalism and its neoliberal convention of 'selling nature to save it' (Bakker, 2010, 2012; McAfee, 1999).

Following this introductory chapter the research questions are addressed according to the following thesis structure (also depicted in Figure 1.1). Chapter 2 presents the theoretical framework which underpins the research. It begins by framing market environmentalism, private governance, and financialisation within international carbon emission reduction economies. This is then linked to GVC analysis and epistemic circulation to further understand the REDD+ commodity and evaluation practices. The research methodology is described in Chapter 3, and illustrates the types of information and breadth of public and private informants that were targeted in Indonesia and beyond. I explain how I approach three case study projects exploring PSF and governance, while also reflecting upon my positionality as researcher. Chapter 4 outlines the contextual setting of this research within the global program of REDD+ and its expression in governance arrangements in Indonesia. Chapters 5, 6, 7, and 8 discuss the results of the research. 


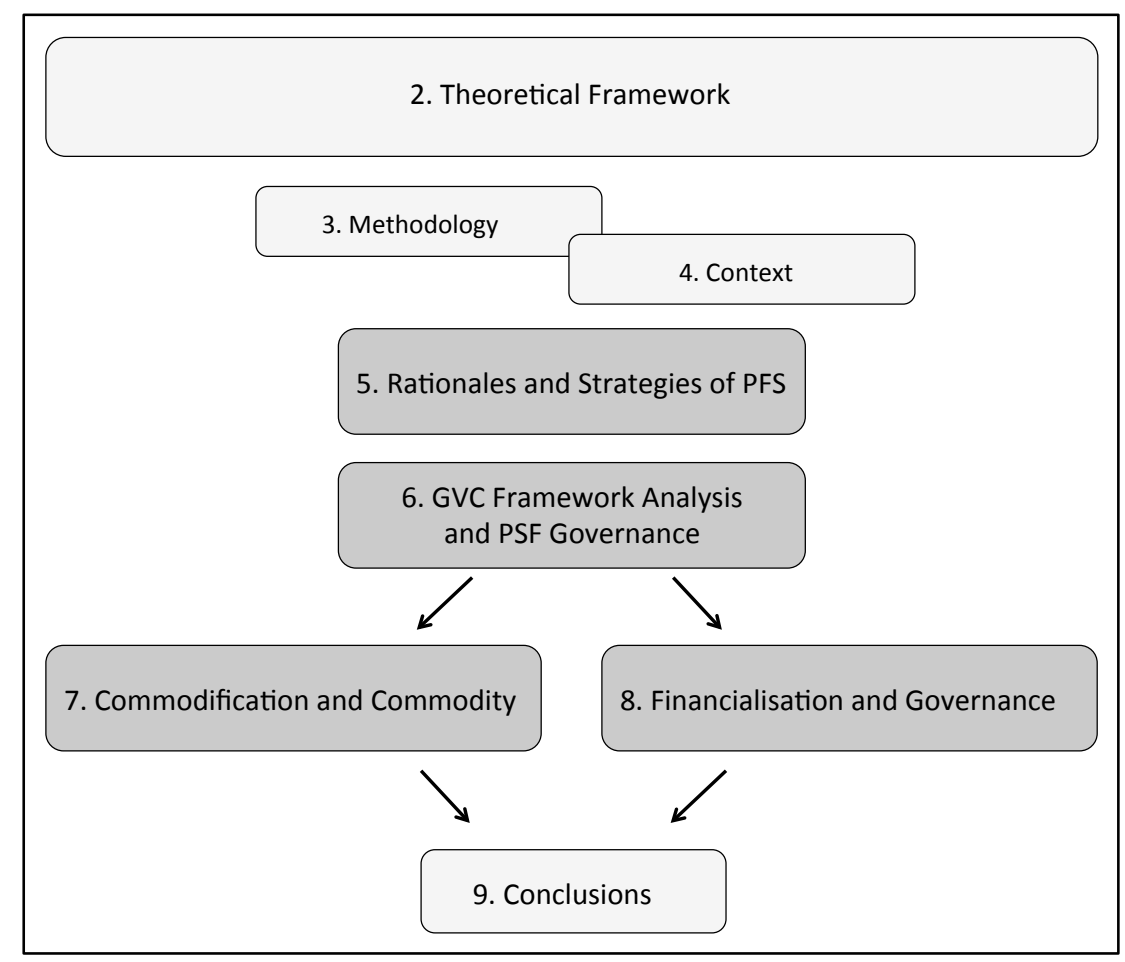

Figure 1.1: The following thesis structure.

Chapter 5 lays out the role of PSF within the context of Indonesia's emergent REDD+ programme and reflects upon this in the context of the privatisation of governance and market environmentalism. It expands on types of PSF and the strategies of PSF actors - most specifically, how they have responded to the REDD+ experiment in Indonesia. Chapter 6 draws on the GVC framework to analyse REDD+ in Indonesia using three case study REDD+ projects. Chapter 7 refers to the case studies to discuss processes of commodification, the character of the REDD+ commodity, and how PSF actors evaluate it. Chapter 8 presents evidence of financialisation within Indonesia's REDD+ program, exploring how financial mechanisms influence the governance of REDD+ projects, their commodities, and knowledge economies. Chapter 9 concludes the thesis and responds to the overall research aim of understanding the governing influence of PSF in Indonesian REDD+ projects. 


\section{Theoretical Framework}

\subsection{Introduction}

This chapter lays out the theoretical framework underpinning the research. It begins with an exploration and theoretical justification of REDD+ as market environmentalism. Next, the global value chain framework is introduced. The ways in which a GVC approach illuminates the mechanics of REDD+ market environmentalism, specifically processes of commodification and the commodity, are discussed. The section following this links the REDD+ GVC framework to concepts of the knowledge economy and 'epistemic circulation', which provide insight into the characteristics of the REDD+ commodity, its value, and the processes of evaluation that support it.

The thesis therefore makes theoretical contributions in three areas: the conceptualisation of the REDD+ commodity, the exploration of value within GVC theory, and the motivations and governing influence of PSF within REDD+. The concepts introduced in this chapter are applied and expanded upon in the subsequent discussion chapters. Figure 2.1 below illustrates the narrative of this theoretical framework and reiterates the research questions. 


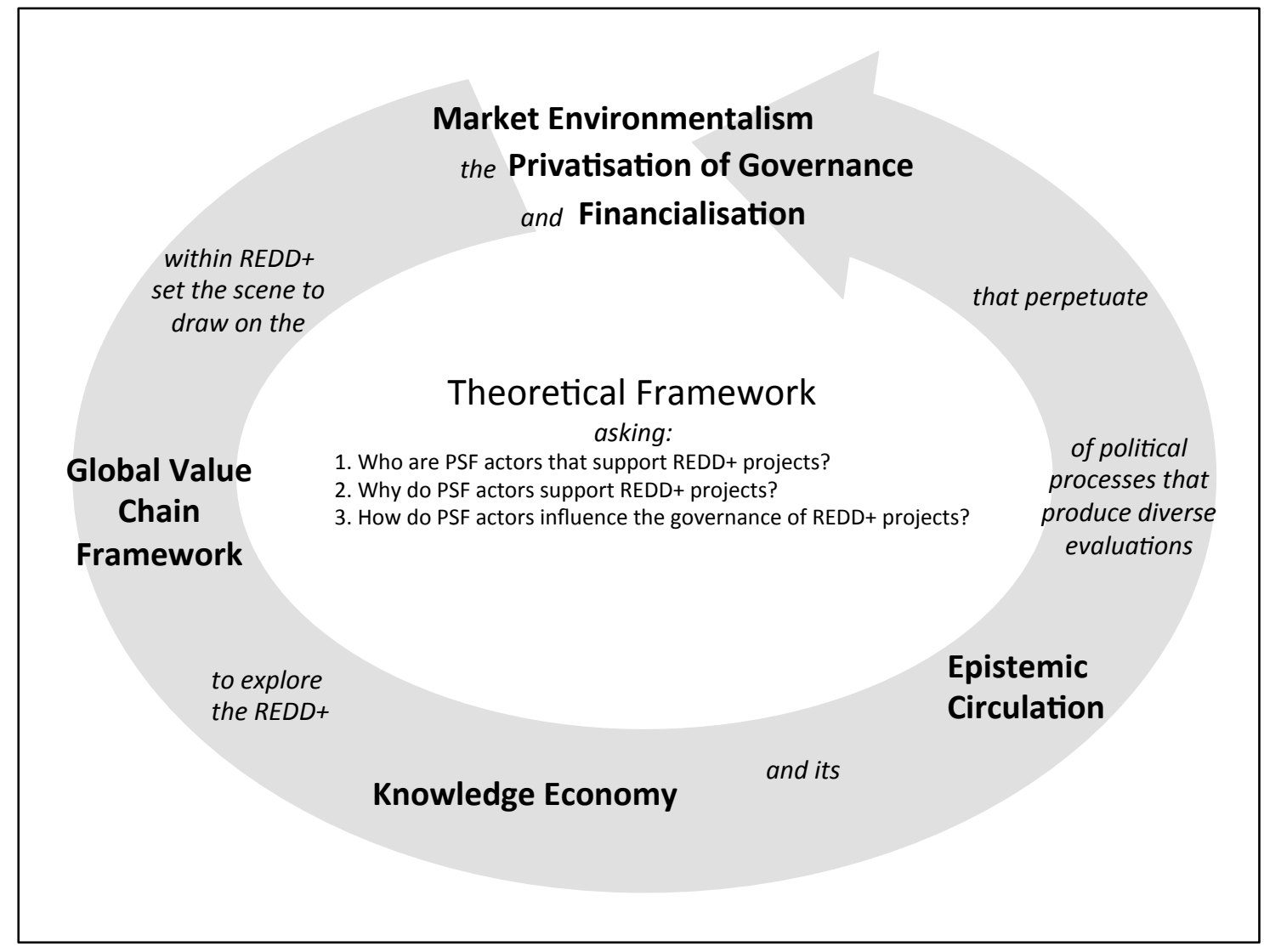

Figure 2.1: Narrative and approach Chapter 2.

\subsection{Market environmentalism}

Market environmentalism's 'putting a value on nature' typically manifests putting a price on environmental services. Damaging those services costs more - making them less attractive to market actors and thus facilitating more sustainable decisionmaking (Bakker, 2005). Processes within REDD+ projects ascribe attributes (conservation and enhancement of forest carbon stocks, sustainable management of forests, community development, biodiversity conservation) that REDD+ markets evaluate and price in their program of 'selling nature to save it' (McAfee, 1999). Subsequently, PSF actors satisfy their desire to associate and attach these attributes to their identities by financing a REDD+ project.

The literature on market environmentalism intersects with work on the neoliberalisation of nature (Bakker, 2005). The latter describes the prevalence of neoliberal capitalist regimes in environmental governance and resource 
management (Bakker, 2005). The neoliberalisation of natural resources and natural places (such as forests) frequently entails practices of commodification to facilitate market exchange (Bakker, 2005). Market environmentalism uses these practices to attempt a type of 'moral economy' with 'moral commodities' that either rely on or subvert customers' moral compass and willingness to 'care at a distance' from the where they are produced (Bryant \& Goodman, 2004; Goodman, 2004; Sayer, 2003).

There has been increasing interest in how consumers consume such moral commodities (Barnett, Cloke, Clarke, \& Malpass, 2005; Clarke, 2008), particularly regarding carbon and offset commodities (Ciscell, 2010; Lovell, Bulkeley, \& Liverman, 2009; Spaargaren \& Mol, 2013). Globalised society and economy appears to be relying on market environmentalism and green products to facilitate consumers 'purchasing' their economies out and away from the climate change issue (Krahmann, 2012; Girod, van Vuuren, \& Hertwich, 2014). In these cases a corporate approach to carbon accounting and management has become standard practice (Pinkse \& Busch, 2013), and PSF actors and customers are investing in offsets in the hope that capitalism and consumption can solve the problem (Ervine, 2012). As McGregor et al. (2015, p. 141) point out, the "pervasiveness of this market environmentalism... as 'common sense' is evident in the design and rationale of REDD+". However, this market-based allocation of resources under capitalism remains subject to critique.

Critique of market environmentalism engages its neoliberal roots (Bakker, 2010, 2012; Castree, 2008). It directs attention to the ways that capitalist modes of production exacerbate inequality within society whilst harbouring an insatiable appetite to perpetually accumulate value (Bakker, 2005; Harvey, 2006) - the same appetite that is credited with the existing environmental and social damages that REDD+ is attempting to remediate through the revaluation of forests (Dunlap, 2015). In this way, REDD+ is reflected as a re-embedding and 'renaturing' of the economy (Boyd et al., 2011; Bumpus, Liverman, \& Lovell, 2010; Dunlap, 2015; Dwyer \& Ingalls, 2015; Lohmann, 2010; Robertson, 2012). This illustrates the literal contradictions of capitalism that McAfee (McAfee, 1999, 2012) captures in the phrase 'selling nature 
to save it'. Critics suggest that capitalism's inner private-profit ambitions may not align with ecologically sustainable societies (Bakker, 2010). As Bakker (2012) points out, scholarship of neoliberal natures:

moves us beyond neoliberalism-as-doctrine, through offering a rebuttal to proponents of 'free market environmentalism' (or 'green neoliberalism,' as opponents term it). This is accomplished through documenting the limits to nature's neoliberalisation (Bakker, 2012, p. 111).

This research aims to contribute to this broad area of work through exploration and documentation of the behaviour of PSF actors in evaluating and governing REDD+ projects in Indonesia. At the same time, it is important to recognise that neoliberalisation is not a homogenous and universally pernicious process, and demonising it risks missing potential opportunities to improve environmental and social wellbeing (Bakker, 2005; Castree, 2003). Bakker (2005, p. 561) cautions against causal assumptions that the neoliberalisation of natures is negative:

Acknowledging that market environmentalism is implicated in broader processes of reregulation, which do not necessarily have negative implications for the environment, may open up opportunities for securing improvements in environmental quality.

This, according to proponents, is precisely where REDD+ sits. Whist clearly being an exercise in privatisation and commodification, it is potentially advantageous to reserve judgement as to the negative connotations that such paradigms often bring, and take up the opportunity to explore the "geographical dimensions of neoliberal contradictions" (Mansfield, 2004, p. 571). As Lefebvre (1991, p. 341 emphasis in original) writes "[t]he commodity is a thing: it is in space and occupies a location". Thus the REDD+ commodity might also express essential, tangible and diverse geographical roots as it generates value and meaning. Importantly, Bakker (2005, p. 560) recognises that: 
this approach avoids the pitfall of assuming that neoliberalisation is hegemonic; rather, acknowledging that the architects of privatization lacked a clear blueprint for how a privatized system would function (beyond the abstractions of economic theory) allows for a focus on the ensuing process of experimentation and reregulation, thereby recasting commodification as transient and partial. In refusing to treat neoliberalism as a totalizing project, this approach opens up analytical opportunities for undermining the narratives of resource triumphalism often associated with projects of neoliberal nature, such as market environmentalism.

The reregulation process of market environmentalism usually involves three interrelated processes of privatisation, commercialisation and commodification (Bakker, 2005). Privatisation refers to increasing private sector management and governance. Commercialisation refers to the ways that a project's principles, methods and objectives are increasingly geared to and shaped by the market (Leys, 2001). Privatisation is the 'who', while commercialisation is the 'how' and neither necessarily require the other (Bakker, 2005). Commodification is the 'creation of an economic good through the application of mechanisms intended to appropriate and standardize a class of goods or services, enabling these goods or services to be sold at a price determined through market exchange' (Bakker, 2005, p. 544). The process of commodification positions commodities as the 'DNA of capitalism' as they embody the capitalist programming that enables market exchange (Watts, 2014).

Neoclassical economics recognises commodification as a precondition for efficient and optimal allocation of resources; where rational evaluation decisions are predicated upon options being known and decision makers being informed (Gasparatos, 2010; Lo \& Spash, 2013; Sijtsma, Van der Heide, \& Van Hinsberg, 2013). However, political economics understands commodification as more complex for things formally outside marketised spheres, and draws attention to the socioeconomic (pricing, charging, allocation and exchange mechanisms), discursive (transforming identities and values of things abstracted from their natural context) and material (isolating and extracting desired nature(s) as standardised goods for exchange) dimensions of commodification (Bakker, 2005; Kaika \& Swyngedouw, 
2000; Robertson, 2000; Castree, 2003). These dimensions are often ongoing processes that evolve and change the nature of the commodity through its commodification (Bakker, 2005; Swyngedouw, 1999). In this sense commodification "is not so much a durable state as a series of passing moments, and is continually being negated in consumption or use" (Sayer, 2003, p. 345) where commodities are perpetually re-created. This re-creation is exacerbated by the changing emotional attachments and meanings that consumers often bestow upon commodities (Bakker, 2005; Bridge \& Smith, 2003). These insights recognise that "commodification is transitory, imbued with symbolic as well as economic meaning and may be destabilized through consumption" (Bakker, 2005, p. 545). Some 'natural' commodities are uncooperative as they embody biophysical and spatial characteristics that contradict the requirements of capitalist markets and commodification (Bakker, 2005).

REDD+ essentially entails a variety of schemes oriented at generating payments for ecosystem services (PES) on the basis of techniques of natural capital accounting. These techniques attempt to create a sustainable global market system by rewarding activities that facilitate the ecosystem services necessary for sustainable development but whose contribution had previously been unaccounted for. Natural capital is a concept that accounts for the ecosystem services that a particular ecosystem (e.g. a forest) performs (Costanza et al., 1997; Gasparatos, 2010; Neumayer, 2004). The services that an ecosystem provides (a forest provides clean water, oxygen and food) are monetised into units of capital to facilitate their comparison with monetised human activities that threaten to degrade the same ecosystem. The monetisation of the ecosystem services rests upon calculative accounting practices created and legitimated by the emerging industry around natural capital accountancy (Burkhard et al., 2012; Corbera, 2012). These calculations are designed to measure the benefit that the ecosystem provides for neighbouring and distant human and non-human systems. However, these calculations are extremely difficult to achieve with any realistic accuracy, and carry with them sizable assumptions (Burkhard et al., 2012; Corbera, 2012). 
In natural capital accounting hypothetical scenarios are played out where the costs and benefits of particular actions are compared with the costs and benefits of inaction. By putting a price on ecosystem services, cost benefit analysis can be attempted. If environmental degradation delivers a net benefit then it continues. If degradation delivers a net cost then it does not continue. In determining which is more beneficial - a forest or an agricultural plantation - a cost-benefit calculation facilitates the decision by accounting for and internalising the previously externalised benefits of ecosystem services into the financial system. However, these decisions often rest within deeply politicised contexts and despite appearing objective, are rarely straightforward (Corbera, 2012; McGregor et al., 2015).

If this natural capital calculation finds it most beneficial to maintain the ecosystem and its services, like a natural forest, then this might be facilitated by payments, known as payments for ecosystem services (Büscher, 2014; McAfee \& Shapiro, 2010). Payments for ecosystem services are usually financial and reward or compensate the stewards for their conservation activities. It is this end of generating financial payments for natural forest conservation activities that attracts the interest of PSF actors to REDD+ in Indonesia. PSF actors can profit from on-selling the ecosystem services they have conserved.

Natural capital accounting and payments for ecosystem services schemes demand evidence to legitimately quantify and measure the services provided. Activities within REDD+ projects are compared with each other and against the outcomes that PSF actor's desires and demands. Specific private standards govern and legitimate the quantification and commensuration of REDD+ attributes, including carbon emission reductions, sustainable management, biodiversity conservation and community development (Bernard et al., 2012; Fosci, 2012; Roe, Streck, Pritchard, \& Costenbader, 2013). REDD+ standards (such as VCS, CCB and Plan Vivo, introduced in Chapter 4) perform a core function in affording confidence to PSF actors that REDD+ projects actually embody the attributes that they profess to. The standards offer a brand that REDD+ projects can attach themselves to, and that PSF actors can seek out (Bryant, 2013; Pike, 2015). This is especially relevant where finance is seeking 
particular REDD+ standards that align with certain desires and motivations. REDD+ standards facilitate the efficient exchange of environmental goods and services that market environmentalism and the privatisation of environmental governance espouses.

These standards are particularly important in the case of REDD+. There are considerable risks with the REDD+ program. Given the wide variety of forest types and governance arrangements, protecting them is very difficult and cannot always be guaranteed. The more straightforward financial returns of plantation development are very tempting for profit-seeking actors seeking to satisfy their profit targets. This becomes a significant issue in forest areas where governance is problematic, activities like illegal logging are prevalent, officials engage in corrupt activities, and the disenfranchisement of forest communities is normalised. Even when a forest can be protected via REDD+ there are risks that the activities causing carbon emissions are relocated, or leaked, to other areas. The role of standards - to ensure that the specific outcomes of a REDD+ project are legitimate - is important as it directly connects the influence of private governance to the REDD+ project. If PSF actors or their supporters (e.g. investors and shareholders) do not consider a project to be legitimate then the chances of capital being allocated to support it are significantly diminished. This positions legitimacy as being of prime importance within market environmentalism. However, as legitimacy is a perception held by observers, a REDD+ project can invoke a variety of indicators to construct legitimacy in line with the evaluative tendencies of target financiers.

The outcomes of each REDD+ project must correspond to the natural capital accounting methods of the associated REDD+ standard(s). However, that does not necessarily exhaust the attributes that the REDD+ project has created. It may have created attributes beyond what the REDD+ definition and its standards request. The profit-seeking actors that allocate finance to these projects may be including some of the extra attributes into their calculations when comparing or developing REDD+ projects. The desirability of a REDD+ project as perceived by PSF actors may involve a mix of the REDD+ aims, standards and extra attributes. Despite what draws PSF 
actors to REDD+, it is the overall market environmentalism framework and neoliberal nature rationale that has legitimised its presence in the unfamiliar territory of improving forest governance.

\subsection{Privatisation of environmental governance}

The processes of privatisation, commercialisation and commodification that constitute market environmentalism are re-shaping environmental governance. Governance responsibilities that traditionally rested with offices of state administrators are shifting towards the logic of market exchange (Bakker, 2005) and into the hands of profit-seeking actors. Market exchange begins to weigh on the allocation of resources, contesting and displacing some of the authority of state administrative systems. In this way, capitalist market actors are positioned as influential agents in climate governance, and environmental governance more generally (Lövbrand \& Stripple, 2012; Okereke et al., 2009; Steurer, 2013). Importantly, this does not simply necessitate research on non-state governing actors, but rather on new configurations of actors, and changing rationalities and strategies of governance. Therefore, while this research focuses on actors engaged in financing REDD+ projects for financial profit, the central concern is the different strategies they pursue, and their role(s) in shaping REDD+ projects. The project is interested in "the ways in which business activity is both a response to, as well as constitutive of, environmental governance at the global level" (Levy \& Newell, 2005, p. 2).

Boyd et al. (2011, p. 604) describe the 'carbon economy' as "an historically unparalleled experiment in marketised environmental governance". Through the making of carbon markets, climate change is reconstituted as a business opportunity - or rather multiple new opportunities for capital accumulation (Bumpus \& Liverman, 2008; Paterson, 2012) - rather than only a business risk. In this sense, while carbon markets appear as a particular mechanism for the governance of climate change, carbon markets themselves are reliant on considerable enablement and regulation by governments and multilateral authorities; the markets themselves 
emerge as a field in need of governing. This is particularly the case for voluntary markets, including the market for REDD+ offsets. Very few REDD+ exchanges are directly regulated by formal state-based institutions, but they do occur in the shadow of regulation, in interaction with existing and anticipated compliance markets, and in the context of increasingly social and ecological interpretations of business risk.

The most obvious source of governing authority in the voluntary market is perhaps the various private voluntary carbon standards, which verify emissions reductions and certify project compliance with social and ecological safeguards in the form of REDD+ standards. These have been a focus of recent research on non-state climate governance (Bakker, 2012; Lovell \& Liverman, 2010; Melo, Turnhout, \& Arts, 2014), but their importance in shaping how REDD+ projects unfold varies. Guthman (2007) points out how these types of voluntary standards and branding attempt to bring nature back into market exchange but at the same time privatise property creating access and exclusion barriers where none previously existed (see also Li, 2014). Certification to a given standard provides a basis on which projects and offsets are differentiated in the market, becoming sources of branding and acts of governance (Bryant, 2013). There is also scope to go above and beyond these brands to attract investors and buyers with 'charismatic' carbon credits (Corbera, Estrada, \& Brown, 2009; Wang \& Corson, 2015).

Pinpointing important loci of governance within REDD+ is difficult, as programmes and projects are complex, heterogeneous, and multidimensional (VisserenHamakers, Gupta, Herold, Peña-Claros, \& Vijge, 2012). Governance arrangements implicate broad constellations of actors in pursuit of a variety of (sometimes competing) ends. Furthermore, roles often overlap and while project development, financing, brokerage and so on may be performed by distinct actors, this need not be the case. Therefore, it is of limited value to examine actors in isolation, or to locate governing agency a priori with certain categories of actors (Mol, 2012; Steurer, 2013). The focus on strategies and motivations of finance is not intended to reify a certain set of actors, but rather seeks to explore one locus of governing agency 
(Harmes, 2011) and an aspect of the wider REDD+ governance assemblage that remains under-researched (for instance, in comparison to voluntary private standards or public regulation).

Subsequently, this research adopts an open approach to private governance. The research focuses its questions on how private governance is emerging and shifting in light of REDD+ projects. Such hybrid state and market exchange governance systems have been theorised in the literature on 'non-state market driven' and 'private market-based' governance (Angelsen, Brockhaus, Sunderlin, \& Verchot, 2012; Bernstein \& Cashore, 2007; Cashore, 2002; Loconto \& Busch, 2010; Schroeder \& Lovell, 2012). This body of research is particularly concerned with how private entities become politically legitimate through such hybrid governance systems, which "encourage compliance by recognizing and tracking, along the market's supply chain, responsibly produced goods and services" (Bernstein \& Cashore, 2007, p. 347). Because of this they are recognised as offering the greatest potential to "socially embed global markets" that align with a functioning form of market environmentalism (Bernstein \& Cashore, 2007, p. 347). Bumpus, Liverman and Lovell (2010, p. 1) recognise:

emerging self-regulation of the voluntary carbon market as companies set quality standards in order to respond to criticisms and to anticipate and steer government rules... standards aim to provide a legitimacy that can support both innovation and credible carbon reductions driven by the private sector, rather than imposed by regulatory policy.

Okereke, Bulkeley and Schroeder (2009) also recognise non-state actors as influential governing agents, dovetailing with Lövbrand and Stripple's (2012, p. 671) observations of the "replacement of formal and hierarchical techniques of government with more indirect regimes of calculation". In this sense, commodification and disambiguation methods to package measureable and fungible attributes of REDD+ projects are empowering financial rationales. Paterson (2012, p. 83) recognises that carbon markets "have become popular because they have 
enabled businesses to imagine a cycle of investments, profits and growth centred on these markets that may help processes of decarbonisation". Both Paterson (2012) and Lövbrand and Stripple (2012) also expect these carbon market rationalities to continue to influence climate governance in the future. The inevitability of hybrid public-private governance of the climate response has been recognised by Newell and Paterson (2009, p. 81):

like it or not, neo-liberal capitalism(s) will provide the context and historical moment in which action has to take place. This implies engagement with prominent actors in neo-liberalism from business and finance, whose strategies need to be aligned with the goal of climate protection.

In this view the role of markets, and private finance actors' involvement in them, shifts the focus away from 'whether' and towards 'how' markets and private finance actors can be involved in sustainable governance (Mol, 2012; Mol \& Janicke, 2009). This understanding of how PSF influences environmental governance is where this research contributes, exploring variations within market environmentalism. These are typically expressed as a gradient between unconstrained market activities on one hand, and institutional arrangements for limiting the mobility of financial capital and thereby constraining its "structural power" on the other (Gill, 2003, p. 98). Clearly the financialised influence of investors and shareholders is becoming more important in governance (Fieldman, 2013; Knox-Hayes, 2013).

\subsection{Financialisation in REDD+}

A key factor shaping financial strategies within a market economy is the degree to which PSF actors are influenced by the desires of their shareholders for maximal financial returns, and how much freedom they have to enfranchise their own motivations and supportive actors (Fieldman, 2013; Knox-Hayes, 2013). These variations in financial structures refer to the increasing role of financial motives, markets, actors and institutions in the operation of economies which are "intended to accelerate the rate of profit accumulation from the exchange of financial 
instruments" (Knox-Hayes, 2013, p. 120; Epstein, 2005). These processes are captured by the term financialisation. Their influence on how a corporation is governed sets the tone for its external relations and hence the nature of the economy it contributes to (Fieldman, 2013; Lazonick \& O'Sullivan, 2000). This distinction is relevant as "innovation of any kind is more likely to occur when the power of shareholders over management is constrained, enabling managers to turn their attention inward and towards innovative processes" (Fieldman, 2013, p. 10). This constraint on shareholders enables capital investment in long-term projects with a financial commitment to innovation and long-term gains, like those demanded by REDD+ projects (Crepaz, 1995; Fieldman, 2013; Jahn, 1998; Luttrell, Resosudarmo, Muharrom, Brockhaus, \& Seymour, 2014; Scruggs, 2003).

Without sufficient limits on the influence of certain financial actors within markets, corporate and managerial functions in businesses can be limited and disintegrate into a subservient pursuit of financial profits (Fieldman, 2013; Harmes, 2011; Lazonick \& O'Sullivan, 2000). This is particularly pertinent as the collective power of institutional investors, and customers that help constitute them, can put pressure on companies to prioritise their stock prices and financial profits over corporate innovation (Lazonick \& O'Sullivan, 1997). The phenomenon of financialisation within market environmentalism has positioned private finance actors such that they tend to find themselves bound to deliver financial profits for their stakeholders, while seeking to reshape operations through remediating environmental and social externalities (Fieldman, 2013; Harmes, 2011; Lazonick \& O'Sullivan, 2000).

Ervine (2013) argues for the separation of carbon finance from carbon markets for precisely the reasons that the latter have become mechanisms of capital gain subject to risk volatility and collapse, "since carbon's market value functions as the primary factor determining levels of investment" (Paterson, 2012, p. 8). The World Bank's 2012 'State and Trends of the Carbon Market' report supports this, stating that the growth seen throughout 2011 in the global carbon market was not driven by a demand for offsets, but rather for quick re-sale or to manage risk (Kossoy \& Guigon, 2012; World Bank, 2014). Ervine (2013) sees this as the reason carbon was 
recognised as 2011's worst performing global commodity, and as such sees "a pressing need to step back and problematise the increasing reliance on marketbased carbon finance as the predominant mechanism through which mitigation funds are to be delivered to the global South" (Ervine, 2013, p. 3). The opportunity for financial speculation within carbon markets is risking their diversion from their purpose to mitigate climate change (Mol, 2012). This tendency is recognised by Hiraldo and Tanner (2011b, p. iv), who observe that the drive for "cost effective climate change mitigation mechanisms, national government impetus on growth and the productive power of capitalism within environmental governance has led to the prevalence of market-liberal approaches", including REDD+.

There is a substantial literature on the transformation of ecosystem services into commodities and derivatives that can be traded on financial markets (e.g. McAfee, 1999; Lohmann, 2011; Paterson, 2012). Several authors have discussed how international climate change governance has developed within a "permissive normative context" of contemporary neoliberalism (Paterson, Hoffmann, Betsill, \& Bernstein, 2011, p. 3). That is, climate change governance has preferred market mechanisms and permitted the structural power of capital interests in policy discourse and practice (Bailey \& Maresh, 2009; Ervine, 2013; Lohmann, 2010; Newell \& Paterson, 2010; Paterson, 2012; Spash, 2010). This discussion has been helpful to understand the character of 'environmental' commodities but, as Fieldman (2013, p. 3) points out, three key areas have received little attention, namely:

\footnotetext{
financial liberalisation as a transformative global process influencing state-level social structures of accumulation, the corporate governance systems that are prominent parts of these institutional ensembles, and finally corporations themselves.
}

Essentially, Fieldman (2013) argues that understanding the governance relationship between corporations and their neighbouring actors that express financialised influence is an important part of understanding ecosystem service and climate change commodities and the involvement of PSF in conservation more generally 
(Harmes, 2011; Knox-Hayes \& Levy, 2011; Lazonick \& O’Sullivan, 2000; Lohmann, 2011; Pattberg, 2012).

Securing sufficient time and financial commitment for innovative programmes like REDD+ demands that long-term efforts for sustainable development are rewarded rather than short-term profit-seeking motives. However, the financialisation that has been normalised in contemporary neoliberalism is such that the demands and whims of shareholders and customers tend to directly and immediately impact decisions, and thus the allocation of finance in the global economy. This degree of financialisation risks demanding a level of responsiveness beyond what REDD+ activities are capable of and may distract REDD+ projects from social and ecological goals. Much depends on the motivations, strategies and tactics of PSF actors that gravitate towards REDD+ in Indonesia, something this thesis will focus upon, in part by drawing on a global value chain approach.

\subsection{Global Value Chain analysis}

Global value chain (GVC) research and analogous approaches (for instance, global commodity chains and global production networks) hold considerable potential for researching REDD+. GVC analysis is an analytical frame highly suited to the exploration of geographies of globalising production and consumption in the context of what has been termed an emerging 'network-led development paradigm' (Sturgeon, 1999; Starosta, 2010a; Selwyn, 2012). GVC analyses have been employed effectively to explore different aspects of globalisation - including geographies of production, trade and development, divisions of labour, governance, firm upgrading, power relations, and market dynamics (Durand, 2011; Gereffi et al., 1994; Gibbon et al., 2008; Hartwick, 1998; Hopkins \& Wallerstein, 1994; Hughes, 2001; Selwyn, 2012; Starosta, 2010a, 2010b).

This research is centrally concerned with the relational dynamics between PSF actors and their governance of REDD+ commodity chains. That is, it considers how these actors determine chain structure and dynamics, and how this reflects their efforts to 
maximise the share of value captured (Starosta, 2010a). In this respect, the spatial dimension of GVCs (Yeung, 2007) - insofar as this refers to the geographical relocation of competing capitals, and to network reorganisation in pursuit of profit maximisation (Harvey, 2006) - is also relevant. This is consistent with Lansing (2011), who finds that the spatial and organisational character of forest carbon offset chains shift and meld to capitalist logic as chain participants pursue maximum value (see also Durand, 2011; Xue \& Chan, 2013).

Despite the economic and material focus of GVC research, value chains themselves are importantly shaped and reproduced through politics and contestation within and between places where they 'touch down' (Challies, 2008; Neilson, Pritchard, \& Yeung, 2014). Indeed much GVC research to date has investigated the politics, power, governance and coordination of these chains (Bernstein \& Campling, 2006a, 2006b; Bumpus \& Liverman, 2011; Gereffi, Humphrey, \& Sturgeon, 2005; Palpacuer \& Parisotto, 2003; Starosta, 2010a). Starosta (2010a) observes that the concept of governance within GVCs was originally used to illustrate authority and power relationships that co-ordinate the global division of labour. For example, Gereffi (1994) understood GVC governance structure as socially mediating the material interdependency that characterises "how financial, material, and human resources are allocated and flow within a chain" (Gereffi, 1994, p. 97; see also Gibbon et al., 2008). In this way, governance of the GVC for REDD+ offsets can be seen as an expression of a dynamic forest carbon commodification process (Stephan \& Paterson, 2012).

Drawing on GVC analysis facilitates an investigation of REDD+ value chains across four dimensions (Gereffi, 1994). This involves: 1) understanding the chain's institutional context in terms of the rules and norms within which production activities operate; 2 ) determining the geographic locations of actors engaged in these global chains; 3 ) analysing the 'input-output' structure by which chain actors exchange production material and information in the process of constituting and adding value to the commodity; and 4) interpreting the governance characteristics of the chain and the ways in which key actors influence one another and direct the 
'production process'. Exploration of these four elements can shed light on the creation of the REDD+ project as a commodity and illustrate its social and ecological implications. Viewing the establishment of REDD+ projects, and the activities of associated actors through a GVC lens exposes and helps structure the flurry of activity and investment around REDD+. By drawing on this approach the research can illuminate how PSF actors shape and influence the governance of emergent REDD+ projects. The first element is described and analysed in Chapters 4 and 5 to set up the institutional context of REDD+ projects. The remaining three elements are then analysed in Chapter 6 to expose the workings within REDD+ projects and how PSF actors influence their governance.

Bernstein and Campling (2006b) describe the process and challenge of GVC analysis as extracting a slice from the wider world system, enabling 'isolation' and examination of a discrete network of actors and places engaged in the productionconsumption of a given commodity. Interpreting the slice requires close engagement with the context from which it is extracted, and implies a not unproblematic exercise of reinsertion and re-contextualisation (2006a, 2006b), described in detail in Chapter 6. Exploring REDD+ by drawing on the GVC framework has not been done before although the potential contributions of applying a GVC approach have been hinted at by some authors (Bumpus \& Liverman, 2011; Gibbon et al., 2008). Understanding the relations between profit-seeking actors integrated along GVCs offers important insights into value chain governance (Rabach \& Kim, 1994), and thus private governance more generally.

Gereffi et al. (2005) posit five ideal-type network modes that link profit-seeking actors in GVCs: market, modular, relational, capture, and hierarchy (Gereffi et al., 2005). These structures are separated by high or low degrees of transaction complexity, codifiability of information, and capabilities of actors. These variables together determine the structure, process, and nature of knowledge transfer and legitimation methods, and the extent to which this information can be codified and transmitted efficiently between actors and the capabilities of these actors to do so (Bair, 2009; Gereffi et al., 2005). These five types of GVC governance provide a useful 
framework to make sense of governance within REDD+ GVCs, and are described below and in Figure 2.2 .

Modular networks are reliant on knowledge that is codified for easy exchange, rather than tacit knowledge that is more complex to exchange (Bair, 2009). In this sense, codes replace trust with a lower asset specificity (the degree to which a thing is restricted to specific exchanges) which allows wider, more efficient exchange among actors (Bair, 2009). Relations between actors are highly formalised, with prescribed information structures that facilitate sharing of large amounts of information at considerable economies of scale without relying on trust-based relations (Sturgeon, 2002). Voluntary private REDD+ standards can be seen as an attempt at establishing this type of relation in a similar way to ethical trade certifications like Fair-Trade (Neilson, 2008; Taylor, 2005).

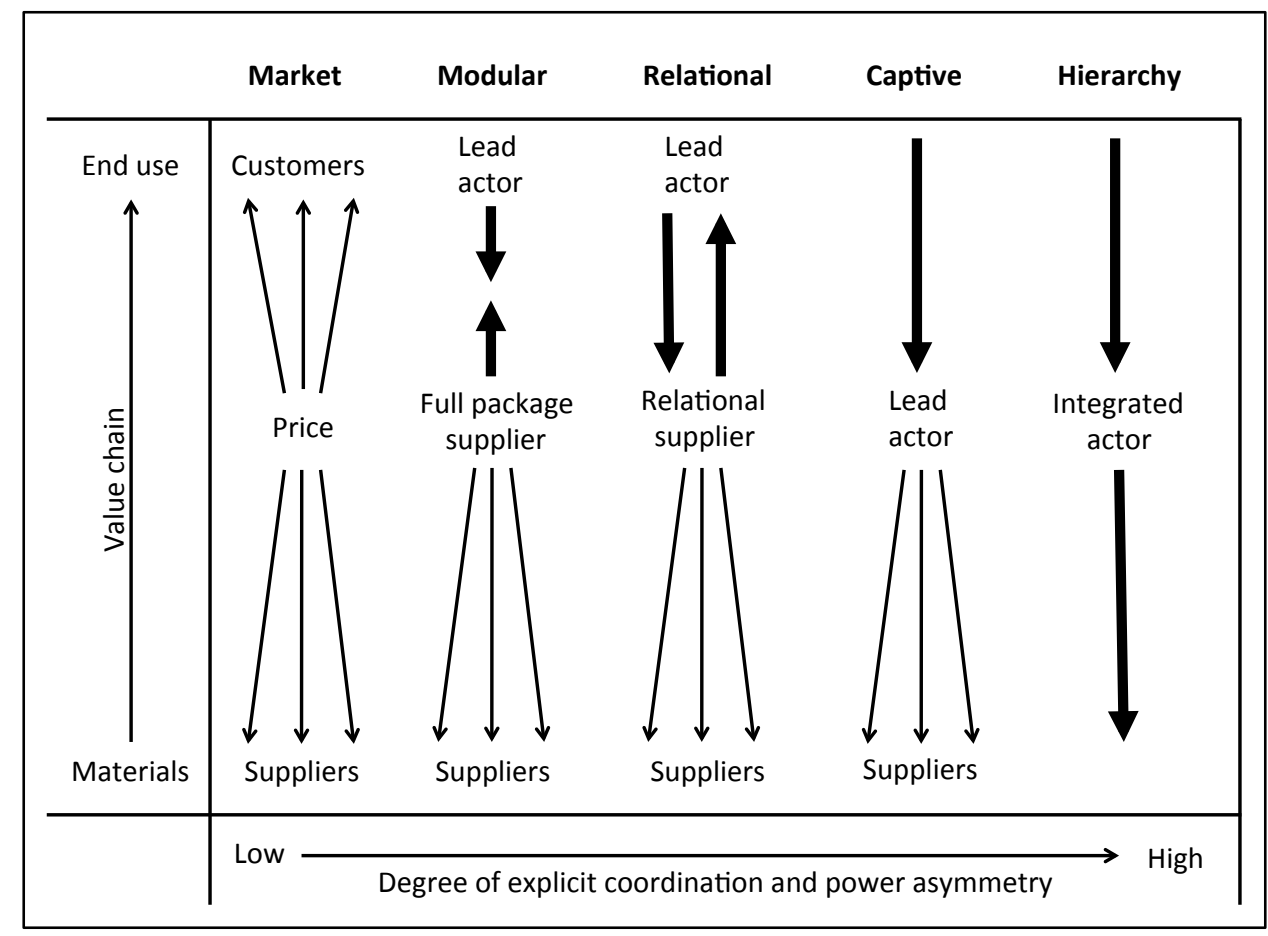

Figure 2.2: Types of GVC governance adapted from (Gereffi et al., 2005, p. 89).

Relational networks describe governance situations where interpersonal relations and communication between profit-seeking actors is frequent and important. Under Gibbon and Ponte's (2008, p. 382) analysis of GVC governance, relational 
coordination is not simply one form of network, but an "overriding prescription" to optimise all exchanges. Such coordination illustrates the ways that relations and exchanges on GVCs are intelligently coordinated, rather than depending on the presence or absence of prescriptive codes. These networks create mutual expectations and relations of trust that overlay market and hierarchy exchanges with social content. This social content amplifies that particular relationship within the wider governance context of the chain, providing for interactive and collaborative action not experienced within markets and hierarchies that are governed more by contractual and legal mechanisms. Relational networks facilitate an enhanced ability to transmit and learn new knowledge and skills.

Captive networks are more asymmetrical, where a certain actor has allocated considerable capital to develop the capacity of other actors, such as suppliers. These vested profit-seeking actors need their allocated capital to deliver a required rate of return in order to remain financially profitable. Consequently these actors demonstrate controlling strategies to retain those actors whose capacity to supply inputs they have enhanced.

These three types of GVC governance are bordered by hierarchical networks and market networks. Hierarchical networks structure an actor to have complete command and control over the happenings between all actors on a GVC. In market networks, in contrast, no actor is structurally positioned as more influential than others, and exchange is absolutely efficient, fungible and without asset specificity (Dicken, 2007; Gereffi et al., 2005). These governance ideal-types of entire GVCs offer helpful frames but can also be understood as 'forms of coordination' at discrete segments of GVCs and at varying times as they develop (Ponte \& Gibbon, 2005). Subsequently, these descriptors are useful for exploring the governance of the whole GVC, and the coordination of particular parts of it, in Chapter 6 where the governance characteristics of REDD+ projects and 'supply chains' are examined and compared. 
According to Sheppard (2011, p. 235), conceptualising a commodity simply as a function of a production chain risks "violence to the complexity, contingency, uncertainty, materiality and complex spatio-temporalities that accompany production". These entanglements, which are inherent in commodity production, ensure it is a highly politicised process where pre-existing power dynamics tend to influence 'who finishes up with what' (Robbins, 2004). Several authors have made a deliberate analytical distinction between the agency exerted by actors seeking to govern GVCs for their own benefit, and the wider indirect capitalist logic that GVCs rest within.

In this vein, Marxian critiques argue that the external manifestations of capital and labour allocations along GVCs are not solely the prerogative of chain actors, but are also subject to indirect capitalist logic (Rainnie, Herod, \& McGrath-Champ, 2011; Selwyn, 2012; Starosta, 2010a, 2010b). The traditional treatment of value within GVC analysis has been to understand it as the change in price of the tracked commodity as it passes through a network of actors, as an input and an output (i.e. 'value added') (Gereffi et al., 1994; Gereffi \& Fernandez-Stark, 2011). Starosta (2010a, 2010b), in particular, delivers a comprehensive value theory analysis of this approach on GVCs (see also Rainnie et al., 2011; Selwyn, 2012; Taylor, 2012; Xue \& Chan, 2013). It is argued that the role and value each actor contributes to a commodity along a GVC is instead largely a product of their position within the global economy, their relationships with other actors, and how competitive they are (Durand, 2011; Bailey, Gouldson, \& Newell, 2011; Xue \& Chan, 2013). These competitive capitalist logics constitute important indirect influences within the REDD+ industry, and are integral to the hybrid, networked, non-hierarchical, marketbased arrangements emerging through collective governance.

Actors within and between groups on GVCs capture and accumulate surplus value to maximise their benefits and by doing so express the scope of their agency (Barrientos \& Smith, 2007; Descheneau \& Paterson, 2011; Lansing, 2011; Rainnie et al., 2011; Selwyn, 2012; Starosta, 2010a, 2010b). The understanding of value distribution, commonly found in the GVC literature, as a function of profitability 
(Giuliani, Pietrobelli, \& Rabellotti, 2005) overlooks where value is actually 'produced' (Vorley, 2003), as well as deeper and exploitative capital-labour relations (Rainnie et al., 2011; Selwyn, 2012; Starosta, 2010a, 2010b). Understanding how these dynamics shape value is crucial for understanding how actors pursue benefits and for their role in REDD+ GVC governance more generally (Gibbon et al., 2008; Starosta, 2010a; Vagneron \& Roquigny, 2011). As Vagneron and Roquigny (2011, pp. 326-327) put it, "[a]lthough the distribution of value within global value chains should seem at the heart of the analysis, this question is often ignored".

Building on some of the critiques cited above, a framework proposed by Selwyn (2012) integrates traditional approaches to GVC analysis (focused on competitive upgrading and rents) with Marxian value theory. The framework relies on a central understanding that capitalism as a system is "based upon two fundamental relationships - competition between capitals and the exploitation of labour by capital" (Selwyn, 2012, p. 222). It is these relationships that give capitalism its character, "implying that new zones of production, markets and working classes will be forever in the making and unmaking" (Selwyn, 2012, p. 222). This has also been conceptualised by Gibbon et al. (2008, p. 324) as a governance process of re-aligning practices to mirror the 'normalised' actions that GVC participants 'should' take under capitalist logic.

Understanding the above conceptual positioning of value within capitalism and GVC analysis becomes important for REDD+. As Lansing (2011, p. 747) points out, "it is not the carbon-in-the-ground that gives an offset its use value. Instead, it is the relational ordering between the spaces of carbon storage, the carbon dioxide emitter, and the atmosphere itself that ultimately makes a forestry offset useful" (see also Newell \& Bumpus, 2012). The significance of this relational ordering is echoed by Bernstein and Campling (2006b, p. 439 emphasis in original) who note that "what most commodity/value chain analysis focuses on above all is relations between capitals". It is this focus, on the relationships between capitals (and actors responsible for them) and how these produce value and influence governance through REDD+ commodification, that GVC analysis has to offer. The above 
understandings of the GVC framework and analysis are further elaborated in Chapter 6 , to explore the three case study REDD+ projects in Indonesia. The following section introduces the idea of epistemic circulation alongside GVC analysis to further guide this research into REDD+ PSF and governance.

\subsection{Epistemic circulation in REDD+ GVCs}

Epistemic circulation refers to the "circulation of interpretations of value through space and time", including those between actors on GVCs and their institutional context (Büscher, 2014, pp. 79-80; Graham, 2006). Here the idea of a GVC is stretched beyond linear material and actor exchanges that have traditionally concerned GVC analyses of value and governance types illustrated in Figure 2.2 (Büscher, 2014). Büscher (2014, p. 80 emphasis in original) identifies the limitations of GVCs in this regard and elaborates that:

Exactly what is meant by 'value' remains unclear ... Value seemingly can be found in almost any material or non-material commodity; as long as it conjures up performances, ideas or knowledges that consumers want to buy (into), it can become a source of profit and hence capital.

These understandings of value are important in the modern global knowledge and finance economy, where many of the goods and services in circulation are less tangible, more ephemeral, and often purely financial (Büscher, 2014; Castells, 2000). The knowledge economy is an economy of meaning where certain classes of meaning are privileged, so "that there are more and less valuable meanings; that access to these meanings is restricted; and that meanings can in fact be owned and exchanged, if not entirely consumed" (Graham, 2006, p. 4; see also Büscher, 2014). Subsequently, value within a knowledge commodity is an idea and experience to be managed and manipulated (Büscher, 2014). Büscher (2014, p. 86) describes how "[t]he commodity here is these new worlds" and how interventions like REDD+ are influenced significantly by the ways in which meanings are produced, exchanged, and evaluated by actors. As financialised markets encourage perpetual and 
accelerated exchange of such knowledge commodities they can become un-hinged from their grounded interventions (Knox-Hayes, 2013).

Meaning-making through demonstrating an interest in environmental, social and governance $(E S G)^{5}$ issues within investments has been recognised by REDD+ PSF actors as serving, corporate social responsibility (CSR) and branding purposes (Hamilton, 2011; Girod et al., 2014; Goldstein \& Gonzalez, 2014). These commercial ESG and CSR interests intersect with literatures that investigate the geographies of branding in value chains and attempt to expose the episteme within knowledge commodities (Pike, 2009a, 2009b, 2011, 2013, 2015), particularly regarding forests and trees (Kronenberg \& Mieszkowicz, 2011). Callon (2005, p. 6) calls the web of "heterogeneous actors ... including marketers, packagers, advertisers, designers, merchandisers, sellers, etc." that perform the branding that becomes knowledge commodities "professionals of entangling". Graham (2006, p. 5) conceptualises knowledge commodities as very strange in the ways that:

they conflate the problems of meaning (the production of socially exchangeable knowledge), mediation (the processes through which meanings are distributed and exchanged), and evaluation (the situation of various classes of meanings within hierarchies of social significance and desirability). To understand the implications of our knowledge economies we need to understand the processes by which meanings are produced, exchanged, and evaluated, and how such processes shape the political character of any given social system.

Both Büscher and Graham recognise that to understand the way that meanings are produced, exchanged and evaluated, and then contribute to shaping social systems, it is necessary to analyse how actors attribute meaning to interventions and how they mediate and evaluate these meanings - specifically, how "performances, ideas, or ways of meaning-making in the marketing of interventions need to be directed at particular donor or policy audiences" (Büscher, 2014, p. 81). The ways in which GVC

\footnotetext{
${ }^{5}$ Environmental, social and governance (ESG) issues refer to aspects of investments that PSF actors consider or enact that demonstrate CSR and responsible investment, whilst serving marketing and branding outcomes.
} 
actors go about 'meaning-making' within REDD+ projects assists this research to understand why PSF actors are involved and how they evaluate REDD+ projects.

Büscher (2014, p. 87) draws on Marx to position epistemic circulation within the neoliberal capitalist political economy where capital is a "value in process [emphasis added]" and depends on the form and velocity of its own circulation to have value (that is, if capital is not circulating it has no value). This 'value in process' is most clearly apparent in financial derivatives, futures and the like, which are particularly mobile (Büscher, 2014). Such instruments are not too dissimilar to those of REDD+ projects, where forest ecosystem services depend upon consistent capital payments to remain valuable. The challenge remains how, empirically, to analyse these knowledge commodities that circulate according to complex geographies of capitalism (Büscher, 2014). In responding to this, Büscher aligns with Starosta (2010a, 2010b) in cautioning against the narrow interpretations of value often present within GVC work, and draws on the complex arrangements of knowledges that influence evaluation practices. Büscher found that epistemic circulation "seems to be emphasized in particular when it comes to value creation in the neoliberal political economy of conservation and development" (2014, p. 87), demonstrating the importance of adapting the GVC framework when applied to REDD+ interventions. Büscher (2014, p. 87) continues, stating:

tracing knowledge commodities through time and space helps us to understand the power and politics of value creation in contemporary conservation/development, while appreciating the complex nature and forms of this value.

Büscher identifies the task ahead as being "to trace the meanings, mediations, and evaluations around an intervention in relation to particular epistemic communities in time and space so as to clarify how ideas about success become capital or 'value in motion'" (2014, p. 81). As such, the challenge for a GVC-inspired analysis of REDD+ is to expose the multiple meanings, mediations and evaluations playing out within REDD+ interventions. Examining these through a GVC lens opens a pathway to understanding epistemic circulations within projects seeking to capture and 
commodify those notions of success that actors desire to be attached to.

Furthermore, because "value statements are malleable 'productions of evaluation"”, actors' evaluations of commodities are observable political processes that signify the 'production' of perceived value (Büscher, 2014, p. 82). These political processes of evaluation are where this research endeavours to engage GVC analysis with the epistemic circulation of REDD+ in Indonesia.

\subsection{Evaluation in REDD+ GVCs}

The above framing of REDD+ GVCs as a financialised form of epistemic circulation offers an opportunity to reflect on the understanding of value and private governance within the GVC literature. This project, therefore, responds to Bernstein and Cashore's (2007, p. 364) call for future empirical research into private governance to involve "theory testing that includes a systematic assessment of the full range of actor motivations, and the factors that influence them, within and across [non-state market-driven governance] communities as these systems evolve".

If something serves some purpose then it is considered to be of value. It has an essentially practical dimension that is socially-determined, influenced to a greater or lesser extent by social norms and practices (Lee, 2011a). Thus "[v]alue is itself socially constructed in and through the social experience of its consumption and production and in the transactions and exchanges involved in its circulation" (Lee, 2011a, p. 374). The exercise of evaluation - to assign something a value - is a social exercise performed as a function of an actor's desire. This desire rests on knowledges that are shaped by complex and reflexive political relationships between material (commodities, objects and things) and social (people in their relationship network) experiences (Lee, 2011a, 2011b). The material experiences influence the social experiences, which then influence the material experiences, with each turn shaping and influencing the knowledges, desires and evaluation processes of actors exposed to these experiences. Such knowledges of what is valuable become recurring fixtures upon which decisions are made and evaluations based (Lee, 2011a, 2011b). For example, a customer's experience of a certain product shapes their 
relationship with the product's company and brand, which in turn influences the products that the company produces, their brand, and so on.

This illuminates the importance of geography and place in understanding how actors in different locations form their knowledges, desires, motivations and subsequent evaluations of commodities in unique and diverse ways (Lee, 2011a, 2011b). GibsonGraham (2006) highlights the diversity within economies as they are practiced within and across places, stressing the significance of geography in understanding how things are valued. In Gibson-Graham's (2006, p. 195) words, one of their goals has been to illuminate political economy's traditionally “impoverished conceptual ground with a rich diversity of economic practices and organizations ... The language of the diverse economy brings into visibility a great variety of economic sites and practices in any particular location".

This increased visibility creates room for further 'novel economic performances' and establishes "the economic landscape as a proliferative space of difference" (GibsonGraham, 2006, pp. xxi-xxii). Diversity between economies in place, and the influence of place on economies, speaks to the plural and reflexive evaluation experienced by actors across Indonesia's REDD+ GVCs. This diverse influence aspires and reflects "a vision of global transformation through the accretion and interaction of small changes in place" (Gibson-Graham, 2006, p. 196) offered by the diverse and grounded roots of REDD+ knowledge commodities (Bakker, 2005; Hughes, 2005). In this way, exploring REDD+ as an example of geographies of alternative exchange and circulation within market environmentalism is a way to test how traditionally 'capitalocentric' such projects are in Indonesia (Gibson-Graham, 2006; Jackson \& Palmer, 2014).

This understanding assists the interpretation of why PSF actors are involved in REDD+ projects in Indonesia and their governing influence on GVCs. As long as there is geography and place then different knowledges, desires, social relations and evaluations of commodities will continue to be recreated. The conceptual model in Figure 2.3 below illustrates this dynamic across the GVC production of REDD+ 
knowledge commodities within market environmentalism. Each actor draws on their place-based knowledges to evaluate incoming material and information, which in turn influences their knowledges and future evaluations before passing on outputs to the next GVC actor. All of which operates within contexts of financialisation and the epistemic circulation of knowledge commodities.

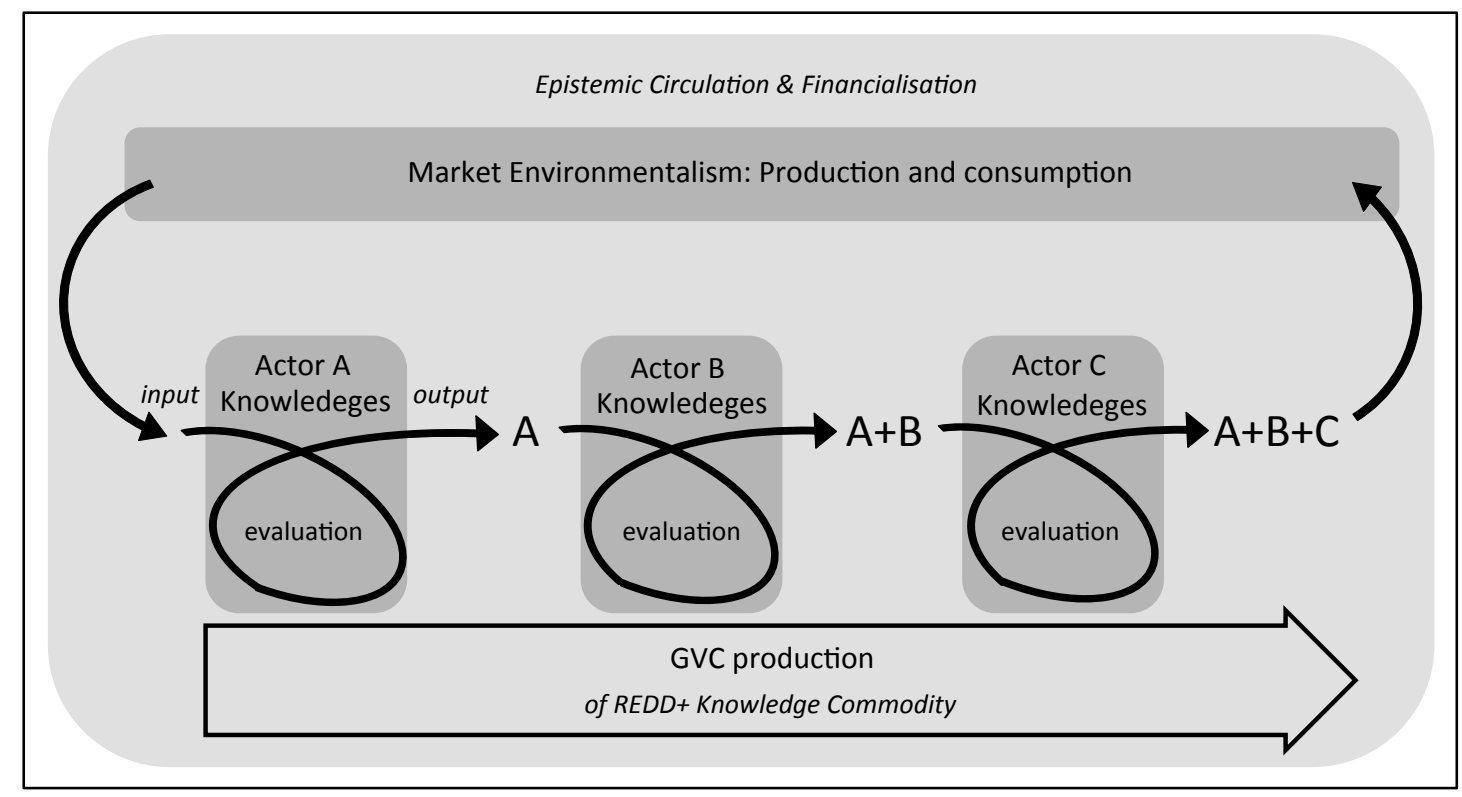

Figure 2.3: Conceptual model of REDD+ market environmentalism in Indonesia.

In this light, the challenge for REDD+ may become less about finding or putting a value on nature (e.g. in the sense of an international carbon price), and more about influencing how values are socially constructed through knowledges and evaluations that engage questions of sustainable development (Büscher, 2014). The test in this research, guided by the conceptual model above, is how these types of questions are playing out among the financial actors within Indonesia's REDD+ projects, whose shareholders and consumers have been, are starting, or are expected to ask such questions.

\subsection{Conclusion}

The theoretical strands discussed in this chapter initially linked REDD+ to market environmentalism, the privatisation of governance and financialisation. I then 
introduced the GVC framework and concepts of epistemic circulation and knowledge commodities that lend tools to investigate REDD+ commodification and evaluation. The spatiality of REDD+ market environmentalism and evaluation was complemented by the place-specific reflexive evaluations of alternative capitalisms, illustrated above in Figure 2.3.

Taking up these theoretical frames, the research addresses the three core research questions: 1. who are PSF actors that support REDD+ projects?, 2. why do PSF actors support REDD+ projects?, and 3. what are the governance implications of PSF actors on REDD+ projects? The commodification and governance outcomes of REDD+ market environmentalism offer interesting insights into the knowledge, desires and evaluations of PSF actors engaged in REDD+ GVCs as alternative and sustainable forms of exchange and circulation. The following chapter lays out the methods used to explore these questions. 


\section{Methodology}

\subsection{Introduction}

This chapter describes the methods by which the research was undertaken, including a fieldwork component between April 2013 and March 2014. The first section outlines the qualitative case study approach taken, and explains how the GVC analysis was used. I outline how key informants were selected and how they were involved, and describe which methods were employed for each type of informant, and why. The chapter then discusses how my positionality, personal characteristics, and circumstances influenced the fieldwork and subsequent interpretation.

\subsection{The case of REDD+ in Indonesia}

Because this research is interested in generating in-depth knowledge and understanding about REDD+ projects and value chains and the process of evaluation within the REDD+ private sector, a qualitative approach to data gathering was employed (Bulmer \& Warwick, 1983b). The research adopts a case study approach of "studying phenomena in a real-life setting" and in this respect followed an inductive approach whereby the 'real world' is tested to generate a theory of practice (Kitchen \& Tate, 2000, p. 225; see also de Vaus, 2001; Sarantakos, 1993). However, the research also took a deductive approach, as upon entering the field it set out to apply a GVC-informed conceptual framework to the evaluation practices of private finance (de Vaus, 2001).

Kitchen and Tate (2000, p. 225) discuss the importance of and opportunities provided by case studies in qualitative research, in allowing "a particular issue to be studied in depth and from a variety of perspectives" (see also Bulmer \& Warwick, 1983b). Following a purposive sampling strategy (Bradshaw \& Stratford, 2000), the 
cases studied here were selected to reflect the typical diversity amongst REDD+ projects in Indonesia and the accessibility of them and their informants. The concerted emergence of REDD+ pilot projects involving PSF in Indonesia offered ideal research case studies to investigate the research questions (Bumpus \& Liverman, 2011). Indonesia was selected as the country of study as part of a wider team project, with three case studies of REDD+ projects analysed in depth for this thesis. I have termed them The Swamp, The Valley, and The River; after their biogeographical character and in order to maintain the anonymity of interviewees and key informants. To facilitate exploration of the complexity of these case studies, and maintain anonymity of respondents, descriptive titles are used to capture the type of organisation and actor (for instance, 'Indonesian Business'), along with a unique number identifier, and their project of origin (such as 'INGO Informant 4, The River'.

Stephan and Paterson (2012) call for analyses of emerging carbon markets that scrutinise, deconstruct, and problematise their taken-for-granted routines and norms; investigating "how different forms of emissions reductions are being produced, commensurated and commodified and hence being made tradable on the carbon market" (Stephan \& Paterson, 2012, p. 550). Such an approach, they argue, can "open up new perspectives on carbon markets, giving us a better understanding of their functioning as well as their possibilities and limitations" (Stephan \& Paterson, 2012, p. 551). This involves investigating the key technologies and practices the market relies upon, whilst recognising and accounting for "the messiness of commodification and market creation processes, illustrating their contingency and highlighting the power structures at play" (Stephan \& Paterson, 2012, pp. 550-551).

The thesis responds to this challenge by seeking to shed light on the inner workings of carbon markets through applying an adapted GVC analysis. I draw on Stephan's (2012, pp. 622-623) investigation of the commodification of avoided deforestation, which is described as "an active problematisation of the commodification of avoiding deforestation" that is then followed by "a phase of retroductive reasoning - moving 
back and forth between the empirical material and theory development - to articulate a plausible explanation to the research problem". A similarly reflexive inductive - deductive approach to testing REDD+ project case studies was adopted to apply the GVC methodology and framework in Chapter 6. Given the emergent nature of REDD+ projects and GVCs this logic of critical explanation accommodates the often "messy process of experimentation in the field" (Campbell, 2002, p. 123) and the shortage of primary research on carbon offsetting and REDD+ from a GVC perspective (Lovell \& Liverman, 2010).

\subsubsection{Approaching REDD+ GVCs}

The approach employed here draws on GVC analysis to investigate actors and their relationships and interactions in the creation of REDD+ projects. These 'REDD+ GVCs' involve fewer actors and relationships than the wider REDD+ network that surrounds them, and delimiting them as a manageable object of study is an important and difficult challenge (Bair, 2009; Bernstein, 2011). GVC approaches and attendant methodologies to do this have been frequently described in the literature, and typically begin with a mapping of actors involved in the production of the commodity and their respective functions (Bernstein, 2011; Gereffi \& Fernandez-Stark, 2011; Gereffi \& Lee, 2012; Vagneron \& Roquigny, 2011). Gereffi and Fernandez-Stark (2011, pp. 5-6) argue:

The role of the researcher is to link these pieces of information and create a united and self-explanatory chain that includes the principal activities of the industry. The segments of the chain illustrate how different value adding processes contributed to the product or service, and in turn, the differing returns netted for the chain actors behind them.

Gereffi and Fernandez-Stark (2011) describe how each segment of the GVC has specific characteristics and dynamics, and the importance of identifying the types and characteristics of stakeholders involved in the industry. They continue that this stakeholder examination should result in all industry actors being mapped in the GVC and their role explained. Such an approach enables the analysis of local 
dynamics within which the GVC is embedded and aids in understanding its governance structure (Gereffi \& Fernandez-Stark, 2011).

In a later publication, Gereffi and Lee (2012, p. 29) outline a methodology to map GVC governance structures in two steps: 1) "[map] the input-output structure of the GVC, specifically the value created, captured, and moved" and 2) "[o]verlay the main companies involved in different stages of the supply chain and figure out where the

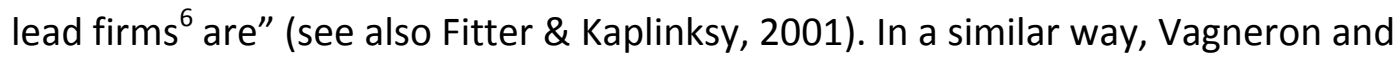
Roquigny (2011, p. 327) describe the GVC approach as:

tracing the commodity from its original producers to its final consumers, identifying the main actors involved at each stage of the chain and their respective responsibilities and estimating the amount of value added at each stage of the chain (and its distribution among the various chain actors). All these stages involve interviewing the different stakeholders of the ... value chain.

These framings focus on actors, broadly defined here as any organisation or individual that expresses agency to produce or add value to the commodity generated within the REDD+ project. All actors involved in production exert personal and professional influence on an individual and organisational level. As such, 'actors' includes organisations of multiple individuals with a common purpose, and individuals within and between these organisations, provided they are contributing to the production of the commodity.

Lovell and Liverman (2010, p. 257) recognise that specialist knowledges, technologies and discourses within emission offsetting have meant that "offset organisations are key players in understanding how carbon offsets are produced and consumed". Consequently, their research examines actors along the length of REDD+ GVCs, both 'upstream' and 'downstream' from on-the-ground REDD+ projects in their institutional contexts. This research also draws on Boyd and Goodman's (2011)

\footnotetext{
6 'Lead firms', in traditional GVC lexicon, describes the actors within a GVC that are the most influential in governing the GVC and the other actors within it.
} 
function based typology of actors within carbon offset GVCs and uses key informants from producers to buyers across geographic spaces from Indonesian forests to head offices in consuming countries. In identifying informants beyond immediate and more obvious GVC actors, who occupy institutional and governing roles or positions that indirectly contribute value and production, I follow Bernstein (2011, pp. 27-28), in an effort to:

identify political communities wherever they form, whether in professional or technical networks, relevant marketplaces, transnational or local civil society, or the traditionally demarcated 'international society' of diplomats and state officials.

As Bernstein (2011) acknowledges, this endeavour is empirical and interpretive, and potentially fraught. Each REDD+ project case revealed itself and became known gradually through extended field research. By mapping the context within the GVC analysis, the relationships between actors and institutions can be analysed and used to develop an understanding of how REDD+ projects are governed.

In conventional GVC analyses, the commodity generally equates to primary products, or manufactured goods where "value added is the difference between the cost of inputs and outputs at each stage of the chain" (Gereffi \& Fernandez-Stark, 2011, p. 18; Bair, 2009; Sturgeon \& Gereffi, 2009). However, as Gibbon et al. (2008) point out, this approach has its limitations for measuring value on GVCs. Importantly, such approaches would struggle to characterise the complexity of the REDD+ commodity in any depth. Selwyn $(2012$, p. 206) has also expressed concern with the way that many GVC case studies are conducted, remaining "somewhat sceptical of the ability of any single researcher to incorporate all the relevant actors, relationships and network configurations [that constitute a GVC] in a meaningful way". However, Selwyn (2012) concedes that the GVC framework does offer methodological and theoretical insights into the specifics of commodity production that can be reformulated to facilitate valuable empirical investigation into governance and capitalism. 
This research adapts the GVC framework to explore REDD+. It draws on Bernstein and Cashore's (2007) call for more empirical research into private governance on these networks including systematic assessments of actor motivations and the factors that influence them. The discussion of the GVC approach and methods here is to indicate the overall approach that forms the basis of the research. The methods employed to gather this information are described below.

\subsection{Field research strategy in Indonesia}

Before entering the 'field', several experienced Indonesian researchers from the University of Indonesia, the Centre for International Forestry Research (CIFOR), the Clinton Climate Initiative and Fauna and Flora International were consulted to advise on the field research strategy. I collaborated with these and other academic researchers throughout the fieldwork period, sharing ideas about useful informants and research sites. The fieldwork was based in Indonesia's forestry research capital, Bogor, south of Jakarta on Java, where CIFOR is located. To address the research questions, information was gathered via interviews with various actors across REDD+ GVCs and their supporting institutions. These included international and Indonesian Government institutions, public and private sector financiers, project developers, businesses, consultants and contractors, international non-governmental organisations (INGOs), local NGOs (LNGOs) and forest community members (see Table 3.1).

The first phase of the research concentrated mainly on interviews with English speaking representatives of global governance institutions, governments, NGOs and PSF actors in Bogor and Jakarta (see Appendix C for list of non-government and PSF informants). These initial interviews were generally broader contextual discussions about Indonesia's national REDD+ situation, the culture, institutions and language (Parfitt, 2005). This built cultural and subject matter competence and preparedness for the more challenging second phase of the research, involving interviews with key informants from specific REDD+ project case studies. Speaking with a wide variety of informants allowed for comparison and triangulation among the accounts of 
different actors, providing a 'checking procedure' for the reliability of findings and the quality of the research (Bradshaw \& Stratford, 2000; Parfitt, 2005).

Table 3.1: Number of informants of different types.

\begin{tabular}{|l|l|c|}
\hline Informant type & Description & No. \\
\hline $\begin{array}{l}\text { Global governance } \\
\text { institution }\end{array}$ & $\begin{array}{l}\text { Non-profit actors that receive their mandate from a global } \\
\text { constituency (e.g. UN-REDD and the World Bank) }\end{array}$ & 19 \\
\hline International NGO & $\begin{array}{l}\text { Non-profit actors that work with international businesses, } \\
\text { governments, investors, developers, and contractors }\end{array}$ & 17 \\
\hline Government & $\begin{array}{l}\text { Actors that represent a sovereign government unit or agency } \\
\text { (including at supra- and sub-national scales) }\end{array}$ & 19 \\
\hline $\begin{array}{l}\text { Local NGO and } \\
\text { community }\end{array}$ & $\begin{array}{l}\text { Non-profit community actors that are active within local villages } \\
\text { and contribute to forest carbon conservation activities }\end{array}$ & 7 \\
\hline Investor & $\begin{array}{l}\text { For-profit actors that are actively investigating or contributing to } \\
\text { a forest carbon conservation activity (e.g. investment funds and } \\
\text { banks); including 1 foundation and 1 sovereign wealth fund }\end{array}$ & 33 \\
\hline Investor/developer & $\begin{array}{l}\text { For-profit actors that are both investing in a specific forest } \\
\text { carbon conservation activity and responsible for its delivery (e.g. } \\
\text { private REDD+ companies) }\end{array}$ & 15 \\
\hline Extractive industry & $\begin{array}{l}\text { For-profit actors whose supply chains intersect with forest carbon } \\
\text { conservation issues and activities (e.g. palm oil plantations and } \\
\text { manufacturers) }\end{array}$ & 25 \\
\hline Contractor & $\begin{array}{l}\text { For-profit actors that help investors and extractive industry } \\
\text { achieve their financial and forest carbon conservation goals (e.g. } \\
\text { consultants, universities and research institutes) }\end{array}$ & 40 \\
\hline
\end{tabular}

\subsubsection{Interviews and observation}

The sampling method followed what Bradshaw and Stratford (2000, p. 44) describe as 'snowball' or 'chain sampling', whereby cases of interest or informants are pursued following recommendations from earlier informants; and 'opportunistic sampling', where there is flexibility to follow new leads and take advantage of the unexpected. Snowball sampling is used extensively in academic fieldwork, relying on a 'trait' or commonality that is shared by the participants allowing the researcher to "seek out more easily interviewees with particular experiences or backgrounds" (Parfitt, 2005, p. 117; Browne, 2005). As the key informants pursued within phase one were part of the community of REDD+ organisations in Indonesia, these methods were the most appropriate. The first informants to be contacted were recommended by one of my supervisors, who was researching a broader project, and identified by searching relevant organisations on the internet. Initial contact 
with these informants was via email or telephone to establish a suitable opportunity to meet.

During these phase one interviews particular examples of REDD+ projects were identified, with certain informants having a good knowledge of successful and unsuccessful cases, and the organisations involved. On this basis it was possible to connect with a wide variety of government, finance, project developer and INGO organisations within specific REDD+ projects. The case studies then proceeded using a variety of methods including further semi-structured key informant interviews, informal interviews, and participation in and observation of events (Bulmer, 1983). It is recognised that the rich detail that this approach offers is accompanied by limits to the generalisability of findings, given the subjectivity of informants (Bulmer \& Warwick, 1983a). However, the research does not seek to support wide generalisation from the cases studied, but rather aims for an analysis of actors, activities and meaning in context (Bradshaw \& Stratford, 2000).

Open and informal interviews can allow informants to "construct their own accounts of their experiences by describing and explaining their lives in their own words" (Parfitt, 2005, p. 111), allowing spontaneous responses to express their "experiences, feelings and opinions" (Kitchen \& Tate, 2000, p. 213; Parfitt, 2005). As the research is interested in gathering these perceptions from various participants within the case studies, informal and semi-structured personal interviews were employed (see Appendix B for ethics approval, information sheet and consent form). The structure and style of these interviews varied according to the profession and social situation of the respondent, ranging from what Dunn (2000) describes as professional interview styles, for situations requiring formal conduct (such as a work place), to creative interview styles where the informant is relaxed in an informal atmosphere (such as a café). Semi-structured interviews allowed a conversation-like atmosphere to develop around relevant issues of interest to the informant, whilst ensuring that all the relevant topics were covered (Dowling, 2000; Kitchen \& Tate, 2000). An interview guide (see Appendix A) was used to ensure this and facilitate comparability between responses (Bulmer \& Warwick, 1983a; Dunn, 2000; Kitchen \& 
Tate, 2000; Wuelker, 1983). This was the primary method used for gathering data from key informants from the types of organisations listed above and contacted through a snowball sampling technique.

Often these interviews were conducted at the margins of a conference, seminar or workshop that had gathered groups of REDD+ experts and stakeholders together. Following Mikecz (2012) these gatherings were targeted as a way to gain access to otherwise often distant and time pressured elite informants such as investors, project developers, international NGO representatives, policymakers and other governing actors, and private sector actors and businesspeople (Mikecz, 2012; Welch, Marschan-Piekkari, Penttinen, \& Tahvanainen, 2002). This enabled me to approach potential informants at a time when they were away from the immediate pressures and problems of their office and were exposed to external ideas and narratives of REDD+. In many ways this prepared them for my type of questions, and made them more willing to talk about their role within Indonesia's REDD+ sector. While these interviews were relatively informal, advance preparation to familiarise myself with these 'elite' informants and their roles, was invaluable and made informants far more receptive and prepared to engage in a longer, more in-depth discussion (Mikecz, 2012; Yeung, 1995). This was particularly important given the popularity of REDD+ research in Indonesia, and the risk of research fatigue among key informants, as one informant advised:

There are so many PhD students studying REDD+ that we have to have a PhD filter. Every week we get a question. We just can't do it ... You need to be specific with people and do background research before you take their time. Everyone has students demanding of them (INGO Informant 2 The Swamp).

Previous GVC analyses involving similar elite informants have found qualitative interviews to be highly appropriate for this type of research (Yeung, 1995). The 'studying upwards' of highly positioned and influential elites and investors in this way meant that a small number of particularly important key informants for the case 
studies could not be met in person and had to be contacted via email, phone or webconferencing (Aguiar \& Schneider, 2012).

\subsubsection{Case study REDD+ projects}

Through snowballing, and multiple meetings with REDD+ actors, close relationships were built with key informants and stakeholders in REDD+ projects. These relationships, along with essential characteristics and accessibility, then informed case study selection. Other case study sites were available in Indonesia, but many of these had attracted so much attention from researchers that key informants were fatigued and less open to assisting another PhD student. The relationships in selected case studies proved very beneficial and informative, often because the research questions were of direct interest and relevance to informants; whose feedback helped refine them (Cook, 2005; England, 1994). There were many opportunities for informal conversations and interviews with additional information gathered through observational techniques. My observational presence during the undertakings of the REDD+ projects led to informants quickly embracing and involving me in their operations, their day-to-day responsibilities and the issues that they encountered. This direct 'participatory observation' allowed me to become a "research instrument", and cross-check what had been said in interviews about the actors involved, specifically private finance and project developers (Cook, 2005, p. 186; see also Dowling, 2000; Kitchen \& Tate, 2000).

Between 10 and 15 key informants from across each of the three REDD+ project case studies offered interviews, often welcoming additional follow-up interviews and observation opportunities. These informants covered the breadth of informant types needed to comprehensively map REDD+ GVCs and included all of the most important actors involved, including community members, NGOs, contractors and investors of Indonesian and international ethnicities and both males and females. Some of these informants were based near the REDD+ project areas, but most were situated nearer cities in Indonesia and internationally. Subsequently between one to two weeks were spent in or near each REDD+ project area, whilst informants outside these 
areas were accessed separately. Further details of the three case study sites and their informants are shared in Chapter 6. Some case study informants encouraged my active participation in the development of REDD+ projects given my experiences across the industry:

You should raise your hand in REDD+ meetings and ask why the private sector is not there. That would be really helpful for this problem. You're a stakeholder that has probably spent more time speaking to private sector than they have. NGOs and public sector are often very grateful to hear frank input from us. That makes you more interesting than other consultants in REDD+. Some consultants are bound to the company line and some don't know as they have only worked with the Indonesian government (Investor 1, The Swamp).

However, this is not something I felt comfortable doing, and I did not act on it. Instead, I restricted my participation to conversations with actors and informants. To retain an overview of developments in Indonesia's REDD+ programme and particular REDD+ projects, a daily research journal was kept (Kitchen \& Tate, 2000; Brockington \& Sullivan, 2003).

The second stage of the field research involved interviews in or near the forests of the case study REDD+ projects, typically involving local people, their groups and the NGOs based there. Very few of these informants spoke English, so translating assistance was often needed. The use of translators, however, comes with inherent problems, as the additional information filter can bring translator interpretation and bias, misunderstanding and equivalence issues (Bulmer \& Warwick, 1983a; Leslie \& Storey, 2003; Müller, 2007). There were times in this research where translation was provided by the same INGO that was supporting or responsible for implementing the case study REDD+ project under question. This raised unequal power relations in the interview and risked the INGO translating to support their own version of events and offering similarly compromised interview question guidance. 
Bulmer and Warwick (1983a, p. 32) recognise qualitative methodologies as "a western product which cannot be straightforwardly exported to the developing world". They list the translation of questions and responses as an issue affecting the quality of information gathered (see also Wuelker, 1983). During the analysis of these INGO responses and those they were translating, care was taken to crossreference them with previous responses and those of other relevant informants. Despite these risks, the guidance of these INGOs did ensure that interviews and questions were culturally specific and appropriate (Bulmer \& Warwick, 1983a; Wuelker, 1983).

Furthermore, the involvement of local community and NGO members in discussions about the REDD+ project may have restricted the answers of some project developers to those that would be supported by the on-looking constituency (Kitchen \& Tate, 2000). Although, on comparison between answers from developers with and without local members present, there does not appear to have been any significant difference in the nature of the responses received. However, it was these encounters that offered insight into the experiences and perspectives of the local communities and NGOs as they drew confidence in each other's supportive presence and information seemed to flow quite freely (Kitchen \& Tate, 2000).

\subsection{Coffee and batik to beer and suits: Positionality and reflexivity}

During the entirety of my time in Indonesia my social position was obvious and inescapable. In all my social encounters I carried with me my "bodily presence" and associated personal characteristics such as race, sex and age that Kearns (2000, p. 110) recognises as potentially carrying affiliated power dynamics (see also Dowling, 2000). In the Indonesia context, these personal characteristics worked to my advantage in many ways. Being a young, white, English-speaking male conducting postgraduate research in a Muslim community, where white people often associated with easy money and power, opened doors to people and places that may not have opened had I been a local (Brockington \& Sullivan, 2003; Dowling, 2000; Kitchen \& 
Tate, 2000). Furthermore, my outsider status enabled me to ask for explanations in conversations, and for responses to be clarified, where a local researcher may have been seen as incompetent for doing so.

Researching across GVCs placed me in a wide variety of social situations, ranging from the company of the poorest in the community to the wealthiest. Leslie and Storey (2003, p. 187) describe this as "moving up and down power structures". They ask "how do you scale hierarchies successfully and ethically?" (Leslie \& Storey, 2003, p. 187). I found myself adopting roles in order to blend into the immediate setting and to put the informant at ease; from drinking coffee and wearing batik (customary Indonesian dress shirt) with Indonesian informants, to drinking beer and wearing a suit with foreign funding elites, and all manner of mixing in-between. These appearance adaptations proved vital; one informant advised regarding the agents of major investors, "they'll probably only tell you over a stiff drink" (Investor 1 The Swamp). In a similar sense, I was advised "don't be a TOB - a task orientated bastard" (International Volunteer 1 the River) - meaning to remain patient and vigilant, to go with the flow and wait for the right moment before asking any questions regarding my research. In some cases this might take several meetings or occasions before the relationship was at a point where informants were comfortable 'getting down to business'. It's likely that this personal approach and relaxed attitude helped me to gain the insights that I did.

Traversing the REDD+ project GVCs like this led to occasions where those in forest communities knew I was conversing with influential government and investor informants, and vice versa. An example of this was captured where one informant from a REDD+ project asked, "so you must be the most important guy right, you're in touch with the investors!" (Indonesian Consultant 1 The River). Sometimes these groups were pursuing conflicting interests, which placed me in awkward positions where I felt like my 'allegiance' to either 'side' was being questioned. To negotiate this I had to be flexible and improvise and represent myself according to the situation. It was important not to deceive informants, but to remain as open and objective as possible, without ignoring my own positionality (Leslie \& Storey, 2003). I 
found it impossible not to sympathise with forest communities and their advocates that were struggling to improve their livelihoods through REDD+, and hence hold a position of bias against those elites in power who the disadvantaged begrudged. This has no doubt influenced my understanding of the research. The importance of such a tendency and my awareness of it has allowed and encouraged me to minimise its influence in my analysis.

In some of these social situations, especially with marginalised informants, there is some risk that they would seek to appease me with answers they thought I wanted to hear, or give answers they understood they should be giving, thereby concealing actual personal opinions (Valentine, 2005; Wuelker, 1983). Among the forest communities and local NGOs I was often seen as an external expert and professional. Often I was initially mistaken for an NGO representative (Brockington \& Sullivan, 2003; Kitchen \& Tate, 2000). This occasional perception of my role as 'powerful' and even 'superior' in a postcolonial setting was further augmented by apparent affiliations with the project developers I was seen with (Valentine, 2005). Members of forest communities and local NGOs gave a lot of their time, and offered their homes and their hospitality, which was significant, given their financial means. This special treatment may have also been reflected in informants' responses and behaviour, insofar as they may have felt "beholden to cooperate" (Valentine, 2005, p. 125).

In a similar sense, the positionality of several REDD+ case study informants, who also acted as guides and translated for other informants in the field, will have influenced the research in some way, as discussed in the previous section (Pasquini \& Olaniyan, 2004; Valentine, 2005). One such informant that was locally embedded and possessed extensive knowledge of REDD+ in Indonesia was able to quickly develop an understanding of the research. This informant facilitated highly informative discussions with community and NGO members, such that at times I felt (like Pasquini \& Olaniyan, 2004) that I was observing the interview rather than conducting it. This informant's respectful and professional demeanour created a relaxed conversational space within which informants appeared pleased to share. 
Of the four translators used in the case study areas, two would sometimes struggle to verbally express themselves and would compensate with animated personal expression and translation books and computers. It was stressed at the outset that the translation should not develop into interpretation of informants' responses. This was to prevent the alteration of the information given by informants through the translators' own perceptions of what information was relevant, what was not, and what it meant (see Leslie \& Storey, 2003, p. 133). These translators and I grew to understand each other very well, developing a hybrid vocabulary of limited English and Indonesian between us. However, whilst useful, this shared vocabulary risked allowing single words to carry with them a variety of different meanings, potentially limiting the information gathered from informants. As Müller (2007, p. 207) observes, "the transfer of cultural meanings, embedded in linguistic expressions, from one language to another constitutes one of the most challenging tasks of translation". Bulmer and Warwick (1983a) further recognise a host of equivalence issues in translation; such as whether words and concepts will carry the same meaning in questions, and if not then how can responses be measured and will response patterns give the same meaning across these cultures. This is particularly important given the complexity of the REDD+ context, as one case study informant expressed:

I am very conscious of the power that the meanings of words can do to a frame of thinking. It's very apparent in REDD+. Like 'benefit sharing' and 'safeguards'. It's hard in an organisation where people develop their own language and meanings for things and then try to communicate this to others. I try and break this down, but it's hard (INGO Informant 2 The Swamp).

Consequently, it could not be taken for granted that the languages and discourses of the REDD+ industry - relating to complex and contested principles like community participation, green growth, and sustainable development - that Indonesian speaking informants adopted were intended to carry the same meaning as I understood them to mean. The use of some of these terms may serve other 
purposes, such as demonstrating (apparently) complex knowledge of REDD+ or familiarity with the English language. This tendency risked clouding the understandings shared between the translator and myself, presenting a potential weakness of the research and could have been avoided had I had an advanced grasp on the Indonesian language. Subsequently, a shared communication strategy catering to the abilities of each translator was established to ensure the meanings of terms were clarified and confusing REDD+ jargon was avoided as much as possible.

Many of the investor, developer, international NGO, global governance, extractive industry, and contractor informant types were in positions of power, spoke English, and were often in secure career positions. Therefore they could be considered to be foreign or local elites. There is an established literature on issues around interviewing elites (Brockington \& Sullivan, 2003; Desmond, 2004; Smith, 2006) that inverts the assumption that the interviewer has the power (Lindsay, 1997; Valentine, 2005). For example Sabot (1999) found that elites may be open and encouraging of local researchers, but reluctant to cooperate with foreign researchers. It was apparent during my own research that this was an influencing factor, with some informants cancelling last minute and others taking phone calls from friends and joking with colleagues during the interview (Brockington \& Sullivan, 2003; Lindsay, 1997).

Furthermore, several times elite informants asked who I had already spoken to, putting me in an awkward position as refusing to divulge would appear rude, while providing names risked offending or embarrassing informants, possibly altering responses, and breaching confidentiality assured to previous interviewees. To avoid being rude, when asked who I had spoken to I explained how I was not able to divulge that information, or give names of people or organisations I hoped to speak with. This became less of an issue as the snowballing technique progressed to the point where I had a comfortable understanding of the informants relevant to my research. There were even situations where I had a preceding reputation, where interviewees had heard about me and my questions before I had approached them. Furthermore, throughout my 11 months in Indonesia I would often 'catch up' with 
relevant informants irregularly and by coincidence at formal or informal events. This enabled me to follow their story through time and as their REDD+ project and Indonesia's REDD+ context evolved and offered opportunities to 'cross check' and revisit informants' predictions regarding the REDD+ industry and voluntary forest carbon projects and markets (Hopkins \& Wallerstein, 1994).

\subsection{Summary}

Considering my position within this foreign cultural context and the confusions and misunderstandings that could potentially accompany it, a structured and inflexible approach would not have been the most effective and efficient approach to this research. The suitability of the case study approach to the GVC framework and the specifics of the Indonesian context required my persona and methodology to be flexible and open to all forms of qualitative information. Doing so enabled the development of an in-depth understanding of the REDD+ situation in Indonesia and the role and governing influence of profit-seeking finance within it. The potential disadvantages of this approach discussed above are outweighed by its ability to facilitate a reflexive approach to applying the GVC framework to suit REDD+ projects. The following chapter introduces the contextual setting within which the research is situated. 


\section{Context of REDD+ in Indonesia}

\subsection{Introduction}

The emergence of REDD+ projects in Indonesia has come about within a context characterised by dynamic and rapid but often frustrating change. Since 2009 the Indonesian Government has achieved a number of important milestones, namely: committed to ambitious emission reduction targets; established national climate and REDD+ plans with UN-REDD and the World Bank; agreed to a memorandum of understanding with Norway and aid partnerships with Germany, Japan and Australia; and established a presidential REDD+ task force and REDD+ pilot provinces and projects. However, all these efforts have been frustrated because the expansive agricultural drivers of deforestation continue, particularly palm oil plantations. Many PSF actors appear to prefer clearing forest for these agricultural land-uses rather than establishing REDD+ projects (GCP, IPAM, FFI, \& FI, 2014; Luttrell et al., 2014), perpetuating Indonesia's high deforestation rates (Indrarto et al., 2012; Margono et al., 2014). This chapter explores this shifting context surrounding REDD+ rhetoric and reality in Indonesia, and situates REDD+ PSF within this. The chapter begins with the development of REDD+ policy and institutions in Indonesia. It then introduces the Indonesian land-use concession system and the extractive industries that surround and compete with REDD+. Together these accounts illustrate the political economic context shaping the roll-out of REDD+ in Indonesia.

\subsection{REDD+ regulatory frameworks in Indonesia}

The idea of a global mechanism to finance the reduction of emissions from deforestation and forest degradation began development in 2005 (Luttrell et al., 2014). REDD+ surfaced as part of the 2007 Bali Action Plan from COP $^{7} 13$ of the UNFCCC. The United Nations and World Bank began to allocate funding and

\footnotetext{
${ }^{7}$ Conference of the Parties, where all States that are Parties to the UNFCCC are represented.
} 
development resources towards researching and preparing countries for REDD+ economies (Indrarto et al., 2012). The UNFCCC continues to develop and refine the design of REDD+, and it is not yet recognised as an official offset mechanism in formal compliance markets.

The former Indonesian President Susilo Bambang Yudhoyono's 2009 announcement of ambitious emissions reduction targets generated considerable interest in REDD+ because of Indonesia's large forest area and vulnerable, carbon dense peatlands (Indrarto et al., 2012). Several donors have responded in support, the most notable being the Norwegian government, which in 2010 signed a Letter of Intent (Lol) with Indonesia to set up a bilateral arrangement related to REDD+ (Luttrell et al., 2014). This arrangement promised $\$ 200$ million to assist with achieving governance readiness for REDD+, and $\$ 800$ million for performance based payments. Conditions included consultations concerning the design of a REDD+ national strategy, the establishment of an independent agency for measuring, reporting and verification (MRV), a presidential decree for a moratorium on issuing new land-use concessions on forest land, and the selection of a province for pilot implementation (Indrarto et al., 2012). Each of these are underway. In parallel, additional support came from the UN-REDD program, the World Bank's Forest Carbon Partnership Facility (FCPF) and the Forest Investment Program, all of which work with the Indonesian Government to finance and develop 'REDD readiness' (Indrarto et al., 2012; Luttrell et al., 2014). Financial and technical support for the Government from the governments of Australia, Germany, France, the United Kingdom, and Japan (among others) has also been directed towards governance readiness and pilot REDD+ projects to advance Indonesia's preparedness (Dermawan \& Sinaga, 2015; Indrarto et al., 2012).

To facilitate these readiness activities, and in response to the Lol between Norway and the Indonesian Government, the ad hoc REDD+ Task Force was established in 2010 to coordinate institutions involved with REDD+ in Indonesia. These included the National Development Planning Agency (Bappenas), the Ministry of Forestry (MoF), and the President's Working Unit for Development Supervision and Control (Indrarto et al., 2012). The REDD+ Task Force's terms of reference included six main tasks: 
- ensure the development of a National REDD+ Strategy and a National Action Plan to Reduce Greenhouse Gas Emissions (RAN GRK)

- prepare the establishment of REDD+ institutions

- prepare instruments and mechanisms for REDD+ funding

- establish an independent and reliable REDD+ MRV agency

- develop criteria for selecting pilot provinces and ensuring their preparedness; and

- implement other activities relating to preparing implementation of the Lol with the Government of Norway (Indrarto et al., 2012).

The Task Force was also responsible for establishing the National REDD+ Agency to replace itself in 2013. The Agency reports to the President and is the designated national authority for REDD+ in Indonesia, assisting the President in coordinating, synchronizing, planning, facilitating, managing, monitoring, overseeing, and controlling REDD+. ${ }^{8}$ The Agency is establishing a funding instrument for REDD+ in Indonesia termed FREDDI ${ }^{9}$ to administer the different funds investing in REDD+ projects. FREDDI provides national and subnational initiatives to implement REDD+, competitive cycles where REDD+ implementers compete for funding, and small scale grant initiatives (Dermawan \& Sinaga, 2015).

The Agency is also developing a safeguard program termed Principles, Criteria, Indicators for REDD+ Safeguards in Indonesia (PRISAI) as a basis for implementing REDD+ projects. PRISAI is developed alongside and complemented by the REDD+ safeguard information system (SIS-REDD+) coordinated by the newly combined Ministry of Environment and Forestry (MoEF) (Dermawan \& Sinaga, 2015). The Agency is also responsible for developing a national measuring, reporting and verification (MRV) system to support the National REDD+ Strategy and a National Action Plan to Reduce Greenhouse Gas Emissions (RAN GRK) and ensure compliance

\footnotetext{
${ }^{8}$ A change in government and President in 2014 saw the Government reposition the REDD+ Agency into the newly combined Ministry of Environment and Forestry (MoEF). It remains unclear what this means for the future of REDD+ and the Agency, with concerns the Agency may be dissolved into the MoEF (Dermawan \& Sinaga, 2015).

${ }^{9}$ Fund for REDD+ Indonesia.
} 
with UNFCCC REDD+ standards (Dermawan \& Sinaga, 2015). The system will take advantage of a combination of satellite, forestry, agricultural, and topographical data to calculate and monitor carbon emissions (Dermawan \& Sinaga, 2015). By 2013 the MRV design document had been prepared and undergone consultation with stakeholders (Dermawan \& Sinaga, 2015).

The Agency has identified priorities for preparing for REDD+ implementation at the provincial level, including the development of provincial strategy and action plans, the development of baseline data and a comprehensive map (termed 'OneMap') of forest lands and land-use concessions (Dermawan \& Sinaga, 2015). By 2013 provincial action plans had been finalised in 33 provinces. The Agency plans to establish memoranda of understanding with provincial and district governments on REDD+ implementation and establish a reference carbon emission level across Indonesia to assist with MRV design (Dermawan \& Sinaga, 2015).

The Indonesian Government has also released regulations regarding REDD+ demonstration projects and the associated movement of finance. Four national regulations have emerged directly related to REDD+. These include regulations dealing with establishing pilot projects (Ministerial Decree P.68/2008); mechanisms (Ministerial Decree P30/2009); permit and benefit sharing procedures (Ministerial Decree P36/2009); and, principles and criteria for pilot projects and the rights and obligations of proponents (Ministerial Decree P20/2012). These policies are widely regarded as opaque and confusing, particularly as the regulation on benefit sharing has continued to be resisted and contested within the government itself (Luttrell et al., 2014; Costenbader, 2010; Luttrell et al., 2013; Indrarto et al., 2012; Minang et al., 2014; Jaung \& Bae, 2012; Ituarte-Lima, McDermott, \& Mulyani, 2014). However, they have provided some regulatory guidance for the private sector and PSF actors developing REDD+ projects alongside the bilateral government agreements and strategies.

These REDD+ regulations compete and co-exist with previous forest land-use regulations, particularly those regulating land tenure. These regulations suggest that 
carbon rights and tenure belong to those with rights to a forest's environmental services, which include carbon sequestration (Indrarto et al., 2012). The Government's control over state forests means that carbon rights and tenure in state forests are limited to the right of enterprise, not ownership. But just like the use of forest products by extractive industries such as timber and mining, the benefits of carbon enterprise (i.e. carbon offsets) can be sold to other parties (Indrarto et al., 2012). The following section elaborates on existing tenure regulation within Indonesia's forests and its relationship to REDD+ projects.

\subsection{Forest tenure and land-use concessions}

For the past four decades Indonesia has focused on exploiting natural forest to drive development in rural areas and generate national revenue from the export of wood products (Luttrell et al., 2014). The timber industry was the industry of choice for investors, provided important employment opportunities and made a significant contribution to the Indonesian economy (Indrarto et al., 2012; Luttrell et al., 2014). Today, most productive lowland areas have been subject to a mixture of logging, burning and clearing, with many in a state of degradation that leaves very limited profitable intervention options for commercial forest enterprises (Wana Hijau Nusantara, 2011).

Many remaining forest areas have been abandoned but remain prone to further degradation, especially from forest fires and illegal logging and clearance for agriculture (Wana Hijau Nusantara, 2011). This neglect of concessions with partially degraded forests has been a growing concern for the MoF, which released regulations in $2004^{10}$ to initiate the concept of ecosystem restoration licenses (ERC) within the production forest estate. ERC's are defined as:

A license for business given to develop an area of natural forest within production forest that contains important ecosystems. The purpose of such development is to

\footnotetext{
${ }^{10}$ Minister of Forestry (Minister of Forestry) Regulation No. SK 159/ Menhut-II/2004 regarding Ecosystem Restoration in Production Forest, and Minister of Forestry Regulation No. P.18/Menhut-II/2004 regarding Criteria for the Provision of IUPHHK-RE Licenses in Production Forest Using Ecosystem Restoration Activities.
} 
restore the biotic and abiotic components of an ecosystem to its original state, including through planting, enrichment, separation, animal breeding, release of flora and fauna to restore biological substances (flora and fauna) as well as non-biological substances (soil, climate and topography). Once restored to its original state, biological and ecosystem 'equilibrium' will have been achieved (Wana Hijau Nusantara, 2011, p. 15).

Further MoF regulations in 2007 and 2010 set out the processes for issuing ERC's. Interest in securing ERC's originally came from conservation groups, who helped pioneer the concept and set the precedent for managing a significant proportion of Indonesia's State forests (Wana Hijau Nusantara, 2011). This accompanied ERC's exemption from the license moratorium and the MoF's commitment to issue them over 2.5 million hectares of State Forest by 2014 (Wana Hijau Nusantara, 2011). These pieces came together to resemble a viable framework of secure tenure to develop REDD+ projects and PSF actors began to gain confidence to develop ERC business models (Wana Hijau Nusantara, 2011).

Whilst most early REDD+ pilots in Indonesia were ERCs, regulation exists for the MoF to issue land-use concession types for smaller areas of forest within customary or community boundaries (Jaung \& Bae, 2012; Minang et al., 2014; Myers Madeira et al., 2010; Indrarto et al., 2012). These types of land-use concessions ${ }^{11}$ remain the custody of the community and permit a variety of otherwise restricted forest uses, including carbon sequestration services and their sale (Indrarto et al., 2012). Although also fraught with legislative inconsistencies and uncertainty, they offer an entry point for communities to secure tenure over their own forest areas and REDD+ projects (Indrarto et al., 2012). This tenure is an important motivator for these forest communities, who have struggled to achieve land title since about 70 per cent of Indonesia was nationalised as state forest area in the 1960s (Indrarto et al., 2012; Li, 2014).

\footnotetext{
${ }^{11}$ Examples include Hutan Desa (village forest) and Hutan Kemasyarakatan (community forestry).
} 
Each of these ERC and community type concessions followed their own separate and complex processes through the Indonesian bureaucracy. The experiences of applicants with these processes are characterised by frustration and confusion (Indrarto et al., 2012). Opaque and conflicting advice from across local, provincial and national levels of the Government leave concession applicants to determine processes themselves through a bureaucratic back-and-forth between officials (Indrarto et al., 2012; Luttrell et al., 2014). The details of these experiences are specific to the circumstance of each applicant and the relationships they share with relevant positions of authority. The GVC case studies in Chapter 6 explore three of these in detail. However, here it is helpful to introduce the tenure and land-use concession challenges that Indonesia's REDD+ projects generally face. The political economic conditions that make these REDD+ land-use concessions so contested have important governance implications and are introduced below.

\subsection{Politics of Indonesia's land use and REDD+}

Indonesia's economy is dependent upon natural resource extraction and trade, and particularly the products of palm oil, timber and mining (Indrarto et al., 2012; Luttrell et al., 2014). Each of these are significant drivers of deforestation and forest degradation in Indonesia, and underpin the Government's economic growth plan (Indrarto et al., 2012; Luttrell et al., 2014). Indonesia's palm oil plantation estate grew from 1.7 to 8.4 million ha between 1989 and 2010 (Indrarto et al., 2012). High prices for palm oil, driven by increased demand in food products and biofuels, are expected to have expanded Indonesia's palm oil plantations to over 10 million ha by 2015 (Indrarto et al., 2012). Mining is also a major cause of deforestation but is generally underestimated in the shadow of the palm oil industry. Illegal logging of forests has attracted a lot more attention for its role in deforestation in the past, but now it also appears to be overshadowed by palm oil plantations, despite remaining a major cause of deforestation and degradation (Indrarto et al., 2012). More recently, forest fires have increased in frequency and scale within Indonesia and are understood to be the consequence of human activity such as clearing and cultivating lands for agriculture and to secure tenure (Indrarto et al., 2012). 
These important drivers of Indonesia's economy are inevitably set to collide with the ambitions of REDD+ policies and programmes (Dermawan \& Sinaga, 2015; Luttrell et al., 2014). A stark example is the projected loss of $\$ 3$ billion from Indonesia's economy because of the Government's moratorium on new concessions in forest lands to facilitate REDD+ (Luttrell et al., 2014). Attempts to reconcile this include the facilitation and encouragement of voluntary sustainability standard systems for palm oil plantations, through which higher value palm oil can be sold. These standards are facilitated through the international Roundtable on Sustainable Palm Oil (RSPO) and the Indonesian counterpart, the Indonesian Sustainable Palm Oil Foundation. Requirements include the preservation of high conservation value forests within palm oil plantations (Richardson, 2014; UNEP, 2014). Global corporations that source palm oil from Indonesia are increasingly subscribing to these initiatives and pledging to buy from plantations with such accreditations, in response to their customers and shareholders demanding sustainable production and business models (Oosterveer, 2015).

Additionally, parts of the Indonesian timber industry have been implementing changes to pursue sustainable forest management principles. Two important examples include the voluntary sustainable timber standards of the Forestry Stewardship Council (FSC) and the Forest Law Enforcement, Governance, and Trade regulations that ensure timber exports to Europe are from legal operations (Cashore, 2002; Dermawan \& Sinaga, 2015). Indonesia is no stranger to sustainable development initiatives for forest conservation. Traditionally these have taken the form of integrated conservation and development projects; particularly amongst local communities and in a similar way to REDD+ (Blom, Sunderland, \& Murdiyarso, 2010).

However, there is debate within government as to whether these efforts and the wider economy can continue to grow at their desired rate alongside REDD+, adding to the stressed relations between business and government across local, provincial, and national levels (Luttrell et al., 2014). Luttrell et al. (2014, p. 67) describe how 
"[p]oliticisation of the bureaucracy and increasing business-government relationships are important features of the parliamentary dynamic at the national level and are reportedly intensifying at the local level". This local level politicisation of bureaucracy is particularly relevant for REDD+ projects, as the land-use concessions required to secure tenure over the project area depend upon achieving the approval of these local bureaucrats. However, these actors often depend on election campaign contributions and endorsements in exchange for promises to grant land-use concessions to palm oil plantations (Indrarto et al., 2012).

As such, REDD+ initiatives have intruded upon local bureaucracy's traditional territory of forestland exploitation and tenure (Dermawan \& Sinaga, 2015). The question of Indonesia's ability to govern, and the legitimacy of its institutions, including new REDD+ institutions, recur throughout this research and emerge notably within the GVC case studies presented in Chapter 6. Corruption and poor governance within Indonesia's forest land-use sector became a background assumption raised in every informant conversation, and many in the REDD+ community believe it explains why Indonesia's REDD+ initiative appears to have stagnated, despite its earlier rapid progress (Dermawan \& Sinaga, 2015; Luttrell et al., 2014). This is so much so that hopes for the future of REDD+ in Indonesia are increasingly linked to Indonesia's recently formed Corruption Eradication Commission (KPK) (Dermawan \& Sinaga, 2015; Luttrell et al., 2014).

\subsection{REDD+ standards and processes}

By way of navigating these problems, various voluntary REDD+ standards have been developed and applied at jurisdiction and project levels. Jurisdictional standards aim to certify national and subnational territories such as a region or a province, like those involved with the UN-REDD, FCPF and REDD+ Social and Environmental Standards (REDD+ SES) processes. ${ }^{12}$ The Indonesian REDD+ Task Force has adopted

\footnotetext{
12 The REDD+ SES were developed through engaging governments, NGOs, civil society organisations, Indigenous People's organisations, international policy and research
} 
such standards into its PRISAI, FREDDI and Central Kalimantan pilot province jurisdictional approaches. Project-level standards address REDD+ projects designed for investment or development purposes by private entities or NGOs in the voluntary market, and may also enable integration or nesting into overarching jurisdictional systems. These standards seek to safeguard against a mix of social, environmental and procedural issues within REDD+ to secure its permanence ${ }^{13}$ and additionality, ${ }^{14}$ summarised below in Table 4.1.

REDD+ standards had diverse beginnings as the voluntary and industry led REDD+ program evolved. They respond to the criteria in Table 4.1 in different ways, with some being included and others being excluded (Roe et al., 2013). REDD+ standards for projects are established by a variety of organisations, each adopting a slightly different methodology. Primarily these concern the biomass and carbon within forests, but also extend to include wider environmental, social and procedural safeguards. The initial proliferation of REDD+ standards in the 2000 s slowed, and the field has coalesced around a few core standards that certify the majority of current REDD+ projects (Seifert-Granzin, 2011). As one informant observed: "In the last 5 to 10 years it went from in-house standards to everyone using VCS or other credible standards" (Contractor 19). The REDD+ project standards relevant to the case studies conducted in this research include the popular Verified Carbon Standard (VCS); the Community, Climate and Biodiversity standard (CCB); and the less prevalent Plan Vivo standard (Roe et al., 2013).

\footnotetext{
institutions and the private sector to set out a comprehensive, clear and easy set of guidance that comply with UNFCCC standards (Roe et al., 2013).

${ }^{13}$ Permanence refers to whether the net benefit of an action, such as carbon removed from the atmosphere, will remain fixed for a long period, or whether the process may soon be reversed.

${ }^{14}$ Additionality is defined as whether an emissions reduction or removal would have occurred in the absence of new incentives, such as a payment for emissions reductions.
} 
Table 4.1: Common criteria and sub criteria of REDD+ standards (Roe et al., 2013).

\section{Social Criteria}

- Application of free, prior and informed consent (FPIC) ${ }^{15}$

- Consideration of vulnerable groups

- Support of tenure and resource rights

- Enhancement of livelihoods and labour rights

- Inclusion of guidance on benefit-sharing ${ }^{16}$

- Provision related to the avoidance of resettlement

Environmental Criteria

- Mitigation of environmental impacts

- Enhancement of biodiversity and other ecosystem services

- Avoidance of reversals and displacement of emissions

Procedural Criteria

- Integration of safeguards in policies, laws and regulations

- Rules mandating transparency

- Requirement of stakeholder participation

- System for monitoring and reporting (Safeguard Information Systems)

- Established grievance mechanism to address concerns and conflicts

- Regulated compliance assessment process

The VCS provides a robust quality assurance standard for greenhouse gas (GHG) emission reduction projects, with the purpose of issuing credits for voluntary markets. It is the most widely applied voluntary carbon standard, with 58 per cent of voluntary market share in 2011 (Roe et al., 2013). The VCS Standard comprises criteria, procedures, and approved GHG methodologies for REDD+ projects, and for 'Jurisdictional and Nested REDD+' that integrate projects, jurisdictional and/or national REDD+ systems. The VCS methodology details the calculation of baseline carbon emission scenarios in the absence of the REDD+ project, and also how the project will prevent and measure these avoided emissions. The VCS has also partnered with the CCB standard to promote dual registration and certification, and

\footnotetext{
${ }^{15}$ The concept of FPIC is that parties acquire free, prior and informed consent from local and Indigenous communities before adopting and implementing development, administrative measures, projects or other interventions that would affect them, their lands, or their livelihoods (Roe et al., 2013).

${ }^{16}$ Benefit sharing safeguards ensure that benefits are distributed equitably among stakeholders, including local communities, government, concession holders, project developers and facilitators (Roe et al., 2013).
} 
a more robust system for accounting for social and environmental safeguards (Seifert-Granzin, 2011).

The CCB standard represents a partnership and initiative of non-governmental organisations, corporations, and research institutions. The CCB does not account for carbon and is therefore typically used in addition to a forest carbon standard (like the VCS) and is the dominant 'co-benefit' standard in the REDD+ market. The CCB is used to exclusively evaluate the social and environmental performance of a project's design, and includes fourteen mandatory performance criteria and three optional 'Gold Level' measures. Only projects using best practices and providing significant climate, community and biodiversity benefits earn CCB approval (Roe et al., 2013). An important part of this is community involvement in management of the forest area and in deciding how REDD+ payments are used. Typically funds are distributed as compensation for required activities (such as forest patrols, nurseries, planting, and community education); the development of existing and new small-scale businesses through micro finance loans and grants; and provisions for community welfare, education and health services (Roe et al., 2013).

The Plan Vivo standard is similar to CCB in that it does not include a GHG emissions accounting component. Consequently, like CCB, Plan Vivo is considered a co-benefit standard and would require a forest carbon standard like VCS to engage in with REDD+. Plan Vivo is designed to be accessible for smallholder- and community-led projects. The standard is underpinned by four principles: (1) livelihoods, (2) transfer of capacity and continuous improvement of projects, (3) restoring and conserving native ecosystems, and (4) equitable distribution of benefits.

Each of these standards prescribes a similar establishment process for REDD+ projects, beginning with the Project Idea Note (PIN). The PIN outlines the deforestation trends and feasibility analysis of the proposed REDD+ project to the standard secretariat (Seifert-Granzin, 2011). Following the secretariat's positive reception of the PIN an in-depth analysis of how the project will engage the relevant environmental, social and procedural criteria (see Table 4.1) is undertaken and 
compiled within the project's proposed methodology. This methodology is often supplied by the REDD+ standard and customised by project proponents; however, new methodologies occasionally need to be developed. This culminates in the Project Design Document (PDD) (or Project Description (PD) in the case of VCS) and is submitted to the secretariat for validation (Seifert-Granzin, 2011). If validated by the standard secretariat the project is effectively operational and follows the monitoring, reporting and verification (MRV) plan specified in its PDD (SeifertGranzin, 2011). If the prescribed MRV review of the project verifies that it is keeping to the plan in the PDD then it is issued the agreed amount of verified emission reductions (VERs) (Seifert-Granzin, 2011).

These processes are investigated in further detail in Chapters 6 and 7 when analysing REDD+ project development and commodification processes. Voluntary standards like these continue to dominate the sector, and despite negotiations within the UNFCCC having made considerable progress on the design of a global REDD+ mechanism, they are yet to secure funding for its implementation within any future climate agreement (Fischer, 2015; Leonard, 2015). However, the UNFCCC's Green Climate Fund, which aims to mobilise an annual \$100 billion from public and private sources by 2020 for global climate change mitigation efforts, will likely direct a proportion towards funding REDD+ type mechanisms and projects being developed in Indonesia (Bernard et al., 2012; Fischer, 2015; Kanak \& Henderson, 2012; Hiraldo \& Tanner, 2011a; UNEP-FI, 2014). The following chapter investigates the ways that PSF actors have engaged REDD+ in Indonesia, and explores the strategies and tactics of PSF actors in this emerging field. 


\section{Rationales and strategies of PSF in REDD+}

\subsection{Introduction}

This chapter presents an analysis of the changing rationales and tactics of actors engaged in mobilising PSF for Indonesia's REDD+ programme. Despite limited flows of finance from PSF actors so far, they have been responsible for a great deal of development and innovation in the forest carbon sector in Indonesia, and have thus played - and continue to play - an important part in shaping the country's REDD+ programme. This chapter focuses on the roles, tactics and strategies of actors engaged in efforts to generate financial profits from REDD+ projects in Indonesia. A range of financing and governance activities that are commonly assigned to the realm of PSF are examined. In this way, this chapter provides an important contextual and institutional background to the REDD+ GVC framework analysis that follows in Chapter 6.

This chapter seeks to unsettle straightforward notions of the 'private sector', and 'private finance', which tend to be of only limited analytical value to understanding the behaviour of REDD+ actors and finance observed in Indonesia, and further justifies the adoption of the term 'profit-seeking finance' (PSF). There are a variety of PSF actor motivations, strategies and tactics to be found within the range of activities taking place in Indonesia under the aegis of REDD. Many of these depart considerably from the common understanding of REDD+ as avoided deforestation funded through carbon offsets. As non-state actors from the private sector and civil society increasingly shape emerging REDD+ projects, they assume important roles as agents of environmental governance - working through a variety of market and hybrid voluntary modes of forest/climate governance. By examining the motivations and behaviour of these actors an improved understanding of the nature of profitseeking REDD+ finance in Indonesia is generated, which lays a foundation for later 
discussions of the implications, potential and limits of private, profit-seeking, market-based climate governance.

The mix of finance to develop and purchase REDD+ Verified Emissions Reductions (VERs) has remained relatively limited and is only gradually increasing (Fosci, 2013). REDD+ offsets deliberately retain traceability to originating projects, resembling "not a standardized commodity, but ... a product market where preferences, prices, and projects vary greatly" (Peters-Stanley \& Yin, 2013, p. 58). Whilst recognising the importance of market environmentalism critiques, this research does not advance a particular position 'for' or 'against' REDD+, noting with Lovell and Liverman (2010) that these often polarised debates may fail to do justice to the variety of experiences on the ground. By drawing attention to the character of REDD+ finance, however, the research responds to calls for greater attention to climate governance beyond the international climate regime (Lövbrand \& Stripple, 2012; Okereke et al., 2009), and helps to lay the groundwork for more critical, nuanced and differentiating accounts of 'the carbon economy' and carbon markets (Boyd et al., 2011; Harmes, 2011; Pattberg, 2012). Research to date generally concludes that little is known about the motivations and forms of involvement of private sector or PSF actors in REDD+ (Bernard et al., 2012).

As discussed below, the complex and diverse nature of PSF engagement with REDD+ in Indonesia means that the programme itself is being realised in highly diverse ways. A variety of tactics and strategies are evident in the behaviour of PSF actors within Indonesia's emergent and evolving REDD+ sector, from philanthropic and charitable donors to speculators and 'carbon cowboys'. How the character of finance - the strategies pursued by different financial actors - influences and shapes REDD+ on the ground is explored; illuminating how many activities that are presented and officially listed as REDD+ projects arguably bear little resemblance to REDD+ as commonly understood. Insofar as the future of REDD+ is tied to PSF, and policy interventions are structured around incentivising capitalist investment, the chapter provides important insights into the PSF actors involved and the ways in which their strategies and tactics produce different expressions of REDD+. The chapter discusses 
the state of financial capital in Indonesia's emergent REDD+ sector, remaining cognisant of contextual factors that shape challenges and opportunities for PSF actors. It then outlines the motivations and tactics of PSF actors as they seek to set up and steer REDD+ projects in Indonesia to various ends, and concludes by reflecting on their implications for market-based governance of REDD+ projects.

\subsection{Financial capital in Indonesia's REDD+ programme}

Alongside national-level developments, REDD+ pilot projects have proliferated in Indonesia since 2008. Scattered throughout the Indonesian archipelago - but particularly concentrated on the islands of Kalimantan and Sumatra - these projects encompass areas ranging from 30,000 to $1,000,000$ hectares. Most REDD+ projects are co-funded and co-implemented by a range of actors, including governments, local and international NGOs, consultancies, research institutes and private companies. REDD+ finance in Indonesia is rapidly evolving and somewhat tumultuous, and although there has been national-level progress in developing institutional structures for REDD+, there have also been recent high-profile examples of donors and investors effectively abandoning major projects having made little headway. $^{17}$

Some $\$ 2.4$ billion has been committed, $\$ 158.1$ million has been approved and \$102 million disbursed to date from a variety of bilateral and multilateral funds for REDD+ in Indonesia, including funds from the $\$ 1$ billion committed by Norway. ${ }^{18}$ Figures are less clear for non-state funds, as there is no publicly available official record. However, since the programme's inception, some $\$ 44.9$ million is reported to have been committed by public funds to private sector efforts, ${ }^{19}$ and about $\$ 10$ million is attributed to private offsetting transactions in Indonesia (Peters-Stanley \& Yin, 2013). Despite Indonesia's best efforts, and the efforts of PSF actors to consolidate a

\footnotetext{
${ }^{17}$ For example the dissolution of the Kalimantan Forest Carbon Partnership with Australia.

${ }^{18}$ See Climate Funds Update (www.climatefundsupdate.org) and the REDDX initiative (http://reddx.forest-trends.org/country/indonesia/overview), which both track, monitor and report on climate change and REDD+ funds.

${ }^{19}$ See the REDDX initiative (http://reddx.forest-trends.org/country/indonesia/overview).
} 
domestic REDD+ 'industry', some PSF actors have since departed. It appears that current arrangements in Indonesia's REDD+ programme are not attractive for market-based finance, and that donors and non-profit organisations may be left to fund REDD+ activities for the foreseeable future (GCP et al., 2014; Luttrell et al., 2014; Streck, 2012; Streck \& Parker, 2012). Despite the bulk of REDD+ funding to Indonesia having come from governments, many developments at the project scale can be attributed to non-state private sector and civil society actors.

Indonesia's experience with private sector and PSF actors for REDD+ has been shaped to a great extent by injustices and unfulfilled promises of easy money associated with the activities of early speculators and 'carbon cowboys'. Informants from across the REDD+ industry offered an understanding of REDD+ PSF actors that were very much influenced by these experiences. Many communities remain highly sceptical towards promises of financial returns from avoided deforestation, even though much of the hype and speculation around REDD+ has subsided in recent years. As one project developer and investor noted:

Carbon cowboys were attracted because they thought you just protect the forest and don't have to do anything and you make a bunch of money ... Most investors are attracted to that simplicity. They don't know it's so complex and part of a bigger story of natural resource management. But they've left and now we have public money. They cannot invest, so just do capacity building and safeguards because of the cowboy story. But people are scared to do project level because of carbon cowboys, so they focus on readiness and safeguards. But now they're stuck because readiness and safeguards are so hard. So now they want to move back to project level activities (Investor and Developer 6).

One of the more high-profile cases exemplifying these sorts of behaviours is the project known as Ulu Masen in Aceh. Colloquially, because of its flaws, Ulu Masen has become something of a fable: “Ulu Masen's Dorjee Sun [the project developer] had an innocence about him that he was going to make a billion dollars and save the 
world. He wasn't embarrassed or uncomfortable about it either" (Contractor 4). As one informant remarked:

Ulu Masen was stupid on a number of levels, but showed how little everyone knew at the time. I think it was a 100 million or 200 million [dollar] type deal. Ulu Masen was already a reserve, already protected by law. So what's changed? So that law's either working or it isn't. If it isn't working, how's your project going to change that? If it is working, why is your project needed? ... To protect the forest Dorjee Sun said they were going to arm the ex-GAM [Acehnese separatist group] to protect it and tell locals what they can and can't do in their own forest. Then Dorjee Sun sells Carbon Conservation [the project development company] to a Canadian oil firm, which now has a deal with the Aceh government to unprotect that forest to do oil exploration (Contractor 1).

The Indonesian REDD+ projects that are still active are being developed in a variety of directions. However, it is possible to distinguish between a group of high-profile projects that have secured relatively large land-use concessions for ecosystem restoration activities - for instance, the Rimba Raya Biodiversity Reserve and Katingan Peatland Restoration and Conservation Project (Central Kalimantan) and the Harapan Rainforest Project (Sumatra) - and a greater number of lower-profile projects that have slowed or stalled as it became evident that there would be considerable delay in the issuance of necessary land-use concessions and licenses. The various experiences of these different projects offer important insights into the rationales and behaviour of PSF actors within REDD+ in Indonesia.

The numerous projects still pursuing land-use concessions have tended to become defined by that pursuit. Some of these have been developed by Indonesian proponents, while others have been developed by international proponents. Informants often distinguished among projects on this basis; several of the Indonesian-proposed projects were "intended for local investors, their friends and partners that are well connected in government who could pre-package an investment terrain for external investors to buy ... about 12 were in the pipeline" 
(Contractor 1). However, such projects appear to have struggled. As one embattled investor reflected, "when I started this five years ago there were about twenty of us [investors], now there are about two ... I think anyone like me is probably crazy" (Investor and Developer 5). Foreign investors have inevitably needed to do more to build relationships with local partners than Indonesian investors:

They started with great local government partnerships that were interested in conservation and community development; and working with local palm oil companies that were interested in shifting their concession or giving up one in exchange for help to get another somewhere else (Contractor 4).

While investor enthusiasm was initially high, increasing instability with the expansion of the forest carbon market served to undermine many of these projects: "carbon value dropped, and palm oil was a proven short-term development opportunity, nobody believed anymore that forests are worth more standing than as palm oil. Not even close [... and] one by one those projects fell apart" (Contractor 4). One informant succinctly described these REDD+ projects: "You're just a forestry company that's got a pretty shitty way of making money out of forests" (Investor and Developer 1). NGOs and NGO-led projects have also been affected by the uncertainties surrounding REDD+, effectively caught in the middle between forest communities and international finance in search of projects and programmes to invest in:

NGOs working on peat domes were about working with local government and communities to make REDD+ a viable business model to support conservation. For NGOs it was all about conservation and making it pay for itself. A national park to pay for itself (Contractor 4).

With the departure of financial support for these projects, only very limited finance remains for forest carbon investments. However, motivated by the need to address deforestation, climate change and related social and ecological problems, NGOs 
have tended to persevere with REDD+. One investor and project developer described this as 'keeping the faith':

It will be very hard to go back if we lose the carbon market. The people that are still around are those who keep the faith, who operate at the conviction level, not the basic return calculation level ... It's like a rite of passage; once some private money has been committed then public money will flow. I think that's what's going to happen (Investor and Developer 6).

Other investors and project developers have moved away from forest carbon and towards other projects (mainly 'sustainable commodities' initiatives) that align with their corporate strategies. Many such projects are orientated towards social and ecological certification of traditional products such as timber and palm oil. Examples include the efforts of Keep the Habitat, Earth Innovation Institute, and consultants involved with community teak plantations in central Java. As one investor and project developer claimed: "if it's not a healthy business, not providing profits, not providing revenue to the communities and investors, it will die. If after all that, you get carbon credits then it's a bonus" (Investor and Developer 10). Others are more direct about their relationship with REDD+: "we're focusing on deforestation, because REDD+ has become a sector all of its own and I think it's for the worse. Stakeholders hate the term REDD+, so we're moving away from it" (Contractor 22). These examples are suggestive of the range of strategies that actors involved in financing activities have adopted to confront challenges facing REDD+ in Indonesia. The following section explores these various actor and strategy types in the context of financing the Indonesian REDD+ programme.

\subsection{Beyond carbon as core business? Shifting rationales and strategies}

As Boyd et al. (2011, p. 610) note regarding climate change mitigation finance, "[m]obilising the influence of powerful factions of capital means identifying viable accumulation strategies that are compatible with the goal of decarbonisation". Given 
the manifold issues with which REDD+ intersects across scales (McGregor et al., 2015), REDD+ projects are potentially compatible with a range of investors and investments. There is certainly a need for policymakers and project developers to understand better the nature and determinants of different business and investment behaviour (Levy \& Newell, 2005) if PSF is to be harnessed for REDD+. An important but under-researched field, then, is that of the strategies and behaviours of actors financing REDD+ at the project level. These actors face turbulent market conditions, political uncertainty and, consequently, high business risks; they adopt out of necessity a variety of adaptive and innovative tactics. Interviews with investors and other actors engaged in mobilising REDD+ finance in Indonesia confirm that many are new to the mixture of conservation, social development and investment finance that REDD+ activities demand (see also Agrawal, Nepstad, \& Chhatre, 2011; Corbera $\&$ Schroeder, 2010). At the same time, however, the apparent 'win-win-win' potential in REDD+ (Brockhaus \& Angelsen, 2012) was reported as having attracted most of these diverse actors to work together. The actor rationales and tactics described below continue to evolve in response to changing conditions within the Indonesian REDD+ programme as discussed in section 5.3. The four broad strategy 'types' addressed are identified as: (1) investment in REDD+ VERs; (2) corporate social responsibility (CSR); (3) sustainable commodities; and (4) impact investment.

These strategies are not mutually exclusive - actors might adopt any mix to meet their goals. The strategies pursued by financial actors directly shape the REDD+ activities they support, in terms of both outcomes sought and relationships involved. In this sense, the character of PSF actors has considerable influence in the governance of REDD+. The following focuses on PSF actors engaged at the REDD+ project level, and how they balance and trade-off financial benefits with social and environmental co-benefits. Figure 5.1 maps key types of PSF actors in relation to the broad types of strategies being pursued within Indonesian REDD+. PSF actors in this context are understood as belonging to one of six groups identified during the interviews, namely: corporate sponsors, foundations, sovereign wealth funds, 
extractive industry, corporate offsetters, and institutional investors. ${ }^{20}$ This classification is based on actor approaches to balancing financial returns and social and environmental outcomes from forest carbon and REDD+.

Corporate sponsors and foundations are the only PSF actor types that typically accept zero direct financial return on investment. Some foundations, however, may require some return, or that a portion of disbursed funds is repaid, although conditions can be very flexible and are sometimes unenforced. Much like public finance, corporate sponsors' and foundations' lesser need for financial returns from REDD+ projects allows them to pursue alternative outcomes and co-benefits. While corporate sponsors typically do not require direct financial returns, most do seek legitimate VERs to use as offsets. These actors may prioritise social and environmental outcomes from such projects, provided this does not erode their financial bottom line. One corporate sponsor stated: "As a banker, when I first looked at REDD+ I thought: 'how can I make money whilst still doing the right thing?' I didn't know about triple bottom line, I was a banker" (Investor and Developer 5). In contrast, corporate offsetters require REDD+ VERs for emissions reductions or carbon neutrality, and may also maintain the option for resale. Therefore they typically seek cheap and fungible VERs. These actors tend to pursue social and environmental outcomes to legitimate their offsetting, but only so far as this does not undermine profits. This is generally in contrast to the rationale of corporate sponsors, who usually provide much smaller-scale finance for social and environmental outcomes.

The three remaining groups represent actors more clearly motivated to profit directly from REDD+ and less likely to compromise on financial returns. Sovereign wealth funds typically pursue low-risk investments for relatively low financial return given their large size and long-term outlook. This is compatible with the nature of forestry investments, and REDD+ project developers tend to target these actors as

\footnotetext{
${ }^{20}$ The terms 'corporate sponsor' and 'corporate offsetter' refer to, respectively, corporate actors associated with REDD+ primarily for CSR or brand association reasons, and corporate actors associated with REDD+ primarily for emissions reductions and offsetting reasons.
} 
investment partners. On the other end of the 'required financial return' spectrum are institutional investors, whose tolerance of high risk in pursuit of high financial returns over short timeframes fuelled euphoria and great expectations in REDD+ early on. Such actors have investment options worldwide and weigh investment decisions (including on REDD+) on a cost, benefit and risk type analysis. Finally, extractive industry are at the nexus of forestry and land use in Indonesia, where palm oil, timber, mining, and rubber operations are attractive options for those in control of forested lands. Any decision to engage REDD+ entails weighing opportunity costs in terms of these alternative land-use and commodity options.

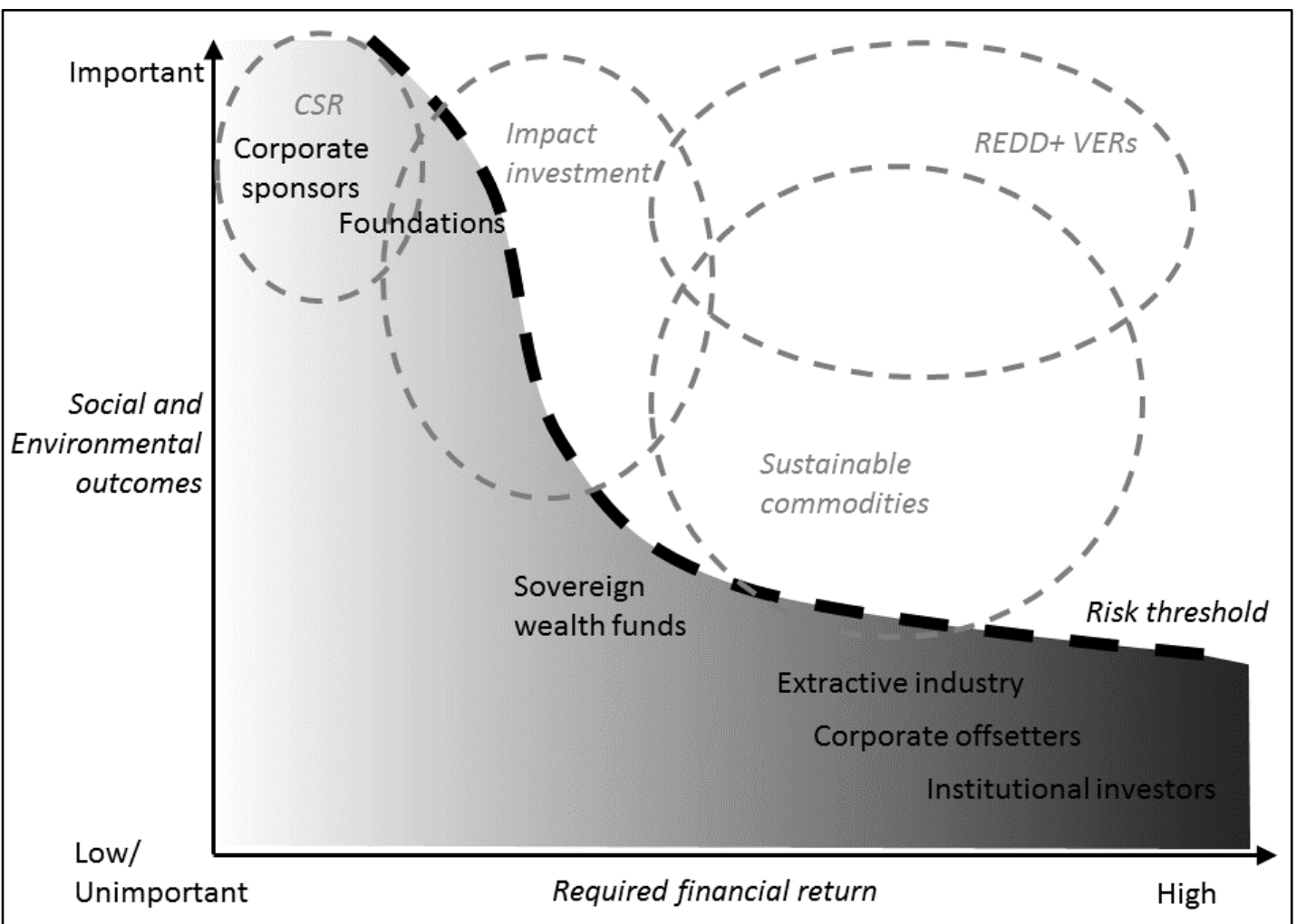

Figure 5.1. Financial bottom lines, social and environmental benefits, and risk in REDD+ finance in Indonesia.

Figure 5.1 locates key types of actors (in plain font), and types of investment and financing strategies (grey dashed circles), according to: ( $x$ axis) financial bottom line, or minimal financial return required by a given actor to justify investment, and; ( $y$ axis) social and environmental outcomes sought by a given actor alongside financial returns. The risk threshold (dashed line) represents the frontier beyond which the 
pursuit of social and environmental outcomes becomes too risky for actors requiring the corresponding financial return. The relative positions of the risk threshold, actor types, and investment strategies are based on information gathered via key informant interviews.

Figure 5.1 shows how actors within each of these PSF groupings typically balance financial profits and social and ecological benefits. Most interviewees put this in terms of 'triple bottom line' management. Such a schematic helps to map out diverse rationales and strategies of actors, but should not underplay the continuing importance of financial returns that typically underpin the full spectrum of activities, as depicted by vertical shading in Figure 5.1. Generally, quantity of available finance is related to an actor's position on the $x$ axis. That is, the greater the required financial return, the greater the quantity of finance potentially available. Thus initiatives supported by institutional investors, corporate offsetters, and extractive industry actors tend to involve larger amounts of finance and land than those supported by corporate sponsors and foundations. Sovereign wealth funds are an exception, as they typically have the greatest financial resources, but pursue a lower financial return.

Figure 5.1 is based on the strategies and rationales of key actors as expressed in interviews in 2013 to early 2014. Included within it are the four most popular strategy types. The proximity of actors and strategies in the figure is indicative of the likelihood of such an actor adopting such a strategy. Each of these strategy types is explored below.

\subsubsection{REDD+ VERs}

The first PSF strategy focuses on pursuing REDD+ VERs as the central activity and source of financial profit. The primary market in VERs involves transactions between project developers and end users who use them to offset particular emissions and retire them. A smaller secondary market comprises onward transactions among offset retailers, traders and buyers. End users of VERs - who predominantly occupy 
the manufacturing, energy, transport, and finance and insurance sectors in Europe and North America (Peters-Stanley \& Yin, 2013) - are seeking to either voluntarily reduce emissions, or prepare for a compliance environment (known as precompliance purchases). Organisations that adopted this strategy are typically institutional investors directly concerned with selling VERs for financial gain. These investors are often able to shift their finance to and from REDD+ (e.g. towards lowerrisk CDM activities), managing a balance of REDD+ VERs to match their risk appetite and in case the market becomes positive. One international fund manager described how a REDD+ project that was stalled by provincial governance issues, while frustrating at the time, may have been a 'blessing in disguise', as it prevented them from investing more in a REDD+ project 'without an investment case' within an uncertain context 'that you would not call a market' (Investor 1 The Swamp).

Despite uncertainties around the robustness of REDD+ markets and governance that have driven the departure of important actors previously committed to funding Indonesian VER projects, some PSF actors remain committed to the pursuit of financial profits via REDD+ VERs. These actors persevere, seeking advance market commitments with developed country governments in search of carbon offsets or corporations pursuing CSR outcomes (Kanak \& Henderson, 2012). However, given the current low demand for REDD+ VERs, these actors are struggling to secure sales and funding.

\subsubsection{Corporate social responsibility}

A considerable share of REDD+ finance in Indonesia has shifted away from VERs towards CSR type strategies. According to Peters-Stanley et al. (2013), 58 per cent of forest carbon offset purchases from projects in Asia are motivated by CSR activities. The notion of CSR covers a broad range of (not unproblematic) strategies on the part of corporate actors (Carroll \& Shabana, 2010; Prieto-Carrón, Lund-Thomsen, Chan, Muro, \& Bhushan, 2006). Here the concern is generally with corporate/financial strategies wherein the importance of carbon accounting diminishes (in relation to a project's capacity to generate and showcase social and environmental benefits. 
There is a documented growing interest in 'charismatic' forest carbon projects amongst corporate sponsors and foundations that are interested primarily in the legitimation of other core-business processes and products, as opposed to VER sales (Peters-Stanley \& Yin, 2013).

This approach, like CSR generally, can be critiqued for not delivering genuine social or environmental change proportional to the scale of an organisation's operations or effects (Bernard et al., 2012). Despite this, and following recent decline in corporate offsetting from REDD+, key informants describe CSR as the funding 'life-line' to which REDD+ projects in Indonesia are currently gravitating: "if the market is going to be private companies at its heart, it's either because its capped, or for CSR reasons" (Investor and Developer 1). Without corporate sponsors and foundations developing and expanding their interests in this area, many REDD+ project activities would not have been able to continue over recent years. Shifting funding partnerships associated with the growth of CSR strategies within REDD+ have seen project developers adapt and repackage their activities in line with the requirements of new types of PSF actors. As one contractor explained:

It's not as though the profit seekers have suddenly gone green. They're in this space because they see business opportunity. So if these two parties that are not traditionally working together, suddenly are, it's more likely that the NGO has somehow shifted their motivations than it is the business partner. I think that's what the nature of those relationships reflect (Contractor 4).

Generally speaking, changing demands of capital are shifting emphasis away from pure carbon accounting and towards social and ecological indicators and monitoring. Most project developers involved with CSR strategies are not-for-profit organisations, and are in many ways returning to 'integrated conservation and development project' approaches. Such CSR strategies are arguably rather distant from the original REDD+ concept of performance based payments and carry their own unique risks: 
But there's a risk that's built into corporate sponsorship model. You can't sign an enforceable agreement for 25 years of corporate sponsorship support of a charitable donation. You just have to continually nurture relationships so you have that longterm commitment of donor support, who are basically getting nothing substantive in exchange beyond that CSR stamp (Contractor 4).

In the context of CSR, social and environmental outcomes bolster brand legitimacy and competitive advantage. These rewards derive less from actual ecological and social benefits generated at the project level, than from the stories they underpin. The large-scale cap and trade model envisaged by REDD+ proponents would potentially deliver far more finance for forest conservation than what CSR-driven investment can deliver. Indeed the view among PSF actors seems to be that CSRoriented REDD+ is bound to remain a limited source of finance. While CSR is not new, the process by which diverse CSR activities have embraced and been incorporated within REDD+ in Indonesia highlights the tendency for REDD+ to reshape underlying landscapes of conservation and development finance, and 'soak up' pre-existing activities.

\subsubsection{Sustainable commodities}

REDD+ projects are increasingly interacting with a variety of corporate strategies for 'sustainable' commodity production. In Indonesia there are several examples of such strategies, through which corporate actors in the agribusiness and extractive sectors attempt (more or less genuinely) to address social and environmental impacts of commodity production. The aspiration is that business models and supply chains are reformed or even revolutionised through 'self-regulation' for sustainability (Steurer, 2013). It is asserted that such strategies, applied across sectors, but particularly in the primary sector and land-based industries, can engage the underlying drivers of deforestation (Butler, Koh, \& Ghazoul, 2009; Indrarto et al., 2012; Pacheco, Putzel, Obidzinski, \& Schoneveld, 2012). Perhaps most notable are the cases of the Roundtable on Sustainable Palm Oil (RSPO) and the Forest Stewardship Council 
(FSC), both of which have been 'adopted' by REDD+ project developers into their repertoires.

The rationale (and the subsequent story that is available for marketing) becomes one of protecting forests - and thereby mitigating climate change - through 'sustainable' commodity production (of, for example, palm oil or timber). As one informant expressed: "we were about VERs but there's no business case for them now - so we're just about profitable FSC community timber. There's a window for forest carbon and REDD+, should it become viable again" (Investor and Developer 10). Such activities, then, will likely continue to account for carbon in case REDD+ and carbon trading does deliver some financial benefit in a future market. This new "focus on critical interplay between sustainably sourced commodities, forest carbon mitigation, and forest protection" (Peters-Stanley \& Yin, 2013, p. 27) has been described as an important trend in REDD+. In exploiting these emerging opportunities, project developers have begun to "experiment with 'stacking' forest carbon assets onto other certified forest and agricultural commodities" (PetersStanley \& Yin, 2013, p. 66); such as including sustainable timber and agriculture certifications within REDD+ projects. Such projects are reported to be producing higher-value VERs than those with, for example, only third-party voluntary certification. The additional revenue associated with sustainable commodities projects means they are perceived as less risky, and are therefore more attractive to investors, than projects relying on VERs alone. However, as Figure 5.1 suggests, this type of strategy is currently compatible with a rather limited subset of PSF investors that are closer in character to sovereign wealth funds and foundations.

\subsubsection{Impact investment}

'Impact investment' is a small but growing class of investment that will not forgo meaningful social and ecological outcomes for financial returns. This type of approach parallels sustainable commodity strategies but is not restricted to forest carbon outcomes. Impact investments are typically defined by a minimal financial return and are designed to avoid financial loss by delivering social and 
environmental benefits through, for example, fostering sustainable community enterprise. This type of investment might include government-guaranteed (but potentially unsecured) bonds, where the risk is shouldered by profit-seeking financial capital (albeit backed by Northern governments or institutions). Other models include variations on equity-sharing, and funds explicitly designed to disperse risk among investors and realise financial profits through financial surplus or the sale of the business (see Fosci, 2012). Many interviewees perceived such investments as high-risk, with one fund manager describing them as offering "nowhere near any risk adjusted rate of return, we're not even thinking in those terms" (INGO Informant 1 The Swamp).

Of central importance to impact investment strategies, then, is a social/ecological 'impact'. As one fund manager explained, "it's a low return, high risk opportunitybut a very high environmental and social impact" (INGO Informant 1 The Swamp). As with sustainable commodities strategies the risk is considered too high for most PSF actors, and financing is typically sourced from corporate sponsors and foundations. As one fund manager observed, "when there are clear pay back opportunities then they [investors] will be interested. But if it's REDD+ credits or something then they'll be less interested"' (Investor 22). Sovereign wealth funds are a potential PSF supporter for impact investment approaches, but given their reaction to REDD+ thus far, the risks are likely still seen as too great. These types of activities remain relatively early in their development in Indonesia.

\subsection{Conclusion}

This chapter has mapped out some of the diverse and sometimes contradictory rationalities and behaviours that characterise PSF within Indonesian REDD+. While all actors supporting REDD+ in Indonesia are in pursuit of some combination of benefits (economic, social, environmental), the discussion has highlighted how diverse the rationales and tactics of profit-seeking financial actors are. The chapter has provided some insight into the types of motivations, behaviours and strategies of PSF actors in the context of Indonesia's evolving REDD+ programme. 
Considerable public sector finance has gone into REDD+ institution and capacity building at the international scale and within Indonesia, but the evolution of REDD+ at the project level has been driven to a large extent by non-state actors and PSF in the context of the voluntary carbon markets. The relative lack of formal regulation of REDD+ has seen a diverse array of projects unfolding. This is attributable on one hand to the space afforded to project developers and investors to innovate with project types and methodologies in the absence of regulation. On the other hand, on-going regulatory and market uncertainty has dampened profit-seeking investor interest in REDD+, and driven many of those already involved to seek out new ways of securing returns from REDD+ investments. The strategies pursued by financial actors in Indonesia's emergent REDD+ sector are illustrative of these dilemmas, and fundamental in influencing how REDD+ takes shape.

The behaviour of PSF actors in this regard, can be explored in relation to the mix of benefits they pursue, but specifically, how financial imperatives are balanced against non-financial benefits. This is found to depend on where finance is drawn from, and whether actors are primarily in search of independent financial profits, or rather prepared to accommodate lower short-term financial returns in the scheme of a wider project, such as a CSR initiative or sustainable commodity scheme. Generally, the most active participants in REDD+ type activities at present tend to be those actors most willing to derive little or no financial return. PSF actors engaged in activities prioritising financial profits are typically found to have paused or slowed their activities pending improved market conditions. Others are currently either spreading (hedging) risk across CSR initiatives, sustainable commodities projects, or impact investments, or withdrawing from REDD+ altogether. Essentially, investment focused purely on REDD+ VERs is increasingly deemed too risky for almost all PSF actors.

The four broad strategies sketched in this chapter are neither mutually exclusive nor exhaustive, and cases are observed of actors adopting multiple strategies. Each actor effectively has a particular mandate and rationale, which uniquely shapes their 
behaviour. The research broadly confirms, however, that despite evident diversity in the tactics and strategies pursued by financial actors, most are still primarily concerned with their financial 'bottom line', and therefore reluctant to pursue REDD+ VERs in isolation given their current low market demand and high production cost and risk. However, the variety of projects created with, and attracting, PSF in Indonesia suggests varying degrees of VERs (or carbon) centrality in REDD+ projects and that offsets are being replaced by a number of other co-benefits. For actors adopting CSR, sustainable commodities, or impact investment type strategies, the delivery of VERs has itself taken on the nature of a secondary co-benefit or contingency to be engaged if VER markets stabilise in the future. This illustrates how the original vision of the mechanism being driven by REDD+ VER strategies has shifted due to the difficulties and risks in producing VERs and the market's reduced demand for carbon offsets. This has attracted different types of PSF actors and given rise to different types of REDD+ projects and GVCs. Based on these insights the following chapter presents an investigation of the specific commodification processes within three REDD+ projects - conceptualised as value chains - to better understand their value, the PSF actors involved, their governing influence and how they evaluate REDD+ projects. 


\section{A GVC framework and analysis for REDD+ in Indonesia}

\subsection{Introduction}

This chapter analyses REDD+ projects supported by PSF in Indonesia. To do so, it draws on and adapts a global value chain framework, as discussed in Chapters 2 and 3. The GVC framework helps to provide insights into PSF and governance within REDD+ projects, REDD+ as a process of commodification, and the REDD+ commodity itself. In what follows the GVC literature is drawn upon to adapt a GVC framework for this REDD+ analysis. The three Indonesian REDD+ project case studies are then introduced in section 6.2, and analysed using the developed framework, with attention on their input-output commodification structures and general governance and coordination dimensions. Section 6.3 then focuses on the specific governance and coordination implications of PSF actors on each of the case study REDD+ projects. This analysis thus contributes to addressing research questions 2 and 3, which are concerned with understanding, respectively, why PSF actors support REDD+ projects, and how PSF actors influence the governance of these projects. The case studies detailed here are also drawn upon in Chapters 7 and 8.

\subsection{Applying GVC analysis to REDD+}

GVC analysis employs well-established methods for analysing globalised capitalist production networks and their governance (Gereffi \& Fernandez-Stark, 2011; Gereffi \& Lee, 2012; Kaplinsky \& Morris, 2001). Recent work has called on commodity chain researchers to expand and deepen their approach to institutional and governance components (Starosta, 2010a). Visseren-Hamakers et al. (2012) argue that this is necessary for REDD+ research given its unique and complex global environmental 
governance characteristics. Bumpus and Liverman (2011) suggest that value chain analyses of REDD+ could offer important insights into how value is captured throughout its production and consumption in commodity form. Selwyn (2012) offers a framework that can support interdisciplinary, holistic and historicised analysis of GVCs, an approach that is adapted and applied here to three case study REDD+ projects.

A GVC approach typically includes the analysis and mapping of the tangible inputs and outputs to the 'production process' on commodity chains (such as land, labour, offices, consultants/expertise, audits, finance, and information), and the strategies and practices of key actors at each stage along the GVC (Gereffi \& Fernandez-Stark, 2011; Gereffi \& Lee, 2012; Kaplinsky \& Morris, 2001). This approach also accommodates calls to explore REDD+ commodification requirements to measure, disentangle and commensurate the attributes and additionality of REDD+ projects, and actors' balancing of profits with ethical production (Lansing, 2011; Selwyn, 2012; Stephan, 2012; Vagneron \& Roquigny, 2011; Xue \& Chan, 2013). While the notion of 'input-output structure' may seem less applicable to the REDD+ context, it is nevertheless relevant, as inputs and outputs are of a less tangible, but no less real, nature. I focus on these 'inputs' of actors, flows and activities to provide insights into each actor's role in producing a REDD+ project, and to thereby better understand what the REDD+ project and commodity is. In so doing, this chapter provides empirical groundwork for discussions in later chapters that engage research question 2, why do PSF actors support REDD+ projects?

In what follows, the movement of value on these REDD+ GVCs is graphically presented in the connections and flows between actors involved in the case study REDD+ projects. Each relationship and the types of information, processes and actions that actors are involved in is analysed in detail. This assists with tracing flows of materials, finance and information through the GVC, in order to illustrate who shapes specific aspects of projects on the basis of what information. The inputoutput structures of these chains reflect a geography of globally connected actors. These actors range from international investors and consultants, to project 
developers and NGOs, to Indonesian forest communities. The requirements of finance and information culminate into specific components within REDD+ projects through the establishment and operational phases of each REDD+ project. The descriptions of actors, networks and strategies in each case study REDD+ project are overlain with their institutional context.

Analysis of the institutional context within which GVCs are embedded is important, as it significantly influences their governance characteristics (Gereffi \& FernandezStark, 2011; Gereffi \& Lee, 2012; Kaplinsky \& Morris, 2001; Lansing, 2011; Selwyn, 2012; Stephan, 2012; Vagneron \& Roquigny, 2011; Xue \& Chan, 2013). Analysis of the institutional setting of REDD+ in Indonesia is therefore important for engaging research question 3, what are the governance implications of PSF actors on REDD+ projects? The institutional context introduced in Chapter 4 and analysed in Chapter 5 is revisited and drawn upon in the final discussion of this chapter.

There are two aspects of the broader institutional landscape that are particularly important to understanding the development of REDD+ in Indonesia - the national land-use governance framework, and international REDD+ standards (covered in Chapter 4). Attention is directed to how actor strategies are formed and evolve within a land-use context where contending forces attempt to secure structures and practices to their advantage. This requires recollection of the REDD+ industry and actor context outlined in Chapter 4, which encompasses global governance institutions and research organisations that, while operating at a distance, have a very real effect on the structure and dynamics of specific REDD+ GVCs. Retaining links to these contexts is important when re-embedding them for a situated analysis, something this research implemented through its contextual establishment and framework within Chapters 4 and 5 (Bernstein \& Campling, 2006a, 2006b).

Both the material input-output arrangements and the institutional context of REDD+ projects influence REDD+ GVC governance. The REDD+ standards and accompanying MRV methodologies are examples of project components that bridge the material components and their institutional contexts. Standards and methodologies have 
considerable influence on processes of commodification as they explicitly detail methods of implementation and exactly who will do what over the course of a project's development and operation (Gupta, Lövbrand, Turnhout, \& Vijge, 2012; Pearse, 2012; Xue \& Chan, 2013). The prescriptions within REDD+ standards and methodologies graduate a project to the degree of the selected standard, but are not a limitation upon a project's ambition. Project developers and their partners can go beyond these measures to incorporate activities and meanings additional to the conventional definitions of a REDD+ project. The following section details the approach to GVC analysis taken in this research.

\subsubsection{A GVC framework for REDD+ projects}

In order to make sense of the complexity inherent in the development of a REDD+ project, a common template of the material basis (in actors, flows, activities) of such projects was developed (see Figure 6.1). This template, developed inductively and iteratively on the basis of fieldwork, assisted in identifying and analysing aspects of the three REDD+ projects to be discussed. Relationships among key actors are analysed in detail and illustrated as flows of finance and information in the diagrams. These diagrams are schematic representations of the REDD+ projects as global value chains. They are not mapped as unilinear chains linking producers to buyers. Rather they are 'slices' of complex global networks of actors, illustrating multi-directional flows of finance and information as inputs and outputs that produce a REDD+ project and exchangeable commodity. The common requirements of REDD+ projects in Indonesia can effectively be divided into separate but closely integrated components. The four key stages are detailed below.

\section{REDD+ project establishment}

Reading Figure 6.1 from the left side, the process begins with 'REDD+ Project Establishment'. The four generic components (1. Stakeholder and community engagement, FPIC and analysis, 2. Land-use concession and legal compliance, 3. Nature modelling and measurement'; and 4. 'Carbon modelling and measurement') within REDD+ project establishment. These components constitute the necessary attributes for a project to be considered a REDD+ activity; consistent with recognised 
REDD+ standards and the UN definition of REDD+. These attributes derive from prescribed methodologies that are designed to ensure: a) that these attributes are achieved to a certain standard (in accordance with the project's rationale and ambition and/or a given REDD+ standard); b) that this delivers benefits to the forest area and associated communities beyond the benefits of projected future scenarios without the project, referred to as the baseline or 'business as usual'.

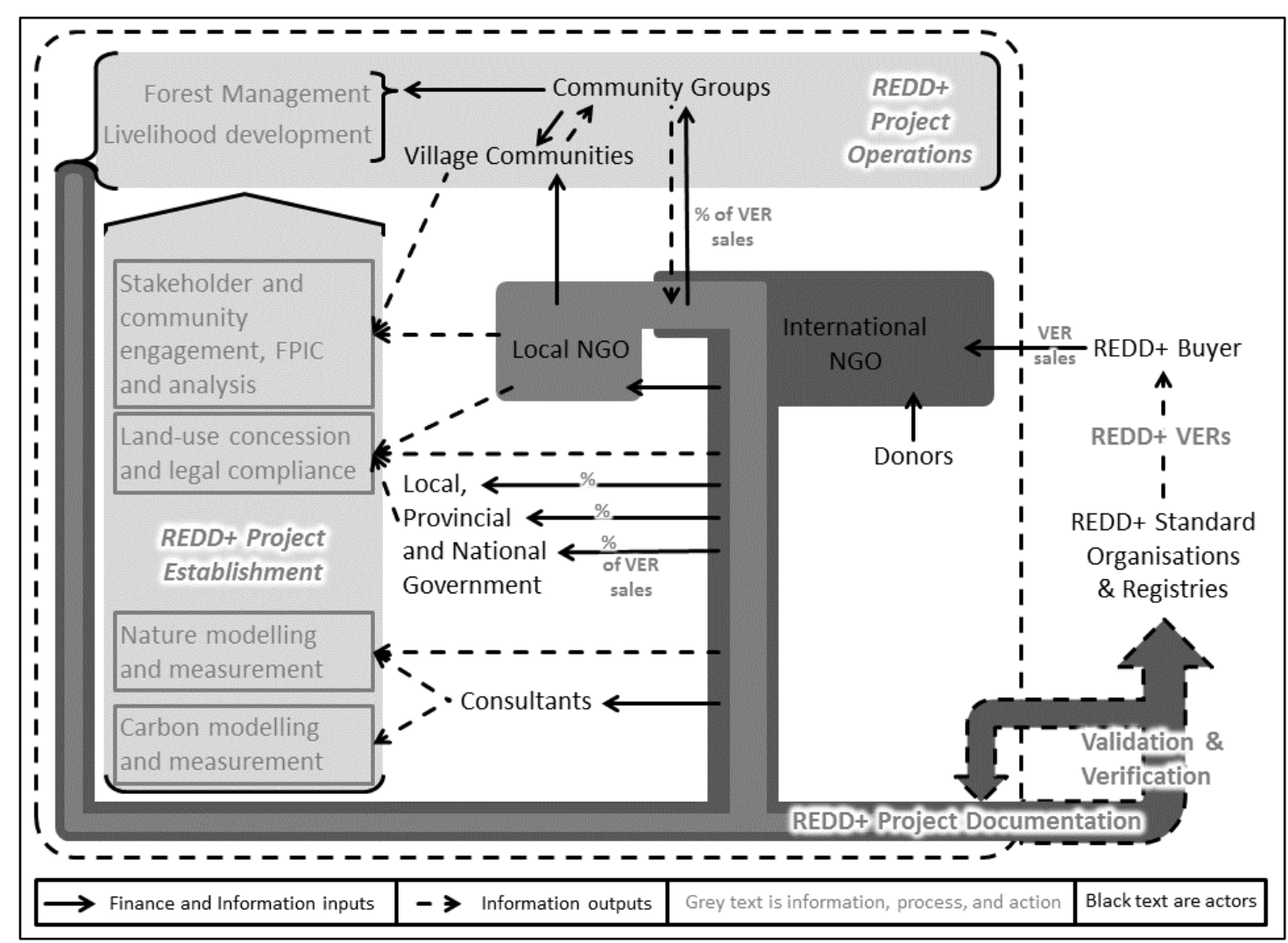

Figure 6.1: REDD+ project template (populated with sample actors/activities).

Activities within the 'Stakeholder and community engagement, FPIC and analysis' component typically include community livelihood mapping, establishing institutions for project governance, management plans, and institutions to manage project finance. It is assumed that these processes will contribute to sustainably governed forests. The 'Land-use concession and legal compliance' component involves legally securing tenure of the project area and compliance with national land-use and carbon laws. The 'Nature modelling and measurement' and 'Carbon modelling and measurement' components concern the establishment of future scenarios for the 
project area. These components also determine the methodologies that the project will use to conserve and improve the area's natural character and demonstrate carbon sequestration and storage. The processes and actors involved in the development of each of these components are illustrated to the right as a mixture of international NGOs, local NGOs, governments, consultants, village communities and others, each with arrows indicating the nature of their involvement. These components then feed into the second REDD+ project stage: 'REDD+ Project Operations'.

\section{REDD+ project operations}

'REDD+ Project Operations' encapsulates the processes and actors that will be responsible for the REDD+ project after it has been established. Its operation should be consistent with, and refer to, the plans and methodologies developed during the establishment phase. Operative activities typically involve village communities and community groups and comprise forest management and livelihood development.

\section{REDD+ project documentation}

'REDD+ Project Documentation' refers to the REDD+ project reporting and documentation that confirms the project's adherence to a selected REDD+ standard(s). In Figure 6.1 both the international NGO and the local NGO are involved in project documentation. This is represented in Figure 6.1 by the point of exit from the dashed line surrounding 'REDD+ Project Establishment', 'REDD+ Project Operations' and the actors and relationships between them. In the language of GVC analysis, this is the down-stream or 'buyer' end of the chain. The path from here is prescribed, following a standardised process for all projects using a given REDD+ standard.

Project methodologies and supporting documents are first subject to validation assessments by standards administrators. Following any required revisions, and approval after a time-bound reporting period, the project and the monitoring documents are then subject to verification processes. Verification should ensure the project is consistent with its operative plan and methodologies. If verification is 
achieved, the quantity of VERs the project is responsible for over the reporting period is listed in a VER registry. It is from this registry that the project's VERs are sold to buyers at a price negotiated with representatives from the REDD+ project. Proceeds from the sale are then transferred to the REDD+ project representatives and distributed through the REDD+ project, consistent with its 'REDD+ Project Operations'.

\section{Actors, inputs, and outputs}

Finally, Figure 6.1 reflects relationships between actors and their roles in delivering finance and information for the development of different stages of REDD+ projects. For example, international and local NGOs occupy a central location, where they manage many of the functions of establishment and operation. Their relationships with other stakeholders are illustrated by the mixed connections between them and the project establishment and operation components.

The international NGO is positioned as the receiver of finance from VER sales and PSF actors and is responsible for its distribution. The solid and dashed arrows intersecting the two overlapping grey boxes of the NGOs indicates that both NGOs are involved in the distribution of finance and information to the community groups, and receive their reciprocal flow of information. This distribution of VER sales would be consistent with Indonesian law, the REDD+ standard, and the benefit sharing strategies developed in project establishment. However, these arrangements of finance, information and actors will also indicate the governing influence PSF actors and capital across these GVCs. The grey box representing the international NGO channels the project establishment and operations components into the 'Project Documents' component. Where the documents are developed by more than one actor, their grey boxes are stacked within each other, as in the example of the local and the international NGOs in Figure 6.1.

\subsubsection{Case study REDD+ projects and GVCs}

Figure 6.1 is intended as an aid to understanding REDD+ projects, and does not constitute a complete description or analysis. The complexity of relationships 
between actors, processers and the project components are discussed in depth within each REDD+ project case study. The GVC diagrams are intended as heuristics to aid in understanding the REDD+ projects, and identify significant similarities and differences among them. Identifying these components helps to untangle and conceptually map the production of each REDD+ project.

REDD+ projects in Indonesia have taken many years to get to their current state and most have not completed their establishment or operation phases, and thus are not yet formally recognised as REDD+ projects. As such, the diagrams presented in the following sections are best thought of as representing an accumulation of past and likely future relations - like a photographic negative left exposed and capturing flashes of activity as relationships illuminate over the project's lifespan. These depictions are informant-articulated histories of actual relations and predictions of relations between actors assembling to create REDD+ projects. Subsequently, the diagrams are best understood as a shifting sum of relations involved within this slice of the REDD+ project's network.

The three REDD+ projects explored here (termed The Swamp, The Valley, and The River) reflect the typical variety of suitable case studies in Indonesia. Each of the case studies have managed to complete biodiversity and carbon modelling and measurement components relatively easily, and are progressing as anticipated with the stakeholder and community engagement, FPIC and analysis components. However, none have managed to secure a land-use concession. The Valley are the closest of the three to having secured this, whereas The Swamp and The River are dealing with local and provincial authorities that are not interested in supporting or allowing the projects. In a similar sense, only The Valley was close to securing future PSF. The other two are either losing the PSF funding they had, or had yet to attract any. The diverse relationships with PSF makes them useful case studies to examine the nature, diversity and influence of PSF in the REDD+ sector. The following sections outline the three GVC case studies that produced the REDD+ projects in preparation for the subsequent section that analyses the role and influence of PSF actors in each. 
Across the case studies, the terminology used to refer to specific actors (such as the Investors, INGO, Indonesian Business and Village Communities) represents the relevant actor of the specific case study being discussed in that section. For example, when the Investors are mentioned in the section about The Swamp then that refers to the specific investor actor involved in The Swamp REDD+ project. These relevant actors are noted within each case study's GVC diagram and can be used as reference.

\section{The Swamp}

The Swamp is the largest of the three case studies, covering an area of forest about twice the size of the other two. This project stands out from the other case studies for its close and strategic partnership between the project developer, an INGO, and a group of institutional investors (the Investors) that together sought to develop premium VERs using CCB and VCS REDD+ standards. However, the project had stalled and the Investors were departing the partnership at the time of writing. The GVC diagram in Figure 6.2 illustrates the material input-output structure, and the actors involved in the project.

The Investors are attracted to the INGO's experience with developing REDD+ projects in similar contexts and its network of relationships in Indonesia, including in the project area. The INGO has a long-established and respected presence in Indonesia and internationally. The INGO could see the benefit in cooperating with the Investor to take advantage of their considerable resources and relationships in finance to help achieve their desired conservation and community outcomes. As such, the partnership aimed to develop several REDD+ projects internationally whereby the Investors would financially support the INGO's activities to facilitate institutional and community capacity for REDD+ projects. 


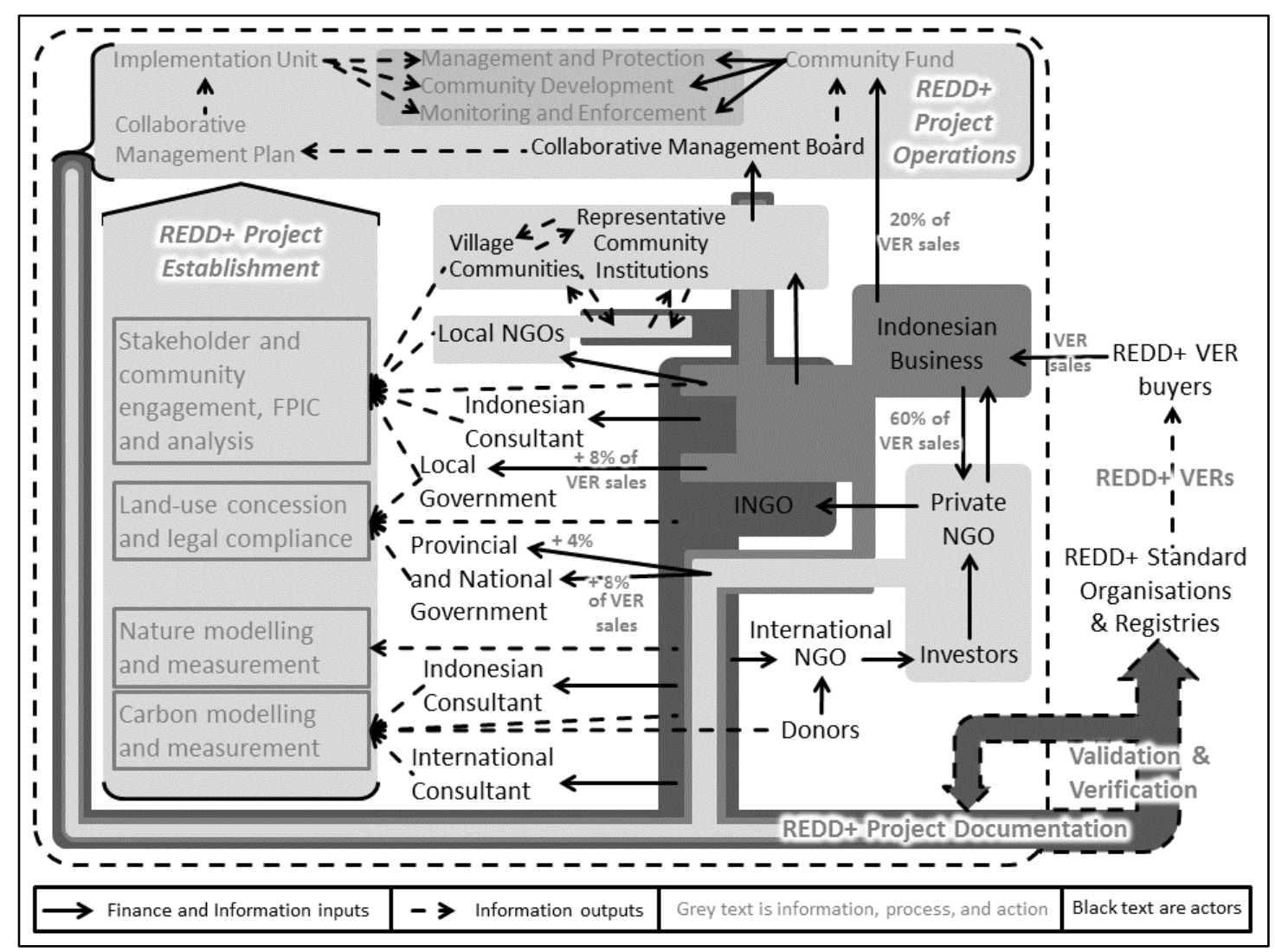

Figure 6.2: GVC diagram of The Swamp REDD+ project.

The INGO and Investors also received supportive finance and research from foreign donors and another international NGO to help establish this project. The two parties describe the beginning of the partnership below:

We caught the interest of the Investors, who approached us with a proposal that they would like to work with us to scope out and identify commercially viable REDD+ globally. There were lots of grand ideas about how many we'd like to develop, timeframes for developing them. That was all very much a result of the optimism and excitement that had come out of the Bali COP ... We had a plan of 6 projects that were generating credits within a three year time frame. It was ambitious (INGO Informant 1 The Swamp).

The whole thing was set up with [the INGO] with a focus on Indonesia. Back in the days that everybody thought it was the EI Dorado of not just REDD+ but of financial instruments (Investor 1 The Swamp). 
In an effort to satisfy the requirements of Indonesian regulation, and to provide a structure that would be flexible enough to accommodate future expansion of activities under the partnership, the INGO and Investors established a private NGO (PNGO) to behave as an Indonesian foundation. The INGO explains:

The [PNGO] is set up for environmental and social benefits in Indonesia. So that makes it a social enterprise, it's not just a company ... It will not have an implementation role on the ground, they're just the highest level of governance. It's not clear at the moment exactly what they'll do. It will evolve depending on what happens and how much money there actually is. We may need to develop funding proposals for the [PNGO] to access additional finance to keep the project going (INGO Informant 2 The Swamp).

This PNGO appeared to offer the INGO and REDD+ project considerable organisational flexibility and opportunity to shape and add social enterprise activities under its structural umbrella within an environment of funding uncertainty. The INGO continues to describe how the specifics of Indonesian regulations enable Indonesian foundations to access sources of finance from Indonesia that foreign organisations cannot:

One thing about having an Indonesian foundation [the PNGO] is it enables us to access Indonesian sources of finance, which international organisations are not allowed to do. So if there's any Indonesian CSR funding, we can access that, whereas international organisations can't access that. So that's quite a big opportunity (INGO Informant 2 The Swamp).

By being able to attract funding from a wide spectrum of sources and collate it across multiple REDD+ projects, the PNGO structure promised to deliver large amounts of easily scalable REDD+ outcomes and associated VERs. The INGO described how the governance of the PNGO was a mix of the Investors, the INGO, and some Indonesian actors that could facilitate the PNGOs mission. This way it could be considered an Indonesian company: 
The Investors have a number of representatives on the [Private NGO] board and our country director's on there too. Then there are a number of independents as well. The founders are international, but the directors dealing with the day-to-day things are Indonesian. It's considered an Indonesian company (INGO Informant 2 The Swamp).

The day-to-day implementation and management of this particular REDD+ project and others under the PNGO's administration involved a separate Indonesian Business. The PNGO finances and directs the activities of the Indonesian Business, and both are based in or near Jakarta. The Indonesian Business is responsible for the land-use concession permit, managing the activities within the concession, and managing the distribution of finance from the sale of VERs to the Community Fund, the National Government, and back to the PNGO and on to Investors. The INGO described the close working and management relationships to implement The Swamp REDD+ project as 'collaborative management', whereby the Indonesian Business leads with collaborative support from the INGO and Local NGO (LNGO):

The level at which the collaborative management would happen is with the [Indonesia Business]. The INGO would support at implementation and director level as well. Along with the [LNGO], they are very much on the community side (INGO Informant 2 The Swamp).

The close working relationship between the Indonesian Business and INGO saw the Indonesian Business benefit from the INGO's expertise and relationships within the Village Communities, all levels of Indonesian Government, and the wider REDD+ project development profession. Figure 6.2 illustrates how closely the INGO and Indonesian Business are involved with each other, and that they are positioned at the epicentre of relationships, remaining closely connected to the Investors.

It was among these actors and alongside LNGOs, Representative Community Institutions, and Village Communities that the majority of collaboration and exchange took place in establishing the project. The INGO would typically instigate 
strategies and lead a group of selected LNGO and community members when reaching out to government institutions and consultants for necessary inputs for the project documents (grey text in Figure 6.2) to be submitted for verification and validation to REDD+ standard organisations and registries. The INGO's position as a central and neutral party between the Indonesian Business and Investors, and the Village Communities and the Provincial Government was one that relied on trust and confidence in delivering the promised REDD+ outcomes. The INGO was a critical and influential governing actor in this regard:

The [INGO] uses the [LNGO] as a local NGO partner. The [LNGO] would not engage with [the Investors], because in Indonesia when you mention the private sector people think you are greedy and you are just capitalist, that you don't consider the people. That's why all the NGOs try and engage indirectly with the private sector (Indonesian Business 3 The Swamp).

Trust was also essential to accessing funding from the private sector and connecting it with Local Government and Village Communities for REDD+ projects: "This is a performance based system and many international organisations doubt Indonesian performance so far, especially in forestry issues" (Indonesian Business 3 The Swamp). Again this is something that the INGO was able to facilitate through its connections and reputation within the global REDD+ community:

That's the benefit of an [INGO], they have access to other relationships and money ... That's what [the INGO] brings as an international NGO. The second is international connections. [The LNGO] and the local government cannot access the private sector to invest. So they need someone to connect them to international buyers ... International buyers will have more trust if there is an international organisation involved. So that's what [the INGO] as an international NGO can bring: capacity, connections, and trust, especially regarding the international REDD+ standards like VCS and CCB (Indonesian Business 3 The Swamp).

The INGO's so-called 'collaborative management' approach structured how the Village Communities will operate the project (illustrated at the top of Figure 6.2). 
The Investor, PNGO, and INGO have representation in and governance of the Indonesian Business, which along with the Community Representative Institution and additional representation from the INGO, form the members of the Collaborative Management Board. The composition of this board has not yet been finalised, but it will be responsible for developing the Collaborative Management Plan (the Plan) and maintaining oversight of project operations.

The Plan will govern the relationship between the Indonesian Business and the Village Communities in the project area. The Plan will be designed and implemented through a joint process with Village Communities, following the INGO's collaborative management approach. This aims to ensure that Village Communities understand the project's potential benefits and risks and have the human and financial capacity to contribute to its development and implementation. The day-to-day implementation of the Plan will be managed by an implementation unit with offices in the closest city and around the project site. The unit's activities will include management and protection of the project area, monitoring and enforcement and community development.

The costs of these activities are met by the Community Fund, administered by the Collaborative Management Board and financed by the Village Communities' 20 per cent share of VER sales. When the project is running smoothly, the INGO will withdraw and restrict their involvement to biodiversity conservation monitoring and reporting. The LNGO will continue their work with the Village Communities as the primary implementer while the Indonesian Business will manage the project from a distance, supporting the LNGO and working with high-level stakeholders like the Indonesian Government.

In the wider context of the conservation finance community, the INGO is positioned as a bridging actor, with the capacity to link the Village Community to the Investors and their Indonesian Business within the project. As such, these actors relied substantially on the INGO. The INGO used their partnerships with the Indonesian Business and the LNGO to strengthen their ability to deliver on their desired REDD+ 
outcomes. This triad became effectively positioned to engage the demands of the institutional context and the ambitions of the REDD+ project.

\section{The Valley}

The second case study involves a smaller forested area and population of community members, best described as a community forest with operative conservation, reforestation, organic farming and healthcare programmes in place before the advent of REDD+. This project was using the Plan Vivo REDD+ standard and was described as more community orientated than other VCS and CCB projects, endeavouring to remain as participatory as possible. The project relationships are depicted in Figure 6.3. The main players in The Valley project involved the collaboration of an INGO, two national NGOs and three LNGOs. These LNGOs have a variety of support from multiple donors, with some being supported by the INGO involved in the project. The INGO was seeking and receiving financial support from two PSF actors (detailed in the following section as the International Business and CSR Agent) and various donor funds.

The close proximity of a national park on one boundary, and state forest on the opposite, positioned this forest area as a type of ecological corridor that attracted the interest of two LNGOs working within the neighbouring forests. These LNGOs could see that the Village Communities were interested in securing rights over their customary forest area through a land-use concession and that doing so might provide a vehicle for protecting the forest area if they didn't need to degrade the forest for their wellbeing. As one LNGO put it:

[Our work] protects these forests by supporting the legal transfer of management rights to those communities that have traditionally managed them... [It] is a practical way to reduce encroachment rates into the National Park by facilitating the creation of local conservation areas around the park that are sustainably used and managed by villagers (LNGO Informant 1 The Valley). 


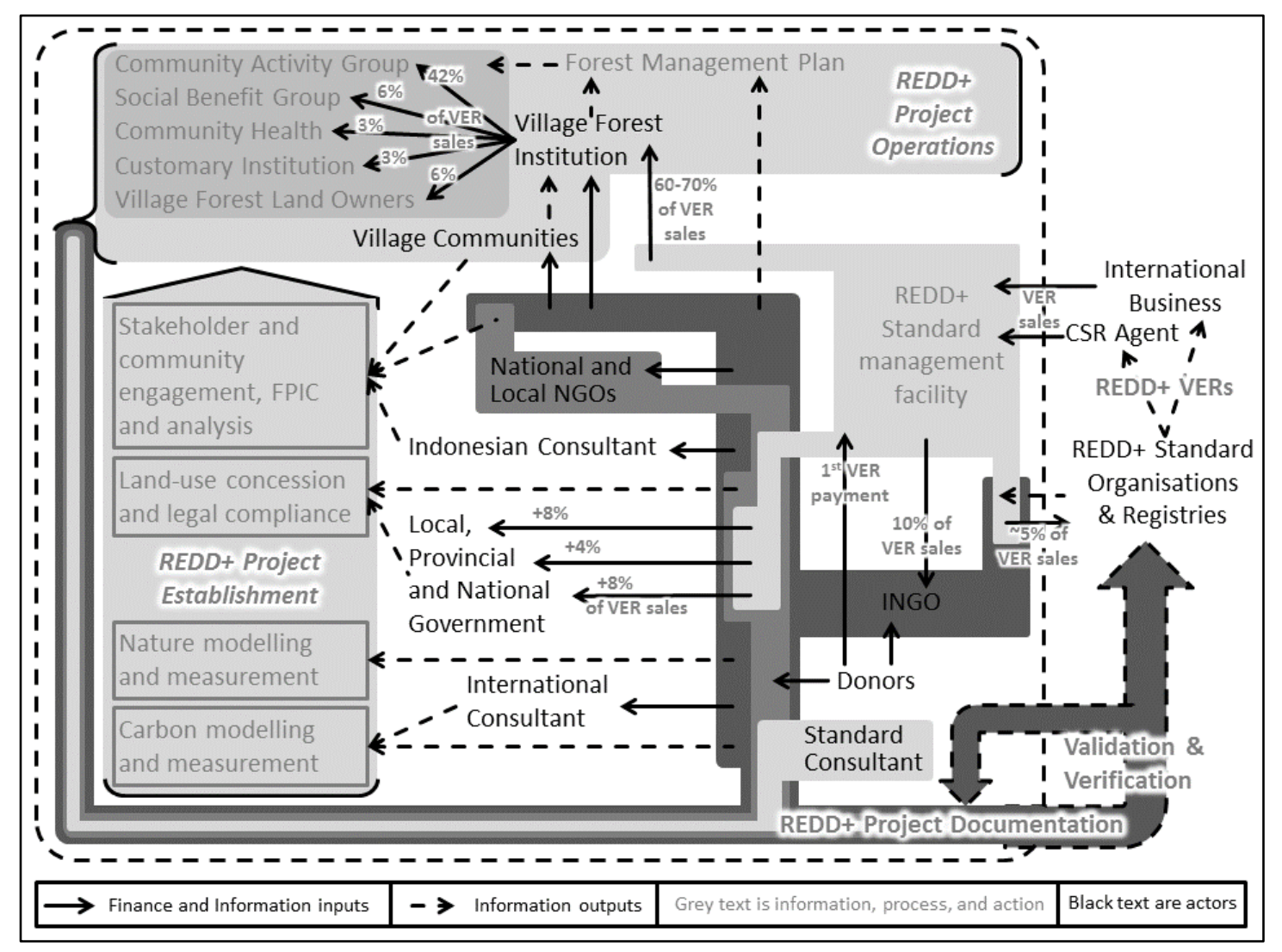

Figure 6.3: GVC diagram of The Valley REDD+ project.

The INGO could also see the potential for this and put the pursuit of the community land-use concession at the centre of its work in the community. The INGO brought considerably more resources to the REDD+ project than the LNGOs, who are trusted in the community and afforded legitimacy to other organisations that they worked with. As such, the INGO and these LNGOs established working relations that focused on gaining land-use concession for the community but also included organic farming, nursery development, reforestation and forest and conservation education. These livelihood development activities sought a pathway for communities to reduce their dependence on practices of unsustainable forest use and to move towards sustainable non-timber forest products. One of the LNGOs described its relationship with the INGO as collaborative, and geared towards the shared goal of securing the land-use concession. However, the same LNGO did express concern that their INGO partner appeared to have their own agenda, rather than pursuing the Village Communities' priorities: 
There are differences between the [INGO] and us. The [INGO] generally have the same idea on approaching the community, but with some difference. We start from what they need. But the [INGO] start with their own standard that they have, like a procedure, for their goals ... The [INGO] have their own schedule and have released it onto the community (LNGO Informant 1 The Valley).

These LNGOs also assisted the INGO when facilitating community mapping and training workshops. These workshops are a necessary part of the participatory FPIC process required to secure land-use concession over the forest for and by the community. In these cases the relationship between the INGO and these LNGO partners appeared to take a subcontracting nature. As one INGO informant put it:

The [INGO] pays one of the [LNGOs] to come in and help with community consultation and the concession. The other [LNGOs] just help the community with conservation efforts and organic farming, they don't know about the involvement of other [LNGOs] and what else they are doing (INGO Informant 2 The Valley).

The INGO was offered the assistance of two national NGOs with running FPIC processes, and technical agroforestry and forestry services, but instead undertook these functions themselves and did not involve the national NGOs. However the INGO did make use of an Indonesian Consultant who had undertaken an anthropological study of the communities in the area several years prior to this REDD+ project. There was a sense that the INGO was deliberate and selective in who they involved with the project and how, and the way they maintained considerable influence over such access to the REDD+ project and the Village Communities.

The INGO influence within these establishment activities was maintained through the operational activities of the project. The REDD+ Standard Management Facility was established and administered by the INGO, and is responsible for the sale of VERs, the distribution of VER finance, and managing agreements with the Village Forest Institution (made up by members of the Village Communities) (Figure 6.3). No payments had been made at the time of writing, but the first payment was ready to 
deliver to the Institution for distribution via the Forestry Management Plan. This Plan also details how ecosystem service payments will be secured through monitoring, reporting and verification processes that enable VERs to be listed on the standards registry and sold. Following this, project sponsors make payments to the Facility (Figure 6.3). The quote below illustrates the approach to PES that is being taken in this Village Communities' forest:

The user groups [in the Plan] report back what they've achieved [via the Institution] and that is checked by the [INGO] and [Facility], and then PES payments are made to the Institution ... At the end of the day the contracts are very simple ... The sooner the money comes through the Institution the better, so they can manage it and pay it to the patrol team who feel that this is really their money that they're earning rather than [INGO] staff passing money to people (Standard Consultant 1 The Valley).

The Institution legally owns the land-use concession and is responsible for its management, including its finance, administration, and the coordination of activities that concern it. This is detailed in the Plan, which is designed and agreed upon by the Institution and the INGO and must remain consistent with the selected Plan Vivo REDD+ standard. Figure 6.3 shows how proceeds from the VERs are to be divided as per the Plan. Within the Village Communities the vast majority is directed to the activities protecting the forest, like boundary patrolling and establishing nurseries and commercial enterprises. PES payments are being sought from two prospective sources and the INGO felt the outcome would be positive.

The INGO's central and pivotal position on the GVC afforded it considerable influence over many relations and processes comprising the establishment and operation of this REDD+ project. As the project developer, the INGO was in a position of having made the commitment that they would deliver a REDD+ project, or at least some sort of forest carbon, conservation and community development initiative involving these Village Communities. This is not to say that the Village Communities are not on board with the project, but it suggests that the package of 
initiatives may not have been entirely the Village Communities' own doing. To satisfy the agreed definitions and standards of a REDD+ project that PSF actors desired, certain attributes need to be present. As the INGO was responsible for developing the project to suit these desires, they are also in the position of being responsible for ensuring that these qualities are realised.

\section{The River}

Of the three case studies, this project can be considered as having made the least progress in developing into a REDD+ project. At the time of the field research, the project was in the process of preparing project development documents (PDD) that the other case study projects had already completed or were about to complete. Furthermore, it had not secured PSF to purchase PES units or VERs, and the charitable finance that had sustained the project had finished. As such, much of the analysis here is based on what informants expected would happen if the project does attract PSF, which the INGO and other actors did expect.

This project concerned a relatively small area of forest serving as a buffer zone between a wildlife reserve and a river. It was championed by a very active LNGO with close and trusting relationships with Village Communities and other groups connected to the REDD+ project area. At the time of writing, the LNGO had sidelined the REDD+ project to focus on other activities that they felt would provide a more certain and immediate benefit to Village Communities, like the development of their businesses and helping them access markets. The following GVC analysis for this project is aided by Figure 6.4 .

The project stemmed from a large INGO becoming interested in the activities of the LNGO and the Village Communities in relation to the buffer zone. Using donor finance, the INGO was developing pilot REDD+ projects to attract sustainable sources of PSF. The LNGO had been working with the Village Communities around the wildlife reserve since 1998, and received a number of grants for their forest conservation and community development programmes. The LNGO used INGO 
finance to commission an International Consultant to undertake a feasibility study and scoping exercise for this REDD+ project.

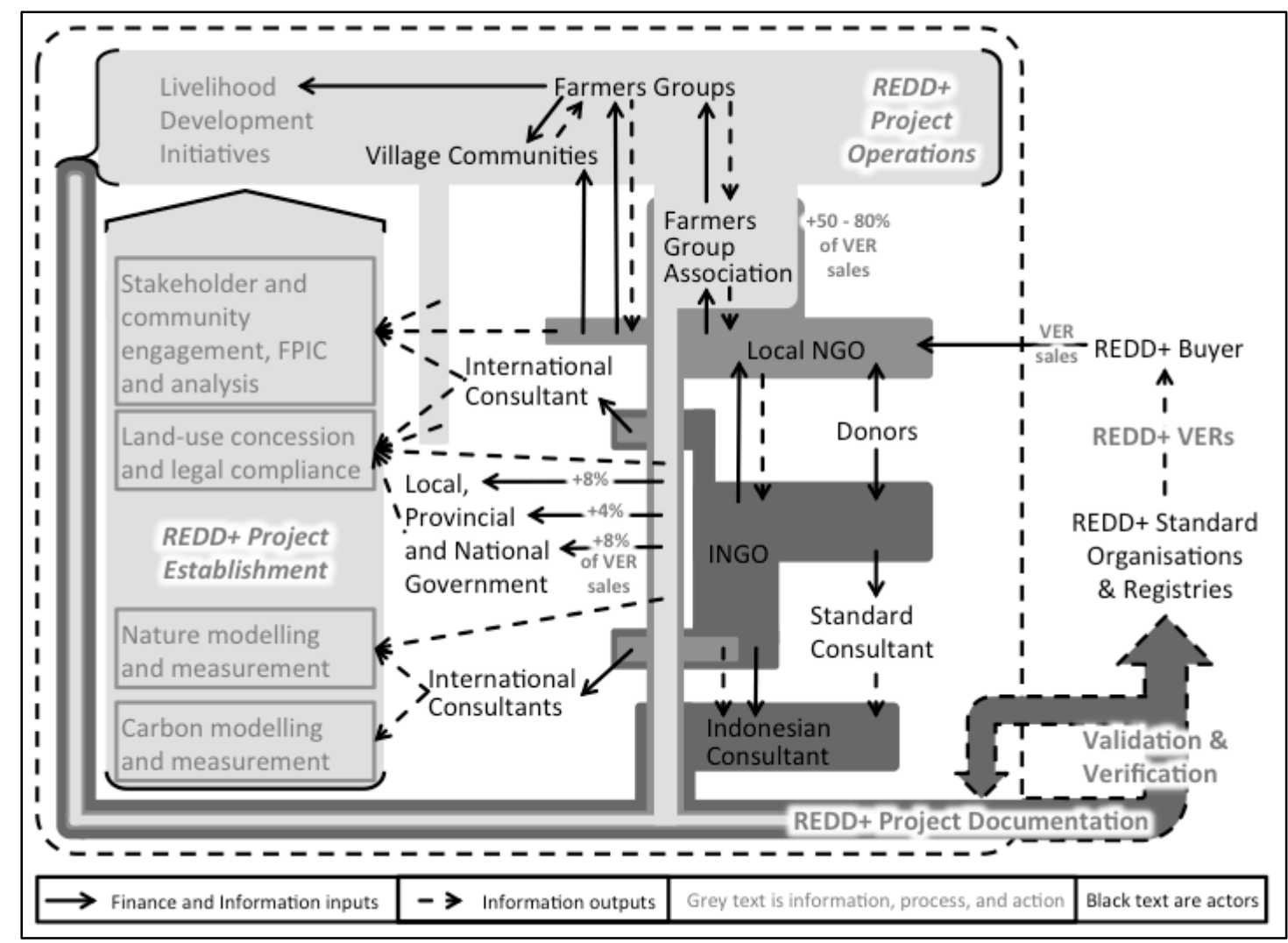

Figure 6.4: GVC diagram of The River REDD+ project.

The INGO was cautiously optimistic about the opportunity that REDD+ might present for Village Communities of this area and was interested in the broad environmental and social benefits that REDD+ might bring. The INGO had extensive practical experience in the Indonesian community development and conservation context, and was drawn to the LNGO and its reputation as an honest and respected broker of information and active implementer of community development and conservation projects. The relations between the INGO and LNGO consolidated, building on relationships between certain key members:

Intimate connections are important. One lead actor from the [LNGO] and one lead actor from the [INGO] went to university together. The [LNGO] actor said to the [INGO] actor that the [INGO] should support the [LNGO] in REDD+. So the [LNGO] and the [INGO] started the project together ... It's based on what the [LNGO] were 
already doing; the [LNGO] see it as a way to support what they were going to do anyway (International Volunteer The River).

The LNGO was establishing farmer cooperatives prior to REDD+, and the INGO's interest in it, and linked some ten cooperatives together to form the Farmers Group Association (the Association). This group became the official REDD+ project proponent. The Association also shared intimate connections with the LNGO, entangling the LNGO into the Village Communities and governance of the project:

Three or four of the representatives in the Farmers Group Association actually work for the [LNGO], so they're intimately entangled. You can't look at the [LNGO] as an external actor; they are of the community. There are only three people in the [LNGO] that aren't from these communities (International Volunteer The River).

Subsequently, there appeared to be a clear hierarchy between the LNGO and the Farmers Groups. The LNGO, Indonesian Consultant and the general direction of the REDD+ project appeared to be governed by the Association, which represented the preferences of the farming families that constituted the majority of Village Communities along the riverside:

The [Indonesian Consultant] does exactly what the [LNGO] tell them to do. The [LNGO] does exactly what the Association tells them to do. The Association have big meetings every two to three months and make decisions. The [LNGO] feeds back to the [Indonesian Consultant] what the Association tell them they decided. The [Indonesian Consultant] writes the PDD based on what the [LNGO] says the Association wants (International Volunteer The River).

The governing influence of the Association and Village Communities was such that the project's CCB standard "would probably be a triple gold REDD+ project because the project proponent is the community" (Standard Consultant 2 The River). Figure 6.4 demonstrates how the Village Communities shared relationships primarily with the LNGO and specific Local Government agencies regarding the land-use concession, protection and mapping of the area. In this sense, the Village 
Communities demonstrated a practiced capacity to participate and manage their own development in partnership with the LNGO and through the Association. Consequently, the participation component of this project was by far its most advanced attribute. The LNGO appeared to have the Village Communities' best interests at heart, as they pursued the land-use concession for community forestry and kept ambitions for REDD+ at a pragmatic distance. This approach positioned the LNGO in a collegial and trusted position with the Village Communities:

We talked about REDD+ last. So everyone in the group understood that REDD+ is not the purpose. The purpose is community forestry (LNGO Informant 1 The River).

If you can live close to the forest, with good management, then REDD+ is a bonus ... Most of us don't know what REDD+ is. We just know that it's additional to forest management and so far it has been free from the [INGO] (Farmers Group Association Member The River).

The PDD for the CCB standard was being collated and developed by a small, recently established Indonesian Consultant. The Indonesian Consultant was based in Jakarta, but intermittently positioned a staff member in the LNGO office to be nearer LNGO information sources, the Village Communities, and the forest. The Indonesian Consultant was trained by a much larger and influential Standard Consultant who was involved in the design and implementation of many REDD+ standard methodologies, and validation and verification internationally. The focus on the CCB standard was because it would contribute to the efforts of the LNGO, and if the REDD+ project did not eventuate the Village Communities would benefit from having gone through a community development planning and mapping exercise that might be useful when pursuing future development initiatives. The PDD for the VCS standard was on hold because of the uncertain REDD+ VER market and lack of a confirmed buyer or funder for this project.

Subsequently the details on the project's operation are still being discussed between and within the Village Communities, Farmers Groups, and LNGO. Part of the reason 
for this delay was that the INGO was the primary financier of the REDD+ project, and their support was waning and formally ended in December 2014. The end of this support and the failure of others to step in was interpreted by the Village Communities and LNGO as an indication that the REDD+ project could not be relied upon for their future wellbeing, so it was not prioritised. However, the existing activities of the Village Communities, the Association, and the LNGO offer an illustrative example of what their operative REDD+ project might have looked like; namely the expansion of existing livelihoods using finance from REDD+ VER sales:

Rubber tappers will plant more rubber trees and fisherman will use fish traps. The idea is to leverage the types of existing activities that they already have. But the main aim of the project is to secure the legal status of the land through the concessions so they have access (LNGO Informant 2 The River).

The Standard Consultant, as shown in Figure 6.4, are responsible for instructing the Indonesian Consultant how to deliver the PDD documents to the LNGO and INGO. Although they are the most influential GVC member, the LNGO emphasised: "We still need other parties to help. The [Indonesian Consultant] is the bridge between us and the [Standard Consultant]" (LNGO Informant 1 The River). Similarly, the INGO is positioned as a provider of finance and information to the LNGO, with little other influence on the REDD+ project GVC. On the contrary, the Farmers Groups and Village Communities, in close partnership with their LNGO, constitute an influential backbone through project establishment, operation and documentation.

The participatory nature of the project is one of the reasons the INGO was so attracted to it: “This project is dear to the [INGO's] heart, it's their favourite one. Because of the relationship between the [LNGO] and the communities, and how the communities drive the project" (INGO Informant 3 The River). As the Village Communities are understood as responsible for driving the project, and no buyers for the VERs are identified, there was little outside influence or opportunity to generate and extract financial profits. 


\subsubsection{Summary}

This section has taken a GVC approach to analyse the emergence of REDD in Indonesia. It has enabled a 'mapping' of REDD+ projects as productive processes with inputs and outputs of certain material attributes that represent specific and important carbon, biodiversity, participation and legal compliance components. The section has also explored how these components and attributes come to constitute the projects through REDD+ project documentation and standards. The following sections consider why PSF actors support REDD+ projects (research question 2), and explore how PSF actors influence the governance of REDD+ projects (research question 3).

The REDD+ GVC analyses highlight some commonalities between the three case studies that match and support earlier contextual findings in Chapter 5. First, achieving the biodiversity and carbon components was relatively straightforward. Second, the participation component was both difficult and vital to project success, yet something that project developers are all confident about achieving. Third, achieving the legal compliance component was both extremely important, and difficult to achieve. Fourth, and closely related, financial support and the sale of VERs is crucial to project sustainability, but is exceedingly difficult given the complexities of achieving legal compliance and because of on-going uncertainties with the international carbon market.

The governance characteristics of these REDD+ GVCs shifted throughout the development of the case study projects. Applying a GVC lens helps to shed light on how REDD+ projects are organised and governed, and the role of specific actors in this. The influential roles of certain actors are evident in the individual case studies. The Valley and The Swamp, for instance, are driven by an INGO, whereas The River was driven by a LNGO. These lead actors developed trusting implemention partnerships with other key actors, including PSF, and also developed new business and community entities to expand their influence and satisfy legal requirements. The following section directly engages the roles of PSF actors in these REDD+ GVCs and 
the ways that they influence the character and governance of REDD+ projects and value chains in relation to the wider institutional and political context discussed in Chapters 4 and 5.

\subsection{Governance implications of PSF in REDD+}

The following sections build on the foregoing analysis of the REDD+ case study projects to explore the roles and implications of PSF actors in relation to project governance. This is done by drawing on GVC governance types and forms of coordination as outlined in Chapter 2. Section 6.3.4 draws these case studies together to summarise, compare and re-contextualise the observed governance characteristics and roles of PSF actors in REDD+ projects in Indonesia.

\subsubsection{The Swamp}

The Swamp project was dependant on finance from its Investors to keep the project, and the actors within it, arranged as it had been designed:

In Indonesia we have a term 'in the end, it's all about money'. The [Investors] want the promise and growth of carbon trading and the carbon market. The [INGO] want their agenda of biodiversity. They can use REDD+ and the social funding from the [Investors]. The [LNGO] is the same; they want the community benefit and to keep their program and role in the community, whilst improving the community livelihood and capacity (Indonesian Business 3 The Swamp)

The INGO saw REDD+ as an opportunity to continue to expand their existing biodiversity conservation work; "REDD+ has been a financial mechanism for us to do what we have always done" (INGO Informant 2 The Swamp). The INGO's enhanced ability to access funding enabled them to plan longer term projects with reliable and flexible budgets as well as expanding their own capacities and those of the Investors:

For the [INGO] it's a great opportunity to access funding. Being able to develop new commercial relationships with people like the Investors has been massive. It's 
enabled us to get out of the annual - or every second year - having to develop donor proposals (INGO Informant 2 The Swamp).

A lot of finance was made available. It was really exciting and we went at it all guns blazing and really ran at that opportunity. It was a fantastic opportunity. It allowed us to build our own institutional capacity. There was finance available to do that. It helped the Investors to build their own capacity and understanding of what's important with regards to REDD+ (INGO Informant 1 The Swamp).

The excitement generated by this INGO-Investor partnership, and the sudden influx of funding that accompanied it, was clear. These types of funding arrangements had never been seen before by the INGO, and understandably they seized the opportunity. The partnership offered the INGO the ability to set comprehensive conservation goals, develop their capacity in PES and forest carbon, and assist Village Communities to secure land-use concession and tenure over their forest. Pursuing the expensive land-use concession that was required to secure this tenure was only made possible by the finance that the Investors offered through their partnership with the INGO. It is highly unlikely that such an option would have been available using the typically limited and piecemeal funds that the INGO attracts from donors. However, the Investors departed from the project because of the number of risks that had accumulated and pushed the project beyond what the Investors could accommodate. Therefore, the project's future is uncertain. These risks culminated in the stalling of the land-use concession application and an apparent need for payments that the Investors considered corrupt. The perspective of the Investors is given below:

We haven't put any more resources into trying to obtain those approvals. I'm not sure we would now, given where the REDD+ market is at. So maybe that's been a blessing. Who knows? ... Do we really want to spend two million on a concession fee in a market that looks as it does? A voluntary market with pockets of demand and everything has to be small-scale community; I'm not sure if peat lands in Indonesia do that for buyers (Investor 1 The Swamp). 
This project was really our foray into REDD+ over-the-counter projects. Unfortunately it ran into licensing issues with the Governor. So we gave up and stopped. I remember an awkward discussion with the guy from [the Investors] about the Governor wanting to be paid off for his signature. He was asking me 'should we pay him?' There's only one answer I can give you from our organisation - no (Shareholder 1 The Swamp).

The Investors are the primary implementing agent amongst the shareholders that had invested in the fund supporting the REDD+ project. One of these shareholders questioned whether the Investors had the capacity to manage the types of relationships that REDD+ in Indonesia demanded: "I don't think [the Investors] had the Indonesian experience. The relationship got messy between the [Indonesian Business] and the Governor" (Shareholder 1 The Swamp). The above quotes illustrate that retaining these Investors would have required that the project remained financially sustainable within their spectrum of acceptable risk. As the project no longer met these financial requirements, the Investors could no longer justify their support and removed themselves from the project and the partnership with the INGO. In this way, the efforts of the project developers to implement REDD+ standards to safeguard communities and ecosystems risked being undermined by financial requirements not being met. The Investors are clear that their involvement in this REDD+ project first and foremost concerned the generation of financial profits via REDD+ VERs, thus appearing to adopt the REDD+ VER strategy introduced in Chapter 5. There was no charitable component to their strategy and very little consideration of the CSR, branding or marketing benefit the project might afford them:

Each of the shareholders want a financial return. They're happy to do it in a clean sector, but in the end they're all return driven organisations. None of them are charitable organisations or anything else ... They're all very ethical investors, but they're very frank and they're interested in returns (Investor 1 The Swamp). 
The INGO recognised this and subsequently did everything they could to retain the interest of the Investors. These efforts to appease the Investors and meet their financial requirements shaped the project significantly, and show how the Investors' financial motives influenced the project's governance. The quote below from an informant not working directly on this REDD+ project, but observing closely, recognises that reliance on profit-seeking finance could be fickle and even jeopardise the project if market conditions deteriorate and investors depart:

With [The Swamp], when the market fails, the project fails. That's a lesson ... If there's no Investors, then there's no money, and no project for the [INGO]. The [LNGO] in [The Swamp] has no money. It's funded by the [INGO] and was brought in because it had good networks in the communities (INGO Informant 2 The River).

Other informants witnessing the events of this REDD+ project from the margins sensed that the INGO risked straying from its ideological roots and harming its reputation as it wrestled with appeasing the profit motives of the Investors:

There was an array of motivations here. The cowboys were for profit, and the NGOS were for conservation to pay for itself. [The INGO] was an NGO that was in a weird awkward space. They've always worked with business, but they were making that type of pitch very strongly. They were looking at partnering with an investment bank to fund REDD+ projects. So when you put this ambition and partnership together it started to look as though the [INGO] was in this for some conservation and money to be made. They're a charity so they don't take it home. It'll be invested in other program development. But it started to take on this uncomfortable mix (Contractor 4).

This 'uncomfortable mix' of the Investors' influence on the partnership with the INGO is evident, and established the platform upon which the project's strategy and framing emerged, thereby directing key elements of the project. Evidence of this PSF governing influence was clear in the capitalist logics that structured the PNGO to be able to scale-up REDD+ projects and deliver greater financial returns whilst reducing or limiting risks and costs. The Investors' desire for financial returns is also the 
justification behind the project's pursuit of the largest possible forest area land-use concession so as to secure high numbers of VERs for sale. Furthermore, the VCS and CCB standards are adopted as they will position the project's VERs on the most lucrative VER registries and increase the likelihood of sales and high prices.

To minimise risks and costs to the project, the INGO found itself positioned at the relationship crossroads of this GVC between PSF actors and Village Communities. The INGO is in tight partnership with the Investors and Indonesian Business because of its established reputation for delivering similar projects, therefore reducing the risk that this project would encounter complications and jeopardise the Investors' investment. The project plan also promises to position forest patrol and management offices and staff near the forest area, in the nearest town, and in the provincial capital. This comprehensive method of control and risk reduction attempts to safeguard the forest VER accounting area and Investors' capital from any dissent or mismanagement from within or near the REDD+ project.

These examples illustrate the influence that the pursuit and reliance on PSF has on the governance of this REDD+ project and appear to permeate across its GVC. Figure 6.5 below illustrates the modes of governance and forms of coordination between actors and components on this REDD+ GVC that were described above.

The source of the arrow indicates the direction of the governance and coordination relationship whilst the style of the arrow indicates the governance or coordination character of that relationship - across the spectrum between market, modular, relational, captive and hierarchy types. As outlined in Chapter 2, the market end of the spectrum experiences low explicit coordination and low power asymmetry, and highly codified information. The hierarchy end experiences high explicit coordination and high power asymmetry, and low codified information. The forms of coordination illustrated above are drawn upon in the summary section below to inform a comparison between the three REDD+ GVC case studies. 


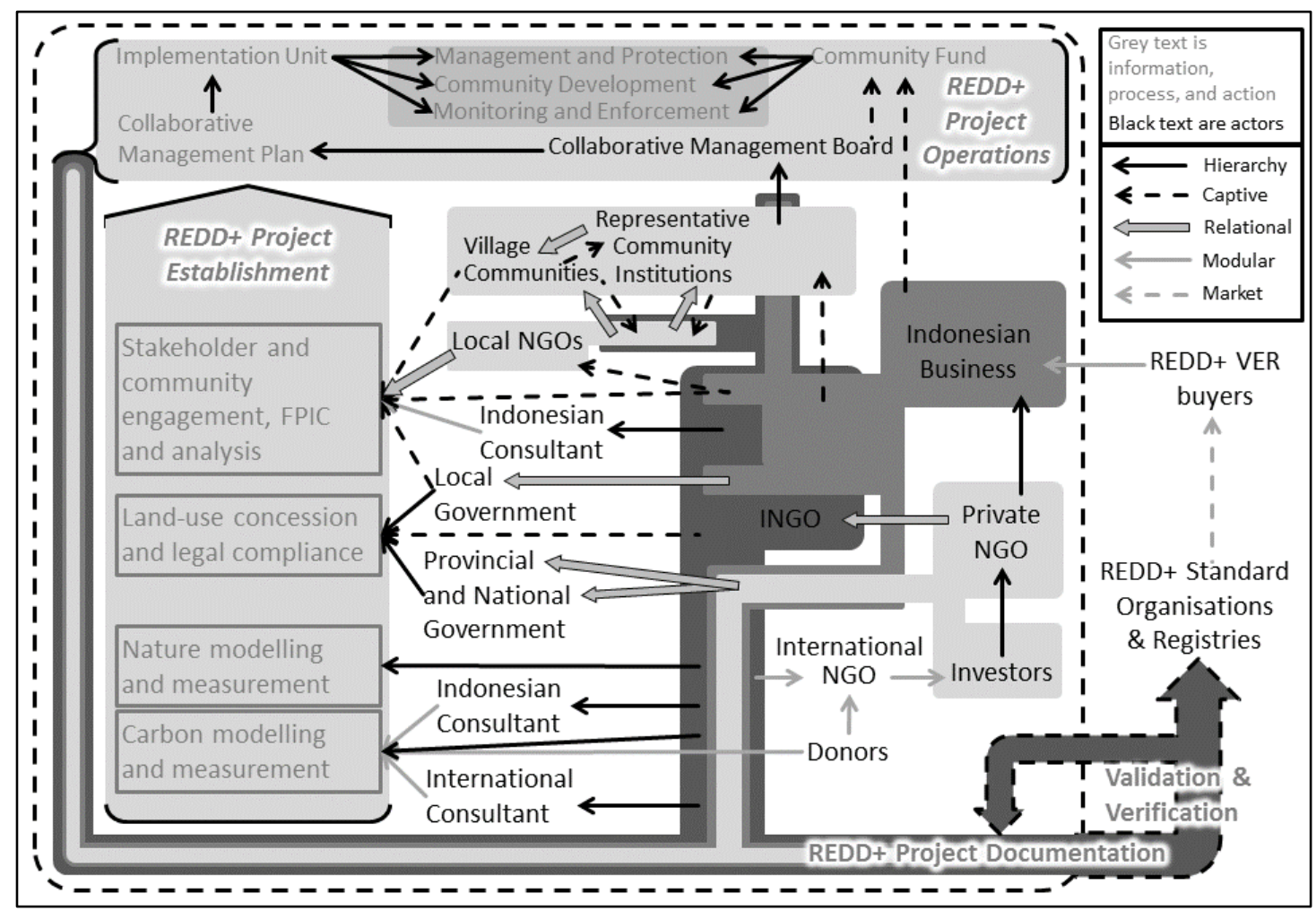

Figure 6.5: Governance types and forms of coordination on The Swamp REDD+ project.

\subsubsection{The Valley}

The INGO in The Valley project has proven to be an influential and opportunistic actor throughout the development of the project. The INGO is developing a reputation for packing the project full of attractive features and characteristics that deliver 'wins' for everyone. This project is actively developing the most advanced systems for carbon accounting, biodiversity monitoring, legal compliance methodologies, and FPIC and community participation that it can find to deliver forest carbon conservation and community development. The INGO is striving to develop the project as a best practice example to help guide others embarking on such work. The Standard Consultant recognises the INGO as going far beyond the monitoring requirements for a REDD+ project:

I suppose [the INGO] want to combine the VCS technical aspects, plus a bit of stuff mixed in with $C C B$, plus a bit of stuff from themselves, plus a bit of stuff from Plan Vivo, all thrown into the same cooking pot. It won't get certified by these other 
standards, it'll just be certified by Plan Vivo ... They've been working to conceptually combine them all as best practices. So while they're doing Plan Vivo, they recognise that maybe the outside world doesn't see the technical elements of Plan Vivo as rigorous as necessary, so they wanted to meet and establish their own best practices. So in a way developing their own standard (Standard Consultant 1 The Valley).

The INGO appears to be looking to take advantage of REDD+ funding to create premium examples of REDD+ projects that prove the REDD+ concept and provide guidance in Indonesia. As one consultant put it, the INGO "were active here prior to this program. The threat to the forest was there, the baseline was there, and the land-use concession was there; so they thought they'd try REDD+" (Standard Consultant 1 The Valley). The Standard Consultant pointed out that the INGO's exhaustive efforts may be because they have not secured funding in the competitive REDD+ market, and funders are cautious. Furthermore, the history of some failed REDD+ projects, and the subsequent poor reputation of REDD+ in general, may have encouraged the INGO to focus on quality as a way to compensate for and distance themselves and their projects from those reputations:

I think it's also driven by this fear from the carbon market, that people want to overdo it and want to show that whilst they may be related to carbon they're doing it in a certain way and not a part of the cowboys and the negative impacts that can happen (Standard Consultant 1 The Valley).

The inclusion of such comprehensive and premium attributes into the REDD+ project was not demanded by the Standard Organisation or the Village Communities and appeared to reflect the desires of the INGO. One consultant felt that the Village Communities may have exploited this trait of the INGO so that they would stay active in their community: "I think that's a way of keeping the [INGO] interested; 'we have 5 orangutan's! Come over here [INGO]!'” (Standard Consultant 1 The Valley). The INGO is continuously interpreting such signals, adapting the project to ensure they have support from the Village Communities, and remaining consistent with the 
Standard Organisation. In addition, the INGO was balancing the desires of the two potential PSF funders and VER buyers - the International Business and the CSR Agent.

The CSR Agent is a not-for-profit organisation that collates a mix of carbon, community, and environmental sponsorship aspirations on behalf of its clients and, with their money, seeks projects that can provide the desired profile for appropriate sponsorship. Their clients include both public and private sources of finance that between them seek a mix of charitable and profitable investments that consistently deliver ethical, low carbon outcomes and carbon offset outputs. The second PSF actor is an International Business that seeks elements of discrete ethical and emission reduction attributes to associate with its own operations and triple bottom line commitments.

The perspectives and approaches of the CSR Agent toward this project and forest carbon initiatives more generally position them as a connector of businesses with carbon credit offsets. The CSR Agent's approach to carbon offsetting is anchored within what they refer to as high quality fair trade carbon credits:

With the [CSR Agent] you offset your emissions with the finest and fairest carbon credits on the market ... You offset your emissions with fair traded carbon credits. The [CSR Agent] offers carbon credits from pre-financed projects that conform to the highest standards ... and each with a personal story. The [CSR Agent] also offers exclusivity on carbon credits from a specific region or town ... You receive a certificate with serial numbers and promotional materials. In this way you can communicate to clients and partners that you proudly take corporate social responsibility; for your clients, for the climate, and for families in developing countries (CSR Agent The Valley).

The CSR Agent uses this fair trade approach to portray the carbon offsets that they offer as more than carbon. These offsets promised to be attached to improvements in the wellbeing of producers, and to be accompanied by personal stories of that 
improvement. In doing so they endeavour to ensure that the maximum amount of benefit from the sale of carbon credits reach the producers of that credit. Subsequently the CSR Agent would best fit the Corporate Sponsor PSF type introduced in Chapter 5. While they were seeking offsets for corporate entities, their financial expense and return on the VERs was of low importance relative to the social and environmental outcomes of the project. The INGO recognised the CSR Agent's approach as the most likely model to assist them with accessing finance for the REDD+ project and are very interested in the prospect of partnering with them:

Consultants are telling us that for the voluntary market there is most potential to attract a funder that wants CSR. They say that this [CSR Agent] goes to the company and helps them with the carbon neutral calculation and certification. The carbon they cannot reduce they will offset, and that creates the demand for voluntary credits. It has nothing to do with Kyoto ${ }^{21}$ or anything. But they also use money from governments to set up the projects. Whereas other brokers just do the brokering. These guys do brokering and then help bring the funding ... The community-tocommunity exchange, ... we really like the [CSR Agent] for this approach. They agree with us that it has to be fair, fair carbon (INGO Informant 1 The Valley).

The INGO perceived partnering with the CSR Agent as an opportunity to develop a direct community-to-community relationship between the Village Communities in The Valley and the communities represented by the potential government funder using the CSR Agent as a broker. This community-to-community carbon partnership and exchange was something that aligned with the INGO's own preferences of how REDD+ should or would best be implemented and enabled the INGO to pursue them. This ideological alignment enabled the INGO to pursue their comprehensive 'premium' community development and forest conservation approaches. It also couched the CSR Agent's governing influence as enabling the INGO, rather than an imposition of separate or additional preferences and attributes beyond the INGOs pre-existent activities.

\footnotetext{
${ }^{21}$ The Kyoto Protocol of the UNFCCC established the first compulsory GHG emission trading mechanisms - notably the Clean Development Mechanism (CDM).
} 
The perspectives and approaches of the International Business toward this REDD+ project and forest carbon initiatives more generally are different, and appeared to carry a more commercial and marketing connotation:

We use the voluntary market for its vibrancy. We like new projects, rather than old, or the continuation of projects ... We like to use partners, like NGOs. About 80-90 per cent of our offsets come from NGO partners. We each have a reputational stake in the projects. The project works just like we want it to work. As far as contracting goes that's important for us. That enables us to easily enter agreements with these projects. That model works for us. The rest are over-the-counter certified emissions reductions, but that's just to back fill what we can't get with our partnerships (Investor 25 The Valley).

The focus of the International Business appeared to be on offsetting their carbon emissions, and doing so through the security and novelty of new projects in partnership with NGOs to assist in sharing and minimising project risk. They elaborated how REDD+ projects are particularly attractive as they offer vibrant stories and compliance opportunities that support their corporate strategy and enable them to quickly 'knock-off' multiple goals at a time with minimal risk, despite their frustration that the trees would not grow faster:

We've done REDD+ projects, we're big supporters of REDD+. If it wasn't for the voluntary market and its vibrancy, such as VCS and the CCB, we wouldn't be comfortable playing in it. But the vibrancy and the compliance nature of the verification standards and their ability to get these projects off the ground has really worked well for us ... We like reforestation projects, but the problem with them is that they have such a slow ramp-up. But we like them and the story it tells and the other co-benefits that comes with it ... We love forestation projects, because as part of our CSR strategy we have goals of ecosystem protection, watershed protection, habitat protection, and reforestation is a wonderful way to knock off more than one goal with one project. So we love reforestation projects and are always looking for more to do (Investor 25 The Valley) 
The INGO recognised the motivations of the International Business as essentially reputational and as searching for projects that they could attach their businesses brand to; "It's their own money. It's CSR money for conservation" (INGO Informant 1 The Valley). The International Business expressed specific interest in the wildlife components of The Valley REDD+ project, particularly resident orang-utan and tiger. Consequently, this became something that the INGO focused on in their funding application to the International Business:

The wildlife they're interested in is orang-utan and tiger, that's the focus. They believe that the [INGO] is doing work on that so it's really up to the [INGO] to put this in the proposal (INGO Informant 1 The Valley).

The International Business had already granted some money to the INGO for the Valley REDD+ project that was going to be used as the first PES payment within the Village Community's Village Forest Institution. However, the INGO was not sure whether the International Business perceived the grant payment as part of the PES model for the VER component of The Valley REDD+ project and what they had planned for those VERs that they had effectively bought. The INGO believed that the International Business was not particularly concerned with the carbon component of The Valley project or whether the VERs would increase in value. The International Business appeared to be far more interested in the CSR attributes it would be afforded by supporting a conservation project that also reduced carbon emissions:

They just want to hear that the money helped reduce the reduction of the size of habitat. Then they can say that in addition to saving orang-utan habitat, the project retired the carbon credit, or something like that (INGO Informant 1 The Valley).

The INGO felt that the International Business may be pursuing a range of reputational CSR attributes across community development and forest and biodiversity conservation that they could draw attention to as it suited their commercial and branding demands. Subsequently, the International Business would 
best fit the Corporate Sponsor PSF type introduced in Chapter 5. Despite this, the Standard Consultant felt that the INGO would continue to pursue the accreditation for the carbon emission reductions as it was something they want to achieve and learn from for future REDD+ project implementation:

The [INGO] have the [International Business's] money and it's relatively open what they use it for. It doesn't have to be for verifiable emission reductions from the project. But the [INGO's] interested in the idea of having the system and the standard of Plan Vivo behind it, some kind of process (Standard Consultant 1 The Valley).

This sort of flexibility from the International Business allowed the INGO freedom to develop the project as they wished. Any restrictions "depends on how the [INGO] sells it to [the International Business]" (INGO Informant 3 The River). Between the International Business and the CSR Agent, it becomes clear that, more generally, these PSF actors are interested in delivering CSR services to themselves or their clients. The INGO developing this project understood this as:

It's either about responsibility or image. Some of them it's about access to market as they then have the paper certificate. Some of them they have to provide offsets for the carbon they cannot reduce. According to the analysis this market is big... I don't think there is any business motive with these funders. But there is an indirect link, as the reason is to strengthen their business. They see sustainability as their business sustainability - to continue profiting! (INGO Informant 1 The Valley).

For this type of PSF actor the story of the project is important, the narrative that REDD+ projects like The Valley deliver. These are appealing and desirable to PSF actors as instruments of marketing and promotion within their professional circles; amongst peers, competitors, supporters, and customers. An informant pointed out that within relatively small areas of forest like The Valley this may be the more feasible option to sustain the project; "As a project developer, like this [INGO] in [The Valley], that's a nice pitch. There's all the biodiversity, carbon, community values. Probably a far greater income, than from carbon credits" (Contractor 4). 
These PSF actors perceived The Valley as bringing a package of social and environmental attributes that ticked the boxes of their corporate strategies and positioned them at an advantage when compared to competitors. The influence and pressure of time is also evident here, with the International Business having a 'problem ... with such a slow ramp-up' and being drawn to REDD+'s 'ability to get these projects off the ground' and 'knock off more than one goal with one project'. The efficiency of REDD+ to deliver these multiple and vibrant responsibility goals at a relatively rapid rate and with legitimately 'personal', 'fair trade' certification that 'conform the highest standards' is clearly very appealing to these types of funders. Importantly, it is these types of PSF actors that the INGO are monitoring closely for future support.

Subsequently it is understandable that the INGO should want to shape their projects so as to attract the interest of this growing funder group. The approach of the INGO to 'cover-all-bases' with premium REDD+ projects is a strategy to ensure support for their projects. The INGO also responds to these funder desires more directly and specifically. Most notably, the key interest of the International Business in orangutan and tiger, saw the INGO adjust their monitoring strategy and demonstrate this within its funding proposal. This change afforded them a better chance of securing funding and future support from the International Business, and PSF.

Catering to these specific and general PSF desires for premium REDD+ projects requires the INGO's influence be spread across the GVC (as illustrated in Figure 6.3) to ensure the project is crafted appropriately and to minimise any risks to their desired 'best practice example' of REDD+. This is reflected in the comments above by informants who felt that the INGO harbours a certain program and agenda for the REDD+ project and its Village Communities. This implication of INGO involvement is evident in the character and design of the Village Forest Institution, its Forest Management Plan and constituent expenditure and community activities. The INGO leads the development of these by facilitating participatory events with Village Communities and certain LNGOs, guiding their decisions towards those that 
resemble premium REDD+ outcomes and stories. The character of these governance relationships across the project's GVC, and the influence of the two PSF actors, are illustrated in Figure 6.6 below.

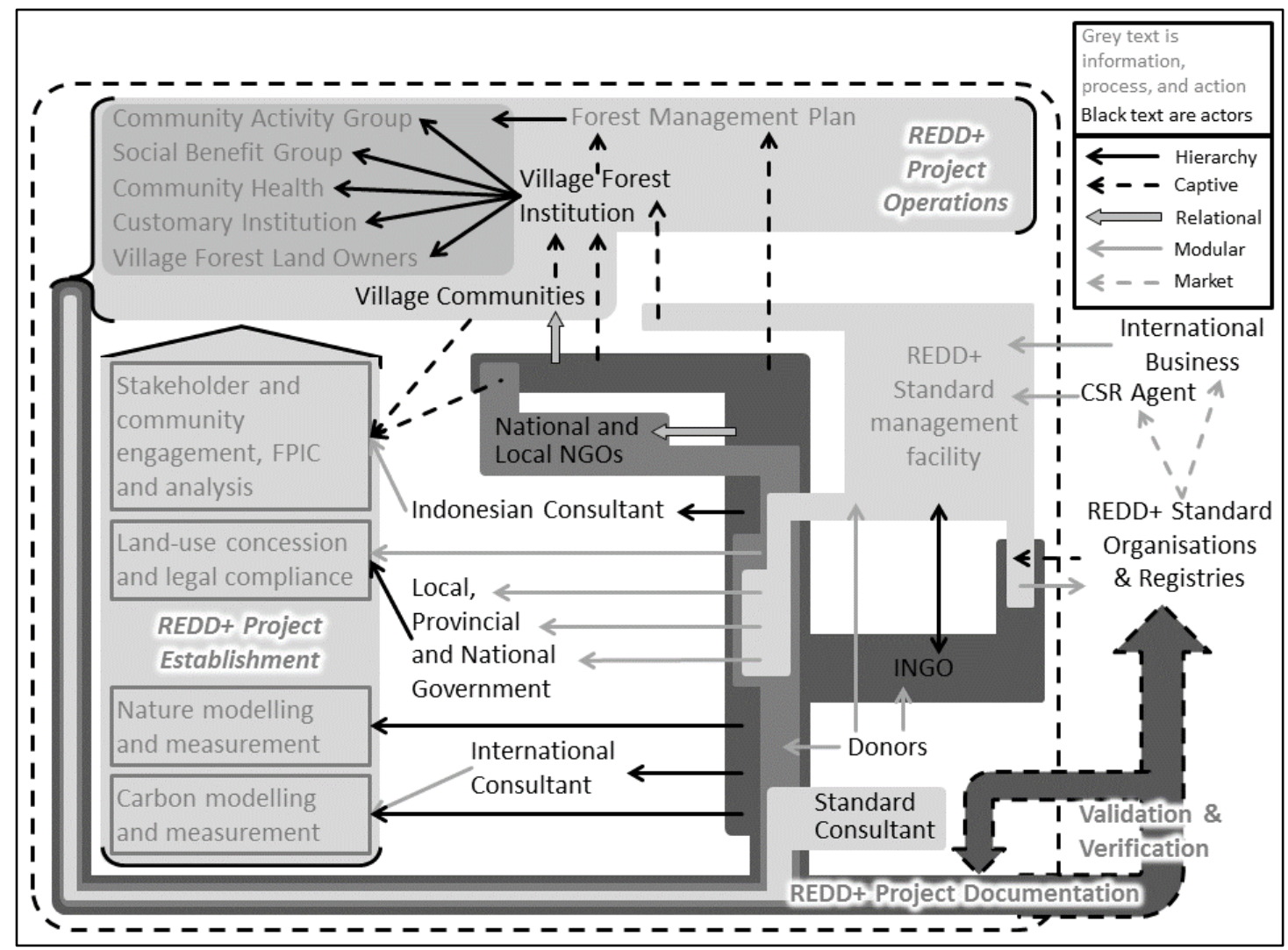

Figure 6.6: Governance types and forms of coordination on The Valley REDD+ project.

\subsubsection{The River}

While The River REDD+ project is yet to formally attracted interest from PSF, anticipation of PSF still influences project development. This is evident in the ways that the LNGO has shifted its focus from the VCS PDD to the CCB PDD so as to concentrate on the non-carbon co-benefits that the certification will bring to the PES project. This risks disqualifying the project from meeting the REDD+ definition, as there is no carbon verification. The LNGO does not appear concerned about this and is confident that their efforts to facilitate development in the Village Communities away from the forest degradation will attract project funders. The greater CSR emphasis of PSF over VER interests underpinned this decision. 
Some of the actors brought in to assist in the development of the project are interested in the financial profit prospects that REDD+ offered. The Indonesian Consultant is frank about rationalising its involvement in the REDD+ project as commercial, expressing how they hope to leverage off this project to develop their expertise and grow their business:

We'll adapt the PDD from this project to the other [INGO] projects. We want to know how the budget and all the costs play out with this PDD so we can learn for others ... I hope we can position ourselves on the top by getting in early, but we don't know... This is a business. For me this is a business (Indonesian Consultant 1 The River).

Overall though, as no VER buyer is established for this REDD+ project, it is difficult to analyse the PSF governing influences. It is unclear why this project did not attract finance, particularly as it initially foresaw itself selling VERs on the open market to PSF. However, the character of the project provides hints as to why PSF might be deterred. The control that Village Communities have over the project may deter PSF actors as it would likely limit their ability to pursue financial profits or shape the project to their ends. As such, PSF may consider it an unpredictable investment, harbouring too much risk and liable to fail or become something that VER buyers do not identify with. That PSF have not materialised has ensured the project is developed in ways relatively disconnected from direct interests of PSF, but remains a set of activities justified by the attraction of PSF finance for certain social and environmental outcomes. The governance characteristics and forms of coordination across this REDD+ GVC are illustrated below in Figure 6.7 and drawn upon in the summary below. 


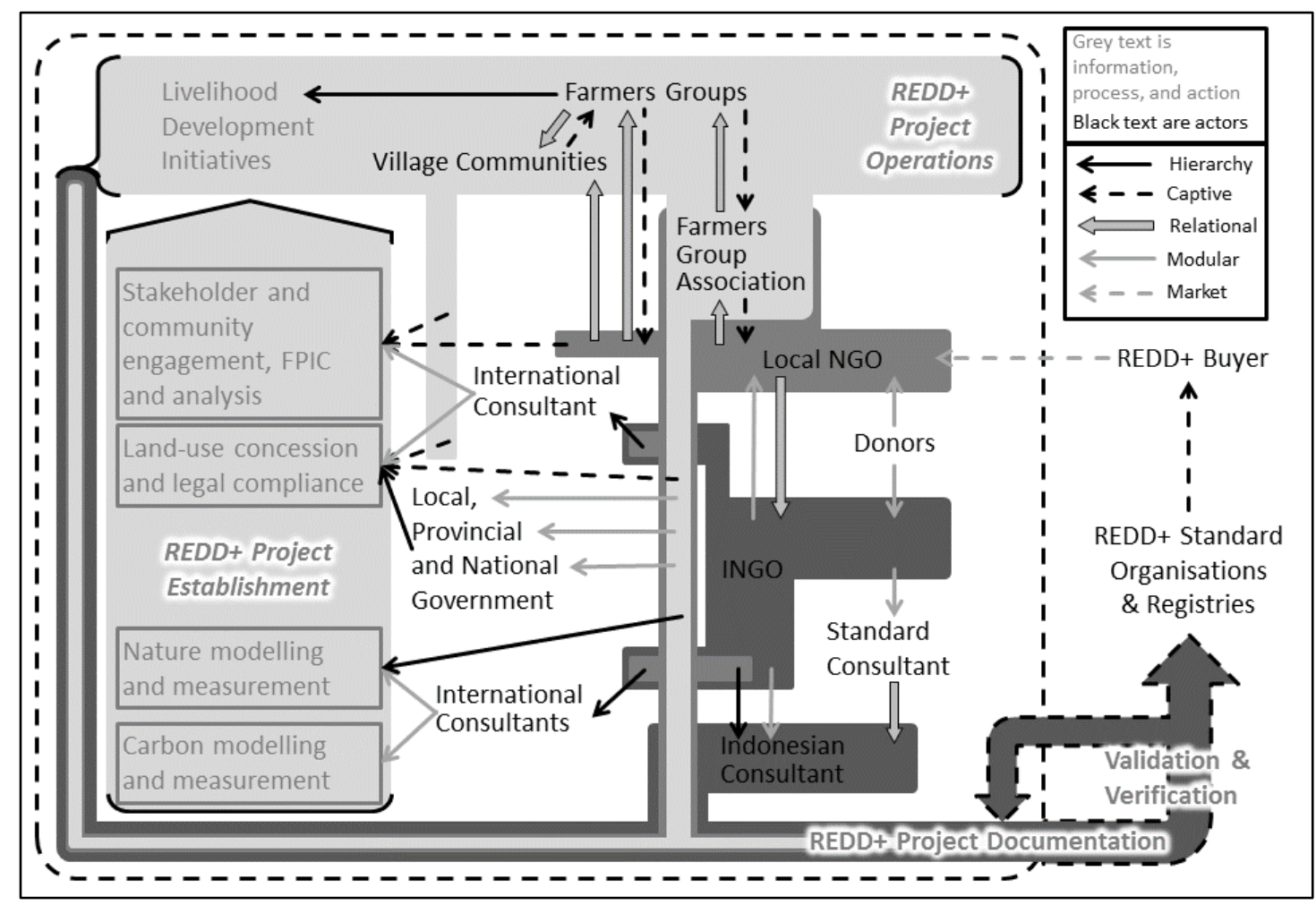

Figure 6.7: Governance types and forms of coordination on The River REDD+ project.

\subsubsection{Summary}

The following compares each of the three REDD+ GVCs and re-contextualises them with respect to their PSF types, strategies and conceptual location on the same framework developed in Chapter 5 - illustrated in Figure 6.8 below - and compares their governance characteristics. Re-contextualising these case study GVCs in light of the analyses in Chapter 5 assists in understanding why certain behaviours and governance modes were witnessed. The governance types and forms of coordination witnessed on these REDD+ GVCs present a mixture of the ideal-types outlined in Chapter 2. The GVC governance and coordination mapped in Figures 6.5-6.7 above illustrated the roles of PSF actors in these REDD+ GVCs and how that permeated through to other relationships on the GVC. Tables 6.1-6.3 below capture the most notable of these and categorise them by the forms of coordination witnessed on each GVC and describes their type of governance. 


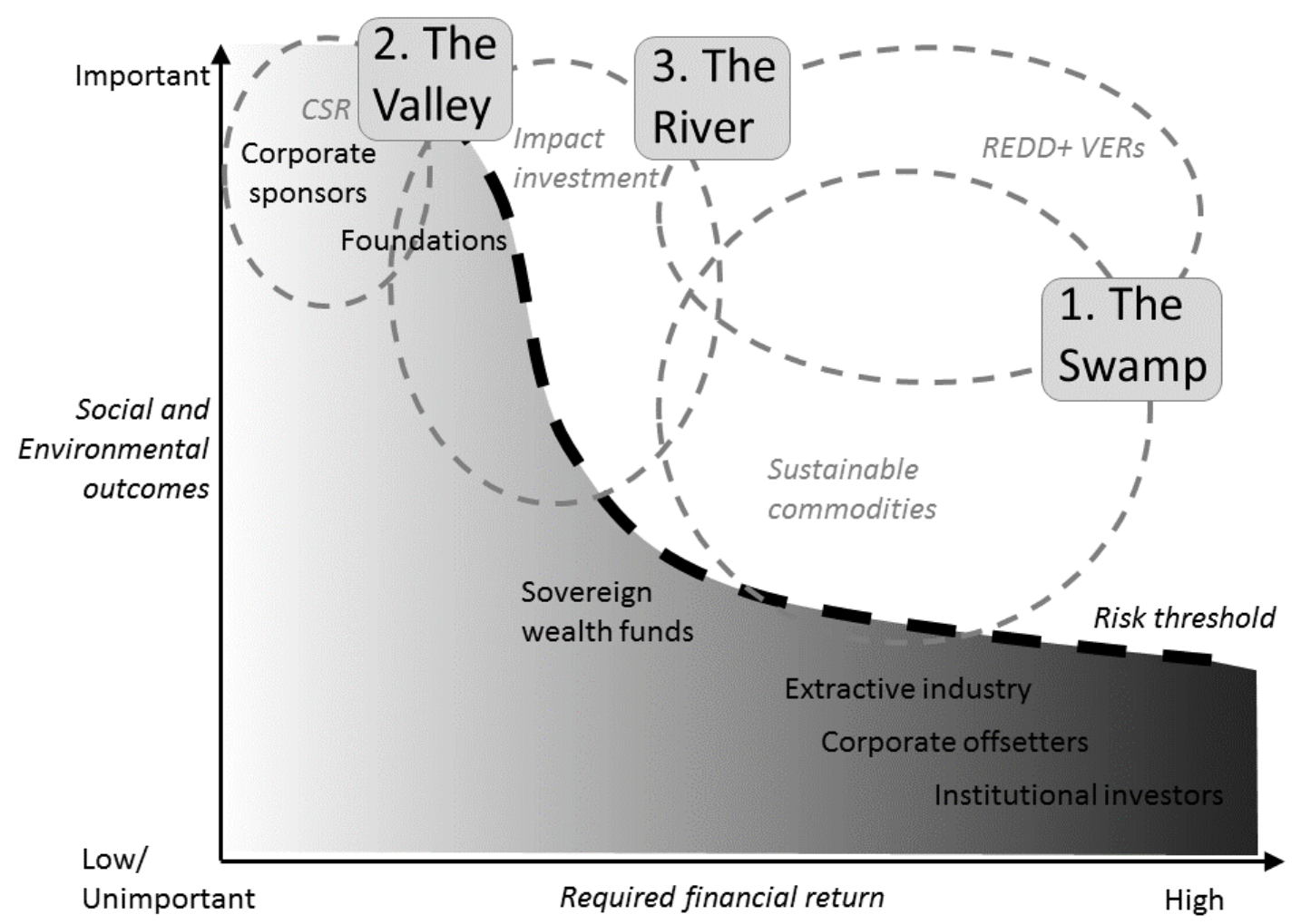

Figure 6.8: The conceptual locations of the three REDD+ GVC case studies. ${ }^{22}$

Of the input components of REDD+ projects, PSF actors consider both the land-use concession and legal compliance and the carbon modelling and measurement components as essential to securing each project's permanence, additionality, conservation and development outcomes, and subsequent VER sales. Stakeholders around each of these projects told of how the communities are interested in achieving land-use concessions just as much as (if not more than) VER payments. The forest tenure and access enabled by these land-use concessions offered communities greater opportunity to secure their livelihoods alongside control of sites of cultural importance. However, these desires are sometimes in contention with the ambitions, or lack-there-of, of formal Government institutions. Particularly those institutions responsible for processing the land-use concession at district, provincial and national levels; experiencing similar trials of delay and deferral faced by other REDD+ projects in Indonesia (Dixon \& Challies, 2015; Indriatmoko, Atmadja,

\footnotetext{
${ }^{22}$ Figure 6.8 builds on Figure 5.1 from Chapter 5 and adds the conceptual locations of the three REDD+ GVC case studies.
} 
Ekaputri, \& Komalasari, 2014; Indriatmoko, Atmadja, Utomo, Ekaputri, \& Komalasari, 2014; Luttrell et al., 2014).

The inability of Case Study 1, The Swamp, to achieve its land-use concession directly contributed to the departure of its investment partners and the project's stalling. The Investors in The Swamp project required sufficient financial returns to justify their involvement in the project and thus the project is located to the far right of the Figure 6.8, pursuing REDD+ VERs as its investment strategy. This places it far beyond the acceptable risk tolerance of the types of institutional investors that were involved but have since departed. While The Swamp did pursue environmental and social outcomes, its requirement for financial return was greater and thus the project was positioned further towards the bottom of the diagram than the other case study projects. As The Swamp INGO pointed out, evoking the direct financial drivers that underpin market environmentalism, "If we hadn't been taking a REDD+ approach we wouldn't have had the finance, we wouldn't have had the drivers" (INGO Informant 1 The Swamp).

The strategies and rationales of this PSF actor are reflected in the forms of coordination witnessed across the project's GVC, and tend to fall on the captive and hierarchy end of the spectrum, shown in Table 6.1 below. There are clear mechanisms for control that the PNGO, Indonesian Business and INGO all press upon the LNGOs, Village Communities and general project. Within this there are examples of relational and more market forms of coordination, namely concerning the REDD+ standards and ultimate VER sale. 
Table 6.1: Comparison of governance and forms of coordination across The Swamp REDD+ GVC.

\begin{tabular}{|c|c|c|c|c|}
\hline Market & Modular & Relational & Captive & Hierarchy \\
\hline $\begin{array}{l}\text { Investor's } \\
\text { planned sale of } \\
\text { VERs for the } \\
\text { highest price }\end{array}$ & $\begin{array}{l}\text { Codifying VERs, } \\
\text { conservation and } \\
\text { community } \\
\text { development } \\
\text { outcomes within } \\
\text { the VCS and CCB } \\
\text { standards for the } \\
\text { Investors } \\
\text { Land-use } \\
\text { concession to } \\
\text { secure legal } \\
\text { compliance and } \\
\text { project } \\
\text { permanence }\end{array}$ & $\begin{array}{l}\text { INGO and } \\
\text { Investor } \\
\text { partnership } \\
\text { INGO's } \\
\text { engagement with } \\
\text { LNGOs and } \\
\text { Village } \\
\text { Communities to } \\
\text { develop the } \\
\text { Project } \\
\text { Operations } \\
\text { component }\end{array}$ & $\begin{array}{l}\text { The Investor's } \\
\text { attempt to } \\
\text { 'salvage' their } \\
\text { investment and } \\
\text { manage the } \\
\text { project through } \\
\text { onsite offices } \\
\text { PNGO's } \\
\text { management of } \\
\text { multiple projects } \\
\text { Delegation of } \\
\text { Investor interests } \\
\text { through the } \\
\text { Indonesian } \\
\text { Business } \\
\text { Indonesian } \\
\text { Business and } \\
\text { INGO's } \\
\text { management of } \\
\text { the Project } \\
\text { Establishment } \\
\text { and parts of the } \\
\text { Project } \\
\text { Operations } \\
\text { components }\end{array}$ & $\begin{array}{l}\text { The direction } \\
\text { from the } \\
\text { shareholders to } \\
\text { the Investors } \\
\text { From the } \\
\text { Investors to the } \\
\text { PNGO } \\
\text { PNGO, } \\
\text { Indonesian } \\
\text { Business and } \\
\text { INGO's } \\
\text { construction of } \\
\text { the Project } \\
\text { Documentation } \\
\text { component } \\
\text { INGO's use of } \\
\text { consultants }\end{array}$ \\
\hline
\end{tabular}

Case Study 2, The Valley, was close to gaining land-use concession. The Valley was also the only project that could be considered as operating as a REDD+ project at the time of writing. The character of the PSF actors involved in The Valley positioned it within the risk threshold in Figure 6.5 above. The various forms of coordination between actors across this GVC are summarised in Table 6.2 below. Notably there is a relatively even mix of coordination forms around this project, and the INGO is an important actor in most of them. The influence of PSF actors on this GVC was most evident in the use of the Plan Vivo standard, and their desire for the INGO to secure certain biodiversity conservation 'storylines'. 
Table 6.2: Comparison of governance and forms of coordination across The Valley REDD+ GVC.

\begin{tabular}{|c|c|c|c|c|}
\hline Market & Modular & Relational & Captive & Hierarchy \\
\hline $\begin{array}{l}\text { CSR Agent } \\
\text { marketing VERs } \\
\text { as 'premium fair } \\
\text { trade' } \\
\text { The International } \\
\text { Business' use of } \\
\text { the project's } \\
\text { story, orang-utan } \\
\text { and tigers in its } \\
\text { marketing and } \\
\text { promotion }\end{array}$ & $\begin{array}{l}\text { INGO and PSF } \\
\text { actors } \\
\text { The PSF actors' } \\
\text { preference for } \\
\text { the Plan Vivo } \\
\text { standard to } \\
\text { secure the } \\
\text { project's story } \\
\text { Community land- } \\
\text { use concession } \\
\text { to secure legal } \\
\text { compliance and } \\
\text { project } \\
\text { permanence }\end{array}$ & $\begin{array}{l}\text { INGO } \\
\text { engagement } \\
\text { with Standard } \\
\text { Consultant, } \\
\text { LNGOs and } \\
\text { Village } \\
\text { Communities to } \\
\text { develop the } \\
\text { Project } \\
\text { Operations } \\
\text { component }\end{array}$ & $\begin{array}{l}\text { INGO and } \\
\text { management of } \\
\text { the Project } \\
\text { Establishment } \\
\text { component } \\
\text { INGO and design } \\
\text { of some } \\
\text { community } \\
\text { monitoring and } \\
\text { conservation } \\
\text { activities and } \\
\text { planning in the } \\
\text { Project } \\
\text { Operations } \\
\text { component }\end{array}$ & $\begin{array}{l}\text { International } \\
\text { Business } \\
\text { direction from } \\
\text { shareholders } \\
\text { INGO's } \\
\text { management of } \\
\text { the REDD+ } \\
\text { Standard } \\
\text { management } \\
\text { facility } \\
\text { INGO } \\
\text { construction of } \\
\text { the Project } \\
\text { Documentation } \\
\text { component } \\
\text { INGOs use of } \\
\text { consultants }\end{array}$ \\
\hline
\end{tabular}

Case Study 3, The River, had yet to achieve land-use concession and attract PSF, effectively stalling the REDD+ project. However, while being too risky for PSF, the project's prioritisation of social and environmental outcomes position it at the top of Figure 6.8. This shows how it is most likely to attract future finance from PSF actors seeking impact investments, or potentially REDD+ VERs if the project revives its PDD for the VCS standard. Because this project was the 'least progressed' the relationships and forms of coordination across its GVC were fewer and less diverse (see Table 6.3). It was clear the LNGO was the most influential throughout the GVC and shared mostly relational types of coordination, but maintained more control regarding the project components that constituted the project documentation. 
Table 6.3: Comparison of governance and forms of coordination across The River REDD+ GVC.

\begin{tabular}{|l|l|l|l|l|}
\hline Market & Modular & Relational & Captive & Hierarchy \\
\hline & $\begin{array}{l}\text { INGO } \\
\text { relationship with } \\
\text { LNGO and } \\
\text { consultants }\end{array}$ & $\begin{array}{l}\text { LNGO } \\
\text { relationship with } \\
\text { INGO, Farmers' } \\
\text { Groups and } \\
\text { Village }\end{array}$ & $\begin{array}{l}\text { Farmers Groups } \\
\text { engagement with } \\
\text { their Farmers' } \\
\text { Group } \\
\text { Association and } \\
\text { Use concession } \\
\text { to secure legal } \\
\text { compliance and } \\
\text { project } \\
\text { permanence }\end{array}$ & $\begin{array}{l}\text { The LNG } \\
\text { management of } \\
\text { the Indonesian } \\
\text { Consultant } \\
\text { developing the } \\
\text { CCB PDD and } \\
\text { Project } \\
\text { Documentation }\end{array}$ \\
& & $\begin{array}{l}\text { LNGO's } \\
\text { development of } \\
\text { the Project } \\
\text { Establishment } \\
\text { and Operations } \\
\text { components }\end{array}$ & \\
\hline
\end{tabular}

The forms of coordination were seen to vary across the REDD+ GVC case studies. The use of REDD+ standards and VERs illustrated forms of market or modular coordination, enabling codified information to be exchanged openly. At the opposite end of the spectrum, hierarchical and captive forms of coordination are also seen to be influential, particularly amongst actors responsible for project development. However, most forms of coordination reflected the importance of interpersonal and trust-based relationships, often depending on the collaborative actions of respective project developers as brokers between interests. Subsequently, as a governance descriptor across these REDD+ GVCs, they can best be considered as relational networks. The relationships of trust and shared learning between PSF, INGOs, LNGOs, Village Communities and other key partners have an important influence on the formation, structure and governance of the projects. The importance of trust indicates that the exchanges between parties on these GVCs are dependent on person-to-person relationships and are generally organised deliberately as relations are established and understandings of the project and its activities emerge.

\subsection{Conclusion}

This chapter has explored how PSF actors have shaped and influenced the governance of REDD+ projects unfolding in Indonesia (research question 3). Each of 
the above case studies demonstrated aspects of PSF's governing influence as direct responses and indirectly through their anticipation of PSF actor preferences. Each of the project developers (the INGOs in The Valley and The Swamp, and the LNGO in The River) shifted the emphasis of their project towards social and conservation benefits, while delaying the carbon components of the projects. The irony in this is that these component attributes were originally considered as incidental or 'cobenefits' to the REDD mechanism, alongside gains from the generation of carbon offsets. This shift was in large part a response to the shifting interests of PSF towards CSR - and the stories they gain from REDD+ (discussed in Chapter 5). PSF actors on The Valley GVC in particular clearly wanted to invest in projects that demonstrated a social and environmental story that their business could identify with and be connected to through a "direct supply chain relationship" (Investor and Developer 7).

The governance implications of the tendency for PSF actors to reduce risk within the case study REDD+ projects are immediate and direct across their GVCs. Examples include the semi-permanent positioning of INGO staff in The Valley and The Swamp to oversee and implement REDD+ measures. This type of oversight from an international body was not present in The River, which likely garnered PSF perceptions of it being more risky, contributing to their deterrence. Conversely, the monitoring systems and procedures in The Swamp, controlled by a private Indonesian Business rather than the community, may have allayed the concerns of financiers. A similar emphasis was placed on operational and organisational structures to securely manage the protected area and business groups in The Valley. However, within The River the structural empowerment of Farmers Groups and their Association to specifically implement REDD+ positioned their leaders as the preferred channel of management. This made the Association a narrow and influential channel through which The River project was governed, beyond the influence of the INGOs, LNGOs, and ultimately PSF. Its failure to secure funding hints that PSF has certain requirements that might conflict with approaches that encourage local empowerment. 
The above accounts of REDD+ PSF help to provide a rich understanding of the diverse motivations, characteristics and impacts of PSF actors within the GVCs for REDD+ projects. Viewing the case studies through a GVC lens reveals how PSF influences the character and likely success of projects, shaping how they are governed to ensure that PSF actors secure desired benefits. Through examining case study REDD+ projects, this chapter also points to how the actions of PSF actors can influence the character of the REDD+ industry and context more generally. Specifically, PSF actors were influential through their pursuit of 'best practice' to standardise and benchmark other projects, or exiting from projects because of high costs and risks that then deter other PSF actors from investing in REDD+. The experiences of these PSF actors with REDD+ projects contribute to the general body of knowledge that other PSF actors then draw upon when evaluating REDD+ as an investment opportunity. However, PSF actors were still seen to respond in unique ways to the specific challenges and limitations of each REDD+ project. This qualifies PSF as worthy of consideration beyond their traditional reputation as uniform agents of linear financial supply in exchange for commodities. The formation of such REDD+ commodities is another important aspect of market environmentalism and private governance, and is the topic of the following chapter. 


\section{REDD+ Commodification and Commodity}

\subsection{Introduction}

The programme to commodify forests through REDD+ is recognised as one of the most complex and diverse attempts to disentangle, qualify and commensurate carbon emissions reductions into financial instruments for market exchange (Stephan, 2012; Boyd \& Goodman, 2011; Lovell et al., 2009; Descheneau \& Paterson, 2011; Lovell \& Liverman, 2010; Bumpus \& Liverman, 2011; Lansing, 2011; Descheneau, 2012). The following chapter analyses REDD+ as a commodity by drawing on the three REDD+ GVC case studies and the voices of PSF actors within REDD+. Conceptualising REDD+ as a commodity directly contributes to understanding what the value of REDD+ projects is or, alternatively, why PSF actors support REDD+ projects (research question 2).

The GVC analyses in the previous chapter demonstrated that REDD+ project development is deliberately designed to imbue prearranged attributes into a packaged and exchangeable form. The nature of the commodification process influences the character of the REDD+ project. PSF actors are shown to have exerted a governing influence within this process, shaping projects as best they could to suit their desires. The packaged and exchangeable commodity form that was the REDD+ project came to reflect the sum of its GVC relationships and governance characteristics.

This chapter lays out how PSF actors perceived and evaluated REDD+ as a program and as a commodity. The diverse arrangements and emphases within REDD+ project commodities are outlined following the shift from focusing on VERs to focusing on 'co-benefits'. This begins with an analysis of what REDD+ was and is, its multiple forms, and preference for VERs. With a clear understanding of the REDD+ commodity, the supporting attributes and characterisations of REDD+ projects are 
analysed, delving into the complexity in the REDD+ programme. These culminate in a series of mixed meanings about the REDD+ commodity that align with the goals of sustainable development. Such ambitions and associated meanings leave ample space for creative interpretation, and lead the character of the REDD+ commodity to be one of knowledge circulation. The following illustrates how PSF actors perceived and desired REDD+ projects as storied commodities.

\subsubsection{REDD+ projects and PSF stories}

Chapter 6 demonstrated how PSF actors are seeking to be involved in stories that are a part of REDD+ projects. The flexibility of REDD+ to be customised to serve multiple modern investment desires highlights the complexity and diversity of PSF actors' motivations and logics. One informant remarked: "It's everything to everyone. Pressing all buttons at once. Everyone loved it so all this money came in. Capitalists loved it because it made money. It's a carbon credit, it's a carbon credit with some fluff, or it's just fluff' (Investor and Developer 1). 'Fluff' in this context referred to the community development, conservation and sustainable development outcomes that REDD+ facilitated. The same informant described how their strategies to connect PSF to REDD+ projects involved designing and customising these 'fluffy' CSR stories to the desires of specific PSF actors:

Find the company first then find the offsets that will capture all those benefits they want. It makes sense; if you've got to buy these things then you'll make the most of it. Something in line with your business and your ethic. Here's one in Kalimantan with some monkeys, and here's one in Peru with some monkeys. Monkeys sell. Monkey credits. With some basket weaving. This is the plus-plus-plus; monkeys, websites, field trips and all the rest of it (Investor and Developer 1).

Incorporating a variety of attributes or benefits into REDD+ projects to meet clients' demands was similarly articulated by another investor and developer informant who, speaking at an industry summit, emphasised that it also enabled the VERs from the REDD+ project to attract a premium price: 
You've got to tailor your message to the person you're talking to. What do they want to hear? Are they interested in biodiversity? Carbon? Community development? Forests more generally? You've got to gauge the audience. REDD+ is what you call story credits. So when you're in a voluntary market it's a story and it's about what attributes they find interesting, and therefore you can demand a premium for that (Investor and Developer 3).

When responding to a mining company representative who expressed interest in supporting a REDD+ project, the same informant proclaimed: "I can do that! How would you like it to look?!" (Investor and Developer 3), effectively offering to craft a REDD+ project around a storyline to match the desires of the mining company. Another informant assisting with REDD+ project development expressed the importance of these stories to attracting and maintaining the interest of PSF actors:

If we don't have that storyline there to use to advocate, the consistent messaging is not there. It looks like self-interest if it's from projects or consultants. We need a much clearer deliverable for parties concerned so they understand what role they play (Contractor 6$)$.

The complexity involved with REDD+ projects requires that accessible stories are available to easily enable PSF actors to grasp what REDD+ projects offered them and their role within them. Several informants described how PSF actors are highly motivated to become attached to these pre-packaged and tailored REDD+ stories. Such stories offered an appeal beyond the pragmatic type of rationality that sustainable development often relies upon. These REDD+ stories offered something more, along with potentially attracting premium prices:

The company isn't necessarily looking for emissions reductions purely for the sake of reducing their emissions. They're looking for opportunities to paint a strong picture around their social responsibility. They're projects that are providing a social benefit, environmental benefit and a climate change benefit, and that's a very powerful story to tell. Essentially that's CSR. Telling that story is one way that you can have one project that demonstrates all three of those streams. That is packaged extremely 
conveniently because there are these units you can purchase. It's quite a nice package in many ways (INGO Informant 1 The Swamp).

From the point of the corporate investor, REDD+ credits offer a story, not a fungible commodity. It's a coherent credible story about a place, the biodiversity in the place. The story is very powerful. From the point of view of the corporate investor achieving their CSR goals and greening their image and offsetting the carbon etcetera. This is a beautiful way to do it. Big powerful companies have a nice budget for this kind of thing (Investor 6).

Understanding these stories that PSF actors are interested in becoming attached to through REDD+ projects contributes to the analysis in previous chapters of their motivations and the character of the finance they manage. The following seeks to peel back these REDD+ stories to locate and examine the REDD+ commodity and understand its value and how it is evaluated amongst PSF actors.

\subsection{Locating the REDD+ commodity}

The vast majority of informants working within the Indonesian and international REDD+ assemblage recognised the diverse ways in which the program had been interpreted and adopted. Informants representing investors, consultants, NGOs and project developers all expressed how projects are different and how this complicated and complemented their exchange with PSF. However, there was little consensus on what a REDD+ project actually was and how it might be defined:

It's hard to put bounds around what REDD+ is, particularly at this moment (Contractor 19).

Calling it a commodity, which in the voluntary market it isn't, it's not fungible at all (Investor 1 The Swamp).

In addition to the influences of diverse PSF actors, the causes of this diversity and incommensurability of REDD+ projects was attributed to the demands of the specific 
forest context and the corresponding design needs of each project: "It's going to be done a zillion different ways around the world, because it has to be. There are so many different contexts, policy and historical backgrounds" (INGO Informant 2 The Swamp). Another informant captured the diversity and definitional challenge facing REDD+, stating:

The thing with REDD+ was that it was a new source of financing that was coming from a particular source. Once you don't have that any more, which is kind of the way it's going, do you have a REDD+ story anymore? Or are you just talking about financing sustainable landscapes? ... To me that's what REDD+ was. It wasn't the activity (Contractor 2).

Here, REDD+ is defined as the method by which the outcomes of a project's activities are financed. Those outcomes must include avoided deforestation and forest degradation, sustainable management of forests and conservation and enhancement of forest carbon stocks. These specific outcomes will be referred to from here on as 'REDD+ Outcomes'. Importantly, the outcomes of the project are not restricted to this, as demonstrated by the 'premium' 'best practice' approaches within The Valley case study REDD+ project.

If the method for financing these REDD+ Outcomes and additional outcomes is through payments for VERs then the project can be considered to be REDD+. Under this definition, the range of activities that might qualify as REDD+ projects is immense. Provided the payment is in exchange for achieving the REDD+ Outcomes, there is no limit to the scope of activities in a project and it will remain a REDD+ project:

REDD+ is used to explain a lot of things, but it's actually something quite specific: to protect and restore natural forest through carbon finance [emphasis added] (Investor and Developer 1).

REDD+ achieves a lot more than a ton of carbon. But at the end of the day you're financing something based on carbon. If not, then you're moving away from the 
protection for climate initiative. But that doesn't mean that it cannot be linked to sustainable supply chains and CSR (Contractor 19).

This definition of a REDD+ project - achieving at least REDD+ Outcomes whilst receiving (planned) finance through VER exchange - albeit broad, is helpful in delineating what projects and activities are and are not part of REDD+. The pace at which, and the ease with which, REDD+ projects have become so diverse is also explained by their rapid absorption and addition of outcomes over and above the defined REDD+ Outcomes, whilst maintaining VER exchange. However, since the essential aspect and defining feature of a REDD+ project is the delivery of REDD+ Outcomes through VER exchange, conceptualising REDD+ as a commodity refers directly to this specific characteristic. This exchange moment, where REDD+ Outcomes and VERs are traded for finance, is fundamental to the REDD+ commodity, as illustrated in Figure 7.1 below.

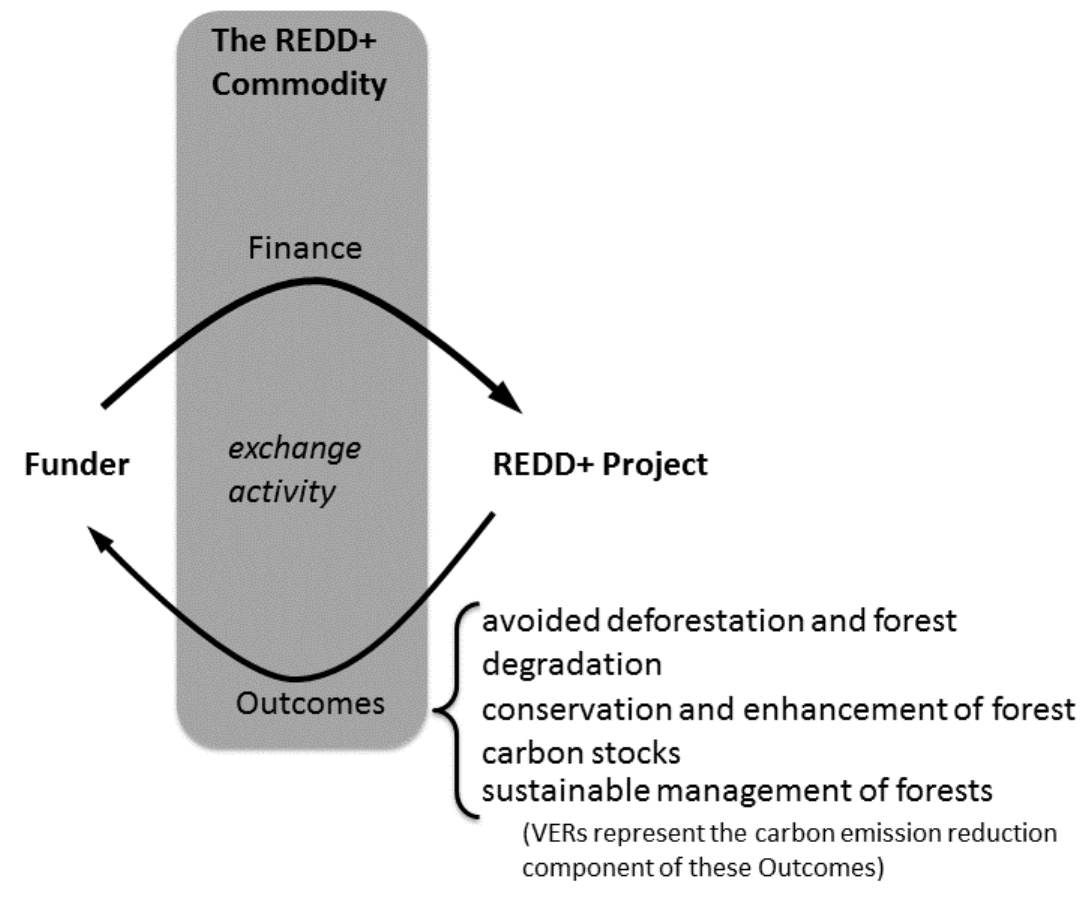

Figure 7.1: The REDD+ commodity of exchange.

In this moment of exchange the REDD+ commodity is at its most tangible. Within the exchange activity there are two sides (Figure 7.1): the side of the exchange with the 
REDD+ Outcomes and VERs, secured and legitimated by REDD+ standards and supporting regulations (right); and the side of the exchange possessing the finance (left). To be clear, for the remainder of this thesis when referring to 'REDD+ projects' the research is referring to this definition.

There is an established infrastructure that supports this REDD+ exchange commodity. REDD+ registries and standards play an important role in facilitating the exchange and securing the value of REDD+ VERs, and thus REDD+ projects:

Our REDD+ standard was founded to create credibility in the market and the most robust credit market ... That ensures the value of the project; it in fact defines the value of the project. Without being able to credibly account for the emission reductions, you don't actually have a commodity to sell (Contractor 19).

Another informant working with REDD+ VER registries described the robustness of their registration and accounting system to ensure that these valuable assets are not misplaced or misappropriated, serving the REDD+ industry like VER and REDD+ commodity banks:

We have the whole transaction cycle. VERs can be transferred just like you can transfer money in your back account, or you can buy and sell any kind of asset. ... It's just like a bank account. These assets are quite valuable and that's why people want to get hold of them (Contractor 21).

Similarly, some informants felt that any REDD+ commodity was simply a reincarnation of existing commodities, and specifically that the REDD+ exchange commodity for REDD+ Outcomes and VERs was adopted from existing financial security mechanisms that are already providing similar services for many other (noncarbon) commodities:

Everybody thinks REDD+ and carbon is this totally new thing. But actually, you can buy coal or t-shirts under very similar contracts (Investor 1 The Swamp). 
It's not as novel as people think it is. I haven't sold you the tree or the carbon in the tree. You've bought the assurance that I won't cut it down. That's a service (Investor and Developer 1).

Other informants felt that these financial mechanisms would emerge and adjust in response to the interests of PSF actors in REDD+ projects. They felt that the REDD+ exchange commodity would emerge and assume its form in response to whatever was required to facilitate $R E D D+$ exchange:

Once you have the goods, the commodity, the financial mechanisms will come. But we don't have the goods yet because we don't have the regulation. Replace REDD+ with a car and it's the same thing. You can finance it many ways. But you have to have the car (Investor and Developer 6).

In this sense the specific exchange activity that defines the REDD+ commodity was ready and waiting for legitimate REDD+ Outcomes to exchange. The following discusses how non-VER REDD+ Outcomes used this REDD+ exchange commodity and its VER component.

\subsubsection{The VER hook for REDD+ Outcomes}

Informants working with REDD+ standards reported how PSF actors are interested in securing the ability of their performance-based-projects to adapt and link to payments schemes, whatever their nature. The example of The Valley and Plan Vivo standards illustrated the importance of adding a carbon metric component to the project from another standard to assure that it would be available to PSF and help secure its value, even though that PSF actor had not specifically requested it. This desire for REDD+ projects to be able to adapt to different payment schemes illustrated how PSF actors evaluated a project as more valuable if it was more likely to be able to receive payments: 
The value is in the linking and ensuring that they can appropriately account for emission reductions in a way that allows the country, state, or project to be paid based on performance. Whether that's a carbon market or a fund-based mechanism, the focus has been on results-based financing (Contractor 19).

The same informant, also involved with REDD+ standard institutions, described that in addition to a project's VERs and ability to link to performance-based-payment systems making it valuable, its involvement with the CCB standard was also an important value contribution. In this way the carbon emission reductions component of these projects became an important hook that the rest of the project's attributes attached to and travelled upon through this financial exchange. The ability to securely account and manage each project's VERs influenced the evaluation of this REDD+ exchange commodity as a vehicle to deliver REDD+ Outcomes. Informants described how the VER metric was exploited by project developers as a legitimate system from which to hook additional meanings for the project and PSF actors, and may not necessarily mean that the project or PSF actors are interested in REDD+ VERs:

The metric is carbon and that's where you can monetise. It's $x$ dollars per ton for carbon. Because we can measure it. All the other attributes are about increased profitability or a premium for credits. So putting a mixed value on it really ... Even if the client isn't necessarily paying for the carbon. That's the metric that we're utilising because there's standards out there and methodologies that are accepted; it's validated, it's verified ... What they really want to do is get the CSR perspective. That's what they want to hear (Investor and Developer 3).

Carbon is the mechanism to transfer the money to buy a credit. But they're really buying the biodiversity and social benefits. Worst case scenario is that they bought a carbon credit ... We would prefer to sell a biodiversity credit. But there are no standards out there like the VCS (Investor and Developer 7). 
REDD+ has power to deliver impact on the ground in both environmental and social impacts. REDD+ is much more than just a carbon tool. It's a platform to address multiple issues in projects and forests (Investor 3).

As such, while VER metrics and attributes contributed important value to a REDD+ project's exchange, their greatest contribution appeared to be as a hook to attach and transfer the remaining REDD+ Outcomes to. Subsequently, the price PSF actors are paying for REDD+ VERs to support REDD+ projects may have little to do with PSF actors' evaluations of the VER itself, but rather, reflect their evaluation of the other surrounding and supporting REDD+ Outcomes. As such, this brings the common understanding of the market price for REDD+ VERs into question, as to whether it reflects the price of REDD+ VERs themselves, or a mixed evaluation that reflects more PSF actors' desires for the attached REDD+ Outcomes. Furthermore, the REDD+ commodity that PSF actors purchase can develop to become more complex than this and expand to encompass meanings beyond defined REDD+ Outcomes. The following section will explore the attributes of REDD+ projects that go beyond these definitional bounds. There appeared to be little hesitation among PSF actors to build upon the robust and adaptable REDD+ commodity platform, decorating it with charismatic stories to position their REDD+ project as of premium quality.

\subsection{Story meanings beyond REDD+ VER exchange and REDD+ Outcomes}

The commodity that PSF actors purchase when they pay for VERs from a REDD+ project has come to represent more than the REDD+ Outcomes. From a PSF perspective, what is being purchased is a story designed in response to their desires. Such stories may have very little to do with the project components prescribed within the REDD+ Outcomes. They typically have much more to do with non-forest carbon outcomes that encapsulate the community development and conservation attributes of sustainable development that PSF actor's desire. 
These motivations for non-forest carbon outcomes can position REDD+ Outcomes and payment for them (the REDD+ exchange) as secondary to other benefits of the project, although there is often considerable overlap between REDD+ Outcomes and non-forest carbon outcomes. This is especially relevant regarding the REDD+ Outcome requiring the 'sustainable management of forests', which could be interpreted to comprehensively include all meanings within non-forest carbon outcomes and REDD+ combined. This becomes particularly apparent when a broad but accepted meaning of 'sustainable', that includes community development as necessary for forests to be managed sustainably, is considered.

This flexible and contingent approach to developing REDD+ projects enables projects to easily adapt to future changes at the community development and conservation nexus. The REDD+ projects in the quotes below (The Valley and The Swamp) used the REDD+ methodology and VER metrics to attract finance. However, crucially, they are not dependent on carbon emissions reductions to attract finance. Rather they are depending on the non-VER REDD+ Outcomes and the deliverables of non-forest carbon outcomes, that PSF actors interpret as supporting their desired REDD+ story:

We're focused on getting money to local forest communities and right now it's this PES idea, which includes carbon. But at the local level it's not about carbon. It's about community benefits from their biome. The carbon is just a vehicle through which you could achieve it (Standard Consultant 1 The Valley).

I don't think there's a relationship between the standard and the finance source ... They're seeing opportunities for smaller scale CSR type investments that might be packaged slightly differently; that have biodiversity, social and carbon benefits. Not purely sold on a commodity basis that perhaps the VCS projects would have been (INGO Informant 1 The Swamp).

The above disconnection between the source of PSF and the REDD+ standards used in a project indicate how adaptable these REDD+ commodities can be. The above approaches include the REDD+ commodity (delivering REDD+ Outcomes through VER 
exchange), but also include the less tangible story attributes and meanings that PSF actors desire. An investor informant described how in order to satisfy the multiple types of carbon and non-carbon REDD+ deliverables that PSF actors desire, a myriad of REDD+ standards and certifications are required:

Many people might feel that the VCS and CCB are standards of compliance and something that you have to do. But a shortcoming of this in the market is that not one of these standards incorporates or addresses all the issues that the market expects them to address. So in our case, and pushed a little bit by our investors, we do the VCS, the CCB and the IFC ${ }^{23}$ performance standards. So that is a little cumbersome. It's about assurance to the market. From the off-take and investors' point of view, they want to ensure their investment or their contribution to offsetting their carbon footprint, isn't going to be mixed up with any human rights abuses. So it's an incredibly important element (Investor 4).

The pursuit of projects like that described above by Investor 4 has developed to an extent that their stories no longer hinge on the achievement of carbon reductions, or necessarily their use as a point of attraction for finance. However, the benefit of maintaining the REDD+ commodity within these projects has been the standard methodologies and supporting registry infrastructure that produce a stable metric for REDD+ projects and for PSF actors to use as the medium of exchange. The methodologies and registries provide the security and legitimacy that PSF actors require to commit funds.

The VERs borne from the methodologies and registries are robust, but only for the carbon emission reduction component of these complex projects. Remarkably, it's this VER component that many informants agreed was the least desirable attribute of these projects. Whilst other sustainable development outcomes and stories are considered more desirable, there are not robust standards and registries to the same degree to support their legitimation. Sustainable development components of

\footnotetext{
${ }^{23}$ The International Finance Corporation (IFC) is the private sector arm of the World Bank Group, whose performance standards are a leading measure of safeguard prudence and legitimacy (Roe et al., 2013).
} 
projects are attached to VERs through the qualification of standards like the CCB and Plan Vivo, and through stories the project cultivated and portrayed. The refocusing of attention by PSF actors from VERs to sustainable development stories displaced carbon components from the identity of REDD+ projects:

You could say effectively that if you took away the carbon side of things then everything else was the same as it was before REDD+. But I don't think this is so. We now have the CCB standard and Plan Vivo that actually prescribe certain things that need to be in place (INGO Informant 2 The Swamp).

The idea is to bundle a series of formerly carbon projects across Indonesia. [INGO The Swamp] are also looking to get capital to these former carbon projects. They were very focused on carbon until recently (Investor 24).

Informants recognised that REDD+ projects wouldn't be feasible without these sustainable development components to complement the REDD+ commodity and REDD+ Outcomes. REDD+ projects depended upon additional sustainable development components to complete the story so they could attract PSF:

When people look at REDD+ on its own they very quickly come to the conclusion that it's a waste of time. But that's a little bit unfair, because normally if you take REDD+ out of the picture and you think of any other sort of endeavour, whether it's in the land sector or anything else, if you just take one component part on its own then it's not a viable business line (Investor 2).

To this end, REDD+ projects are seen as becoming interventions by PSF actors to pursue their own interpretations of sustainable development, taking advantage of the secure legitimacy of REDD+ standards and methodologies:

The donor is funding Plan Vivo because they believe in the process and the sustainable outcome it can deliver. The story becomes relevant when the PES payments are made. Those funders are buying the story (Standard Consultant 1 The Valley). 
The material that the communities are creating is interesting to us as a raw material. It's not why we invested in them at all, and it's not likely that we will source that. But it helps create a story that resonates and people understand in the company and more broadly about the value of how REDD+ works, and how it works for communities and for micro enterprises (Extractive Industry 1).

In the case of the quote from Extractive Industry 1, above, a clothing producer, part of their REDD+ payments are used to establish sustainable commodity community businesses to produce cotton. Extractive Industry 1 uses cotton in its business, however, their encouragement of community businesses to produce sustainable cotton was not intended as their own supply, but rather to bundle meanings inside a story that connected them with the sustainable commodity, the community, and associated forest and biodiversity conservation. In this way the secure legitimacy of these projects that are extending themselves 'beyond REDD+' shifted from exclusively VER registries and CCB type standards to include unverified but demonstrable $\mathrm{ESG}^{24}$ stories of sustainable development:

ESG and other standards are important for a variety of reasons. We are committed to VCS and CCB and the IFC performance standards. The first is because there's trust between the public and private sector, and these standards help to build that trust. Second, when we look at ESG we look at the performance of the asset itself. We're in the business of helping develop quality assets ... Lastly, when we are talking to our off-take partners, we look at the different stories that could be brought to those companies that could generate CSR values (Investor 4).

Such REDD+ projects are under pressure to deliver perfect forest management arrangements that encompass a comprehensive story of sustainable development in partnership with forest conservation:

\footnotetext{
${ }^{24}$ Environmental, social and governance (ESG) issues that are engaged within investments demonstrate CSR and serve sustainable marketing and branding outcomes for PSF actors.
} 
Right now projects are expensive and include all 'co-benefits'. They're going above and beyond what Plan Vivo and other standards require. This is so demonstration projects cannot be brought into question and are totally legitimate and credible. So they can be used to create a system for roll out at scale that will suit larger funders that need a large outlay and return of donations, CSR, VERs etcetera (Standard Consultant 1 The Valley).

By delivering such premium sustainable development stories using REDD+ metrics of exchange, REDD+ projects sought to secure their chances of attracting PSF to sustain their activities. Premium REDD+ projects brought about a diversity of stories and interpretive meanings of sustainable development.

\subsubsection{Disconnecting from VERs}

The REDD+ commodity within REDD+ projects risks becoming submerged within the additional meanings of non-forest carbon outcomes, particularly as they cater well to desired storylines and increasingly draw a greater share of attention from PSF actors and project developers. In some cases the REDD+ commodity could become so concealed by more attractive non-forest carbon outcomes and detached from any VER value or market price that individual PSF actors could determine the REDD+ commodity price and the meanings it carried through exchange:

I take a look at the prices that they are today, knowing that they are so artificially low, and do an analysis of project value out to 2017-2020 ... It sounds haphazard, but it's so difficult to make that calculation. We're talking more and more about the different risks, prices and future that we see (Investor 26).

This PSF actors' difficulty in evaluating the price of the REDD+ commodity and its attached meanings reflects two interesting points. First, that PSF actors are uncertain how important REDD+ commodities and their stories are; and second, that REDD+ project developers have little say in this evaluation exercise, further illustrating the influence PSF actors can have within REDD+ projects. This gives rise to the scenario wherein PSF actors are purchasing the REDD+ commodity and its VERs 
for the purpose of attaining a mixture of non-VER REDD+ Outcomes, non-forest carbon outcomes and attached stories. This apparent contradiction in the behaviour and demands of PSF actors meant that some REDD+ project developers struggled to implement projects that could cater to this:

The technical specification and all the calculations that the INGO has done and all the money payments are based on this idea of carbon in the end. But the actual payment isn't necessarily coming from a carbon buyer. So that's where I think they're struggling with it (Standard Consultant 1 The Valley).

The bounds of what the REDD+ commodity entailed also bothered some informants who were uneasy with the idea of selling the attribute of community participation in a REDD+ project: "It's the connotation of commodifying human lives that I find difficult" (Standard Consultant 1 The Valley). With every additional layer of sustainable development stories and meanings on top the REDD+ commodity, the desirability and relevance of the project for PSF actors becomes increasingly opaque. These multiple layers of meaning and interpretation around REDD+ projects led to a variety of interpretations among PSF actors. This complexity and diversity led some informants to feel that the REDD+ commodity needed marketing services to untangle it for PSF actors and communicate and facilitate the exchange of projects of REDD+:

What we need is a CSR marketing shop, where developers sign up with a CSR marketing agency that draws demand and provides investors with CSR material; a strategy and design including photos, videos, facilitated visits and raw material for in-house marketers. The project developer would be the farmer of the REDD+CSR projects, not the marketer of REDD+CSR (Contractor 20).

The above quote signals a need for additional services and actors in REDD+ to help PSF actors untangle the diverse and complex sustainable development stories from the core REDD+ commodity. While REDD+ projects continue to negotiate themselves between their core VER exchange, REDD+ Outcomes and additional sustainable 
development storylines, some project developers have let their VER exchange component and the REDD+ label fall aside. The following section will briefly demonstrate this latest episode in the variegated evolution of the REDD+ commodity.

\subsection{Abandoning REDD+ for sustainable commodity revenue}

Along the conceptual boundaries of the REDD+ commodity there are examples of REDD+ projects that are pursuing sustainable commodity production and sales not only as contributions to the project storyline, but also for financial return. This financial return in addition to VER sales was recognised by informants as being necessary for the project to maintain an acceptable risk profile in the eyes of PSF actors and thereby attract their investment. This often pertained to the ability of existing commercial activities within REDD+ projects to be expanded and developed to increase their financial profits:

Our investment thesis does not only rely on the carbon markets; we also look at how to monetise other environmental assets, whether there are agricultural or other sustainable land uses. A key innovation is how we can begin to bundle and layer different environmental assets together. That is much more appealing to off-take partners and it makes special investment sense (Investor 4).

Further complicating the position of the REDD+ commodity is its entanglement with broader policies and measures for sustainable commodity production and land-use management. Some informants articulated REDD+ as becoming a component within palm oil, mining, timber and pulp and paper operations, all major economic operators and contributors to the problems that REDD+ is attempting to mitigate:

No one will pay you for the carbon, the water services, or the biodiversity. That is the transition that REDD+ is trying to make and it's proving tough. But in commodities, there are huge markets and vast turnover of commodities. That's the real economy so that's easy for investors to look at. Can we twin these two things together (Contractor 12). 
It's a pincer movement. REDD+ stampedes the horses. It's too new, too different, too out there. But to sneak it in you use things that already exist. People in Indonesia invest in agriculture products. The plantation systems exist. It's nothing new (Investor and Developer 10).

$R E D D+$ brings this very strong methodological framework to sustainable commodities. REDD+ has evolved as a tool to measure, monitor, and address leakage $e^{25}$ and permanence issues. You don't have this if just focusing on certified commodities (Investor 3).

Such manifestations of REDD+ arguably bear little or no resemblance to the REDD+ exchange commodity as originally envisaged. However, it remains unclear whether such manifestations will necessarily retain the REDD+ exchange commodity and its methodologies. For example, the 'impact investment' approach introduced in Chapter 5 entails PSF investing in the development of businesses in forest communities to improve their livelihoods and reduce dependence on extractive or damaging activities in the forest. These investments are offered to the community as loans or equity in sustainable community businesses, and promise to deliver a financial profit to the invested PSF actors:

One way that we've been packaging this - and that's what a lot of this is about, is packaging - is around an impact investment approach ... about how different conservation activities can have associated revenue generation, and identifying how those can be financed, and where there are opportunities for private finance in REDD+ (INGO Informant 1 The Swamp).

The types of impacts these projects seek are very similar to those sought by REDD+ projects, and still they carry the title of REDD+. However, their financing mechanism does not resemble the REDD+ exchange commodity or VERs, but rather the exchange of commodities that facilitate the conservation of the forest, typically

\footnotetext{
${ }^{25}$ Leakage refers to the fact that while deforestation might be avoided in one place, the forest destroyers might move to another area of forest or to a different country.
} 
agricultural activities that include protected forest areas. Similarly, these impact investment type projects and other project developers may embody some elements of the methodologies to achieve REDD+ Outcomes (from the VCS, CCB and Plan Vivo standards) but specifically exclude the REDD+ label and VER component:

What you have is a lot of REDD+ activities that are not called REDD+. So it may have carbon benefits, but they're not calling it that because they don't want to be associated with its legacy (Contractor 19).

Quite a lot of the projects are dropping REDD+ out of their name. They were conservation projects so put REDD+ in their name to access the funding. But it's turning out to be the opposite. It actually costs a lot more than what you're getting back (Contractor 2).

Furthermore, informants described how they had actively abandoned more than the REDD+ label and VER components of the REDD+ exchange commodity; they also dropped the standards and methodologies related to the remaining REDD+ Outcomes. These informants felt that the project and the communities involved are better off without the association with REDD+:

We've already designed the investment model to accelerate this, with good rates of return. In all this we've ignored the standards - CDM, Plan Vivo, CCB etcetera. Forget it. We go through whole meetings with investors without talking about carbon (Contractor 1).

Another informant shared their understanding and disappointment at this trend, and pointed out that communities will always be at risk in conservation and development projects: "It has become so technical and specific to carbon that it has ignored the fundamental need that community wellbeing can come from their resources" (Standard Consultant 1 The Valley). Accompanying this move away from REDD+ labels, standards, VER exchanges and associated storylines, informants expressed how shifting towards broader interventions for sustainable development would attract a greater interest from PSF actors. These types of projects are financed 
via bonds, which assure PSF actors certain financial returns, while delivering 'sustainable development' outcomes. Informants felt that these bonds would enable the large-scale mobilisation of finance that the REDD+ exchange commodity had originally promised for economy-wide changes by taking advantage of eager and awaiting PSF actors:

We guarantee to get the investor the money if they invest in an impact bond. We guarantee there will be an impact to benefit the community environment carbon additionally and financial returns (INGO Informant 5 The Swamp).

Bonds are attractive for many reasons; they are a familiar product to the investment community and they represent the single largest pool of capital in the world ... Green Bonds capitalise on a growing appetite for 'purpose-driven' finance and can help reduce the risk and complexity of greener investing. They make product selection simple and standardised for investors and they outsource the social and environmental due diligence to credible third parties ... Uncovering the large-scale investor appetite - that cheap private sector capital is eager and available (Investor 19).

These types of large-scale mobilisations of finance for sustainable development described above echo the original ambitions and narratives of REDD+. The migration of the REDD+ commodity away from REDD+ standards, VER exchange and sustainable development stories, and towards bonds and sustainable agricultural commodities demonstrates the adaptability and fluidity of the REDD+ idea to shift in response to PSF actor's perceptions and demands and take forms outside its original commodity definition of delivering REDD+ Outcomes through VER exchange.

\subsection{REDD+ knowledge commodities and epistemic circulation}

At the time of writing, the resting place of the REDD+ commodity seemed be bundled into, and at times hidden within, a diverse collection of sustainable development stories and meanings. These meanings swirl about the REDD+ exchange commodity and REDD+ Outcomes, concealing and exposing the 
commodity and Outcomes in response to PSF actor perspectives and their preferred attributes and components. Subsequently, from the perspective of PSF actors on GVCs, REDD+ projects reflected their desires. Project developers and supporting actors arrange REDD+ projects to generate meanings that suit the desires of target PSF actors, orientating and casting them across the GVC like filters on a spotlight. Project developers maintained their agency to adjust the emphasis of particular project components and their attributes to best respond to these evolving desires of PSF actors.

The way that the REDD+ commodity demanded governance structures to guarantee forest conservation permanence and additionality prevented PSF actors from investing in the VER components of REDD+ projects (for instance, see the discussion of The Swamp case study in section 6.3.1). PSF actors appeared to temporarily subvert this uncooperative reality by drawing attention to the stories that REDD+ projects offered and the associated CSR and branding benefits that they afforded PSF businesses (for instance, The Valley case study in section 6.3.2). This ability of PSF actors to adapt their strategies to suit the material realities of the REDD+ commodity reflects the changing and variable PSF actor strategies illustrated in Chapter 5.

In this sense the REDD+ commodity and the sustainable development components and attributes that cluster around it constitute an adaptable and evolving arrangement of meanings. It is these meanings that move about the GVC alongside finance and within the packages of information that actors share and deliver. These meanings influence the knowledges of actors, and their social relations. INGO Informant 1 from The Valley observed that "price is not everything; it's the creation of the story. So the social relation is like that between an author and a book buyer". Project developers create a story laden with meanings that take PSF actors on the journey they requested. The meanings of the story reflect back upon PSF actors as they 'read' the story, moulding their knowledges of what REDD+ and sustainable development is and can be. Investor 26 described their experience with the meanings of the REDD+ commodity thus: 
To make the qualitative element more quantitative, I embed all that qualitative value into the carbon price. So how important our brand is and mitigating that risk is built into that carbon price. So when business groups start to embed that into cost planning, they're starting to think that way, a way to think quantitatively about those qualitative values (Investor 26).

When in play with sustainable development meanings and stories, the REDD+ commodity no longer appears as a commodity in a traditional sense. INGO Informant 1 from The Valley explains: "I think if you do the full commercial REDD+ thing then it is commodification. But not the community-to-community exchange like this". By linking communities within Indonesia's forests to international communities of PSF actors, the REDD+ commodity is propped up by meanings that change and adapt, and that appear to constitute a commodity of knowledge:

REDD+ will always mean different things to different people (INGO Informant 2 The Swamp).

REDD+ is a hard sell. There's not just one message. It has to resonate with the particular company. How does it fit in the company? Is it about deforestation, sustainable commodities, or broader strategy? (Extractive Industry 1).

Communities go through a whole other process and if in two or three years there's a biodiversity market that is quantified differently ... then the community have to go through that whole process again (Standard Consultant 1 The Valley).

This understanding of REDD+ as a shifting, story-based commodity speaks closely to the knowledge- and finance-based economy that Graham (2006) describes and the epistemic circulation of Büscher (2014). Specifically, REDD+ projects demonstrate economies of meaning, extrapolation, evaluation and mediation where certain types of meaning are privileged and protected and can be owned, exchanged and consumed (Graham, 2006). In this way, the REDD+ commodity comes to embody the character of relationships along the GVC, particularly those shared by PSF actors. 
Lansing (2011, p. 217) recognises the importance of these relationships and their meanings in REDD+ offsets:

$[T]$ he offset commodity becomes an abstraction that is simultaneously imbued with a specific materiality - a materiality that is not limited to the biomass of the forest, but extends to the circulation of reports, maps, photographs and computer servers that hold such information. In other words, for a carbon offset to come into being, both of these [abstract and material] forms are necessary.

PSF actors recognised that the above forms of materiality that assure the additional ecological and social benefits of projects, and the knowledges and meanings that became the sources of value in projects, can become fuzzy as well: "you can always find additionality with REDD+ if you fish around for it. The additionality can get a bit funky after a while" (Standard Consultant 1 The Valley). The Standard Consultant is referring to the way that knowledges and meanings can be created and re-created within projects to suit the privileged knowledges and meanings of PSF actors involved, despite being subject to REDD+ standards (Graham, 2006).

This opportunistic ability of REDD+ knowledge commodities to become figments of the knowledges that PSF actors draw on enabled REDD+ projects and their activities to unfold as NGOs and local partners desired. Informants felt that the activities in communities that constitute REDD+ projects are not necessarily any different to those that came before: "None of the activities we're thinking about doing for a REDD+ project was any different than if we'd just decided to do a normal conservation project" (INGO Informant 1 The Swamp). Subsequently, the activities that underpin a REDD+ project might be easily 'washed-over' by the REDD+ knowledge commodity and adapted to suit the desires of changing sources of finance that evaluate the conservation activities and REDD+ project differently, as illustrated in Figure 7.2 below. 
Coincidently, the same INGO on a separate occasion described how the 'landscape'26 knowledge commodities that many PSF actors now prefer over 'traditional' REDD+ commodities are also "[n]ot that much different than what you'd be expecting to come out of the activities of the REDD+ project. It's just financing it differently" (INGO Informant 1 The Swamp). Such 'landscape' knowledge commodities carry a slightly different set of meanings, brandings, languages, and knowledges that more closely align to broad definitions of sustainable development than REDD+ knowledge commodities. However, and ironically, they typically involve the same activities, standards and legitimation measures and objective evaluations within their projects as REDD+ knowledge commodities. The ability of REDD+ stories to adapt and "bundle the values within the forest landscapes" (Contractor 15) enabled them to be easily subsumed into sustainable development paradigms.

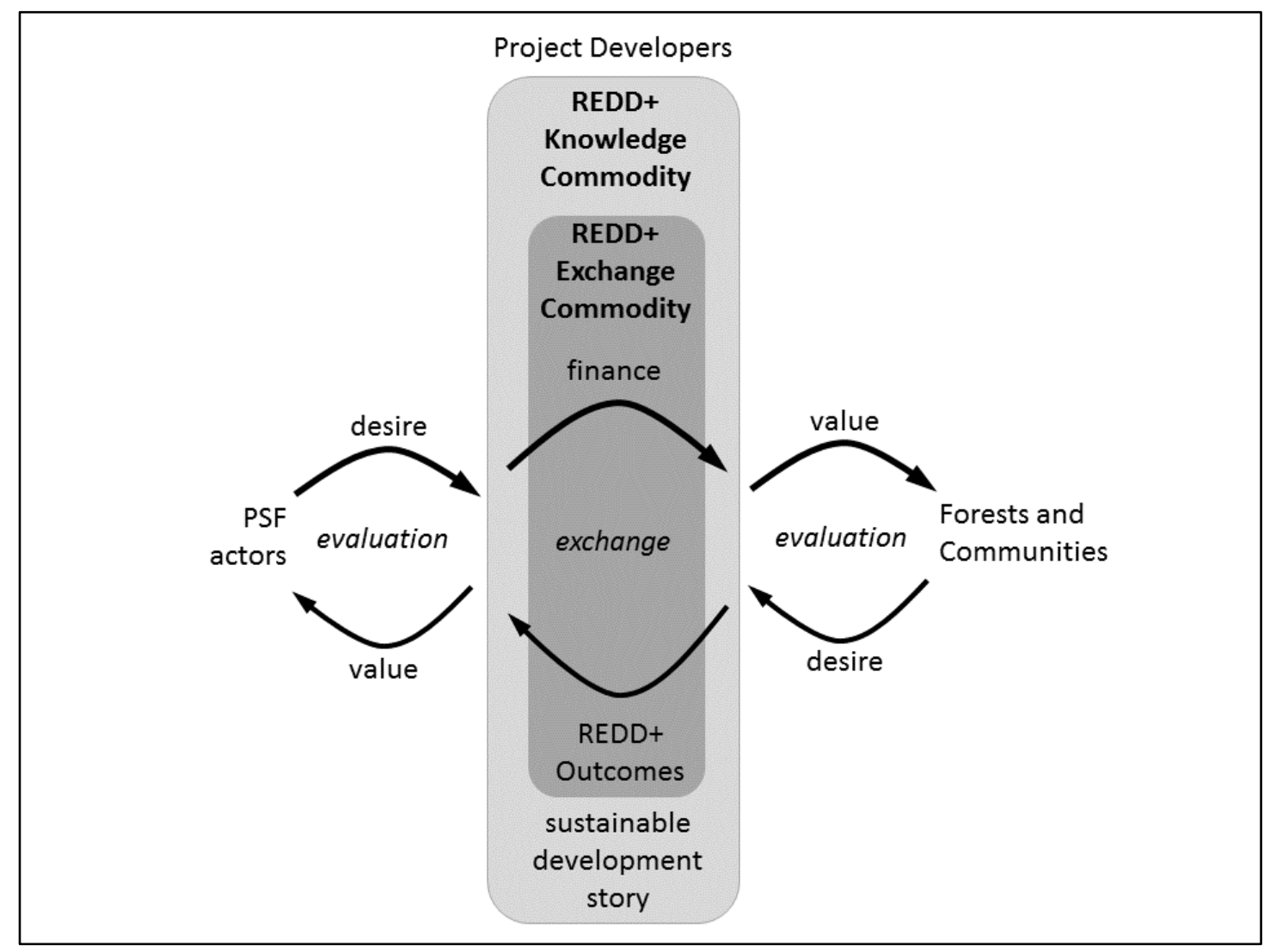

Figure 7.2: The REDD+ knowledge commodity.

\footnotetext{
${ }^{26}$ Recall the 'Landscape Fund' from Chapter 7 that was established to loan finance to sustainable commercial activities in rural communities to protect nearby threatened forests.
} 
Subsequently, the disconnect between PSF actors and the forest and community components of REDD+ GVCs is exposed (see Figure 7.2). Each exploits the knowledges of the other to pander to their evaluation tendencies as they pursue their desires; be it associations with REDD+ knowledges and meanings, or persistent funding for conservation and community wellbeing: "It brought all these different people together who all thought that there was something in it for each of them" (Contractor 2). The privileging of certain meanings and knowledges within the production of a project's REDD+ knowledge commodity reflects the motivations and desires of PSF actors, whose variety complicate REDD+'s foundational principles of fungible market exchange (Lee, 2011b; The Munden Project, 2011).

In this sense the agility of the REDD+ knowledge commodity is such that it can rapidly adapt to portray knowledges that align and reflect those of the particular PSF audience that it seeks to capture. This adaptive characteristic of the REDD+ knowledge commodity helps explain its persistent success whilst simultaneously maintaining such diverse expressions, as illustrated in Figure 7.2 above.

\subsection{PSF knowledges and evaluation}

This section explores how PSF actors evaluate REDD+ projects, and illustrates how the REDD+ knowledge commodity influences that evaluation. This contributes insights into the role and function of value within REDD+ GVCs, and specifically helps to understand why PSF actors support REDD+ projects (research question 2). The GVC members that create REDD+ knowledge commodities include distant and diverse actors, each looking to other actors for knowledge of how to evaluate REDD+. Lansing (2011) recognised that forest offsets experience a perpetual and reflexive process of becoming, whereby calculative practices to collect and embody attributes and components of a project's forest attributes emerge reflexively with knowledges that frame the project: 
[T]he calculative agency of many of the offset's actors was a reflexive one, where the situated nature of their knowledge was itself brought to the forefront in ways that shaped the kinds of practices that were acceptable (Lansing, 2011, p. 217).

The development of REDD+ projects involves reflexive processes of discovery as the knowledge commodity is teased out and customised to the stories desired by the involved actors. This abstracted knowledge commodity and the specific VER and REDD+ standards are necessary for each and emerge through unique articulations by GVC members (Lansing, 2011). As such, "neither markets for carbon, nor the materiality of nature that such markets seek to commodify, can be said to meaningfully pre-exist their mutual entanglements" (Lansing, 2011, p. 218). The idea of 'mutual entanglements' between the PSF side and the forest and community side of REDD+ knowledge commodity resonates closely with the observed responsiveness of the REDD+ commodity to the demands of PSF actors, illustrated above in Figure 7.2. Lansing (2011, p. 218) describes this dynamic as follows:

Understanding carbon's commodification as an ongoing performance shows that both the forest, and the circuits of exchange through which it circulates as a commodity, are co-emergent as temporarily stabilized, mutually imbricated, moments of being.

Conceptualising REDD+ projects as re-creating themselves through circulations of meanings and knowledges between actors and the project provides a helpful platform from which to explore how PSF actor knowledges and desires also reflexed and changed in response to their experiences with the REDD+ knowledge commodity. Informants illustrated how meanings bound up in the REDD+ knowledge commodity influenced the relations between PSF actors and the REDD+ project:

It's a private-to-private exchange. You can't generate the credit and go looking for the buyer; you've got to generate the buyer. The people that are going to buy credits, they don't know it yet. What you're selling is financial securities; if you package it up in a way that is more familiar to them then it is more attractive (Investor and Developer 1). 
In this way the production of the REDD+ commodity was not limited to implementing changes within forests and neighbouring communities and capturing these in REDD+ standards, but also included processes of change in PSF actors themselves to 'generate the buyer'. These changes brought about a shared understanding between actors along GVCs to facilitate the epistemic circulation of REDD+ knowledge commodities, making the story very influential in shaping PSF actor logics and knowledges: "Stories are powerful. If I've learned one thing it's the power of a story, and REDD+ can deliver that" (Investor 6).

\subsubsection{Social construction of value}

To effectively influence PSF actor knowledges, informants pushed for the REDD+ knowledge commodity to be bundled and exposed in strategic messages about valuing sustainable development to influence targeted PSF actors, their GVCs and broader social relations:

We need to think about motivational messages to those we're trying to change, if we want transformational change ... We're trying to get major corporations to change, to value, but they don't. Trying to get governments to value, but they don't. Trying to get consumers to value, but they don't buy the product. Unless there's a message, but we don't have it yet (Contractor 6).

The informant's tone captures the frustrated efforts of certain REDD+ actors to influence PSF and other GVC actors to evaluate REDD+ knowledge commodities as valuable and desirable. Their emphasis on motivational messaging towards these types of actors points to the importance of influencing their knowledges and the cultural norms that underpin their evaluations of REDD+ knowledge commodities. Other informants were more optimistic, describing how these knowledges are recreated within groups of GVC actors to amplify their influence across social networks and influence PSF actor's evaluations: 
We need a critical mass. A tipping point of companies to make this market shift. We need a clear message back to corporates about why this is important and important to them (Extractive Industry 1 ).

How do you start developing a whole set of accounting standards around nature? We really need businesses to just start doing this and then have normalities develop and start to regularise this (Contractor 8).

We need to make sure that the brands and the values that are emotional are totally associated with the environmental message that we want to put through. Then the world will take it over and push it forward (Extractive Industry 9).

The above recognition of 'critical mass', 'tipping points' and 'market shifts' to 'regularise' and 'develop normalities' so that the 'world will take it over and push it' reflect how evaluation of REDD+ knowledge commodities can be socially constructed (Lee, 2011b). Informants recognised how it was crucial to reinforce and recreate those knowledges that delivered positive evaluations of REDD+ commodities amongst GVC neighbours and their social networks to ensure they were as desirable as possible:

Things like REDD+ are definitely good for business. It allows us to speak to the idea of climate change and let people know that there's something we can do about it. It tells a nice story and puts a story behind an action. The more we learn, the more we'll incorporate it into our business (Extractive Industry 8).

The epistemic circulation of the REDD+ knowledge commodity in this way amplifies the spread of its meaning throughout society, shifting evaluation norms and consumption patterns. By incorporating REDD+ knowledge commodities, GVCs showed signs that their stories and knowledges are modified as a consequence, contributing to a revaluation of their products and business models: "Ultimately you've got to look for the future and start preserving your system. That's the fundamental value" (Extractive Industry 3). These fundamental rearrangements of how PSF actors are operating and who they are partnering with illustrates how their 
norms of doing business and coordinating their GVCs are beginning to shift towards sustainability by involving REDD+ knowledge commodities. These shifts represent revaluations that have changed the desires and motivations amongst PSF actors (Lee, 2011b). The following demonstrates how PSF actors were looking to use REDD+ knowledge commodities to influence the knowledges of their GVC neighbours and business partners so they might re-align to match their own (newfound) sustainable development priorities:

Forests are being destroyed for their economic value. Not necessarily to the highest value user ... That's the only idea locals have to generate value from land. That principle also holds true for agricultural business giants ... It was about us needing to do everything we can to add value to this community based on their ability to move down a green development pathway and see whether or not they succeed. So REDD+ is really about transformative rural green development (Investor and Developer 12).

The transformative measures this informant speaks of are not only the activities carried out within REDD+ projects to satisfy standards and legitimacy demands, but extend to the transformation of GVC actors' ideas and knowledges about how they generate value. An important part of this is the recognition that existing and normalised knowledges within local forest communities and agri-business regarding how to generate value might not be most beneficial. Subsequently, influencing these actors with knowledges that would evaluate REDD+ as desirable might prove beneficial whilst guiding them towards business practices that align with sustainable development:

REDD+ offers a learning lab on measuring and managing natural capital and ecosystem services ... REDD+ offers a way for companies to stay ahead of the broader curve of how thinking is emerging around sustainability, environmental and social issues more broadly (Contractor 17).

The above informant recognises that, for PSF actors, REDD+ knowledge commodities offer a 'learning lab' where knowledges are 'emerging' amongst PSF actors and 
within a competitive market context. This recognition illustrates an amenable change in knowledges, evaluations, motivations, and desires of PSF actors towards REDD+. Some PSF actors considered this as a pre-condition for long-term business: "We have long moved to the position that we cannot only create value for shareholders, but also create value for society ... No viable long-term business can ignore this" (Extractive Industry 2).

However, conversely, the quotes above also demonstrate how the knowledges PSF actors use to evaluate REDD+ knowledge commodities are couched within market environmentalism. The use of concepts and terms such as 'ecosystem services', 'green development', and 'natural capital' illustrates the subsumption of REDD+ knowledge commodities into capitalist market logics of evaluation. One informant described these evaluations as: "a materiality screen for the major issues that your business might face if you had to pay for natural capital as it becomes scarce" (Contractor 10). This 'materiality screening' tests the natural inputs and pollution outputs of PSF businesses so they might understand their vulnerability to increases in scarcity of such inputs and costs of such outputs. By doing so it couches REDD+ knowledge commodities within logics familiar to PSF actors and demonstrates their accustomed commercial rationalisation for adopting REDD+ knowledge commodities:

There are lots of cost saving opportunities, innovation opportunities, quality opportunities and marketing opportunities. So there are many other values to be made. Essentially an innovation challenge like any other, just framed a little differently (Extractive Industry 3).

PSF actors' perception of REDD+ knowledge commodities as opportunities to innovate and generate more value for themselves demonstrates their co-option of market environmentalism concepts and REDD+ knowledge commodities to their benefit. This is reinforced when such ideas are easily shared with PSF neighbours on GVCs and their wider institutional contexts, exaggerating the influence of these ideas across the GVC itself. The adaptation of REDD+ knowledge commodities to serve 
profit-seeking outcomes demonstrates the subsumptive ability of capitalist logics within PSF actors and their openness to accommodate them.

\subsection{Conclusion}

REDD+ projects and the REDD+ commodity in Indonesia evolved through time. Early conceptualisations of the REDD+ commodity, as being substantiated by VERs, came to be seen as something that was not likely to be widely realised. Expectations of Indonesian land-use and concession governance are unreasonable and hadn't accounted for the complex story-based desires of PSF actors. Through processes of commodification and experimentation, REDD+ projects developed into something quite different. They became a sum and representation of their sustainable development relations, their story, and their meanings. Almost all projects are now seeking social and ecological improvements for sustainable economies in and about their forests. PSF actors desired attachment to these meanings, reframing REDD+ as a component piece of a sustainable development knowledge commodity.

By isolating these commodification processes, the core nature of the REDD+ commodity can be identified as a process of exchange. REDD+ as a commodity came to be identified as a constituent of Büscher's (2014) epistemic circulation as a demonstration of capitals 'value in motion' where the value of the REDD+ commodity was its process of capital exchange, and ability to carry sustainable development meanings and knowledges in return. Later manifestations of REDD+ projects began to drop the REDD+ exchange commodity as their frustrations with the complexity of REDD+ standards was hampering the motion of capital between communities and PSF actors.

This section also discussed the careful management of REDD+ project developers in crafting the REDD+ knowledge commodity to reflect the desires and underlying knowledges of target PSF actors. It showed how these PSF actor knowledges are reflexively constructed through their experiences with REDD+ knowledge commodities. In this way, PSF actor knowledges maintain a governing influence over 
REDD+ GVCs and knowledge commodities, whilst simultaneously adjusting their knowledges and evaluations in response to their evolving experiences with REDD+. Understanding REDD+ knowledge commodities as processes of knowledge formation and evaluation is helpful in exploring why PSF actors support REDD+ projects (research question 2). The rapidly emerging, experimental, and dynamic arrangements surrounding REDD+ knowledge commodities presented opportune ground to explore value and evaluation within GVC analysis, enabling a deeper insight into PSF actors and REDD+ projects in Indonesia.

The following chapter, Chapter 8 , analyses the implications of this understanding of REDD+ as a knowledge commodity and its epistemic circulation in relation to theories of financialisation. This will deepen the understanding of value and PSF governance within REDD+ GVCs and market environmentalism more generally. 


\section{Financialisation across REDD+ GVCs}

\subsection{Introduction}

This chapter discusses the financialised character of REDD+ GVCs in Indonesia. Financialisation refers to the increasing role of financial motives, markets, actors and institutions in the operation of economies (Epstein, 2005). Financialisation is the process by which the movement and exchange of finance becomes more important to PSF than the underlying real economy that finance represents and depends upon. Here the 'exchange value' of commodities in the form of finance becomes more important and pronounced than their 'use value' (i.e. the contribution of forests to a stable climate), risking the disconnection of finance from the real economy and eroding the legitimacy of commodities like REDD+ (Knox-Hayes, 2013).

REDD+ financialisation is critically linked with extractive industries that directly and indirectly impact forests in their GVCs. These industry actors are experiencing pressure to engage with REDD+, with some starting to support REDD+ activities and incorporate REDD+ knowledge commodities into their operations. Understanding the governance relationship between PSF actors and the financialised economies they comprise is an important part of understanding ecosystem service commodities and the involvement of PSF actors in conservation (Fieldman, 2013; Knox-Hayes \& Levy, 2011; Lazonick \& O'Sullivan, 2000; Lohmann, 2011). Likewise, interpretations of climate risk within investment and business decisions have governance implications across societies and economies, as PSF actors adjust their business models and such changes ripple through their networks (Harmes, 2011; Pattberg, 2012).

Understanding how REDD+ projects and REDD+ GVCs are influenced by processes of financialisation contributes to addressing the second and third research questions, 
asking, why do PSF actors support REDD+ projects?, and what are the governance implications of PSF actors on REDD+ projects? In analysing financialisation, I describe the ways that GVC actors pursue financial profits and the governing implications of that pursuit. The following section discusses the evidence of financial imperatives within the circulation of REDD+ knowledge commodities between PSF actors.

\subsection{Financialisation within REDD+ GVCs}

The number of REDD+ VERs retired as a proportion of those transacted remains low, as does the proportion then transacted on the secondary market among offset retailers, traders and buyers (Peters-Stanley \& Yin, 2013). It appears that VERs are being held by the initial buyers, rather than exchanged onward to other actors, or retired. However, the epistemic circulation of the REDD+ knowledge commodity can be seen as extending beyond the purchaser of the VER, insofar as the purpose of most REDD+ interventions is to create an association of meanings. As such the REDD+ knowledge commodity is likely to continue to be consumed by actors that engage or associate with the initial VER buyers and beyond, to customers and the public. In this sense, the REDD+ project continues to deliver value along an extended GVC network.

In this chapter the REDD+ knowledge commodity is best understood as a branding ingredient within an organisation's marketing mix; an association or characteristic to be 'attached' to select products and financial instruments targeted at particular markets (Ponte \& Gibbon, 2005). Such products that represent carbon are complex and increasingly disconnected from the nature of the emission reductions achieved (Descheneau, 2012). This is not to detract from the tangible change that may have been enacted 'upstream', but it points to the different perspectives of actors along a GVC, where different objectives are prioritised. Like a series of whispers, the REDD+ knowledge commodity at a certain point during its epistemic circulation on the GVC is only a semblance of its upstream original self and the downstream ideas it will morph into. This is characteristic of knowledge commodities as they reform and are re-created (Büscher, 2014; Graham, 2006). 
Furthermore, the fluidity and ease with which REDD+ knowledge commodities circulate among PSF actors is similar to that of finance. PSF actors are positioned as both symptoms of financialisation, and its agents, facilitating and encouraging financial rationales across REDD+. This governance relationship between PSF and their related actors is an important part of understanding REDD+ knowledge commodities and the involvement of PSF in market environmentalism more generally (Fieldman, 2013; Harmes, 2011; Knox-Hayes \& Levy, 2011; Lazonick \& O'Sullivan, 2000; Lohmann, 2011; Pattberg, 2012). Financialisation within neoliberalism is such that the demands and whims of shareholders and customers tend to directly and immediately impact decisions and the allocation of finance in the global economy; thus demonstrating their influence and governing power (KnoxHayes, 2013).

This is particularly pertinent in the ability of REDD+ knowledge commodities to attach to global movements of finance within land-based industries across forest landscapes. Thus, the REDD+ knowledge commodity can become absorbed into wider GVCs and commercial networks of PSF actors - particularly extractive industries that use Indonesian palm oil in their consumer products. Actors within REDD+ recognise the opportunity that financialisation offers, and are attempting to take advantage of its ability to subsume REDD+ knowledge commodities into its exchange. Informants reflect below on how they encouraged PSF involvement in REDD+ because they could then exploit the tendency of PSF actors to search for profits:

The organisation of people along production, supply, value, whatever chain you want to talk about; that's what needs to happen. That's what companies are actually quite good at. But then it's the bottom line they're interested in (Contractor 3).

Our purpose is to facilitate a flow of capital to viable, profitable social enterprises in the REDD+ space, with the intention of making a social impact so we can help capture that value and pass that on to our offset partners (Investor 4). 
This is actually starting to become very core and material to business. This is now something that is discussed in banks and increasingly by public sector players around the world. The opportunity now is to get ahead and stay ahead of the curve (Contractor 17).

The above tendencies of PSF actors to 'stay ahead of the curve' and 'capture value' for 'the bottom line' and their influential reach across supply chains positioned them to be active implementation agents within the wider financial context of REDD+ GVCs. This was evident as informants recognised the diversity of financial influences across REDD+ GVCs; between investors, banks, companies, customers, shareholders, the public, and NGOs. As one informant put it:

REDD+ offers a way for companies to show investors and other stakeholders that the company understands its impacts on natural capital and ... is trying to explore whether investments in environmental assets could be a pathway for moving losses off balance sheets (Contractor 17).

In this way, companies are using REDD+ knowledge commodities to show PSF actors around them that they are shifting to sustainable business models and reducing or removing the costs of unsustainable production from their operations. They are pursuing this because of their need to attract investment in their business. The quote below illustrates how the pressure to accumulate profits can expose the decisions of PSF actors as vulnerable to the shifting whim of where profits come from:

If it's a retail bank that is public facing then you have a stick you can use. Very important that there are companies that are leads, and to deal with companies that are laggards. Shareholder activism is very important (Contractor 18).

The ability of PSF actors to be influenced to engage in REDD+ by public opinion, retail customer preference and shareholder activism demonstrates financial pressure. The ability for a bank's financial manipulation to motivate PSF actors to use their 'lead' 
sustainability companies to influence their 'laggard' companies to adopt REDD+ knowledge commodities into their supply chains is a powerful illustration of the governing influence of financialisation:

Although the financial system must at times seem far removed from forest and agricultural systems, they are in fact intrinsically linked. I urge you to follow and encourage the positive changes taking place in the financial ecosystem, as they can be a powerful force for good in the physical ecosystem (Investor 19).

The whole thing has been shaped around these funders and these donors and that's why I think looking at the source of the money in these projects is interesting. Because it does have a huge amount of sway on how people orientate themselves (Standard Consultant 1 The River).

Whilst recognising the financialised institutional context that REDD+ GVCs shared, PSF informants felt that this was a positive and vital force for sustainable development, identifying that "we have a responsibility to sustainable development" (Investor 16). The quotes below emphasise the willingness of investors and extractive industry actors to include REDD+ knowledge commodities in their businesses and participate in the development of sustainable economies:

There needs to be mainstreaming of environmental and social risk criteria for how they assess credit in the bank. This in addition to the standard criteria in the carbon credit process ... we are in the business of mitigating risk. This is mainstream, this is normal, it makes business sense, so we take it seriously (Investor 23).

The only way we can progress towards green growth, from a financial institution's perspective, is by factoring it into the interest rates that banks show their customers; high or low depending on your environmental liability ... Convince big banks and insurance companies to factor it in directly to products they take to their clients, to visualise it on their balance sheet (Contractor 11). 
If signals are created to allow the private sector to evolve and adapt and improve towards sustainable development then many private sector actors are willing to play (Extractive Industry 7).

Beyond interest rate signals and credit access requirements, PSF actors expressed their willingness to adapt their strategies to actively avoid deforestation in their agriculturally-based supply chains: "We can also help the growers push the buyers' side, and help the buyers to push the growers' side. So we can push both sides and help in that respect" (Investor 15). In addition to this influence, PSF actors that might usually compete with each other are moved to cooperate to facilitate standardisation instruments that would encourage financialised governance of their commercial networks: "We all seem to rely on certification and complaints systems so we banks might work together on making the complaints system more efficient and effective at resolving issues" (Investor 16). Such investors are cognisant of their role in facilitating and driving financialised governance and are actively willing to reshape their practices to encourage it.

\subsubsection{Regulating for financialisation}

Despite this support, PSF actors gave examples of where the voluntary nature of REDD+ and its associated sustainability standards is insufficient to secure its outcomes: "The vast majority of businesses don't have them on their central decision making process. They're important, but not that important" (Contractor 8). Similarly, the complexity of large companies might lead to their inconsistent treatment of sustainability standards, while remaining consistent in their desire of financial profits: "Big companies are like big government; they have different parts that don't necessarily communicate or agree. They have some allegiance to the triple bottom line and some are better than others, but essentially it's the bottom line" (Contractor 3). Incorporating 'triple bottom line' (environmental, social and financial) performance into operations through REDD+ Outcomes voluntarily appeared to be too risky and complicated for some PSF actors. 
Several informants spoke of the need for more regulated action to encourage more financial pressure on PSF actors. One informant pointed out that the Brazilian government "is altering interest rates based in environmental liability. This will have many implications" (Contractor 11). Such innovations drive PSF actors to minimise environmental externalities so as to be able to access low interest rates. In a similar way, informants recognised that insurance companies may charge higher premiums to PSF actors and businesses that cause environmental degradation, and that financial regulators should understand this and facilitate such financial influence in the GVCs of PSF actors:

[It is] very important for financial regulators to see how environmental factors affect non-performing assets [defaulting loans] and how that can be translated into capital dependency ratios [number and variety of investments for acceptable risk exposure] of insurance companies who control these (Contractor 11).

Environmentally unsustainable business models reducing the profitability and ability of PSF actors to repay debts are positioning such businesses as risky investment options and thus costly to insure. However, opportunities to reduce high insurance costs were anticipated if relevant PSF actors were seen to be investing in sustainable development projects, like REDD+. Informants also drew attention to the Equator Principles ${ }^{27}$ and the Basel Accords, ${ }^{28}$ which are attempting to convince more PSF actors and investments into incorporate instruments like REDD+ knowledge commodities. Informants pointed out that the ambitions of the Equator Principles

\footnotetext{
${ }^{27}$ The Equator Principles are a voluntary framework for determining environmental and social risks associated with project finance. They are based on the 'Performance Standards' of the International Finance Corporation (IFC), the private sector arm of the World Bank. The Principles have been adopted by over 70 banks for transactions over $\$ 10$ million, although several loopholes exist and there is a lack of transparency in their application. Notably, the principles are restricted to project finance but PSF actor investment is increasingly using other instruments like bonds and equity to fund their investments; effectively circumventing the principles.

28. The Basel Accords are international banking regulations issued by the Basel Committee on Banking Supervision. These Accords have little formal authority but have been widely adopted by national governments. These Accords demand that banks reduce their exposure to risk and so may increase banks' use of instruments excluded from most regulators risk calculations, like bonds and equity.
} 
and Basel Accords lacked the necessary tools and that this was where REDD+ knowledge commodities could contribute a "major move and now the ideology is mainstream. But nobody knows how to measure and account for these. One of the few domains that knows about this stuff is REDD+" (Contractor 17). Another informant commented on how a similar move by a financial regulator, the Government of the United Kingdom, to require all companies to disclose their emissions and those of their immediate energy suppliers on the London Stock Exchange also effectively created demand for emission offsets, including REDD+ knowledge commodities (Knox-Hayes \& Levy, 2011):

Government does have a role. It does help, on the demand side ... the government can move the bar, and that'll nudge them along from CSR to real reductions ... The real value that the government could do would be to up the bar, ratchet it up. That's the real value, as it drives the demand (Investor and Developer 1).

By 'raising the bar to drive demand' the informant is referring to the ability of the Government of the United Kingdom to require companies on the London Stock Exchange to disclose the emissions from their GVCs. Disclosing this information to shareholders and customers risks a negative response if emissions are high and not offset. As such, a 'ratcheting up' of this disclosure requirement to be listed and exchanged on the London Stock Exchange would effectively require PSF actors to demand more carbon offsets.

One investor expressed the hope that "foreign direct investment regulation of Indonesia will change to allow us access to invest as a majority holder in the market. That way hopefully we can have more influence of the operation of palm oil businesses" (Investor 14). Changing regulation in this way would enable the foreign company to respond to their customers, investors and shareholders to adopt REDD+ knowledge commodities within their palm oil businesses. However, some PSF actors cautioned against exploiting financialisation to influence international PSF actor behaviour: "Some NGOs and parties want the fund to do more good and be used to promote sustainable development. But some argue that the fund should not be used 
to promote foreign policy" (Investor 9). Here, inclusions of natural capital accounting, sustainable development and the REDD+ knowledge commodity are considered potentially inappropriate, not because they might erode profit margins, but because they might intrude upon the governing sovereignty of nations.

\subsubsection{Necessity of standards and opportunity of bonds}

Regulating for transparent natural capital accounting, whether through interest rates, banking standards, stock exchange rules or otherwise, reflects the ongoing financialisation of environmental governance. As PSF actors disclose their emissions, their neighbouring PSF actors are likely to respond to their own environmental risks, seeking offsets or revising their judgement of the financial returns that can be expected from their investments. These financial approaches are regarded by many PSF informants as the most influential governance tool available to the commercial networks that support REDD+ projects. It is these sorts of measures that REDD+ projects, the associated ecosystem services, and knowledge commodity become wrapped up in. It is also where REDD+ standards and their role in natural capital accountancy become especially relevant: "To change this cooperation you need to change policy, prices and institutions. One is accountancy. It's a very important and urgent piece of the puzzle" (Contractor 15). To be effective, accountancy requires defined and reliable information through REDD+ standards:

Business needs accurate timely info to make decisions. The environment is becoming a factor in decisions. In order to build this competence it's very much about common ways of assessing, measuring and defining nature and our impact on it (Contractor 8).

The role of REDD+ standards as a legitimate accounting tool facilitates financialised governance by enabling rapid, codified decisions during evaluation and exchange of commodities that such standards are attached to. As such, and as Chapter 7 identified, standards are recognised by many informants as an effective and efficient way of influencing business practice: 
It's about credibility in the supply chain. About being good enough relative to competitors. Are you good enough on the supply chain and is the standard good enough? The point of certification of the supply chain is that you can trust the system and don't have to do all the checking yourself (Investor 18).

Banks really want certification as a benchmark and a check off ... They frankly don't have the capacity or the interest to go and ask the questions. They rely a lot on what the companies are telling them, so there's a lot of self-reporting (Contractor 13).

We need to be clear and rigorous about what green growth is, especially in complicated areas such as forestry and agriculture. For that we need standards, and then third party verification of those standards (Investor 19).

The key driver for the use of these standards appeared to be the facilitation of quick and easy financial decisions for PSF actors when assessing an opportunity that involves or supports REDD+: "That makes life easy for the investors. It reduces the potential risks of green investing, makes product selection simple and standardised for investors" (Investor 19). However, some informants felt that this approach risks creating a misguided sense of security, and that some banks and investors "rely excessively on certification" (Contractor 13) when making decisions. By doing this, PSF actors risk themselves being exposed to any perceived or actual illegitimacy within these standards that might label their activities as achieving REDD+ Outcomes when they are not, and erode the perceptions of their GVC partners and members that such standards are valid. One promising example of applying these standards is in the context of green bonds (previously introduced in Chapters 5 and 7).

Green bonds promise a certain financial return to the investor at the end of an agreed period, attempting to engage and reduce the contemporary high-risk perceptions of the REDD+ VER exchange commodity. As one investor put it: "Everyone from the world I come from equates green with risk. You need to de-risk the word 'green'"' (Investor 19). What makes green bonds 'green' is that the finance that they attract is only invested in activities that are considered sustainable: " $A$ green bond will have a stated purpose that will be verified independently. So it's a 
purpose in an era where we didn't question purpose and all loans were given" (Contractor 15). Several informants described how these bonds are becoming more popular amongst PSF actors and expressed how their strategy and REDD+ project was adapting to this trend. This is particularly evident among the INGO and their partners in The Swamp case, as they are forced to seek further funding. They recognised that for PSF actors to invest in VERs they require more certainty and that green bonds might be an investment vehicle to provide that certainty:

You know exactly what the risk profile is in terms of the actual capital and what the cost of that capital is. It allows us to take more control of that financing by using the bond as a way of structuring it. It's a method of structuring (INGO Informant 1 The Swamp).

Structuring the investment finance within a bond offered a more secure risk profile of the REDD+ project and, by doing so, promised to provide the financial conditions necessary to attract PSF to this particular REDD+ GVC. The high level of interest and demand for green bonds is also recognised by other investors: "The finance sector is taking green bonds very seriously in terms of underwriting and subscribing to them, and getting our private clients to invest in them" (Investor 19). The same informant also recognised that these green bonds had the potential to dramatically shift economies towards sustainable development:

Where I come from, sovereign wealth funds will be buying green bonds. This activity will lead others to replicate ... People look at that from a business perspective and think that it might be a good opportunity as the market prices the risk (Investor 19).

Here the investment decisions of sovereign wealth funds (a specific PSF actor introduced in Chapter 5) indicate the future directions of economies. Their large size reduces the risk of investing in novel markets like REDD+.

The above section introduced how processes of financialisation concerned with environmental risks are influencing REDD+ GVCs and wider institutional PSF actor 
networks. The advent of novel banking and stock exchange regulations is seen to exert financialised pressure on PSF actors to engage standardised and legitimated tools like green bonds to offset or mitigate their unsustainable activities. This drew attention to REDD+ projects and knowledge commodities that are legitimated by REDD+ standards and are seen to facilitate the epistemic circulation of sustainable and green stories along GVCs and toward would-be investors, customers, shareholders and public stakeholders. Such utility positioned the REDD+ commodity as a promising instrument to attract interest from PFS actors and regulators.

The following sections examine how this form of increasingly financialised governance came to have such influence in the development of REDD+ knowledge commodities. The following focuses on the value drivers of investors (including institutional investors, foundations and sovereign wealth funds); companies (including extractive industry, corporate sponsors and corporate offsetters); peripheral shareholders, customers and public; and local actors to demonstrate how different REDD+ GVC actors influenced and are influenced by financialisation.

\subsection{Investor value drivers}

The search for financial returns by investor PSF actors makes them prominent actors within REDD+ GVCs. Informants felt that financialised governance would shift investors toward sustainable development and REDD+ Outcomes in their investments if they could deliver the required financial returns for their associated risk. Investors are active in Indonesian forestry, agriculture and extractive industries: "We're seen as having impact through our clients. We can have an impact by having dialogue through supply chains, as we're involved in most; kind of omnipresent" (Investor 20). These informants also recognised the large scale on which they could have an influence given the amount of capital under their control:

We're a big international bank and there's more expectation on us to have standards than a small Indonesian or Malaysian bank (Investor 16). 
We're a private sector financial institution so we don't really deal with small businesses. There's a certain scale that is relevant to an international bank (Investor 20).

Their size amplifies their potential to financially adapt and drive changes throughout a large proportion of the international agricultural and forestry land-use economy. The quotes below demonstrate the influence that investors can have on their GVCs to drive companies they invest in towards incorporating REDD+ knowledge commodities:

The most important role of large mainstream investors is to put pressure on the companies in their portfolios and the companies in the supply chains of those companies to protect and value natural capital and internalise those externalities (Contractor 9).

We are starting to see banks say that they're not going to provide finance unless [companies] meet these benchmarks. Some of these commitments have come because some of the international institutional investors and others have said frankly that they're not going to invest in them or provide financial services unless they adopt a 'no deforestation' policy (Contractor 13).

Companies can be excluded if there is an unacceptable risk that they cause severe environmental degradation ... All based on thorough research on the ground (Investor 9).

Despite these broader interests, PSF actors are recognised as ultimately being driven by their pursuit for financial profits: "That's where the bank comes in, and that's our business case. If the client can produce more with less then they are more profitable and pay the loan back more quickly" (Investor 15). Producing 'more with less' in this context refers to their client's ability to create more efficient and sustainable operations to reduce their environmental pollution and degradation; particularly concerning forests. Investors have considerable influence as agents that facilitate and encourage financialised governance, regardless of how novel it may seem: 
"Perhaps natural capital standards are not the role of a bank. We are intermediaries. But we can certainly play a significant role in pushing this process as this does make economic sense" (Investor 23). The same informant offers insight into the specific mechanics of how they drive their GVC members to engage REDD+ knowledge commodities in Indonesia:

We have a number of gatekeeper functions to implement our sustainable policies ... At the point of a transaction or relationship these gatekeepers will intercept and refer it to the sustainability desk. The sustainability desk will look at a transaction via our forest policy which includes no conversion of high conservation value forest ... We do due diligence via a screening using RepRisk, ${ }^{29}$ and $\mathrm{MSCl}^{30}$ risk analysis consultancies. We have a number of ways of getting information on a project. Then we're interested in the asset level; the location becomes everything. We run the screening and can make a best judgement based on levels of comfort. We then get into the due diligence directly with the company ... We're interested in the four C's: commitment (internal controls); capacity (human resource and expertise to continue that commitment); capacity (by far most important: what performance indicators they have and what kind of story they can share with us); and, communications (we're looking for a whole cycle) (Investor 20).

The detailed methodology that this PSF actor follows in their assessment of the sustainability of a client, illustrates a robust and deliberate approach to financialised governance. Their ability to exert influence through such financial controls on the basis of an investment's exposure to risk from unsustainable operations creates an incentive for their clients to engage REDD+ knowledge commodities and other green options.

\footnotetext{
${ }^{29}$ RepRisk collects and analyses negative incidents, criticism, and controversies about companies and projects worldwide, and offers information on activities related to human rights violations, poor working conditions, corruption, and environmental destruction. They help their clients to proactively assess environmental, social and governance (ESG) issues that may present financial, reputation and compliance risks (www.reprisk.com).

${ }^{30} \mathrm{MSCl}$ provides research, ratings and analysis of environmental, social and governance (ESG) related business practices of thousands of companies worldwide. The research and updates help investors uncover risks and opportunities to implement their responsible investment objectives (www.msci.com).
} 
A specific example of an attempt to financially govern forest land use by leveraging REDD+ knowledge commodities is the Landscape Fund (Alforte, Matias, Munden, \& Perron, 2013; Wardell \& Bowie, 2014). The Landscape Fund is the product of a partnership between The Centre for International Forestry Research (CIFOR) and The Munden Project. It aims to advance what has been learnt from REDD+ but move away from the PES-based REDD+ exchange commodity and towards a debt-based model contingent on delivering a similar REDD+ knowledge commodity. At the time of writing the Landscape Fund model was still developing, but it can be understood as a fund to collate and allocate capital through loans for sustainable activities within forested landscapes, similar to the loans behind green bonds. Loans are to be offered to organisations accounting their natural capital and meeting sustainable development standards to incorporate REDD+ knowledge commodities while promising financial return:

The Landscape Fund has an aggregator of preferential loans to environmental performers. The aggregator has a condition to expand the loans and access to capital from the fund. Access is cut if borrowers don't comply with the sustainability requirements. It's conditional access based on performance (Contractor 14).

Informants anticipated that profits from loans would be reinvested into the fund to then supply a greater number and size of loans to borrowers and environmental performers. Notably, the Landscape Fund will actively discontinue access to finance if borrowers fail to comply with sustainability standards and REDD+ Outcomes.

Through such mechanisms financial pressures comes to influence actors within GVCs. Investors are cognisant of this: "I think for some small-to-medium enterprises this would become a challenge straight away inevitably. I think also the local and regional banks will also have capacity challenges" (Investor 20). Subsequently, some investors told of how they focused their efforts to introduce sustainable policies to particular clients that are of a particular scale or impact: "We look at what the most important sectors are, where we have the most customers, then try to introduce a policy and try to ensure that the customers that we support don't have unacceptable 
practices" (Investor 16). These pragmatic moves illustrate a phasing-in of REDD+ knowledge commodities into the operations of investors and their clients.

Some investors are further adapting their processes and standards to be consistent with their industry partners and competitors: "In this case there's a shared interest. If us banks all have the same customer then it's not very helpful if we all have our own policy, it becomes confusing" (Investor 16). By doing so, investors are helping their clients to comply with sustainability standards. Furthermore, some informants explained how they actively assisted companies that are applying to them for financial support to change their operations so they could meet required sustainability standards: "Environmental and social risk assessments are compulsory for clients' credit applications, and we make sure it's done properly and give advice on certificates they should ask for" (Investor 17). By assisting GVC actors to adopt sustainable operations, investors are encouraged to redirect capital towards activities that support the epistemic circulation of REDD+ and other green commodities.

Those actors receiving finance from investors demonstrated that the aforementioned drivers from investors to meet sustainability standards had a measurable impact on their projects and activities. The effect of the conditionality of financial support is evident in The Valley case study REDD+ project where: "INGOs may say that's not what drives it, but essentially they've written a proposal depending on that. They've said they would deliver something that's based on the values of that funding institution" (Standard Consultant 1 The Valley). Here it is clear that investor-driven financialised governance is having a meaningful impact on REDD+ projects. In this case, the project developer, the INGO, has designed its proposal to comply with the values of the funding institution because it depends on the source of finance to maintain its activities. This is a substantial change from complying with in-house or government standards and requirements.

Similarly, when speaking about their investor clients, one contractor shared how: "What's really important to us is that we ensure that we're communicating the value 
to them and delivering value to our clients in that process, to ensure they stick around and keep doing what they're doing" (Contractor 16). This pressure was made clear in The Swamp REDD+ project where the Indonesian-based actors needed to engage an INGO with sufficient capacity to ensure the project would meet the required standards and demands of its investors:

International buyers will have more trust if there is an international organisation involved. This is a performance-based system and many international organisations doubt Indonesian performance so far, especially with forestry issues. ... Local NGOs and local government cannot access the private sector to invest. So they need someone to connect them to international buyers ... That's what the INGO can bring: capacity, connections, and trust, especially regarding the international REDD+ standards like VCS and CCB (Indonesian Business 3 The Swamp).

The importance of investor confidence or trust in the REDD+ project's ability to deliver on its performance necessitated the INGO's involvement as a connector and guarantor that the REDD+ standards will be met. Hence investors are looking to transform their value chains towards sustainability - most directly from their driving position at the head of the GVC, but also by actively modifying and shaping the operations of other actors on their GVCs to most effectively and efficiently produce REDD+ knowledge commodities.

\subsection{Company value drivers}

Pressure on companies to account for natural capital and to adapt their practices to meet sustainability standards, and REDD+ standards in particular, is not simply a response to the desires of their investors or other organisations. Some informants felt that companies' interest in REDD+ knowledge commodities was a response to future profit sources: "Companies are interested in doing it, as long as it's profitable for them" (Contractor 22). Companies pursued profits while keeping up with industry competition, which increasingly required the adoption of sustainable practices: "The game changers are supply chain security. That's a trillion dollars of business that 
needs to be secured. They want to make sure that it works. They're worried about demand and supply side" (Contractor 3 ). In this sense these companies are worried about the security of their GVCs that source from primary producers, through manufacturing and supply to consumer markets internationally. There was concern that the effects of climate change will reduce their ability to supply primary produce to their manufacturing activities. Additionally, they worry that climate change will also reduce the demand from consumer markets because of perceptions of unsustainable businesses and decreased purchasing power as economies become disrupted by volatile and changing climate conditions. These are proving to be powerful drivers for companies to engage in sustainable business:

There is a new paradigm for doing business and the private sector is starting to adopt this. International companies that have been blacklisted ${ }^{31}$ are starting to adopt it, as otherwise nobody will recognise them (Investor and Developer 10).

There's a much bigger move where companies are starting to recognise that they need sustainable servicing ... They're starting to look at developing methodologies around monitoring and changing their supply. They're starting to look at standards and establishing - themselves - standards (Contractor 3).

This increasing turn to natural capital accounting does not necessarily mean that REDD+ projects are favoured. Informants told of how companies are often interested in improving the sustainability of their own GVCs and would typically look for opportunities to incorporate REDD+ knowledge commodity within them: "Big commodity producers are not so interested in REDD+ and offsetting. They use a term called insetting. They want to invest in their own internal supply chain" (Contractor 7). These techniques of 'insetting' are established and implemented through company policies: "There is interest in natural capital. There's growing interest. But it's largely based on company policy" (Contractor 5). In this sense, PSF informants

\footnotetext{
${ }^{31}$ Blacklisted refers to a company being recognised by investors and having a reputation as being unsustainable, risky and an unattractive investment.
} 
felt that their own business practices and those of their competitors would bring about change through competition:

Corporations are in an ideal place to take a leadership role and getting involved in REDD+ and climate projects. It's just the nature of us; we want to keep up with each other. If one of us are taking a leadership role then another company says 'we need to do this, we need to come on board as well'. The more companies that do that I think creates a tipping effect and then the consumer catches on to what all of us are doing. Then the consumer starts to demand more. If the consumers are demanding more and the private sector is doing more then legislation will come and then hopefully we've got a nice perfect storm that evolves (Extractive Industry 8).

This quote describes a dynamic and potentially powerful process of change within and between these companies, which push each other further towards sustainable operations whilst pushing and being pulled by their customers along the way. Other companies described how they preferred to wait for the benchmarks to rise around them and then follow the crowd, rather than pioneering ahead: "We rely on international norms of deforestation ... We are not a front-runner but align ourselves with what seems to be internationally accepted" (Investor 9).

For these actors, the source of the REDD+ knowledge commodity shifted from external projects that PSF actors are associated with through sponsorship or offsetting, to being directly incorporated into the operative norms of GVCs through changing their production activities. This incorporation was ultimately driven by company recognition of the risks of unsustainable operations while those failing to change are being perceived by investors as a risky and unappealing option. Informants described how if a company is unaware of these trends and: "hasn't yet realised what's happening in the world, if they're in a commodity business, then you do not want not be investing in them as they don't even understand their supply chain" (Contractor 1). These types of concerns suggest investors are becoming watchful of companies not adapting to sustainable practices. 
Consultants explained that it is primarily early adopters and already progressive companies that are interested in the REDD+ knowledge commodity: "Trying to sell REDD+ to a corporate is really hard. They don't get it. Most corporates don't have an environmental or social profit and loss sheet. ${ }^{32}$ We have to address at least the early adopter 15 per cent" (Contractor 6). There is only a minority of PSF actors willing to experiment with REDD+ knowledge commodities and pioneer sustainability standards. Doing so exposes these companies to additional costs and risks without guarantee that their customers will support them.

Informants reported that in cases where companies are interested in becoming involved with REDD+ there remained a series of gatekeepers that presented barriers along GVCs; namely carbon offset brokers that connect producers with buyers. One informant explained how they managed to circumvent these barriers and brokers through the knowledge commodity character of REDD+; for the broker to communicate what the offset commodity was, they had to tell its story, which then conveyed who the offset producers were:

We didn't know who was buying what because everyone was buying through brokers ... Our pitch to the broker was that 'you need a charismatic credit with a story'. If the broker pitched that successfully then the company they were talking to knew who we were because they had to tell the story (Investor and Developer 12).

This same informant shared how companies could support projects and interventions to generate the REDD+ knowledge commodity without supporting them financially. Companies could have a promoting effect by being vocal about the importance of natural capital accounting and meeting standards of sustainable practice. By doing so, companies can lend legitimacy to REDD+ knowledge commodities among their customers and the public:

\footnotetext{
${ }^{32}$ Environmental and social profit and loss balance sheet refers to practices of natural capital accounting that also include social costs and benefits of activities.
} 
Many of them communicate with consumers, consumers are voters, voters move governments more than we do. So consumer-facing companies in particular can play a role in promoting these ideas widely (Investor and Developer 12).

The motivations for companies to respond to natural capital accounting and standards that constitute REDD+ appear to be shifting beyond the incorporation of external REDD+ projects (as offsets) and towards the direct inclusion into their GVCs via 'insetting' - further tying the fluidity of REDD+ knowledge commodities and finance together. For example, a company may comply with their investor's requirement to source from sustainable palm oil plantations employing standards modelled on REDD+. The recognition of resource limitations within their supply networks is bringing larger, more influential companies around to accounting for natural capital. In this way, the REDD+ knowledge commodity and constituent standards are becoming an incorporated component of these companies' business. Similarly, these companies are responding to and anticipating the desires of their investors, customers and the public. The following section explores in greater detail the role of customers, the public and shareholders in the financialised governance of REDD+ projects and commodity in greater detail.

\subsection{Customer, public and shareholder value drivers}

Customers and shareholders of companies and their investors occupy a variety of positions on REDD+ GVCs, each contributing to and influenced by public opinion. These actors are often highly interconnected and exert agency over the revenues companies and investors can expect within a consumptive economy. Companies and investors are very concerned with satisfying the desires of their customers, shareholders and the wider public. The following illustrates how these actors influence the pressures and requirements from finance on REDD+ GVCs.

Of the three groups of actors (customers, shareholders and public), shareholders are recognised by one informant as the least likely to push for inclusion of the REDD+ knowledge commodity into a company's operations: "The shareholders have been 
the laggards. In most companies the shareholders can be a significant influence, but historically they haven't been" (Investor Developer 2). The INGO from The Swamp REDD+ project experienced these influences differently, and expressed the complexity that shareholder preferences can have within REDD+ GVCs and commodities:

The way that companies are structured is that shareholder returns are the be all and end all. But there are a lot of things that play into those shareholder returns, which are perceptions of how your company operates and relationships that you have with your stakeholders as well. So even if you were looking at it from a purely commercial perspective, those sorts of softer issues actually come into those calculations of risk as well (INGO Informant 2 The Swamp).

Shareholder preference for 'softer issues' are sometimes incorporated into costbenefit calculation and risk assessments. The INGO sought to take advantage of this and arrange the REDD+ project as best they could to reflect those 'softer issues' within PSF actor's risk calculations. In this sense, shareholders can influence companies to shift their GVC strategies to incorporate REDD+ knowledge commodities:

A large cement company is talking to us about biomass energy because of internal shareholder commitments to reduce GHG emissions. In that sense, it's about more than their supply chains, and more about the way they do business (Contractor 3 )

Here, shareholders are interested in securing the GVCs and profitability of companies they are invested in, but at the same time recognise the importance of sustainable business practice.

Informants reflected that, like shareholders, company staff also influenced company governance as they appealed to the social and environmental justice desires of existing and future employees. By offering attractive careers, companies sought to select and retain the best staff possible to contribute to maximising profits: 
The way companies look at the world is that they have three stakeholders: the customers, the shareholders, and the staff. So the truth is that they care more about their staff ... If you look at the opinions of graduates across the world, what are the characteristics of the company that you want to work for? They all put 'ethics' at the top of the list ... So that is a real driver (Investor Developer 2).

While balancing the interests of shareholders and staff, companies are simultaneously trying to appeal to customers. Companies reiterated that a primary focus was the desires of their customers, because their sales and revenues depended upon it: "It's all about branding; that's how we turn this into a commercial proposition" (Extractive Industry 9). This branding appears particularly important when PSF actors that want to offset their GHG emissions are deciding whether a variation of REDD+ knowledge commodities will best appeal to their customers:

Depends what my customers like: monkeys? Or basket-weaving? It's about carbon, but it's about what other things my customers like. You weigh it up. Will cheap credits from a factory in China cut it? Or do you need something that looks good on your website? (Investor and Developer 1).

Customer preferences are seen to influence the types of REDD+ knowledge commodities that PSF actors are creating and pursuing because they influence the ultimate profitability of their businesses. However, informants reported how these preferential signals from customers are not clear and are the cause for some frustration and confusion amongst PSF actors:

Some companies will take the risk and follow consumer demand. However, the consumer has presented very poor signals (Contractor 5 ).

Hard to know if the customer will want something like $R S P O^{33}$ or something GHG focused like REDD+, we're unsure (Extractive Industry 4).

\footnotetext{
${ }^{33}$ Roundtable of Sustainable Palm Oil (RSPO) is a voluntary sustainable standard for palm oil plantations and includes the preservation of high conservation value forests.
} 
However, while recognising these weak and unclear signals from customers, some informants pointed out that: "The new young consumer will reject products that are not environmentally sound. If you're building your strategy for the mid-term, be aware of that" (Extractive Industry 9). It is these sorts of shifts in market demand towards sustainable commodities that the 'early adopter' companies in the above section are anticipating.

By responding to these customer desires and publicising their support for REDD+ knowledge commodities, PSF actors boost their reception among their customers and the public as well as their attractiveness to each other and across agriculture and forestry supply chains: "Making a public statement on forests is about how can we jointly assist our major clients... If we want to continue to do business then they want us to be doing something" (Investor 12). PSF informants recognised that their CSR response to customer and public opinion needed to be genuine if it was to be effective and reflect their duty as global citizens, rather than misinformation and deception: "It's their responsibility to figure out what is the right thing to do, not just figure out what the public will basically buy because they're dim" (Contractor 1 ). The nature of the marketing and branding benefits from involving themselves in REDD+ knowledge commodities required that PSF actors looked beyond fast profits and towards helping inform customers and the public to transition towards sustainable consumption: "Advertising needs to be more about information and not about pervasiveness" (Contractor 15). If such impressions are not secured then, according to informants, public and consumer opinion could backfire and damage companies' branding and profits. Attempting to appeal to public and consumer epistemic desires that resonate with REDD+ knowledge commodities can appear fickle and be a source of immense risk to PSF actors:

We get a lot of heat for financing these palm oil type activities. We're a target (Investor 14). 
It comes from so far away and it's all mixed up and not transparent for [customers]. They don't trust any of it (Extractive Industry 6).

The thing that really scares me is that one day the consumer is going to say 'I don't want anything to do with you' (Extractive Industry 9).

Additionally, informants had experienced that small groups of customers or members of the public have the ability to influence large numbers of other customers that can have a considerable impact on PSF business: "It's a small percentage of the total customers, but we cannot ignore them as they are active and shape peoples thinking" (Extractive Industry 6). This sort of risk from customers and the public puts pressure on companies to be perfect. This pressure risks and reduces the willingness of PSF actors to involve REDD+, as their actions might be ridiculed and put them at a disadvantage:

"But the markets demand nothing less than maximum, and if we don't, then we lose the credibility and are accused of not really wanting to change" (Extractive Industry $6)$.

"If they put something on the brand they feel they will get a lot of comments on it if it's not perfect. There are too many issues for buyers to take that step" (Investor 15).

This tendency for companies to protect their profits by avoiding engaging or publicising their involvement in REDD+ knowledge commodities has been detrimental to the popularisation of REDD+. This risk-avoidance approach of some PSF informants was driven by the financial pressure to secure their customers and revenue sources. Other PSF informants described how companies, even if they find REDD+ knowledge commodities too risky to invest in, or to incorporate directly into their GVC, could support REDD+ by using their trusted brands and influence to inform their customers of its merits: "The perfection idea is killing the opportunity. So I tell them that I don't care if they don't buy my stuff. Just tell your customers that REDD+ is a good thing. They trust you and your brand" (Investor and Developer 12). The desire of companies to secure the profitability of their brands, and the 
recognition of PSF actors of the influence such brands can have on customers, illustrates the character of the knowledge economy that REDD+ commodities are engaging.

For some companies, the financialised influence of customers reached a point where they felt they had lost control of their brand to their customers. Subsequently, these customers are indirectly deciding the approach companies might take to REDD+ knowledge commodities on the GVCs they share: "Public opinion owns our brand. You have to be transparent. The people that certify our brand, in the same way as people certify REDD+ production, is the consumer" (Extractive Industry 9). The fragility and fluidity of perceptions moving along GVCs that involve PSF actors create complex contexts for REDD+ knowledge commodities to infiltrate and balance. Within this knowledge economy, a company's act of surrendering their brand to public opinion appears to facilitate an entangled and self-directed circulation of finance and knowledge, governed by customers that both produce and consume it. The following section explores the influence of financialisation at the 'upstream' ends of REDD+ GVCs, within forests and forest communities.

\subsection{Local value drivers}

The REDD+ knowledge commodity, at its forest area source, was described differently in different places. It was often presented as a partnership between the forest communities and the consuming community:

A community-to-community exchange where people are mutually supporting and they have different needs that they can support each other with and have a reciprocal relationship of a long-term nature (Standard Consultant 1 The River).

One project developer described how forest communities receive the minimum benefit necessary to influence their relationship with their forests. This minimum is based upon the relatively small proportion of benefits these forest communities 
currently receive from other conventional palm oil, mining and timber type operations that request the use of their forests:

Most of the value does not accrue to the local people but goes out of the forest to the investors. So competing with the needs at the local level is not that difficult because they don't get that much value out of their forests and they don't have very many alternatives (Investor and Developer 12).

Subsequently, providing a better deal to forest communities than their alternative offers was perceived as relatively easy. The financial pressures and rationality of PSF actors from investors, companies, shareholders, customers, and the public coalesced to demand the minimum required cost of REDD+ projects. This left forest communities with restricted scope to influence how REDD+ knowledge commodities are generated. However local communities established a baseline that the project needed to improve upon: "In the end it will be the local people and the local governments that will decide whether the value we're producing for them from their local forests is an adequate substitute for the destructive use that was going on" (Investor and Developer 12). In this way, some forest communities and local jurisdictions are able to push back on PSF actor preferences to develop knowledge commodities at minimal cost. Furthermore, the unconventional management of PES finance by forest communities provided a barrier to the influence other GVC members attempted to express through financial signals:

When community groups get money from their own jobs and businesses they manage that money very effectively. They did risk free or low risk activities with their money. But with the PES money they were doing risky activities ... still treating it like donor money (Standard Consultant 1 The River).

This describes community members using REDD+ PES finance for apparently irrational activities that appear to contradict expected money management strategies by such waged workers. By doing so it indicates that the performancebased payments intended to incentivise certain behaviour and influence the 
governance of forests are weakened at this end of the GVC. This effectively illustrates forest communities as expressing elements of resistance or incompatibility with the processes and governing program of financialisation.

The financial principles upon which REDD+ GVCs rely may become un-hinged as the community do not always share them: "In a capitalist society money becomes necessary. But until then, it's not. This community is in the middle of that somewhere" (Standard Consultant 1 The River). The forest communities associated with the REDD+ projects studied here did not appear to be governed by financial concerns in the same way that the other PSF actors on REDD+ GVCs are. The consumption-based resource allocation system of capitalism that dominates the rest of the REDD+ GVC did not yet appear to have established its roots in the lives of these forest peoples. This is not to discard the influence of REDD+ projects and the knowledge commodities that are created. Project developers acting as intermediaries ensured that the resultant REDD+ commodity delivered on the preferences of its funders, as Chapters 6 and 7 demonstrated. However, it is worth noting that financial rationales met challenges in forest communities.

Conversely, financial concerns did influence the behaviour of local government bodies and politicians: "The only way to influence a local government is through the buyers and who they say they will buy from" (Contractor 22). Here the buyers are international companies looking to buy forestry and agriculture products. Their choice to buy from Indonesian companies that produce sustainable products that incorporate the REDD+ knowledge commodities would mean that local governments in Indonesia would support measures to implement REDD+ projects and develop such knowledge commodities. This illustrates the close and effectual financial relationship between Indonesian authorities and businesses at these local levels of government. Money is influential across all levels of government that are responsible for Indonesia's forest areas; PSF actors that progressed their interests in local jurisdictions typically purchased permissions. 


\subsection{Conclusion}

The above sections have analysed processes of financialisation within REDD+ GVCs in Indonesia. Financially driven governance was witnessed across REDD+ GVCs - among investors, companies, shareholders, customers, and the public. GVCs are seen to transform as each actor adjusts their operations to suit the financial pressures and performance preferences of surrounding and supporting actors. This financial influence, largely driven by the preferences of investors and customers that surrounded companies, jostled actors across GVCs to reposition and legitimise them in an apparently coordinated manner: "The idea you can pay someone upstream and downstream doesn't work. You have to be coordinated. You have to shift the market" (Contractor 3). Shifting GVCs and the market in this way was seen to involve a reformulation of the evaluative norms by which they operated, pushed through by financial interests. The actors on these evolving GVCs are using tools to value attributes within REDD+ standards and natural capital accounting.

Financial mechanisms come with both strengths and weaknesses. They are both quietly influential and obviously exposed, covering the world's networks of exchange and value creation. A decision to allocate capital would send a financial signal to other GVC actors, who may then re-gear their practices and reallocate capital in similar or competitive ways. Like a spider-web with several flies entrapped, each fly's struggle excites neighbours to struggle, which excites their neighbours to struggle, and so on. Each fly is committed to perpetual and repeating actions of response and initiation.

The non-linearity of this is an important feature of financialisation within REDD+. Financial mechanisms function as a complex network of substantive connections and open relationships that facilitate an immense fluidity of action and re-action among actors. When coupled with the epistemic circulation of REDD+ knowledge commodities, financialisation has amplified the efficiency of reflexive knowledge formation and evaluation by PSF actors. In this sense, change is constant, and 
isolating the beginning or starting point of such governance influences is difficult. However, noticeable developments in geographical political economy can be understood to begin when a particular actor allocates finance to produce a particular commodity in a particular way (Sheppard, 2011); in this case, with the epistemic circulation of REDD+.

Financialisation ensured that the knowledge commodity generated favoured arrangements that would deliver the meanings and outcomes desired by finance and the GVC actors aligned with finance, empowering PSF actors accustomed to paradigms of financial accumulation. Previous chapters demonstrated how this typically manifested in a close and effectual relationship between PSF actors and their agents responsible for creating the REDD+ project, to secure their desired REDD+ knowledge commodities. 


\section{Conclusion}

Exploring PSF actors involved with REDD+ projects and knowledge commodities in Indonesia has provided interesting insights into this example of market environmentalism and the revaluation of certain forest areas in the global economy. This chapter draws together the analysis and discussion within previous chapters to respond to the research's aim: to bring to the surface and tease out the diverse characteristics of PSF actors and their influence as agents of private governance within REDD+ projects in Indonesia. This conclusion responds to each research question in turn, and begins by engaging research question 1: who are PSF actors that support REDD+ projects? It then responds to research question 2: why do PSF actors support REDD+ projects? and discusses why these actors evaluate them as desirable. Finally, the conclusion addresses research question 3: what are the governance implications of PSF actors on REDD+ projects?, and discusses private governance in the context of REDD+ market environmentalism.

Whilst engaging these questions this chapter also responds to calls to apply a GVC framework to analyse REDD+ (Bumpus \& Liverman, 2011). It demonstrates the usefulness of the GVC framework when investigating an empirical example of value within a knowledge commodity like REDD+ (Gibbon et al., 2008; Lee, 2011b; Starosta, 2010a; Vagneron \& Roquigny, 2011). Specifically, the GVC lens helped to understand the actors involved and the governance characteristics of the case study REDD+ projects. Mapping and analysing the REDD+ GVCs in Chapter 6 captured the inputs and outputs of REDD+ projects, providing insight into their processes of commodification. The REDD+ GVC diagrams also captured a slice of the wider institutional and governance network that the projects are nested within. 


\subsection{Who are PSF actors that support REDD+ projects?}

The research sought to differentiate within the category of 'private finance' and, more specifically, the adopted frame of 'profit-seeking finance', drawing attention to the different types of finance strategies and tactics in REDD+ projects (Bernard et al., 2012; Lövbrand \& Stripple, 2012). Market environmentalism and associated processes of privatisation and commercialisation are illuminated through this approach (Bakker, 2005; Leys, 2001), which helps to reveal key actors and the ways in which they relate to global markets. Through investigating the institutional context of REDD+ GVCs in Indonesia the research found that PSF actors may be from either the public or the private sector.

Corporate sponsors, corporate offsetters and extractive industry typically used private sources of finance, while the finance within sovereign wealth funds was from public sources. Foundations and institutional investors typically draw on private sources of finance, but could also include a mix of public and private sources. In such cases, public sources are often a way of mitigating the risks to private sources, as any losses can be shared or directed toward the public sources of funds. By managing the balance of risk within investment funds in this way, institutional investors could attract greater amounts of private PSF to invest in their funds. Understanding the types of PSF actors involved in REDD+ projects is helpful in understanding why they are involved.

\subsection{Why do PSF actors support REDD+ projects?}

This section engages with the question of why PSF actors support REDD+ projects, and explores their motivations and desires. The relationship between the mandate that a PSF actor has, and the risk involved with certain REDD+ investment options, is an important determinant of whether that actor will become involved at all. If a project seems unlikely to achieve its goals and fulfil the desires of PSF actors, then they are unlikely to invest. This research finds that certain outcomes are more easily achieved than others. Specifically, social and environmental outcomes tended to be 
more easily achieved than financial returns. This finding was helpful in exploring the above types of PSF actor to better understand why they became involved in REDD+ in Indonesia. The behaviour of PSF actors is mapped in relation to how financial incentives are balanced against non-financial incentives in Figure 5.1. REDD+ PSF in Indonesia is found to have adopted four broad strategies: CSR, impact investment, sustainable commodities and REDD+ VERs.

Given the situation within the REDD+ program in Indonesia at the time this research was conducted, the most active participants tended to be those actors most willing to derive little or no financial return, and comprised mainly corporate sponsors or foundations pursuing CSR strategies. Actors such as institutional investors and corporate offsetters, that prioritised financial returns, were typically found to have paused or slowed their activities, speculating that the price of their VERs might increase. These actions are driven by an anticipated continuation of consumer preferences towards carbon neutral and conservation associations in consumer products, and the UNFCCC's inclusion of REDD+ in the 2015 global climate agreement. Others are either spreading their risk across CSR initiatives, sustainable commodities projects or impact investments, or withdrawing from REDD+ altogether.

Because of this variety of responses and behaviour among PSF actors, the four PSF strategies (CSR, impact investment, sustainable commodities and REDD+ VERs) are best considered as tendencies, rather than discrete categories of mutually exclusive PSF actor behaviour. The research did find that, despite this, most PSF actors are still primarily concerned with their financial 'bottom line' and reluctant to pursue REDD+ VERs in isolation, preferring to adopt aspects of CSR, sustainable commodities, or impact investment type strategies to provide some branding and marketing compensation for projects that had little financial return. In this way, despite being the initial attraction, REDD+ VERs had taken on the nature of a secondary co-benefit or a contingency strategy, to be engaged if the market for carbon offsets stabilised in the future. 


\subsubsection{Why PSF actors desire REDD+ knowledge commodities}

The GVC-inspired analysis of REDD+ project case studies, and the PSF actor types and strategies across these REDD+ GVCs, laid the groundwork for further analysis of why PSF actors support REDD+ projects and view them as desirable (Büscher, 2014; Graham, 2006; Rainnie et al., 2011; Selwyn, 2012; Starosta, 2010a, 2010b). The analysis in Chapter 7 explored REDD+ as a commodification process to imbue certain values into REDD+ projects and deliver a REDD+ commodity to PSF actors. This analysis exposed REDD+ as a commodity that facilitates a specific type of exchange: where specific REDD+ Outcomes ${ }^{34}$ are attached to REDD+ VERs. As such, REDD+ projects are defined as those that access finance by selling REDD+ VERs with REDD+ Outcomes attached. This specific exchange of REDD+ VERs became the hook upon which a variety of meanings (beyond the REDD+ Outcomes) could become attached, thus reflecting 'value in motion' of capital and epistemic circulation (Büscher, 2014, p. 81). This characteristic also mirrors Lansing's (2011) analysis of forest carbon commodities as simultaneously the material inputs and the abstracted knowledges of attached meanings.

The non-VER REDD+ Outcomes (particularly the 'sustainable management of forests') exposed them to infiltration by additional meanings beyond deforestation and forest degradation. This enabled the attachment of general sustainable development stories and meanings to the REDD+ project, its VERs and exchange commodity. Subsequently, the REDD+ commodity came to facilitate a malleable platform to accumulate meanings and knowledges, resembling the characteristic of knowledge commodities (Büscher, 2014; Graham, 2006). These REDD+ knowledge commodities are then integrated into the circulation of objects and ideas between actors. In doing so, REDD+ knowledge commodities become subject to the multiple and diverse mediations and evaluations of actors, which is characteristic of epistemic circulation (Büscher, 2014).

\footnotetext{
${ }^{34}$ REDD+ Outcomes refers to the specific outcomes defined as avoided deforestation and forest degradation, sustainable management of forests and conservation and enhancement of forest carbon stocks.
} 
The extrapolation and mediation of REDD+ knowledge commodities proceeded to the extent that the VER and PES components of some REDD+ projects, along with their REDD+ label, had receded completely from their initial meanings. Such REDD+ components and their associated knowledges and meanings are abandoned in favour of finance from PSF actors willing to invest in developing locally produced sustainable commodities. Removing the REDD+ VERs and exchange commodity component from projects made them no longer technically REDD+ projects. However, importantly, many of the material inputs and legitimacy measures, such as REDD+ standards, are still being used to secure these PSF investments into local sustainable commodity production.

The diverse and nuanced knowledges and meanings that appealed to specific PSF actors are imbued into REDD+ knowledge commodities through the crafting of stories as part of developing REDD+ projects. Material inputs to projects are arranged and legitimised to constitute important ingredients of the story as it is written and embellished for consuming PSF actors. Here, the REDD+ knowledge commodity entailed the commodification of the REDD+ story. This illustrates the creation of value as more complex than some traditional GVC analyses that conceptualise value as the difference in price (Gibbon et al., 2008; Starosta, 2010a; Vagneron \& Roquigny, 2011). By mapping the tangible and knowledge-based inputs in REDD+ projects and their arrangements that became stories and knowledge commodities, the way that PSF actors evaluate REDD+ knowledge commodities could be explored (Lee, 2011b).

The REDD+ knowledge commodity and its story is an important part of how PSF actors evaluate REDD+ projects as desirable, alongside the projects' ability to be financially sustainable and deliver secure REDD+ VERs. PSF actors draw on a mixture of knowledges as they make evaluations and decisions (Lee, 2011b). At the same time, their knowledges are shaped by their experiences with REDD+, which then influence their desires and motivations (Lee, 2011b). Project developers tamper with this dynamic by mediating the production of the REDD+ knowledge commodity 
(shown in Figure 7.2). These project developers, typically NGOs, juggle the attributes of the knowledge commodity to ensure that desirable features are reflected back to PSF actors and forest communities. In this way PSF actors and forest localities see what they want to see and their knowledges are reinforced and recreated.

This reflection of desires came to represent the win-win rhetoric that REDD+ and market environmentalism espouse, whereby both PSF actors and forest communities are happy, and their evaluations and realities are re-affirmed. One informant described REDD+ as mythical: "It's a unicorn discussion. If there was a unicorn: who would feed it, groom it, ride it. The whole thing is a discussion about unicorns" (International Consultant 23). These insights illuminate the inner workings of such a 'moral commodity' and hints that REDD+ projects may be less about rescuing nature and more about satisfying the desires of certain actors (Castree, 2003; Knox-Hayes, 2015; Liverman, 2004).

Therefore, rather than an objective natural capital value measured through REDD+ standards, the value of REDD+ knowledge commodities appear to resemble PSF actors' subjective and reflexive evaluation. This is exacerbated by the shifting meanings that actors bestow upon these commodities, such that their evaluations exist only in transitory moments (Bakker, 2005; Bridge \& Smith, 2003; Sayer, 2003; Swyngedouw, 1999). Value became a moment of judgement - the act of evaluation (Lee, 2011b). In this light, market environmentalism's call to 'put a value on nature' appears to be less about 'putting a value' and more about 'customising value' to attract PSF actors (Sukhdev, 2011).

\subsection{What are the governance implications of PSF actors on REDD+ projects?}

This section responds to research question 3 and discusses the contribution of this research to understanding new non-state governing actors (Bernard et al., 2012; Lövbrand \& Stripple, 2012; Okereke et al., 2009) and the privatisation of governance within REDD+ market environmentalism (Adler, 2002; Bakker, 2005; Ervine, 2013; 
Newell \& Paterson, 2010). The PSF actors in REDD+ have important implications for the governance of REDD+ projects and the program more broadly, and for thinking about the emergence of PSF actors and finance in environmental governance and market environmentalism more generally. The governing implications of PSF actors within Indonesia's REDD+ effort in three key areas that are detailed below: rationales and strategies; GVCs and financialised networks; and evaluation and desires.

\subsubsection{PSF governing rationales and strategies}

Describing the variety of rationales and strategies by which PSF actors pursue for triple bottom line (environmental, social and financial) returns through REDD+ projects helped to understand the governing influence of these actors. Each different type of PSF actor approached REDD+ with certain motivations and rationales that pushed them towards adopting certain strategies. The regulatory and market uncertainty around REDD+, both in Indonesia and internationally, has created opportunities for (and driven) investment and accumulation strategies that have embraced social and ecological co-benefits alongside, and even over and above, REDD+ VERs.

However, despite actors' engagement with these aspects of REDD+ projects, interest appeared to be driven primarily by a hedging or diversification logic, given the perceived high-risk nature of securing REDD+ VERs. Therefore, although actors are found to have engaged in a range of strategies and activities generating combinations of financial, social and ecological benefits, the likelihood that PSF and market-based governance will support a scaled-up REDD+ while ensuring social justice and environmental sustainability (beyond climate change mitigation), remains questionable.

If or when REDD+ VERs become significantly less financially risky, it is not to be taken for granted that PSF actors will continue to pursue social and ecological outcomes with the same enthusiasm found here. It may be that those types of PSF actors that 
prioritise financial returns re-enter the REDD+ market and effectively crowd out the current PSF actors prioritising social and ecological outcomes. In this sense, critiques of capitalist climate governance and market environmentalism may yet be borne out for REDD+. Ironically, this may only become clear once an international agreement has been reached on an avoided deforestation mechanism. Hence the current interest in co-benefits may turn out to be temporary and the character of private finance may exert different pressures in future scenarios. In this way, the different rationales and strategies of PSF actors influence the governance of REDD+ projects in Indonesia and internationally.

\subsubsection{Governing GVCs and financialised networks}

The financial motives of PSF actors also influence REDD+ project governance. The difficulty, risks and costs of securing VERs and the permanence of each project through gaining land-use concession over the forest area, forced the departure of some PSF actors and deterred others. This land-use concession component of REDD+ projects - alongside REDD+ standards - reduces the risk and secures the legitimacy of each project. By doing so, these concessions and standards become codified forms of governance that sends objective signals to PSF actors to inform them whether the REDD+ project embodies specific attributes. In this way, concessions and standards enable PSF actors to more easily grasp what each REDD+ project offers and enables them to make decisions consistent with the time-bound demands of capital.

The governing influence of PSF actors within REDD+ project GVCs becomes clear as project developers attempt to craft their projects around concessions and standards to match the desires of remaining PSF investors. Subsequently, the desires of distant PSF actors are seen to influence the governance of REDD+ projects in subtle but important ways. These are less direct than traditional GVC governance descriptions of chains driven by lead actors, and are more relational and market based where projects are adapted to appeal to the custom demands of different PSF actors (Gereffi et al., 2005). This emphasised the importance of the position and function of 
project developers in managing the customisation of REDD+ stories and knowledge commodities. For example, in the case of The Valley the project developer changed their biodiversity monitoring in a direct and hurried response to the desires of a recently interested PSF actor.

The governing influence of PSF actors is also traced away from REDD+ projects to PSF companies, shareholders, customers and the public. Financial pressures shape REDD+ GVCs by adjusting the character of each actor's operations to suit the financial and performance preferences required. Financial signals are sent across GVCs where each actor then re-gears their operations and reallocates resources in response, influencing their associates in turn (Fieldman, 2013; Knox-Hayes \& Levy, 2011; Lazonick \& O'Sullivan, 2000; Lohmann, 2011). This demonstrated a growing governing influence emerging from finance sources through market environmentalism (Bakker, 2010, 2012; Knox-Hayes, 2013; McAfee, 1999).

PSF actors are very responsive to the preferences of those they are financially bound to, which tended to be other PSF actors (investors, companies and shareholders), customers or the public. Understanding this governance relationship between PSF actors and the financial pressures in their contexts help understand how and why PSF actors influence ecosystem service commodities more generally (Fieldman, 2013; Harmes, 2011; Knox-Hayes \& Levy, 2011; Lazonick \& O’Sullivan, 2000; Lohmann, 2011; Pattberg, 2012). PSF actors' responsiveness to financialisation appears to encourage the epistemic circulation of REDD+ knowledge commodities on GVCs. In this way, PSF actors facilitate the movement of entangled finance and ideas about their networks; appearing as both 'objects and subjects' of governance (Sending \& Neumann, 2006). Their activities seem to respond to pressures to operate sustainable business, and at the same time contribute to and constitute these governance signals and influences (Levy \& Newell, 2005). 


\subsubsection{Governing PSF actor evaluation and desire}

The dynamics of evaluation - of why PSF actors are involved - is seen to have influenced the character of REDD+ projects, their GVCs and resultant knowledge commodities. The function of evaluation acts upon commodities, enabling market exchange and market environmentalism (Bakker, 2005; Watts, 2014). These evaluations drive the circulation of commodities about a neoliberal capitalist economy, governing their allocation in ways that may worsen the deforestation that REDD+ knowledge commodities are attempting to remediate (Bakker, 2010, 2012; Castree, 2008; Dunlap, 2015; McAfee, 2012).

In this regard, REDD+ knowledge commodities reflected market environmentalism's complex processes of renaturing economies with sustainable commodities (Bakker, 2005; Boyd et al., 2011; Bumpus et al., 2010; Dunlap, 2015; Dwyer \& Ingalls, 2015; Lohmann, 2010; Robertson, 2012). REDD+ projects and their knowledge commodities packaged meanings, identities and values to suit PSF actors' desires (Bakker, 2005; Kaika \& Swyngedouw, 2000; Robertson, 2000; Castree, 2003) and in doing so provide an example of how "economics has become the language of policy, whether we like it or not" (Contractor 15), privatising governance so REDD+ responds to the logics of PSF actors.

In these ways, market environmentalism uses the morality within the REDD+ knowledge commodity to service an economy that depends on the moral compass of GVC members (Bakker, 2005; Bryant \& Goodman, 2004; Goodman, 2004; Sayer, 2003). As one informant described: "There was this blinding belief that somehow markets will do that for us and that the fund manager is the conscious keeper of the world" (Contractor 15). REDD+ in Indonesia illustrated the global economy's increasing dependency on PSF actors to desire moral, ethical and sustainable commodities so they might purchase their way out of the climate change issue (Barnett et al., 2005; Ciscell, 2010; Clarke, 2008; Krahmann, 2012; Lovell et al., 2009; Spaargaren \& Mol, 2013). 
However, REDD+ knowledge commodities do not always cooperate with the commodification ambitions of actors on the REDD+ project's GVC (Bakker, 2005). This is demonstrated in the struggle to secure land-use concessions, the displacement of deforestation pressure to areas outside protection zones, the uncertainty that protection zones actually face imminent deforestation pressure, and the non-fungible nature of project stories and knowledge commodities. However, while not consistently delivering VER or PES returns, these commodities do cooperate in that they reflect the meanings that GVC members and supporting PSF actors want to see. These findings support ideas of how transient, partial and plural nature's neoliberalisation, commodification and privatised governance can be (Bakker, 2005, 2012).

\subsection{Summary}

Mapping REDD+ commodification processes and PSF actors' desires and evaluations in Indonesia enabled the research to develop insights into who PSF actors are, why they are involved, and their governing influence. The variety of PSF actors involved saw REDD+ projects as offering a mixture of potential benefits. PSF actors of different types and strategies balanced their desires for financial gain with social and environmental outcomes. The variety of ways PSF actors evaluate REDD+ projects is encouraged by the adaptability of REDD+ knowledge commodities to PSF actors' desires, and their capacity to shape actors' knowledges of what is desirable. This characteristic of the REDD+ knowledge commodity mitigated the otherwise effective demands of PSF actors to actively shape the character and specific activities of REDD+ projects. The governing influence of PSF actors was extended by their tradition of applying and responding to financial pressure - something REDD+ projects were seen to both facilitate and resist.

More generally, this thesis untangled how 'private finance' is conceptualised within Indonesia's REDD+ program providing a unique view on PSF from in-depth fieldwork and observation. This research also provides a unique and important view on REDD+ from the perspective of PSF. In doing so it contributes to broader understandings of 
market environmentalism and private governance. This research illustrates a snapshot of REDD+ projects in-the-making and is restricted by that temporality. Any similar future endeavours could be improved by accessing case studies that present active PSF actors that have achieved land-use concession and progressed toward carbon offset production and sale. This might generate more in-depth insights into functioning REDD+ market environmentalism and may yield additional character aspects of PSF actors, the REDD+ commodity and the relationships they share. Furthermore, such work could deliver insights into the distribution of costs and benefits across these GVCs, particularly if this was accompanied by in-depth analyses of value distributions among communities within REDD+ forests, and consumers of products that support REDD+ projects.

This research found that while the influence of PSF actors within environmental governance is increasing, it is doing so in diverse ways and delivering a variety of benefits for biodiversity conservation, emissions reductions and community development. This is important to remember when analysing interventions of privatised governance, particularly that the accumulation of finance is not always the primary or only motivation. Furthermore, motivations for financial accumulation do not necessarily preclude the pursuit of activities that align with immediate conservation and sustainable development goals. This is not to cast off caution of capitalist motivations, but to posit a blurry optimism in what PSF actors might offer. 


\section{References}

Adger, W. N., Arnell, N. W., \& Tompkins, E. L. (2005). Successful adaptation to climate change across scales. Global Environmental Change, 15(2), 77-86. doi:10.1016/j.gloenvcha.2004.12.005

Adler, J. H. (2002). Free market environmentalism. Cato Journal, 22(1), 182-188. doi:10.1016/0921-8009(93)90052-8

Agrawal, A., Nepstad, D., \& Chhatre, A. (2011). Reducing emissions from deforestation and forest degradation. Annual Review of Environment and Resources, 36(1), 373-396. doi:10.1146/annurev-environ-042009-094508

Aguiar, L. L. M., \& Schneider, C. J. (2012). Researching amongst elites: Challenges and opportunities in studying up. Surrey: Ashgate Publishing, Ltd.

Alforte, A., Matias, D., Munden, L., \& Perron, J. (2013). Financing sustainable agriculture and mitigation: smallholders and the landscape fund. Copenhagen, Denmark: CGIAR.

Anderson, T. L., \& Leal, D. R. (2001). Free market environmentalism. New York: Palgrave Macmillan.

Angelsen, A., Brockhaus, M., Sunderlin, W. D., \& Verchot, L. V. (2012). Analysing REDD+: Challenges and choices. Bogor, Indonesia: CIFOR.

Bailey, I., Gouldson, A., \& Newell, P. (2011). Ecological modernisation and the governance of carbon: A critical analysis. Antipode, 43(3), 682-703.

Bailey, I., \& Maresh, S. (2009). Scales and networks of neoliberal climate governance: The regulatory and territorial logics of European Union emissions trading. Transactions of the Institute of British Geographers, 34(4), 445-461. doi:10.1111/j.1475-5661.2009.00355.x

Bair, J. (2009). Global commodity chains: Genealogy and review. In J. Bair (Ed.), Frontiers of commodity chain research (pp. 1-34). Stanford: Stanford University Press.

Bakker. (2010). The limits of "neoliberal natures": Debating green neoliberalism. Progress in Human Geography, 34(6), 715-735. doi:10.1177/0309132510376849 
Bakker. (2012). The "matter of nature" in economic geography. In T. J. Barnes, J. Peck, \& E. Sheppard (Eds.), The Wiley-Blackwell companion to economic geography (pp. 104-117). West Sussex: Wiley-Blackwell. doi:10.1002/9781118384497.ch6

Bakker, K. (2005). Neoliberalizing nature? Market environmentalism in water supply in England and Wales. Annals of the Association of American Geographers, 95(3), 542-565. doi:10.2307/3693956

Barnett, C., Cloke, P., Clarke, N., \& Malpass, A. (2005). Consuming ethics: Articulating the subjects and spaces of ethical consumption. Antipode, 37(1), 23-45. doi:10.1111/j.0066-4812.2005.00472.x

Barrientos, S., \& Smith, S. (2007). Do workers benefit from ethical trade? Assessing codes of labour practice in global production systems. Third World Quarterly, 28(4), 713-729. doi:10.2307/20454958

Bernard, F., McFatridge, S., \& Minang, P. (2012). The private sector in the REDD+ supply chain: Trends, challenges and opportunities. Winnipeg, Canada: IISD.

Bernstein, S. (2011). Legitimacy in intergovernmental and non-state global governance. Review of International Political Economy, 18(1), 17-51. doi:10.1080/09692290903173087

Bernstein, S., \& Campling, L. (2006a). Commodity studies and commodity fetishism I: Trading down. Journal of Agrarian Change, 6(2), 239-264. doi:10.1111/j.14710366.2006.00121.x

Bernstein, S., \& Campling, L. (2006b). Commodity studies and commodity fetishism II: "Profits with principles"? Journal of Agrarian Change, 6(3), 414-447. doi:10.1111/j.1471-0366.2006.00128.x

Bernstein, S., \& Cashore, B. (2007). Can non-state global governance be legitimate? An analytical framework. Regulation \& Governance, 1(4), 347-371. doi:10.1111/j.1748-5991.2007.00021.x

Blom, B., Sunderland, T., \& Murdiyarso, D. (2010). Getting REDD to work locally: lessons Learned from integrated conservation and development projects. Environmental Science and Policy, 13(2), 164-172. doi:10.1016/j.envsci.2010.01.002

Bowen, A., \& Fankhauser, S. (2011). The green growth narrative: Paradigm shift or just spin? Global Environmental Change, 21(4), 1157-1159. doi:10.1016/j.gloenvcha.2011.07.007

Boyd, E., Boykoff, M., \& Newell, P. (2011). The "new" carbon economy: What's new? 
Antipode, 43(3), 601-611.

Boyd, E., \& Goodman, M. K. (2011). The clean development mechanism as ethical development?: Reconciling emissions trading and local development. Journal of International Development, 23(6), 836-854.

Bradshaw, M., \& Stratford, E. (2000). Qualitative research design and rigour. In I. Hay (Ed.), Qualitative research methods in human geography (pp. 37-49). Oxford: Oxford University Press.

Bridge, G., \& Smith, A. (2003). Intimate encounters: Culture - economy - commodity. Environment and Planning D: Society and Space, 21(3), 257-268. doi:10.1068/d2103ed

Brockhaus, M., \& Angelsen, A. (2012). Seeing REDD+ through 4ls: A political economy framework. In A. Angelsen, M. Brockhaus, W. D. Sunderlin, \& L. V. Verchot (Eds.), Analysing REDD+ (pp. 15-30). Bogor: CIFOR.

Brockington, D., \& Sullivan, S. (2003). Qualitative research. London: Sage Publications.

Browne, K. (2005). Snowball sampling: Using social networks to research nonheterosexual women. International Journal of Social Research Methodology. doi:10.1080/1364557032000081663

Bryant, R. L. (2013). Branding natural resources: Science, violence and marketing in the making of teak. Transactions of the Institute of British Geographers, 38(4), 517-530. doi:10.1111/tran.12006

Bryant, R. L., \& Goodman, M. K. (2004). Political consumption the ecology of "alternative" consumption. Geographical, 29(3), 344-366.

Bulmer, M. (1983). General introduction. In M. Bulmer \& D. P. Warwick (Eds.), Social research in developing countries: Surveys and censuses in the third world (pp. 326). New York: John Wiley and Sons Ltd.

Bulmer, M., \& Warwick, D. P. (1983a). Data collection. In M. Bulmer \& D. P. Warwick (Eds.), Social research in developing countries: Surveys and censuses in the third world (pp. 145-160). New York: John Wiley and Sons Ltd.

Bulmer, M., \& Warwick, D. P. (1983b). Research strategy. In M. Bulmer \& D. P. Warwick (Eds.), Social research in developing countries: Surveys and censuses in the third world. (pp. 27-40). New York: John Wiley and Sons Ltd.

Bumpus, A. G., \& Liverman, D. (2011). Carbon colonialism? Offsets, greenhouse gas reductions and sustainable development. In R. Peet, P. Robbins, \& M. Watts (Eds.), Global Political Ecology (pp. 203-224). Oxon; New York: Routledge. 
Bumpus, A. G., \& Liverman, D. M. (2008). Accumulation by decarbonization and the governance of carbon offsets. Economic Geography, 84(2), 127-155. doi:10.1111/j.1944-8287.2008.tb00401.x

Bumpus, A. G., Liverman, D. M., \& Lovell, H. (2010). The rise of voluntary carbon offset standards: Self-regulation, legitimacy and multi-scalar governance. SSRN elibrary. doi:10.2139/ssrn.1680054

Burkhard, B., De Groot, R., Costanza, R., Seppelt, R., Jørgensen, S. E., \& Potschin, M. (2012). Solutions for sustaining natural capital and ecosystem services. Ecological Indicators, 21, 1-6. doi:10.1016/j.ecolind.2012.03.008

Büscher, B. (2014). Selling success: Constructing value in conservation and development. World Development, 57, 79-90. doi:10.1016/j.worlddev.2013.11.014

Butler, R. A., Koh, L. P., \& Ghazoul, J. (2009). REDD in the red: Palm oil could undermine carbon payment schemes. Conservation Letters, 2(2), 67-73. doi:10.1111/j.1755-263X.2009.00047.x

Callon, M. (2005). Why virtualism paves the way to political impotence. Callon replies to Miller. Economic Sociology. European Electronic Newsletter, 6, 3-21. doi:10.1080/14616690120046941

Campbell, J. Y. (2002). Differing perspectives on community forestry in Indonesia. In C. J. P. Colfer \& I. A. P. Resosudarmo (Eds.), Which way forward?: people, forests, and policymaking in Indonesia (pp. 110-125). Washington, DC: Resources for the Future, Center for International Forestry Research (CIFOR) and Institute of Southeast Asian Studies (ISEAS).

Carroll, A., \& Shabana, K. (2010). The business case for corporate social responsibility: A review of concepts, research, and practice. International Journal of Management Reviews, 12(1), 85-105. doi:10.1111/j.14682370.2009.00275.x

Cash, D. W., Adger, W. N., Berkes, F., Garden, P., Lebel, L., Olsson, P., ... Young, O. (2006). Scale and cross-scale dynamics: governance and information in a multilevel world. Ecology and Society, 11, 8.

Cashore, B. (2002). Legitimacy and the privatization of environmental governance: How non-state market-driven (NSMD) governance systems gain rule-making authority. Governance, 15(4), 503-529. doi:10.1111/1468-0491.00199

Castells, M. (2000). The rise of the network society. Malden, MA: Blackwell Publishers. 
Castree, N. (2003). Commodifying what nature? Progress in Human Geography, 27(3), 273-297. doi:10.1191/0309132503ph428oa

Castree, N. (2008). Neoliberalising nature: Processes, effects, and evaluations. Environment and Planning A, 40(1), 153-173. doi:10.1068/a39100

Challies, E. (2008). Commodity chains, rural development and the global agri-food system. Geography Compass, 2(2), 375-394. doi:doi: 10.1111/j.17498198.2008.00095.x

Ciscell, G. M. (2010). Beyond CO2lonialism: The potential for fair trade certification to embrace voluntary carbon offsets. International Journal of Sustainable Society, 2(2), 121. doi:10.1504/IJSSOC.2010.033625

Clarke, N. (2008). From ethical consumerism to political consumption. Geography Compass, 2(6), 1870-1884. doi:10.1111/j.1749-8198.2008.00170.x

Cook, I. (2005). Participant observation. In R. Flowerdew \& D. Martin (Eds.), Methods in human geography: A guide for students doing a research project (Second, pp. 167-188). Harlow: Pearson Education Limited.

Corbera, E. (2012). Problematizing REDD+ as an experiment in payments for ecosystem services. Current Opinion in Environmental Sustainability, 4(6), 612619. doi:10.1016/j.cosust.2012.09.010

Corbera, E., Estrada, M., \& Brown, K. (2009). How do regulated and voluntary carbon-offset schemes compare? Journal of Integrative Environmental Sciences, 6(1), 25-50. doi:10.1080/15693430802703958

Corbera, E., \& Schroeder, H. (2010). Governing and implementing REDD+. Environmental Science and Policy, 14(2), 89-99.

Costanza, R., D’Arge, R., de Groot, R., Farber, S., Grasso, M., Hannon, B., ... van den Belt, M. (1997). The value of the world's ecosystem services and natural capital. Nature, 387(6630), 253-260.

Costenbader, J. (2010). REDD+ benefit sharing: A comparative assessment of three national policy approaches. The Forest Carbon Partnership Facility, and The UNREDD Programme.

Crepaz, M. M. L. (1995). Explaining national variations of air pollution levels: Political institutions and their impact on environmental policy-making. Environmental Politics, 4(3), 391-414.

de Vaus, D. (2001). Research Design in Social Research. London: SAGE Publications Ltd. 
Dermawan, A., \& Sinaga, A. C. (2015). Towards REDD+ integrity: Opportunities and challenges for Indonesia. Bergen, Norway. doi:10.3945/jn.111.151803

Descheneau, P. (2012). The currencies of carbon: Carbon money and its social meaning. Environmental Politics, 21(4), 604-620. doi:10.1080/09644016.2012.688356

Descheneau, P., \& Paterson, M. (2011). Between desire and routine: Assembling environment and finance in carbon markets. Antipode, 43(3), 662-681.

Desmond, M. (2004). Methodological challenges posed in studying an elite in the field. Area, 36(3), 262-269. doi:10.1111/j.0004-0894.2004.00223.x

Dicken, P. (2007). Global shift: mapping the changing contours of the world economy. London: SAGE.

Dixon, R., \& Challies, E. (2015). Making REDD+ pay: Shifting rationales and tactics of private finance and the governance of avoided deforestation in Indonesia. Asia Pacific Viewpoint, 56(1), 6-20. doi:10.1111/apv.12085

Dowling, R. (2000). Power, subjectivity and ethics in qualitative research. In I. Hay (Ed.), Qualitative research methods in human geography (pp. 23-36). Oxford: Oxford University Press.

Dunlap, A. A. (2015). The expanding techniques of progress: Agricultural biotechnology and UN-REDD+. Review of Social Economy, 73(1), 89-112. doi:10.1080/00346764.2014.988053

Dunn, K. (2000). Interviewing. In I. Hay (Ed.), Qualitative research methods in human geography (pp. 50-82). Oxford: Oxford University Press.

Durand, C. (2011). Interdependent scales of capital accumulation: A research agenda on the possibilities and limits of a conceptual articulation of global commodity chains, accumulation at the world scale and the variety of national accumulation regimes. In Neoliberalism and the crises of economic science Second international conference in political economy. Istanbul University, Beyazit.

Dwyer, M. B., \& Ingalls, M. (2015). REDD+ at the crossroads: Choices and tradeoffs for 2015-2020 in Laos (No. 179). Bogor, Indonesia: CIFOR.

Ekins, P. (1993). "Limits to growth" and "sustainable development": Grappling with ecological realities. Ecological Economics, 8(3), 269-288. doi:10.1016/09218009(93)90062-B

England, K. V. L. (1994). Getting personal: Reflexivity, positionality, and feminist research. The Professional Geographer, 46(1), 80-89. doi:10.1111/j.0033- 
0124.1994.00080.x

Epstein, G. (2005). Financialization and the world economy. Northampton, Mass: Edward Elgar Publishing.

Ervine, K. (2012). The politics and practice of carbon offsetting: Silencing dissent. New Political Science, 34(1), 1-20. doi:10.1080/07393148.2012.646017

Ervine, K. (2013). Diminishing returns: Carbon market crisis and the future of marketdependent climate change finance. New Political Economy, 19(5), 723-747. doi:10.1080/13563467.2013.849672

Fankhauser, S. (2010). The costs of adaptation. Wiley Interdisciplinary Reviews: Climate Change, 1(1), 23-30. doi:10.1002/wcc.14

Fieldman, G. (2013). Financialisation and ecological modernisation. Environmental Politics, 23(2), 224-242. doi:10.1080/09644016.2013.821826

Fischer, R. (2015). The role of the green climate fund in mobilizing private REDD+ finance - progress made and challenges ahead. Retrieved August 4, 2015, from https://unredd.wordpress.com/2015/04/09/the-role-of-the-green-climatefund-in-mobilizing-private-redd-finance-progress-made-and-challenges-ahead/

Fitter, R., \& Kaplinksy, R. (2001). Who gains from product rents as the coffee market becomes more differentiated? A value-chain analysis. IDS Bulletin, 32(3), 69-82. doi:10.1111/j.1759-5436.2001.mp32003008.x

Fleurbaey, M. (2009). Beyond GDP: The quest for a measure of social welfare. Journal of Economic Literature, 47(4), 1029-1075. doi:10.1257/jel.47.4.1029

Fosci, M. (2012). The economic case for prioritizing governance over financial incentives in REDD+. Climate Policy, 13(2), 170-190. doi:10.1080/14693062.2013.745112

Fosci, M. (2013). Balance sheet in the REDD+: Are global estimates measuring the wrong costs? Ecological Economics, 89, 196-200.

Fulton, M., \& Capalino, R. (2014). Investing in the clean trillion: ClosIng the clean energy investment gap. Boston: Ceres.

Gasparatos, A. (2010). Embedded value systems in sustainability assessment tools and their implications. Journal of Environmental Management, 91, 1613-1622. doi:10.1016/j.jenvman.2010.03.014

GCP, IPAM, FFI, \& FI, U. (2014). Stimulating Interim Demand for REDD+ Emission Reductions: The Need for a Strategic Intervention from 2015 to 2020. Geneva, Switzerland: Global Canopy Programme, Oxford, UK; the Amazon 
Environmental Research Institute, Brasília, Brazil; Fauna \& Flora International, Cambridge, UK; and UNEP Finance Initiative.

Gereffi, G. (1994). The organization of buyer-driven global commodity chains: How US retailers shape overseas production networks. In G. Gereffi \& M. Korzeniewicz (Eds.), Commodity chains and global capitalism (pp. 95-122). Westport, CT: Praeger.

Gereffi, G., \& Fernandez-Stark, K. (2011). Global value chain analysis: a primer. Center on Globalization, Governance \& Competitiveness, Durham, NC. Center on Globalization, Governance \& Competitiveness (CGGC), Duke University.

Gereffi, G., Humphrey, J., \& Sturgeon, T. (2005). The governance of global value chains. Review of International Political Economy, 12(1), 78-104.

Gereffi, G., Korzeniewicz, M., \& Korzeniewicz, R. (1994). Introduction: Global commodity chains. In G. Gereffi \& M. Korzeniewicz (Eds.), Commodity chains and global capitalism (pp. 1-14). Westport, CT: Praeger.

Gereffi, G., \& Lee, J. (2012). Why the world suddenly cares about global supply chains. Journal of Supply Chain Management, 48(3), 24-32.

Gibbon, P., Bair, J., \& Ponte, S. (2008). Governing global value chains: an introduction. Economy and Society, 37(3), 315-338. doi:10.1080/03085140802172656

Gibbon, P., \& Ponte, S. (2008). Global value chains: From governance to governmentality? Economy and Society, 37(3), 365-392. doi:10.1080/03085140802172680

Gibson-Graham, J. K. (2006). A postcapitalist politics. London; Minneapolis: University of Minnesota Press.

Gill, S. (2003). Power and resistance in the new world order. New York: Palgrave Macmillan.

Girod, B., van Vuuren, D. P., \& Hertwich, E. G. (2014). Climate policy through changing consumption choices: Options and obstacles for reducing greenhouse gas emissions. Global Environmental Change, 25(1), 5-15. doi:10.1016/j.gloenvcha.2014.01.004

Giuliani, E., Pietrobelli, C., \& Rabellotti, R. (2005). Upgrading in global value chains: Lessons from Latin American clusters. World Development, 33(4), 549-573. doi:10.1016/j.worlddev.2005.01.002

Goldstein, A., \& Gonzalez, G. (2014). Turning over a new leaf: State of the forest carbon markets 2014. Washington, DC: Forest Trends' Ecosystem Marketplace. 
Goodman, M. K. (2004). Reading fair trade: Political ecological imaginary and the moral economy of fair trade foods. Political Geography, 23(7), 891-915. doi:10.1016/j.polgeo.2004.05.013

Graham, P. (2006). Hypercapitalism: Language, new media, and social perceptions of value. New York: Peter Lang.

Gupta, A., Lövbrand, E., Turnhout, E., \& Vijge, M. J. (2012). In pursuit of carbon accountability: The politics of REDD+ measuring, reporting and verification systems. Current Opinion in Environmental Sustainability, 4(6), 726-731. doi:10.1016/j.cosust.2012.10.004

Guthman, J. (2007). The polanyian way? Voluntary food labels as neoliberal governance. Antipode, 39(3), 456-478. doi:10.1111/j.1467-8330.2007.00535.x

Hallegatte, S., Heal, G., Fay, M., \& Treguer, D. (2011). From Growth to Green Growth A Framework (No. 5872). The World Bank: Sustainable Development Network.

Hamilton, T. (2011). Putting corporate responsibility in its place. Geography Compass, 5(10), 710-722. doi:10.1111/j.1749-8198.2011.00454.x

Harmes, A. (2011). The limits of carbon disclosure: Theorizing the business case for investor environmentalism. Global Environmental Politics, 11(2), 98-119.

Hartwick, E. (1998). Geographies of consumption: A commodity-chain approach. Environment and Planning D: Society and Space, 16(4), 423-437.

Harvey, D. (2006). The Limits to Capital. London: Verso.

Héritier, A., \& Lehmkuhl, D. (2008). The shadow of hierarchy and new modes of governance. Journal of Public Policy, 28(01). doi:10.1017/S0143814X08000755

Hiraldo, R., \& Tanner, T. (2011a). Forest voices: Competing narratives over REDD+. IDS Bulletin, 42(3), 42-51.

Hiraldo, R., \& Tanner, T. (2011b). The global political economy of REDD+: Engaging social dimensions in the emerging green economy. Geneva, Switzerland: United Nations Research Institute for Social Development.

Hopkins, T. K., \& Wallerstein, I. (1994). Commodity chains: Construct and research. In G. Gereffi \& M. Korzeniewicz (Eds.), Commodity chains and global capitalism (pp. 17-19). Westport, CT: Praeger.

Hughes, A. (2001). Global commodity networks, ethical trade and governmentality: Organizing business responsibility in the Kenyan cut flower industry. Transactions of the Institute of British Geographers, 26(4), 390-406. doi:10.1111/1475-5661.00031 
Hughes, A. (2005). Geographies of exchange and circulation: Alternative trading spaces. Progress in Human Geography, 29(4), 496-504.

doi:10.1191/0309132505ph563pr

Indrarto, G. B., Murharjanti, P., Khatarina, J., Pulungan, I., Ivalerina, F., Rahman, J., ... Muharrom, E. (2012). The context of REDD+ in Indonesia: Drivers, agents and institutions (No. 92). Bogor, Indonesia: CIFOR.

Indriatmoko, Y., Atmadja, S., Ekaputri, A. D., \& Komalasari, M. (2014). Rimba Raya biodiversity reserve project, Central Kalimantan, Indonesia. In E. O. Sills, S. Atmadja, C. de Sassi, A. E. Duchelle, D. Kweka, I. A. P. Resosudarmo, \& W. D. Sunderlin (Eds.), REDD+ on the ground: $A$ case book of subnational initiatives across the globe (pp. 348-361). Bogor, Indonesia: CIFOR.

Indriatmoko, Y., Atmadja, S., Utomo, N. A., Ekaputri, A. D., \& Komalasari, M. (2014). Katingan peatland restoration and conservation project, Central Kalimantan, Indonesia. In E. O. Sills, S. Atmadja, C. de Sassi, A. E. Duchelle, D. Kweka, I. A. P. Resosudarmo, \& W. D. Sunderlin (Eds.), REDD+ on the ground: A case book of subnational initiatives across the globe (pp. 309-328). Bogor, Indonesia: CIFOR.

Ituarte-Lima, C., McDermott, C. L., \& Mulyani, M. (2014). Assessing equity in national legal frameworks for REDD+: The case of Indonesia. Environmental Science \& Policy, 44, 291-300. doi:10.1016/j.envsci.2014.04.003

Jackson, S., \& Palmer, L. R. (2014). Reconceptualizing ecosystem services: Possibilities for cultivating and valuing the ethics and practices of care. Progress in Human Geography, 39(2), 122-145. doi:10.1177/0309132514540016

Jahn, D. (1998). Environmental performance and policy regimes: Explaining variations in 18 OECD-countries. Policy Sciences, 31(2), 107-131. doi:10.1023/A:1004385005999

Jaung, W., \& Bae, J. S. (2012). Evaluating socio-economic equity of REDD+ in a rightsbased approach: Rapid equity appraisal matrix. Environmental Science and Policy, 22, 1-12. doi:10.1016/j.envsci.2012.05.007

Kaika, M., \& Swyngedouw, E. (2000). Fetishizing the modern city: The phantasmagoria of urban technological networks. International Journal of Urban and Regional Research, 24(1), 120-138. doi:10.1111/1468-2427.00239

Kanak, D., \& Henderson, I. (2012). Closing the REDD+ gap: The global forest finance facility. Ottawa, Canada: WWF Forest Finance Initiative.

Kaplinsky, R., \& Morris, M. (2001). A handbook for value chain research. International Development Research Center. 
Kearns, R. (2000). Being there: Research through observing and participating. In I. Hay (Ed.), Qualitative research methods in human geography (pp. 103-121). Oxford: Oxford University Press.

Kerschner, C. (2010). Economic de-growth vs. steady-state economy. Journal of Cleaner Production, 18(6), 544-551. doi:10.1016/j.jclepro.2009.10.019

Kitchen, R., \& Tate, N. J. (2000). Conducting research into human geography: Theory, methodology and practice. Harlow: Pearson Education Ltd.

Knox-Hayes, J. (2013). The spatial and temporal dynamics of value in financialization: Analysis of the infrastructure of carbon markets. Geoforum, 50, 117-128. doi:10.1016/j.geoforum.2013.08.012

Knox-Hayes, J. (2015). Towards a moral socio-environmental economy: A reconsideration of values. Geoforum, 65, 297-300. doi:10.1016/j.geoforum.2015.07.028

Knox-Hayes, J., \& Levy, D. (2011). The politics of carbon disclosure as climate governance. Strategic Organization, 9(1), 91-99. doi:10.1177/1476127010395066

Kooiman, J. (2003). Governing as Governance. London: Sage.

Kossoy, A., \& Guigon, P. (2012). State and trends of the carbon market 2012. Washington, DC: World Bank.

Krahmann, E. (2012). Green consumer markets in the fight against climate change. European Security, 22(2), 1-18. doi:10.1080/09662839.2012.727184

Kronenberg, J., \& Mieszkowicz, J. (2011). Planting trees for publicity-how much are they worth? Sustainability, 3(7), 1022-1034. doi:10.3390/su3071022

Lansing, D. M. (2011). Realizing carbon's value: Discourse and calculation in the production of carbon forestry offsets in Costa Rica. Antipode, 43(3), 731-753. doi:10.1111/j.1467-8330.2011.00886.x

Lazonick, W., \& O'Sullivan, M. (1997). Finance and industrial development. Part I: the United States and the United Kingdom. Financial History Review, 4(01), 7-29.

Lazonick, W., \& O'Sullivan, M. (2000). Maximizing shareholder value: A new ideology for corporate governance. Economy and Society, 29(1), 13-35. doi:10.1080/030851400360541

Lee, R. (2011a). Ordinary economic geographies: Can economic geographies be noneconomic? In A. Leyshon, R. Lee, L. McDowell, \& P. Sunley (Eds.), The SAGE handbook of social geographies (pp. 368-383). London: SAGE Publications Ltd. 
Lee, R. (2011b). Spaces of hegemony? Circuits of value, finance capital and places of financial knowledge. In J. Agnew \& D. N. Livingstone (Eds.), The SAGE handbook of social geographies (pp. 185-202). London: SAGE Publications Ltd.

Lefebvre, H. (1991). The Production of Space. Production. Oxford, UK: WileyBlackwell. doi:10.1027/1618-3169/a000129

Leonard, S. (2015). The REDD+ framework: Finally complete after almost 10 years. Retrieved August 4, 2015, from http://blog.cifor.org/29000/the-reddframework-finally-complete-after-almost-10-years\#.VcB7H3h999k

Leslie, H., \& Storey, D. (2003). Entering the field. In R. Scheyvens and D. Storey (Eds.), Development fieldwork: A practical guide (pp. 119-138). London: Sage Publications.

Levy, D. L., \& Newell, P. J. (2005). Introduction: The business of global environmental governance. In D. L. Levy \& P. J. Newell (Eds.), The business of global environmental governance (pp. 1-17). Cambridge: MIT Press.

Leys, C. (2001). Market-driven politics: Neoliberal democracy and the public interest. London: Verso.

Li, T. M. (2014). Land's end: Capitalist relations on an indigenous frontier. Duke University Press.

Lindsay, J. M. (1997). Techniques in human geography. New York: Routledge.

Liverman, D. (2004). Who governs, at what scale and at what price? Geography, environmental governance, and the commodification of nature. Annals of the Association of American Geographers, 94(4), 734-738.

Lo, A. Y., \& Spash, C. L. (2013). Deliberative monetary valuation: In search of a democratic and value plural approach to environmental policy. Journal of Economic Surveys, 27, 768-789. doi:10.1111/j.1467-6419.2011.00718.x

Loconto, A., \& Busch, L. (2010). Standards, techno-economic networks, and playing fields: Performing the global market economy. Review of International Political Economy, 17(3), 507-536. doi:10.1080/09692290903319870

Lohmann, L. (2010). Uncertainty markets and carbon markets: Variations on polanyian themes. New Political Economy, 15(2), 225-254. doi:10.1080/13563460903290946

Lohmann, L. (2011). Financialization, commodification and carbon: The contradictions of neoliberal climate policy. Socialist Register, 48, 85-107.

Lövbrand, E., \& Stripple, J. (2012). Disrupting the public-private distinction: 
Excavating the government of carbon markets post-Copenhagen. Environment and Planning-Part C, 30(4), 658-674.

Lovell, H., Bulkeley, H., \& Liverman, D. (2009). Carbon offsetting: Sustaining consumption? Environment and Planning A, 41(10), 2357-2379.

Lovell, H., \& Liverman, D. (2010). Understanding carbon offset technologies. New Political Economy, 15(2), 255-273. doi:10.1080/13563460903548699

Luttrell, C., Loft, L., Gebara, M. F., Kweka, D., Brockhaus, M., \& Angelsen, A. (2013). Who should benefit from REDD+? Rationales and realities. Ecology and Society, 18(4), 52. doi:10.5751/ES-05834-180452

Luttrell, C., Resosudarmo, I. A. P., Muharrom, E., Brockhaus, M., \& Seymour, F. (2014). The political context of REDD+ in Indonesia: Constituencies for change. Environmental Science and Policy, 35, 67-75. doi:10.1016/j.envsci.2012.10.001

Mansfield, B. (2004). Rules of privatization: Contradictions in neoliberal regulation of North Pacific fisheries. Annals of the Association of American Geographers, 94(3), 565-584. doi:10.1111/j.1467-8306.2004.00414.x

Margono, B. A., Potapov, P. V, Turubanova, S., Stolle, F., \& Hansen, M. C. (2014). Primary forest cover loss in Indonesia over 2000-2012. Nature Climate Change, 4, 730-735. doi:10.1038/NCLIMATE2277

Martínez-Alier, J. (2009). Socially sustainable economic de-growth. Development and Change, 40(6), 1099-1119. doi:10.1111/j.1467-7660.2009.01618.x

Martínez-Alier, J., Pascual, U., Vivien, F. D., \& Zaccai, E. (2010). Sustainable degrowth: Mapping the context, criticisms and future prospects of an emergent paradigm. Ecological Economics, 69(9), 1741-1747. doi:10.1016/j.ecolecon.2010.04.017

McAfee, K. (1999). Selling nature to save it? Biodiversity and green developmentalism. Environment and Planning D: Society and Space, 17(2), 133154. doi:10.1068/d170133

McAfee, K. (2012). The contradictory logic of global ecosystem services markets. Development and Change, 43(1), 105-131. doi:10.1111/j.14677660.2011.01745.x

McAfee, K., \& Shapiro, E. N. (2010). Payments for ecosystem services in Mexico: Nature, neoliberalism, social movements, and the state. Annals of the Association of American Geographers, 100(3), 579-599. doi:10.1080/00045601003794833

McGregor, A. (2015). Policy: REDD+ in Asia Pacific. Nature Clim. Change, 5(7), 623- 
624. Retrieved from http://dx.doi.org/10.1038/nclimate2692

McGregor, A., Challies, E., Howson, P., Astuti, R., Dixon, R., Haalboom, B., ... Afiff, S. (2015). Beyond carbon, more than forest? REDD+ governmentality in Indonesia. Environment and Planning A, 47(1), 138-155. doi:10.1068/a140054p

Meadows, D. H., Meadows, D., Randers, J., \& Behrens, W. W. (1972). The Limits to Growth. New York: Universe Books. doi:10.1111/j.1752-1688.1972.tb05230.x

Melo, I., Turnhout, E., \& Arts, B. (2014). Integrating multiple benefits in marketbased climate mitigation schemes: The case of the climate, community and biodiversity certification scheme. Environmental Science and Policy, 35, 49-56. doi:10.1016/j.envsci.2013.02.010

Mikecz, R. (2012). Interviewing elites: Addressing methodological issues. Qualitative Inquiry, 18(6), 482-493. doi:10.1177/1077800412442818

Minang, P. A., Van Noordwijk, M., Duguma, L. a, Alemagi, D., Do, T. H., Bernard, F., ... Leimona, B. (2014). REDD+ readiness progress across countries: time for reconsideration. Climate Policy, 14(6), 685-708.

doi:10.1080/14693062.2014.905822

Mol, A. P. . (2012). Carbon flows, financial markets and climate change mitigation. Environmental Development, 1(1), 10-24.

Mol, A. P. ., \& Janicke, M. (2009). The origins and theoretical foundations of ecological modernisation theory. In A. P. . Mol, D. A. Sonnenfeld, \& G. Spaargarden (Eds.), The ecological modernisation reader (pp. 17-27). London ; New York: Routledge.

Müller, M. (2007). What's in a word? Problematizing translation between languages. Area, 39(2), 206-213. doi:10.1111/j.1475-4762.2007.00731.x

Myers Madeira, E., Sills, E., Brockhaus, M., Verchot, L., \& Kanninen, M. (2010). What is a REDD+ pilot? A preliminary typology based on early actions in Indonesia (No. 26). Bogor, Indonesia: CIFOR.

Nadvi, K. (2008). Global standards, global governance and the organization of global value chains. Journal of Economic Geography, 8(3), 323-343.

Nakhooda, S., Fransen, T., Kuramochi, T., Caravani, A., Prizzon, A., \& et. al. (2013). Mobilising international climate finance: Lessons from the fast-start finance period. London: ODI.

Neilson, J. (2008). Global private regulation and value-chain restructuring in Indonesian smallholder coffee systems. World Development, 36(9), 1607-1622. doi:10.1016/j.worlddev.2007.09.005 
Neilson, J., Pritchard, B., \& Yeung, H. W. (2014). Global value chains and global production networks in the changing international political economy: An introduction. Review of International Political Economy, 21(1), 1-8. doi:10.1080/09692290.2013.873369

Neumayer, E. (2004). Weak versus strong sustainability: Exploring the limits of two opposing paradigms (2nd ed.). Cheltenham: Edward Elgar Publishing.

Newell, P., \& Bumpus, A. (2012). The global political ecology of the clean development mechanism. Global Environmental Politics, 12(4), 49-67. doi:10.1162/GLEP_a_00139

Newell, P., \& Paterson, M. (2009). The politics of the carbon economy. In M. T. BOYKOFF (Ed.), The politics of climate change: A survey (1st ed., pp. 80-99). London; New York: Routledge.

Newell, P., \& Paterson, M. (2010). Climate capitalism: Global warming and the transformation of the global economy. Cambridge: Cambridge University Press.

OECD. (2011). Towards Green Growth. Paris: OECD Green Growth Studies, OECD Publishing. doi:10.1787/9789264111318-en

Okereke, C., Bulkeley, H., \& Schroeder, H. (2009). Conceptualizing climate governance beyond the international regime. Global Environmental Politics, 9(1), 58-78. doi:10.1162/glep.2009.9.1.58

Oosterveer, P. (2015). Promoting sustainable palm oil: Viewed from a global networks and flows perspective. Journal of Cleaner Production, 106, 146-153. doi:10.1016/j.jclepro.2014.01.019

Pacheco, P., Putzel, L., Obidzinski, K., \& Schoneveld, G. (2012). REDD+ and the global economy: Competing forces and policy options. In A. Angelsen, M. Brockhaus, W. D. Sunderlin, \& L. V. Verchot (Eds.), Analysing REDD+ (pp. 51-66). Bogor: CIFOR.

Palpacuer, F., \& Parisotto, A. (2003). Global production and local jobs: Can global enterprise networks be used as levers for local development? Global Networks, 3(2), 97-120. doi:10.1111/1471-0374.00052

Parfitt, J. (2005). Questionnaire design and sampling. In R. Flowerdew \& D. Martin (Eds.), Methods in human geography: A guide for students doing a research project (2nd ed., pp. 78-109). Harlow: Pearson Education Limited.

Parry, M., Lowe, J., \& Hanson, C. (2009). Overshoot, adapt and recover. Nature, 458(7242), 1102-1103. doi:10.1038/4581102a

Pasquini, M. W., \& Olaniyan, O. (2004). The researcher and the field assistant: A 
cross- disciplinary, cross-cultural viewing of positionality. Interdisciplinary Science Reviews, (29), 24-36.

Paterson, M. (2012). Who and what are carbon markets for? Politics and the development of climate policy. Climate Policy, 12(1), 82-97.

Paterson, M., Hoffmann, M., Betsill, M., \& Bernstein, S. (2011). The micro foundations of global climate governance: An analysis of the transnational emission trading network. In Princeton Conference on Research Frontiers in Comparative and International Environmental Politics, 2-3 December. New Jersey. Retrieved from

https://www.princeton.edu/ pcglobal/conferences/environment/papers/bbhp. pdf

Pattberg, P. (2012). How climate change became a business risk: Analyzing nonstate agency in global climate politics. Environment and Planning C: Government \& Policy, 30(4), 613-626.

Pearse, R. (2012). Mapping REDD in the Asia-Pacific: Governance, marketisation and contention. Ephemera, 12(1/2), 181-205.

Peters-Stanley, M., \& Yin, D. (2013). State of the voluntary carbon markets 2013: Maneuvering the mosaic. Washington DC: Forest Trends' Ecosystem Marketplace and Bloomberg New Energy Finance.

Petherick, A. (2011). Refreshing REDD. Nature Climate Change, 1(9), 440-441.

Pike, A. (2009a). Brand and branding geographies. Geography Compass, 3(1), 190213. doi:10.1111/j.1749-8198.2008.00177.x

Pike, A. (2009b). Geographies of brands and branding. Progress in Human Geography, 33(5), 619-645. doi:10.1177/0309132508101601

Pike, A. (2011). Placing brands and branding: A socio-spatial biography of Newcastle Brown Ale. Transactions of the Institute of British Geographers, 36(2), 206-222. doi:10.1111/j.1475-5661.2011.00425.x

Pike, A. (2013). Economic Geographies of Brands and Branding. Economic Geography, 89(4), 317-339. doi:10.1111/ecge.12017

Pike, A. (2015). Origination: The Geographies of Brands and Branding. West Sussex: John Wiley \& Sons.

Pinkse, J., \& Busch, T. (2013). The emergence of corporate carbon norms: Strategic directions and managerial implications. Thunderbird International Business Review, 55(6), 633-645. Retrieved from 10.1002/tie.21580 
Ponte, S., \& Gibbon, P. (2005). Quality standards, conventions and the governance of global value chains. Economy and Society, 34(1), 1-31.

doi:10.1080/0308514042000329315

Prieto-Carrón, M., Lund-Thomsen, P., Chan, A., Muro, A., \& Bhushan, C. (2006). Critical perspectives on CSR and development: What we know, what we don't know, and what we need to know. International Affairs, 82(5), 977-987. doi:10.1111/j.1468-2346.2006.00581.x

Rabach, E., \& Kim, E. M. (1994). Where is the chain in commodity chains? The service sector nexus. In G. Gereffi \& M. Korzeniewicz (Eds.), Commodity chains and global capitalism (pp. 123-142). Westport, CT: Praeger.

Rainnie, A., Herod, A., \& McGrath-Champ, S. (2011). Review and positions: Global production networks and labour. Competition \& Change, 15(2), 155-169. doi:10.1179/102452911×13025292603714

Richardson, B. (2014). Making a market for sustainability: The commodification of certified palm oil. New Political Economy, 20(4), 545-568. doi:10.1080/13563467.2014.923829

Robbins, P. (2004). Political ecology: A critical introduction. Oxford: Blackwell Publishing.

Robertson, M. M. (2000). No net loss: Wetland restoration and the incomplete capitalization of nature. Antipode, 32(4), 463-493. doi:10.1111/14678330.00146

Robertson, M. M. (2012). Renaturing the economy. In T. J. Barnes, J. Peck, \& E. Sheppard (Eds.), The Wiley-Blackwell companion to economic geography (pp. 372-384). West Sussex: Wiley-Blackwell. doi:10.1002/9781118384497

Roe, S., Streck, C., Pritchard, L., \& Costenbader, J. (2013). Safeguards in REDD + and forest carbon standards : A review of social, environmental and procedural concepts and application. Amsterdam, the Netherlands: Climate Focus.

Rogers, P. P., Jalal, K. F., \& Boyd, J. A. (2008). An introduction to sustainable development (Vol. 24). London: Earthscan. doi:10.1016/0305-750X(95)00130-5

Sabot, E. C. (1999). Dr Jekyl, Mr H(i)de: The contrasting face of elites at interview. Geoforum, 30(4), 329-335.

Sarantakos, S. (1993). Social research. Melbourne: MacMillian Education Australia Pty Ltd. doi:10.1080/136455700405208

Sayer, A. (2003). (De)commodification, consumer culture, and moral economy. Environment and Planning D: Society and Space, 21(3), 341-357. 
doi:10.1068/d353

Schroeder, H., \& Lovell, H. (2012). The role of non-nation-state actors and side events in the international climate negotiations. Climate Policy, 12(1), 23-37. doi:10.1080/14693062.2011.579328

Scruggs, L. (2003). Sustaining abundance: Environmental performance in industrial democracies. Cambridge: Cambridge University Press.

Seifert-Granzin, J. (2011). REDD guidance: Technical project design. In J. Ebeling \& J. Olander (Eds.), Building forest carbon projects. Washington, DC: Forest Trends.

Selwyn, B. (2012). Beyond firm-centrism: Re-integrating labour and capitalism into global commodity chain analysis. Journal of Economic Geography, 12(1), 205226. doi:10.1093/jeg/lbr016

Sending, O. J., \& Neumann, I. B. (2006). Governance to governmentality: Analyzing NGOs, states, and power. International Studies Quarterly, 50(3), 651-672. doi:10.1111/j.1468-2478.2006.00418.x

Sheppard, E. (2011). Geographical political economy. Journal of Economic Geography, 11(2), 319-331. doi:10.1093/jeg/lbq049

Sijtsma, F. J., Van der Heide, C. M., \& Van Hinsberg, A. (2013). Beyond monetary measurement: How to evaluate projects and policies using the ecosystem services framework. Environmental Science and Policy, 32, 14-25. doi:10.1016/j.envsci.2012.06.016

Smith, K. E. (2006). Problematising power relations in "elite" interviews. Geoforum, 37(4), 643-653. doi:10.1016/j.geoforum.2005.11.002

Spaargaren, G., \& Mol, A. P. J. (2013). Carbon flows, carbon markets, and low-carbon lifestyles: Reflecting on the role of markets in climate governance. Environmental Politics, 22(1), 174-193. doi:10.1080/09644016.2013.755840

Spash, C. L. (2010). The brave new world of carbon trading. New Political Economy, 15(2), 169-195.

Starosta, G. (2010a). Global commodity chains and the marxian law of value. Antipode, 42(2), 433-465. doi:10.1111/j.1467-8330.2009.00753.x

Starosta, G. (2010b). The outsourcing of manufacturing and the rise of giant global contractors: A marxian approach to some recent transformations of global value chains. New Political Economy, 15(4), 543-563. doi:10.1080/13563460903288197

Stephan, B. (2012). Bringing discourse to the market: The commodification of 
avoided deforestation. Environmental Politics, 21(4), 621-639.

Stephan, B., \& Paterson, M. (2012). The politics of carbon markets: An introduction. Environmental Politics, 21(4), 545-562. doi:10.1080/09644016.2012.688353

Steurer, R. (2013). Disentangling governance: A synoptic view of regulation by government, business and civil society. Policy Sciences, 46(4), 387-410.

Streck, C. (2012). Financing REDD+: Matching needs and ends. Current Opinion in Environmental Sustainability, 4(6), 628-637. doi:10.1016/j.cosust.2012.10.001

Streck, C., \& Parker, C. (2012). Financing REDD. In A. Angelsen, M. Brockhaus, W. D. Sunderlin, \& L. V. Verchot (Eds.), Analysing REDD+: Challenges and choices (pp. 111-127). Bogor, Indonesia: CIFOR.

Sturgeon, T. J. (1999). Network-led development and the rise of turn-key production networks: Technological change and the outsourcing of electronics manufacturing. In G. Gereffi, F. Palpacuer, \& A. Parisotto (Eds.), Global production and local jobs: Can global enterprise networks be used as levers for local development? Geneva: International Institute for Labour Studies.

Sturgeon, T. J. (2002). Modular production networks: A new american model of industrial organization. Industrial and Corporate Change, 11(3), 451-496.

Sturgeon, T. J., \& Gereffi, G. (2009). Measuring success in the global economy: International trade, industrial upgrading and business function outsourcing in global value chains. Transnational Corporations, 18(2), 1-35.

Sukhdev, P. (2011). Put a value on nature! Retrieved June 3, 2015, from https://www.ted.com/talks/pavan_sukhdev_what_s_the_price_of_nature

Sullivan, S. (2013). Banking nature? The spectacular financialisation of environmental conservation. Antipode, 45(1), 198-217. doi:10.1111/j.1467-8330.2012.00989.x

Swyngedouw, E. (1999). Modernity and hybridity: Nature, regeneracionismo, and the production of the Spanish waterscape, 1891-1930. Annals of the Association of American Geographers, 89(3), 37-41.

Taylor, P. (2012). Governance, labour and the global call centre value chain. University of Strathclyde, Department of Human Resource Management, Glasgow, Scotland, UK.

Taylor, P. L. (2005). In the Market But Not of It: Fair Trade Coffee and Forest Stewardship Council Certification as Market-Based Social Change. World Development, 33(1), 129-147. doi:10.1016/j.worlddev.2004.07.007

The Munden Project. (2011). REDD and forest carbon: Market-based critique and 
recommendations. Retrieved from

www.rightsandresources.org/documents/files/doc_2215.pdf?

UN-REDD. (2015). The UN-REDD programme strategy 2011-2015. Geneva, Switzerland: UN-REDD Programme. Retrieved from

http://www.unredd.net/index.php?option=com_docman\&task=doc_download \&gid $=4598 \&$ Itemid $=53$

UNEP. (2014). Building natural capital: How REDD+ can support a green economy. Nairobi, Kenya: UNEP International Resource Panel Working Group.

UNEP-FI. (2014). Demistifying Private Climate Finance. Geneva, Switzerland: UNEP Finance Initiative.

UNFCCC. (2007). Investment and financial flows to address climate change. Bonn, Germany: United Nations Framework Convention on Climate Change.

Vagneron, I., \& Roquigny, S. (2011). Value distribution in conventional, organic and fair trade banana chains in the Dominican Republic. Canadian Journal of Development Studies/Revue Canadienne D'études Du Développement, 32(3), 324-338. doi:10.1080/02255189.2011.622619

Valentine, G. (2005). Tell me about...: Using interviews as a research methodology. In R. Flowerdew \& D. Martin (Eds.), Methods in human geography: A guide for students doing a research project (pp. 110-127). Harlow: Pearson Education Limited.

Visseren-Hamakers, I. J., Gupta, A., Herold, M., Peña-Claros, M., \& Vijge, M. J. (2012). Will REDD+ work? The need for interdisciplinary research to address key challenges. Current Opinion in Environmental Sustainability, 4(6), 590-596. doi:10.1016/j.cosust.2012.10.006

Vorley, B. (2003). Food, Inc.: Corporate concentration from farm to consumer. London: UK Food Group.

Wackernagel, M., Schulz, N. B., Deumling, D., Linares, A. C., Jenkins, M., Kapos, V., ... Randers, J. (2002). Tracking the ecological overshoot of the human economy. Proceedings of the National Academy of Sciences of the United States of America, 99(14), 9266-9271. doi:10.1073/pnas.142033699

Wana Hijau Nusantara. (2011). Technical Proposal: Application for an Ecosystem Restoration Concession License. Jakarta: PT. WHN.

Wang, Y., \& Corson, C. (2015). The making of a "charismatic" carbon credit: Clean cookstoves and "uncooperative" women in western Kenya. Environment and Planning A, advance online publication. doi:10.1068/a130233p 
Wardell, A., \& Bowie, B. (2014). The Landscape Fund. Bogor, Indonesia: CIFOR and The Munden Project.

Watts, M. (2014). Commodities. In P. Cloke, P. Crang, \& M. Goodwin (Eds.), Introducing human geographies (3rd ed., pp. 391-412). New York: Routledge.

Welch, C., Marschan-Piekkari, R., Penttinen, H., \& Tahvanainen, M. (2002). Corporate elites as informants in qualitative international business research. International Business Review, 11(5), 611-628. doi:10.1016/S0969-5931(02)00039-2

World Bank. (2014). State and trends of carbon pricing. Washington, DC: World Bank. doi:10.1596/978-1-4648-0268-3

World Economic Forum. (2013). The green growth action alliance: Progress report from the first year of catalysing private investment. Geneva, Switzerland: World Economic Forum.

Wuelker, G. (1983). Questionnaires in Asia. In M. Bulmer \& D. P. Warwick (Eds.), Social research in developing countries: Surveys and censuses in the third world (pp. 161-166). New York: John Wiley and Sons Ltd.

Xue, H., \& Chan, A. (2013). The global value chain: Value for whom? The soccer ball industry in china and pakistan. Critical Asian Studies, 45(1), 55-77. doi:10.1080/14672715.2013.758821

Yeung, H. W. (1995). Qualitative personal interviews in international business research: Some lessons from a study of Hong Kong transnational corporations. International Business Review, 4(3), 313-339. doi:10.1016/09695931(95)00012-0

Yeung, H. W.-C. (2007). From followers to market leaders: Asian electronics firms in the global economy. Asia Pacific Viewpoint, 48(1), 1-25. doi:10.1111/j.14678373.2007.00326.x 


\section{Appendices}

\section{Appendix A - interview guide}

1. What is your role in REDD+?

2. Why are you/your organisation involved in REDD+?

3. What finance are you using?

4. Why are they financing you?

5. Why do you think they are involved?

6. What do they want from REDD+?

7. How have other organisations helped you / this project?

8. Why are they involved?

9. Where do you think REDD+ is going?

10. How does REDD+ relate to Indonesia's and the global economy? 
Appendix B - ethics approval, information sheets and consent

form

\section{Human ethics approval}

MEMORANDUM

Phone 0-4-4635676

Fax $\quad 0-4-4635209$

Email Allizon.birlmangvuw.acnz

\begin{tabular}{l|l}
\hline TO & Rowan Dixon \\
\hline COPY TO & $\begin{array}{l}\text { Andrew McGregor } \\
\text { Ed Challies }\end{array}$ \\
\hline FROM & Dr Allison Kirkman, Convener, Human Ethics Committee \\
\hline
\end{tabular}

\begin{tabular}{l|l}
\hline DATE & 9 July 2013 \\
\hline PAGES & 1 \\
\hline
\end{tabular}

\begin{tabular}{l|l}
\hline SUBJECT & $\begin{array}{l}\text { Ethics Approval: } 19816 \\
\text { Commodification and Governance on REDD+ Networks in } \\
\text { Indonesia }\end{array}$ \\
\hline
\end{tabular}

Thank you for your application for ethical approval, which has now been considered by the Standing Committee of the Human Ethics Committee.

Your application has been approved from the above date and this approval continues until 1 August 2015. If your data collection is not completed by this date you should apply to the Human Ethics Committee for an extension to this approval.

Best wishes with the research.

Allison Kirkman

Human Ethics Committee 


\section{Interview and observation information sheets}

\section{Commodification and Governance of REDD+ in Indonesia \\ Information Sheet for Interview Participants}

Thank you for your interest in taking part in this research. Please read this information sheet before deciding whether or not to participate.

This research is investigating how the Reducing Emissions from Deforestation and Forest Degradation (REDD+) programme is being implemented in Indonesia. This research aim is to understand the process that organisations and actors go through to create REDD+ offsets in Indonesia and how these processes are governed.

To conduct this research, I plan to interview REDD+ stakeholders in Indonesia. Participants include representatives from: government, Indonesian NGOs, international NGOs, research organisations, donor agencies, the private sector, and academics.

\section{Interview Format}

This interview will take approximately $45-60$ minutes of your time and, with your permission, will be audio recorded. It will follow a semi-structured format, so the exact nature of the questions has not been determined in advance but will depend on the way that the interview develops. Should the line of questioning progress in a way that makes you uncomfortable you can decline to answer any question(s) at any stage.

\section{Translation}

Please inform us if you would prefer to communicate in a language other than English. Translation services can readily be made available.

\section{Participation}

Your participation is completely voluntary and you can leave the interview at any time and retract any statements made before 31 August 2014 without any disadvantage to yourself. On the consent form, you are given the option of using an organisation's name, or a code name to maintain anonymity (for instance, Participant One or a fictional name).

\section{Data Use and Storage}

All the data will be kept confidential and securely stored in a password-protected computer, and only my supervisors and I will have access to the raw data. At the end of the project any personal information 
will be destroyed, except that on which published results rely. These data will be stored securely for a period of five years.

It is intended that this research will form the basis of the researcher's PhD thesis, articles and book publications, and also conference presentations. Direct quotes will be used in the publications and although every effort will be made to keep your identity confidential, anyone very close to the issues may be able to identify you through your comments.

\section{Feedback}

You may receive a final report with the findings if you wish (please indicate on the consent form). You may also receive a copy of any interview transcript. Any request for transcript change will be taken into consideration.

This research has been approved by the Human Ethics Committee at Victoria University of Wellington.

If you have any further questions at any time, please contact either Rowan Dixon (primary researcher) or Dr Ed Challies (supervisor) on the details below.

Researcher: Rowan Dixon, School of Geography, Environment and Earth Sciences, Victoria University of Wellington, PO Box 600, Wellington, New Zealand. Phone:

Email: rowan.dixon@vuw.ac.nz

Supervisor: Dr Ed Challies, Leuphana University of Lüneburg, Scharnhorststrasse, 121335 Lüneburg, Germany. Phone: +49 4131677 1387. Email: challies@leuphana.de 


\section{Commodification and Governance of REDD+ in Indonesia Information Sheet for Observation Participants/Representatives}

Thank you for your interest in taking part in this research. Please read this information sheet before deciding whether or not to participate.

This research is investigating how the Reducing Emissions from Deforestation and Forest Degradation Plus (REDD+) Programme is being implemented in Indonesia. This research aim is to understand the process that organisations and actors go through to create REDD+ offsets in Indonesia and how these processes are governed so that these organisations and actors can benefit.

To conduct this research, I wish to observe REDD+ operations and meetings organized by various REDD+ stakeholders.

\section{Observation Format}

This observation will take place during my time with your organisation and any meetings that I attend. With your permission these observations will be audio recorded. Should any of the participants feel uncomfortable to be observed, they can ask the researcher to exclude any of their statements from the observation notes.

\section{Data Use and Storage}

All the data will be kept confidential and securely stored in a password-protected computer, and only my supervisors and I will have access to the raw data. At the end of the project any personal information will be destroyed, except that on which published results rely. These data will be stored securely for a period of five years.

It is intended that this research will form the basis of the researcher's PhD thesis, articles and book publications, and also conference presentations. Direct quotes will be used in the publications and that although every effort will be made to keep participant's identity confidential (for instance Participant One or a fictional name), anyone close to the issues may be able to identify him/her through his/her comments.

\section{Feedback}

You may receive a final summary report with the findings if you wish (please indicate on the consent form). You may also receive a copy of any observation notes. Any request for notes change will be taken into consideration. 
This research has been approved by the Human Ethics Committee at Victoria University of Wellington.

If you have any further questions at any time, please contact either Rowan Dixon (primary researcher) or Dr Ed Challies (supervisor) on the details below.

Researcher: Rowan Dixon, School of Geography, Environment and Earth Sciences, Victoria University of Wellington, PO Box 600, Wellington, New Zealand. Phone: Email: rowan.dixon@vuw.ac.nz

Supervisor: Dr Ed Challies, Leuphana University of Lüneburg, Scharnhorststrasse, 121335 Lüneburg, Germany. Phone: +49 4131677 1387. Email: challies@leuphana.de

\section{Interview and observation consent forms}

\section{Commodification and Governance of REDD+ in Indonesia}

\section{Consent Form for Interview Participants}

You have been asked to take part in a research study by Rowan Dixon from the School of Geography, Environment and Earth Sciences at Victoria University of Wellington (VUW), New Zealand. This study will explore REDD+ implementation and governance in Indonesia. The results of this study will be included in the researcher's doctoral thesis. It is also anticipated that the findings of the study will be written up for publications.

Thank you for taking part in this research.

- I have read and understood the Information Sheet and had the research explained to me.

- I am aware that participation is purely voluntary and I can withdraw at any time, refuse to answer any questions, or retract any statements before 28 Feb 2014, without any disadvantage.

- I understand that I can request more information at any time.

- I am aware that I may be quoted in any results or publications, but that my name will not be used. A pseudonym or identifier such as 'Interview 1' or 'Participant One' will be used.

- I understand that that information I give will not be used for any purpose other than those listed below and in the information sheet without my consent.

I would like to receive a copy of the transcript of my interview

$\mathrm{Y} / \mathrm{N}$

(please circle)

I would like to receive a final summary report of the research

$\mathrm{Y} / \mathrm{N}$ 
I give consent for the researcher to use my organisation's name

My contact details are:

Email:

Address:

Participant's Statement:

। agree that the research project named above has been explained to me to my satisfaction and I agree to take part in the study. I have read both the notes written above and the Information Sheet about the project, and understand what the research study involves.

Signed

Date 


\section{Commodification and Governance of REDD+ in Indonesia \\ Consent Form for Observation Participants/Representatives}

You have been asked to take part in a research study by Rowan Dixon from the School of Geography, Environment and Earth Sciences at Victoria University of Wellington (VUW), New Zealand. This study will explore REDD+ implementation and governance in Indonesia. The results of this study will be included in the researcher's doctoral thesis. It is also anticipated that the findings of the study will be written up for publications.

Thank you for taking part in this research.

- I have read and understood the Information Sheet and had the research explained to me.

- I am aware that participation is purely voluntary and I can ask the researcher to exclude any statements I have made from the observation notes before 28 February 2014 without any disadvantage.

- I understand that I can request more information at any time.

- I am aware that I may be quoted in any publication of results, but that my name will not be used. A pseudonym or identifier such as 'Participant One' will be used.

- I understand that that information I give will not be used for any purpose other than those listed below and in the information sheet without my consent.

I would like to receive a copy of the transcript of the observation notes $\quad \mathrm{Y} / \mathrm{N}$ (please circle)

I would like to receive a final summary report of the research $\quad Y / N$

I give consent for the researcher to use my organisation's name $\quad \mathrm{Y} / \mathrm{N}$

My contact details are: $\quad$ Email:

Address:

Participant's Statement:

I agree that the research project named

above has been explained to me to my satisfaction and I agree to take part in the study. I have read both the notes written above and the Information Sheet about the project, and understand what the research study involves.

Signed

Date 


\section{Appendix C - list of non-government informants}

- ADM Capital Ltd.

- Aidenvironment Ltd.

- Allianz Ltd.

- Althelia Ltd.

- Asia Pulp \& Paper Ltd.

- Association of Indonesian Forest Concessionaires

- Australian National University

- Baastel Ltd.

- PT. Bank Negara Indonesia

- BioCarbon Group Pte Ltd.

- BioClimate Ltd.

- BirdLife International

- Business for Social Responsibility Inc.

- Carbon Partnership Ltd.

- CARE International

- Carrefourr S.A.

- Climate Advisers Inc.

- Climate and Land Use Alliance

- Climate Policy Initiative Inc.

- Clinton Climate Initiative

- Code REDD

- Credit Suisse Group Ltd.

- PT. Daemeter Consulting

- Desso Ltd.

- Deutsche Bank AG

- EcoAgriculture Ltd.

- Ecosystem Innovation Institute Ltd.
- Eneco Holding N.V.

- Environmental Defence Fund

- Fauna and Flora International

- Forest Carbon Ltd.

- Forest Peoples Program

- General Mills Inc.

- GIST Advisory Pvt. Ltd.

- Global Green Growth Institute

- Golden Agri-Resources Ltd.

- Governors' Climate \& Forests Task Force

- HSBC Holdings plc

- Indigenous Peoples Alliance of the Archipelago (AMAN)

- Indonesia Business Council for Sustainable Development

- Infinite Earth Inc.

- Institute of Chartered Accountants England and Wales

- International Labour Organisation

- International Union for Conservation of Nature

- Kaban

- KeeptheHabitat Ltd.

- Kering Ltd.

- KnowlEdge Srl

- Markets for Change

- Markit Ltd.

- Mars Inc. 
- Mazars Starling Resources Ltd.

- Microsoft Corporation Ltd.

- Migros Group Ltd.

- Millenium Challenge Corporation

- Monsanto Company Ltd.

- Neste Corporation Ltd.

- Nestlé S.A.

- New Forests Ltd.

- Nordea Asset Management Ltd.

- Office Depot Inc.

- Olam International Ltd.

- Oriflame Cosmetics Ltd.

- PT. Penta

- Permian Global Ltd.

- PT Rajawali Corporation

- PT. Astra Agro Lestari Tbk

- PT. Gajah Tunggal Tbk

- PT. Rimba Makmur Utama

- PT. Rimba Raya Conservation

- PT. Wana Hijau Nusantara

- PUMASE

- PWC Ltd.

- Rabobank Groep N.V.

- Saachi and Saachi Ltd.

- Seventythree Ltd.

- Sinar Mas Group Ltd.

- Solidaridad

- Syngenta Asia Pacific Pte Ltd.

- The Asian Development Bank

- The CarbonNeutral Company Ltd.

- The Climate Community and Biodiversity Alliance
- The Economics of Ecosystems and Biodiversity

- The European Investment Bank

- The Forest Carbon Partnership Facility

- The Forest Investment Programme

- The Global Canopy Programme

- The Government Pension Fund of Norway

- The International Finance Corporation

- The International Tropical Timber Organisation

- The Munden Project Ltd.

- The Nature Conservancy

- The Orangutan Foundation United Kingdom

- The Overseas Development Institute

- The Royal Society

- The Verified Carbon Standard Ltd.

- The Walt Disney Company Ltd.

- The World Bank

- Trucost Ltd.

- UK Green Investment Bank plc

- UN Environmental Programme

- UN Environmental ProgrammeFinance Initiative

- UN Food and Agriculture Organisation

- UN Global Compact - Indonesia

- UN Office for REDD+ Coordination in Indonesia 
- UN Principles for Responsible Investment

- UN REDD+ Programme

- Unilever Ltd.

- University of Indonesia

- Volcom Inc.

- Wildlife Works Inc.

- Winrock International Ltd.

- World Agroforestry Centre

- World Wide Fund for Nature

- Yayasan Palung

- Yayorin

- Zoological Society of London

- Zurich Insurance Group Ltd. 